Portland State University

PDXScholar

Spring 5-17-2019

\title{
Examining Human Behavior and Tool Use through Experimental Replications and a Technological Analysis of Ground Stone in the Lower Columbia
}

Kelley Prince Martinez

Portland State University

Follow this and additional works at: https://pdxscholar.library.pdx.edu/open_access_etds

Part of the Anthropology Commons

Let us know how access to this document benefits you.

\section{Recommended Citation}

Martinez, Kelley Prince, "Examining Human Behavior and Tool Use through Experimental Replications and a Technological Analysis of Ground Stone in the Lower Columbia" (2019). Dissertations and Theses. Paper 5074.

https://doi.org/10.15760/etd.6958

This Thesis is brought to you for free and open access. It has been accepted for inclusion in Dissertations and Theses by an authorized administrator of PDXScholar. Please contact us if we can make this document more accessible: pdxscholar@pdx.edu. 
Examining Human Behavior and Tool Use through Experimental Replications and a Technological Analysis of Ground Stone in the Lower Columbia

by

Kelley Prince Martinez

A thesis submitted in partial fulfillment of the requirements for the degree of

\author{
Master of Science \\ in \\ Anthropology
}

Thesis Committee:

Shelby L. Anderson, Chair

Virginia L. Butler

Kenneth M. Ames

John L. Fagan

Portland State University

2019 
(C) 2019 Kelley Prince Martinez 


\begin{abstract}
While ground stone tools represent diverse activities, the technology is analyzed at a coarse level in the Pacific Northwest. Conducting more detailed analyses of ground stone assemblages can inform on regional Indigenous raw material knowledge, resource use, and tool manufacturing and maintenance practices.

In this thesis I addressed questions regarding ground stone technology, including manufacturing time investments, tool recycling, and how ground stone tools were used through the application of experimental tool replication, use studies, and in depth analyses. I replicated tools that are common in the region, including a banded and notched net weight, a maul, two bowls, and a pestle. The replicated tools were all produced with raw materials collected from nearby sources and all ground stone tools were manufactured with cobble choppers. I conducted use wear studies in two phases to examine the impacts of processing both hard and soft materials using the replicated bowl and pestle. The tools underwent an in-depth analysis before and after manufacture and the use wear study to assess manufacturing and use wear attributes.
\end{abstract}

The experimental replications and use study resulted in associating specific attributes with known activities and actions. These insights were then applied to the analysis of ground stone artifacts from the $35 \mathrm{CO} 2$ Rylander assemblage, a private artifact collection from a contact-period archaeological site located in the Lower Columbia. I was able to identify manufacturing and use wear attributes to further explore how the ground stone tools were manufactured, used, and maintained. Additionally, I demonstrated a strong relationship between raw material selection, time investment, and 
tool recycling in the region through the experimental studies and comparative analysis with the Rylander assemblage.

Furthermore, this study highlights the need for more robust ground stone analysis standards. Analyses that include in-depth examination at the attribute level will help expand our understanding of ground stone tool technology. Employing standardized vocabulary, terminology, and referencing attributes in photomicrographs builds more comparable datasets, giving researchers valuable insights into skill level, specialization, and time investment associated with ground stone technology. 


\section{Acknowledgements}

This work would not have been possible without my advisor and mentor, Dr. Shelby Anderson. I would not have been able to tackle this project without her encouragement and guidance. Thank you to my committee members Dr. Ken Ames, Dr. Virginia Butler, and Dr. John Fagan for sharing their passion and expertise throughout my research and thesis writing.

I am also grateful for my colleagues at AINW, particularly Dr. John Fagan, Jo Reese, and Terry Ozbun, who have motivated me, provided personal and professional guidance, and fielded many lithic technology questions over the years.

I extend my appreciation to my fellow grad school students who have become friends and offered encouragement and a sense of solidarity through this process.

Finally, I would like to thank my family and friends for their support and understanding my absences over the last few years. I am indebted to my husband, Stephen, for his endless support, encouragement, patience, and for giving up countless weekends to collect rocks. We did it! 


\section{Table of Contents}

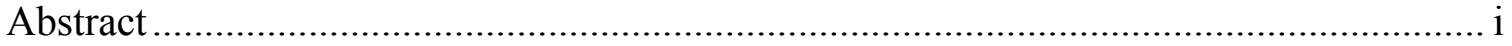

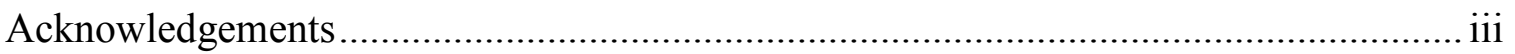

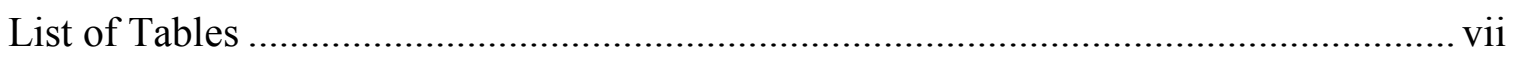

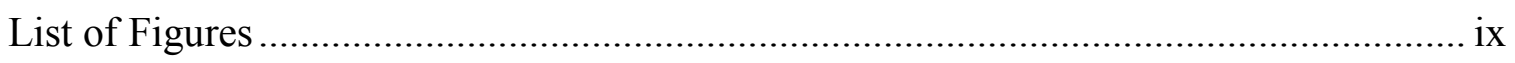

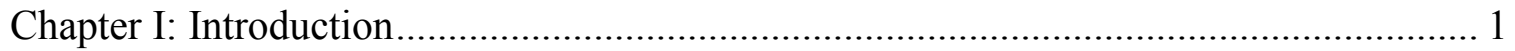

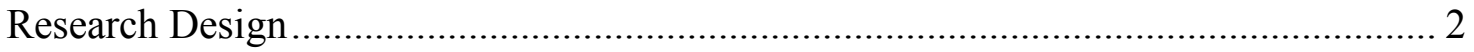

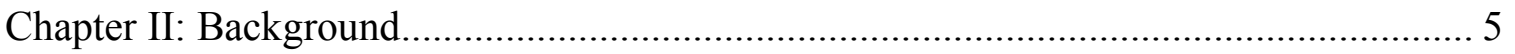

Environmental and Cultural Setting .................................................................... 5

Lower Columbia Ground Stone Studies.................................................................. 8

The Relationship between Ground Stone Production and Food Gathering/Processing 10

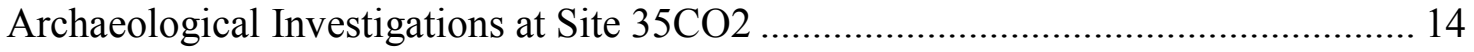

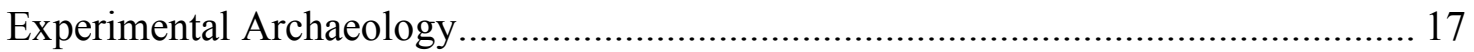

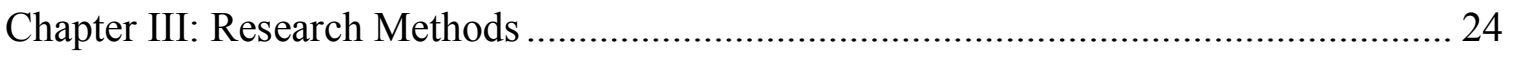

Preliminary Analysis of 35CO2 Ground Stone Artifacts...................................... 24

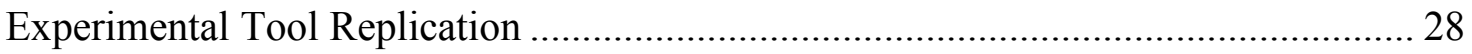

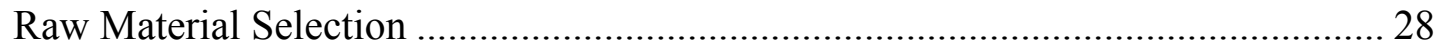

Cobble Chopper Manufacture (KPM-12, KPM-13, KPM-16 through KPM-18, and

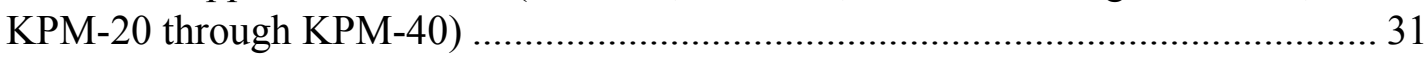

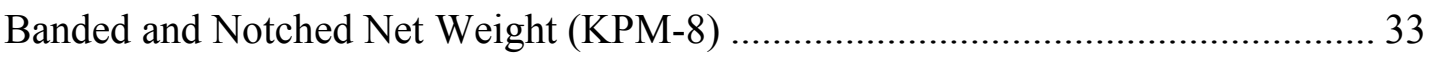

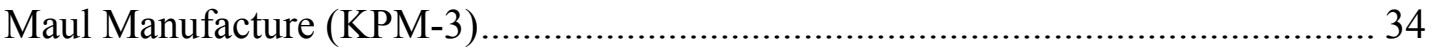

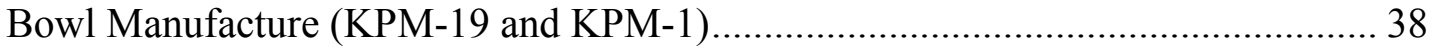

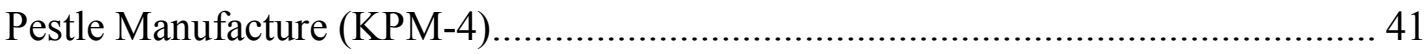

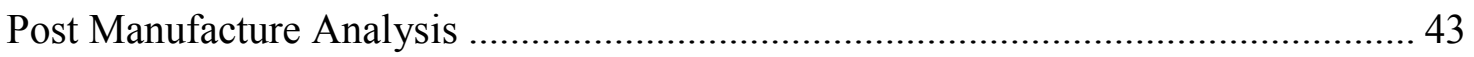

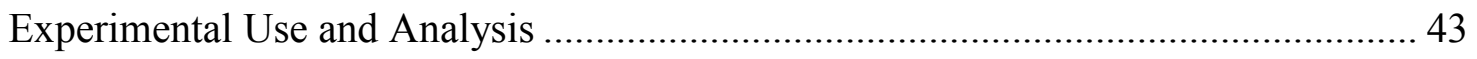

Phase I: Cracking and Shelling Hazelnuts......................................................... 44

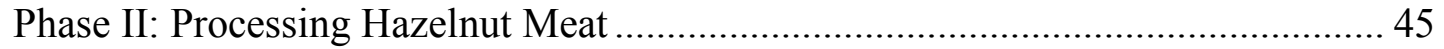

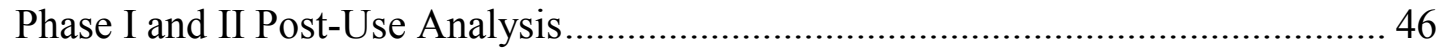

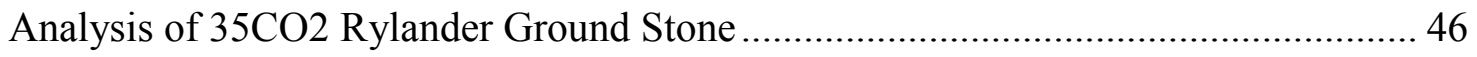

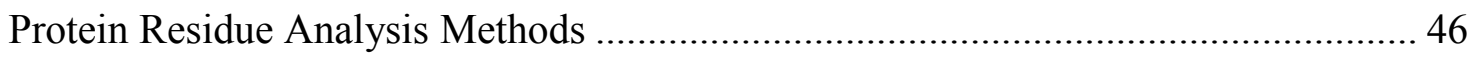

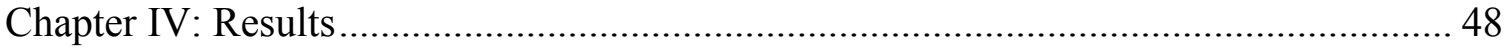


Preliminary Analysis of the 35CO2 Rylander Collection ........................................ 48

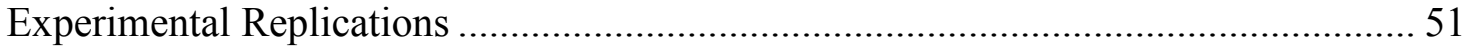

Cobble Chopper Manufacture (KPM-12, KPM-13, KPM-16 through KPM-18, and

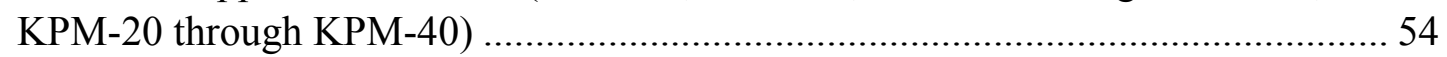

Banded and Notched Net Weight Manufacture (KPM-8) ....................................... 59

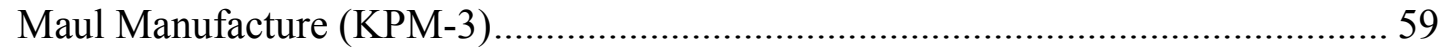

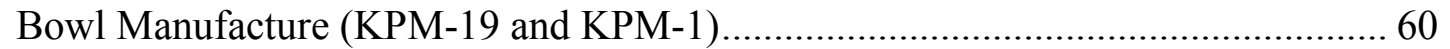

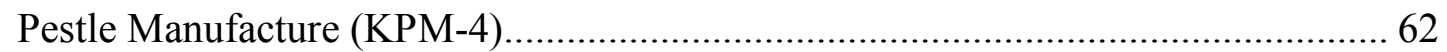

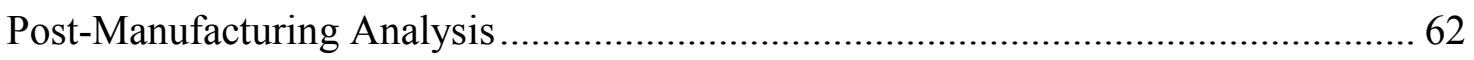

Choppers (KPM-12, KPM-13, KPM-16 through KPM-18, KPM-20 through KPM40) 62

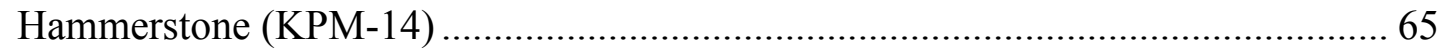

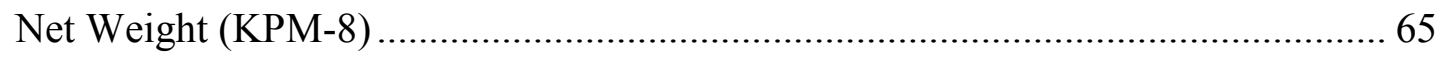

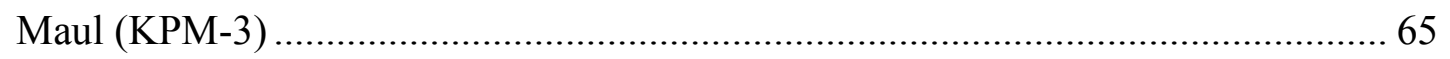

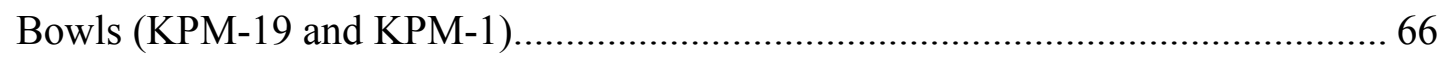

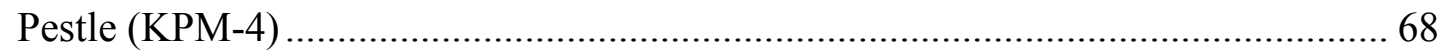

Experimental Tool Processing and Use Wear Analysis ............................................. 70

Phase I: Processing Hard and Sharp Materials Use Wear Results ......................... 71

Phase II: Processing Soft Materials Use Wear Results ......................................... 73

Analysis of 35CO2 Rylander Ground Stone Artifacts ........................................... 76

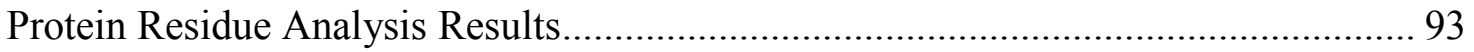

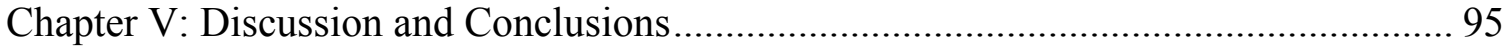

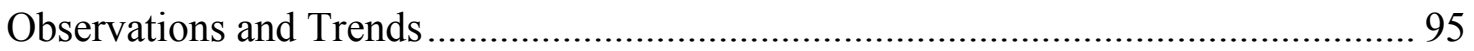

Raw Material and Time Investments ................................................................. 95

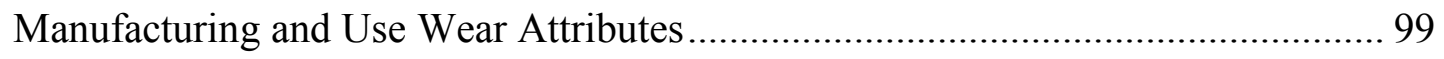

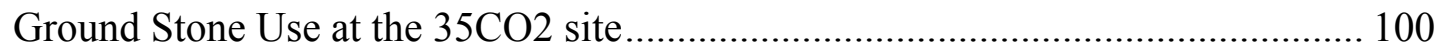

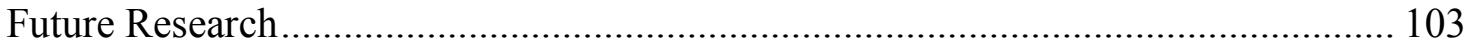

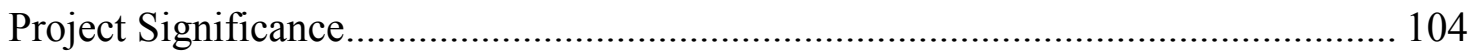

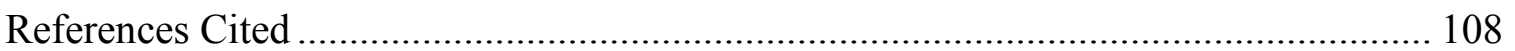

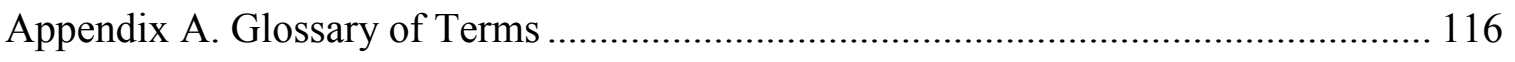

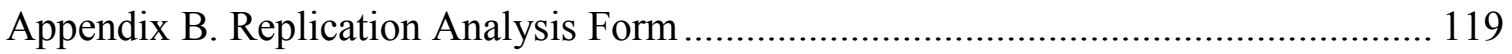




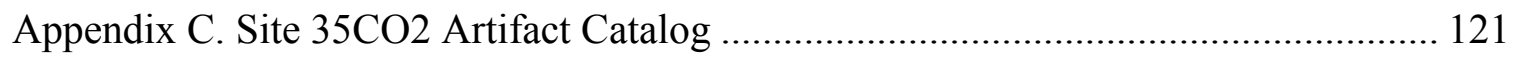

Appendix D. Site 35CO2 Artifact Analysis Form ...................................................... 124

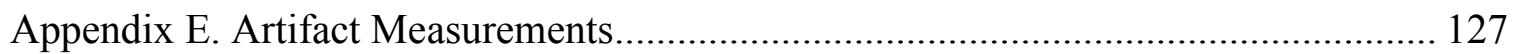

Appendix F. Experimental Replication Pre-Modification Measurements...................... 129

Appendix G. Experimental Replication Post-Modification Information......................... 130

Appendix H. Site 35CO2 Artifact Analysis Descriptions .............................................. 131

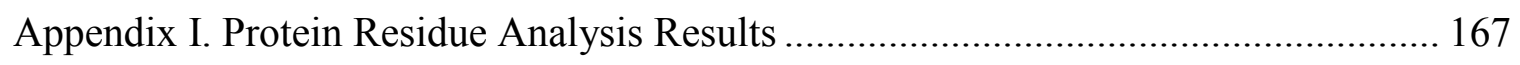

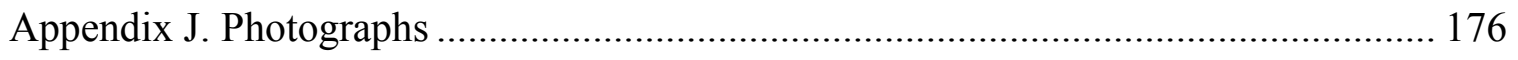




\section{List of Tables}

Table 1. Recorded ground stone totals from OAS excavations by year and Rylander collection totals. These totals represent only a fraction of the ground stone likely recovered from the site. Only the Rylander collection was available for my analysis.

Table 2. Ground stone attributes, descriptions, interpretations, and representative photographs.

Table 3. Summary of research questions, hypotheses, expectations, and means of analyses.

Table 4. Preliminary analysis of $35 \mathrm{CO} 2$ Rylander mauls and pestles.

Table 5. Summary of experimental replication materials, manufacture time, and used cobble choppers.

Table 6. Mohs scale determination of experimentally produced tools. .........................53

Table 7. Cobble chopper replications and manufacture times.

Table 8. Mean and standard deviation of cobble chopper production time by material type.

Table 9. Phase I difference in basin depth and weight of bowl KPM-1 . ...................... 71

Table 10. Phase I difference in tool length and weight of Pestle KPM-4 ...................... 72

Table 11. Phase II differences in basin depth and weight of bowl KPM-1 . ................. 74

Table 12. Phase II difference in tool length and weight of pestle KPM-4.................... 75

Table 13. Ground stone artifacts by class and material type from the $35 \mathrm{CO} 2$ Rylander

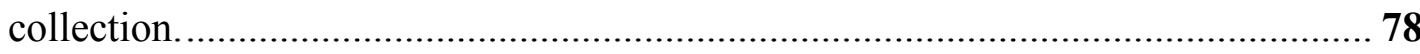

Table 14. Mauls by material type, proximal, and distal styles................................... 79

Table 15. Maul and pestle analysis attribute summary........................................... 79

Table 16. Site $35 \mathrm{CO} 2$ Rylander maul analysis attribute summary by artifact. The ' $X$ ' marks the presence of the given attribute; the blank cells represent the absence of the given attribute.

Table 17. Site $35 \mathrm{CO} 2$ Rylander collection pestle analysis attribute summary by artifact. The ' $\mathrm{X}$ ' marks the presence of the given attribute; the blank cells represent the

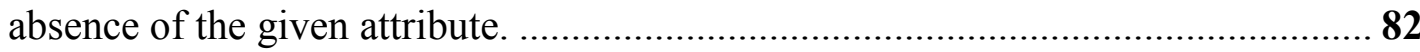

Table 18. Site 35CO2 Rylander collection bowl analysis attribute summary. ...............84

Table 19. Site 35CO2 Rylander collection bowl analysis attribute summary by artifact. The ' $\mathrm{X}$ ' marks the presence of the given attribute; the blank cells represent the

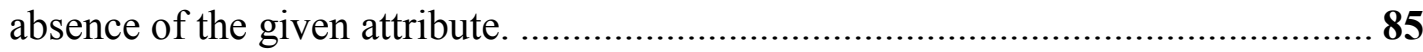

Table 20. Site 35CO2 Rylander collection net weight styles and material type............ 87

Table 21. Site 35CO2 Rylander collection net weight analysis attribute summary........ 89

Table 22. Site $35 \mathrm{CO} 2$ Rylander collection net weight analysis attribute summary by artifact. The ' $\mathrm{X}$ ' marks the presence of the given attribute; the blank cells represent the absence of the given attribute.

Table 23. Site $35 \mathrm{CO} 2$ Rylander collection adze analysis attribute summary.................91 
Table 24. Site 35CO2 Rylander collection adze analysis attribute summary by artifact. The ' $\mathrm{X}$ ' marks the presence of the given attribute; the blank cells represent the absence of the given attribute.

Table 25. Protein residue analysis results for select 35CO2 Rylander collection artifacts.

Table 26. Site $35 \mathrm{O} 2$ Rylander collection ground stone artifact catalog........................ 121

Table 27. Site 35CO2 Rylander collection artifact measurements. ............................. 127

Table 28. Mean values of 35CO2 Rylander collection ground stone by tool type. ....... 128

Table 29. Experimental replication pre-modification measurements. .......................... 129

Table 30. Experimental replication post-modification measurements......................... 130 


\section{List of Figures}

Figure 1. Location of site 35CO2 within the Lower Columbia River Valley.

Figure 2. Line drawings of ground stone wear. (a) Microscopic view of an unaltered stone surface; (b) Microscopic view of abrasive wear; (c) Microscopic view of surface fatigue; (d) Microscopic view of tribochemical wear. Images adapted from Adams (2002)...

Figure 3. Raw material collection site: Sandy River Delta, Troutdale, Oregon.

Figure 4. Raw material collection site: Dredge pile adjacent to the Columbia River, Rufus, Oregon.

Figure 5. (a) and (b) Net weight 35CO2-446; (c) replication net weight KPM-8, which was modeled after 35CO2-446; (d) chopper KPM-12, which was used in the production of KPM-8.

Figure 6. Maul 35CO2-467, after which replication KPM-3 is modeled.

Figure 7. In progress reductions of maul KPM-3, showing pecked grooves in maul shaft.

Figure 8. (a) bowl 35CO2-488, which bowl replications were based; (b) replicated bowl KPM-19; (c) replicated bowl KPM-1. Scale is five cm.

Figure 9. (a) pestle 35CO2-463 after which replications were modeled; (b) pestle replication KPM-4

Figure 10. Shelling hazelnuts during Phase I.

Figure 11. Evidence of tool recycling. Note edge rounding and negative flake scars on the distal ends of the tools. (a) Tool 35CO2-458; (b) Tool 35CO2-459; (c) Tool 35CO2-460; (d) Tool 35CO2-470.

Figure 12. Photomicrograph of remnant chopper scars. Orange ovals mark chopper gouges. (a) 35CO2-441, 6.3x; (b) 35CO2-452, 31.5x; (c) 35CO2-482, 31.5x; (d) $35 \mathrm{CO} 2-485,31.5 \mathrm{x}$.

Figure 13. Mohs scale values of raw materials used in experimental replications......... 54

Figure 14. Hammerstone KPM-14 with visible use wear circled in orange................... 56

Figure 15. Box plot showing the range in cobble chopper production time by material type.

Figure 16. Replicated maul and choppers used in reduction. (a) Maul KPM-3 at the end of replications; (b) Chopper KPM-16; (c) Chopper KPM-17; (d) Chopper KPM-25.

Figure 17. Use wear on cobble choppers used in experimental ground stone tool replications.

Figure 18. (a) Bowl KPM-1 after Phase II use wear showing oil staining within basin and around bowl rim; (b) photomicrograph of basin of KPM-1 showing rounded grains, polish, and remnant hazelnut husk in interstices.

Figure 19. Pestle 35CO2-463 showing flake scars travelling up tool shaft from distal end, in addition to anvil wear on tool shaft. 83 
Figure 20. Bowl 35CO2-482 showing negative flake scars around the bowl rim..........86

Figure 21. Photomicrograph of net weight $35 \mathrm{CO} 2-443$ showing grain rounding and

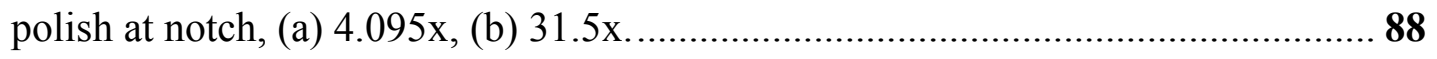




\section{Chapter I: Introduction}

Ground stone, also termed pecked stone, is generally defined as any stone implement that is primarily manufactured through abrasion, polishing, pecking, or is used to primarily perform abrading, polishing, or pecking activities (Adams 2002:1). In the past, ground stone artifacts were not only used in resource gathering and processing, but they also carried culturally significant symbols and motifs, thus representing various important subsistence, social, and symbolic aspects of communities in the archaeological record (Adams 1994:12-25; Adams 2002:46-56; Peterson 1978:5-17; Buonasera 2012:104-106, 139-150). Ground stone tools were manufactured in high frequencies in the Lower Columbia and represent diverse human activities, but, despite their importance, ground stone tools are not often systematically analyzed in this region or more broadly. One of the challenges to a more comprehensive analysis of ground stone in the Lower Columbia is that ground stone is most abundant in private collections, which can be attributed to private artifact collecting. There are limited ground stone collections accessible in museum or repository collections, and even fewer that were collected systematically through professional archaeological investigations. Despite the lack of archaeological context, ground stone artifacts in private collections can help us understand tool manufacturing strategies in the region. Research on local ground stone technology has the potential to inform broader questions about past subsistence, cultural, and spiritual practices in the Lower Columbia. 


\section{Research Design}

To address the dearth of information about regional ground stone technology, I undertook research that examines ground stone modes of production in the Lower Columbia River Valley (Figure 1) through experimental tool replications and subsequent use wear analysis. Additionally, I conducted analysis of ground stone artifacts from a private archaeological collection from site 35CO2 (Figure 1), a contact-period village site located in the Lower Columbia. This research yields new information about local technological choices and lithic production. My research was guided by the following questions:

- What are the manufacturing time investments for ground stone and how do these impact tool lifespan and recycling?

- Can evidence of tool recycling be identified? If so, how?

- What were ground stone tools used for and how were they maintained?

- What were the ground stone tools from the 35CO2 Rylander assemblage used for?

I addressed these questions through an experimental replication and use study of ground stone tools. The replication and use study informs on raw material selection, tool manufacturing strategies, and use wear signatures. After analyzing the tool replicates between the manufacturing and use wear phases, I was able to identify manufacturing and use wear attributes that occurred as a result of known activities. I applied insights from the experimental study about manufacturing and use wear attributes to the analysis of ground stone artifacts from site $35 \mathrm{CO} 2$ to examine how individuals in the Lower Columbia manufactured and used ground stone tools. Blood residue analysis using the cross-over immunoelectrophoresis (CIEP) technique was conducted on a sample of 
ground stone tools from site $35 \mathrm{CO} 2$ to further examine ground stone tool use in the region.

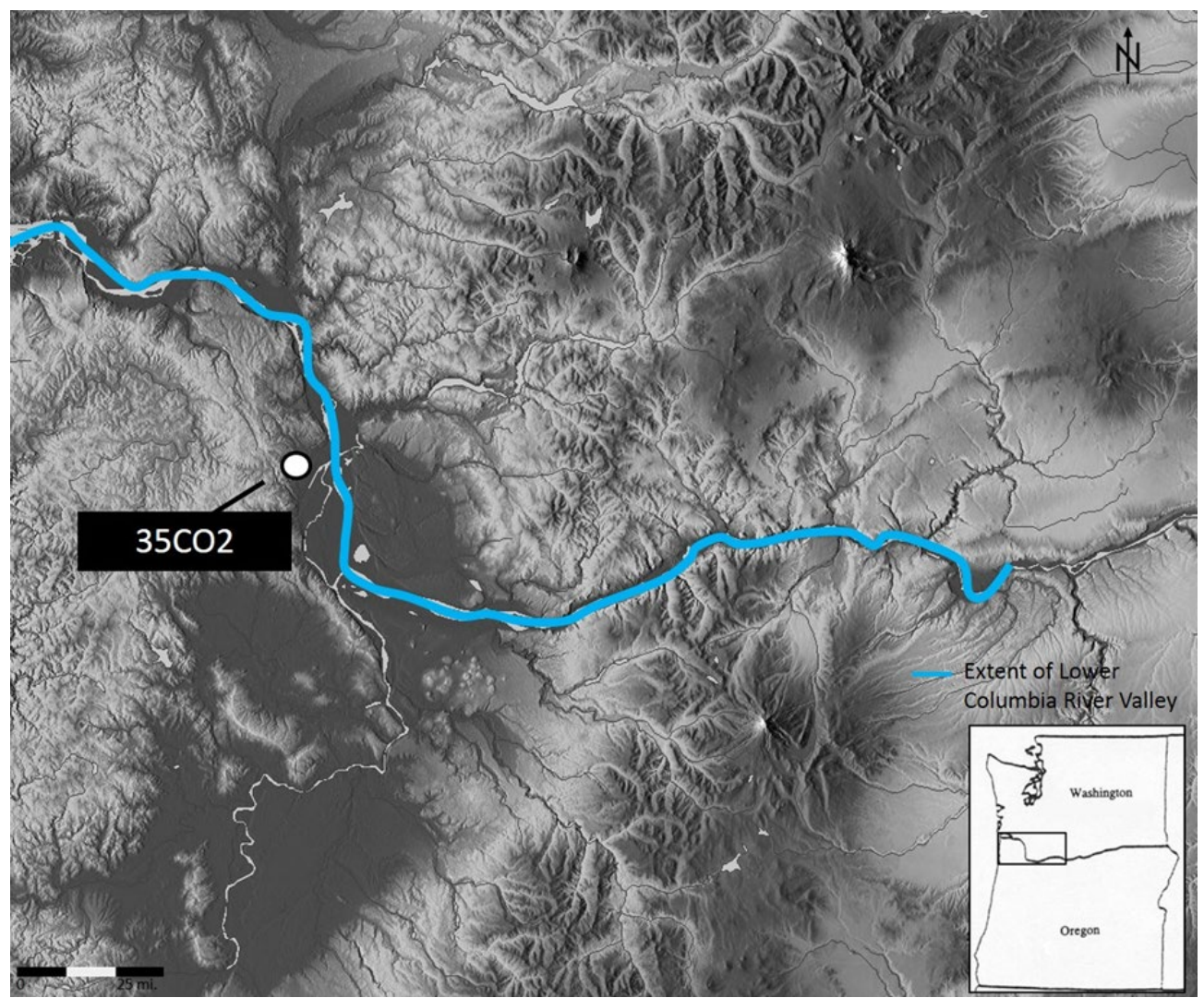

Figure 1. Location of site $35 \mathrm{CO} 2$ within the Lower Columbia River Valley.

As few ground stone-specific analyses have been conducted in the region (Peterson 1978; Pettigrew 1981; Wolf 1994), my research contributes to the Lower Columbia ground stone technology literature, detailing ground stone production, use, and technological choices. Typically, ground stone analysis in the region focuses on a form equals function model, drawing on ethnographic information where available (Pettigrew 1981:74-78; Dunnell and Beck 1979:66-70; Wolf 1994:19-22; Warner and Warner 1975:43-76). My research demonstrates that more detailed analyses provide insights into 
tool manufacturing, use, and maintenance through experimental replications and the examination of use wear.

\section{Thesis Organization}

This thesis begins with an overview of the environmental and cultural history of

the Lower Columbia River Valley in Chapter II. Additionally, I address the relationship between ground stone tools and food gathering and processing activities in the region, previous ground stone research in the Lower Columbia, followed by the excavation history at site $35 \mathrm{CO} 2$, and a review of the experimental archaeology approach.

Chapter III reviews research methods, detailing the analysis of the $35 \mathrm{CO} 2$ Rylander ground stone artifacts, and methods employed in the experimental replication phase. I present the results of the post-manufacturing analysis and use wear analysis of the experimental replications in Chapter IV. Additionally, I discuss general trends in manufacturing and use wear attributes that were observed in both the experimental replications and in the $35 \mathrm{CO} 2$ Rylander artifacts, though the full analyses are located in Appendix H. I conclude Chapter IV with the results of protein residue analyses that were conducted on a sample of 35CO2 Rylander ground stone artifacts. In Chapter V I discuss the results of analysis with respect to my research questions. I revisit the importance of ground stone tools to the inhabitants of the Lower Columbia River Valley and address the importance of in-depth analyses of ground stone tools. 


\section{Chapter II: Background}

\section{Environmental and Cultural Setting}

The Lower Columbia River Valley is defined as the region along the Columbia River from The Dalles to its mouth at the Pacific Ocean (Hajda 1984). A diverse and dynamic environmental region, the Lower Columbia encompasses three distinct environmental zones, the Cascades, the Portland Basin, and the Coast (Saleeby 1983:56). My study area focuses on the region surrounding site $35 \mathrm{CO} 2$, a contact-period village site near Scappoose Bay, which is located in the Portland Basin (Figure 1) approximately 4.6 miles (mi) (7.45 kilometers [km]) south of the confluence of the Multnomah Channel and the Columbia River. The Portland Basin is bound by Willamette Falls to the south, Rainier, Oregon, to the north, the Coast Range to the west, and the Cascade Range to the east (Saleeby 1983:4). Site 35CO2 is located approximately $99 \mathrm{mi}(159 \mathrm{~km})$ west of The Dalles and $82 \mathrm{mi}(132 \mathrm{~km})$ east of the mouth of the Columbia River. Located at the northwestern edge of the Willamette Valley Province, the Portland Basin is located within the Pinus-Quercus-Pseudotsuga vegetation zone, which contains pine (Pinus sp.), oak (Quercus sp.), Douglas fir (Pseudotsuga menziesii), and other riparian forest and grassland species (Franklin and Dyrness 1973:110; Saleeby 1983:8-9). The area surrounding site $35 \mathrm{CO} 2$ would have supported many resources valuable to native communities, such as wapato (Sagittaria latifolia), acorns (Quercus sp.), hazelnuts (Corylus cornuta), camas (Camassia quamash), salal berries (Gaultheria shallon), blackberry (Rubus macropetolus), and salmonberry (Rubus spectabilis), in addition to riverine and terrestrial fauna, including various water fowl, salmon (Onchorhynchus), 
sturgeon (Acipenser transmontanus), elk (Cervus elephus), and deer (Odocoileus sp.) (Saleeby 1983:9,173).

The Lower Columbia is located in the ancestral territory of the Chinook, who inhabited the Columbia River and its tributaries. The Chinookan peoples occupied territory from The Dalles to the mouth of the Columbia River. Based on linguistic and cultural differences, the Chinook are divided into three groups: the Lower, Middle, and Upper Chinook. Chinookan language dialects spoken at villages clustered around the mouth of the Columbia River are referred to as Lower Chinook. Kathlamet, or Middle Chinook, refers to dialects spoken between the upper reaches of the Columbia River estuary to the Portland Basin, which includes the areas surrounding Willamette Falls and the lower Clackamas River (Zenk et al. 2016:9-10). The Upper Chinook includes the dialects spoken at villages located between the Portland Basin and Wasco and Wishram to the east. Many Chinookan place names reference geographical orientation in relation to water, suggesting the importance of the river for both transportation and subsistence (Zenk et al. 2016:11). Archaeological data supports the importance of the Columbia and its tributaries to Chinookan selection of village site locations. Chinookan settlement patterns were dynamic; summer settlements were located along the Columbia River to take advantage of the rich riverine resources, while winter settlements were located in higher elevations with more shelter than the river shores could offer (Ellis 2013:58-60).

Large cedar plank houses, which would have been visible from the shores of the Columbia River, housed dense populations of Chinookan peoples from late fall to early spring. Temporary camps were occupied in the summer, as the groups were more mobile 
while exploiting accessible hunting, fishing, and gathering areas. Canoes were used to efficiently travel up and downstream on the Columbia River to access various resource procurement areas and foster trade relations (Silverstein 1990:538).

Access to rich riverine and terrestrial environments allowed the Chinook to exploit various resources including eulachon, steelhead, sturgeon, salmon, shellfish, waterfowl, deer, elk, bear, and various berries, and roots. As some of these resources were only seasonably available, the Chinook used drying techniques and storage pits, as evidenced by excavations at Cathlapotle (45CL1), the Meier Site (35CO5) (Ames et al. 2008), and Oregon Archaeological Society (OAS) excavations at site 35CO2 (Ellis 2013:46-60). Specialized acorn processing and storage activities were also taking place at the nearby Sunken Village site (Croes et al. 2007).

The Chinookan proximity to the Columbia River allowed for participation in extensive precontact and historic exchange networks. Hajda and Sobel suggest a bias in the archaeological record that favors evidence of trade in durable goods, such as obsidian and other valuable tool stone, as well as historic trade beads and metal objects.

Ethnographic documents may be biased, but suggest extensive and far reaching trade of perishable items such as foodstuffs, animal hides, and Hudson's Bay Company (HBC) blankets (Hajda and Sobel 2013:106-107). The close trade relations and proximity to Euroamericans also caused devastating population loss amongst the Chinook due to the introduction of diseases such as malaria. A series of particularly devastating malaria outbreaks in the 1830s were a factor in the decline in populations of Chinook from 
approximately 15,545 in the early 1800 s (as estimated by Lewis and Clark and the HBC) to around 1,932 in 1841, a population reduction of $88 \%$ (Boyd 1999:84).

The passing of the Donation Land Claim Act in 1850, which distributed large land tracts to Euroamerican settlers, coupled with the severe decline in the Indigenous population, led to a shift in settlement patterns in the region. By 1856, much of the southern portion of Sauvie Island and the surrounding area along the Multnomah Channel was settled by Euroamericans who farmed the area (Matrazzo 2012; Spencer 1950). Though the General Land Office (GLO) survey map of 1854 does not feature development or land claims, the 1866 survey revision reveals land claims all along the Multnomah Channel near Scappoose Bay and the $35 \mathrm{CO} 2$ site area. Because of limited detail, it is difficult to identify the individual claim that encompasses the site area (GLO 1854, 1866). By 1909, the Rylander family moved to the property and developed a dairy and vegetable farm before selling the property in 1949 to L.A. Decker (Anna Marie Updegraff (Rylander), personal communication, 2015).

\section{Lower Columbia Ground Stone Studies}

Bright et al. (2002:178) suggest that as a resource increases in importance, so too will the time invested in tool manufacturing for the required processing. Though this correlation is not discussed directly within the Lower Columbia, it is evident in the greater Northwest Coast region. Ames and Maschner (1999:90-94) hypothesized that increased sedentism and an emphasis on mass food harvesting and food storage economies coincided with an increase in the presence of ground stone subsistence-based processing tools in the Middle (1800 BC to AD 200/500) and Late Pacific (AD 200/500 to AD 1775) periods Ames and Maschner (1999:91-94) also hypothesize that ground 
stone tools associated with major tree harvesting and the splitting of planks also increased in the region during this period; this shift may have been associated with the rise in sedentism and the construction of large plank houses in the Northwest Coast region. However, information about the age of sites in this region, and a lack of synthetic information about the distribution of ground stone, means these hypotheses cannot yet be evaluated. Further complicating any study of ground stone is the probability that ground stone tools were curated due to the time it takes to manufacture ground stone tools, particularly those made from harder materials such as granite or fine-grained volcanic material. Count-based ground stone analyses are problematic as ground stone use at any given time is difficult to enumerate.

Ground stone studies in the Lower Columbia have addressed the documentation and description of mobile stone sculpture (Peterson 1978), the identification and classification of ground stone artifacts (Pettigrew 1981), and the analysis of ground stone tools as markers of status differentials at the Meier Site (Wolf 1994). Additional documentation and analysis of the ground stone assemblages from the Meier and Cathlapotle sites was conducted by Cameron Smith, Greg Baker, and William Gardner O'Kearny (Ames et al. 2017:440-464). A brief technical report was released, which details artifacts classed in the three major ground stone categories encountered at the Meier and Cathlapotle sites, including abraders, mauls/pestles, and net weights. This report (Ames et al. 2017:440-464) focuses on the spatial distribution of ground stone tools to explore craft specialization, status, and prestige associated with ground stone manufacture and use within the household and community (Ames et al. 2017:440-464). 
Ames et al. (2017:449-451) present experimental ground stone replication studies conducted by Cameron Smith. Smith used hammerstones in ground stone manufacture experiments and examined the resulting hammerstone facets. These facets were subsequently examined and quantified on the Meier and Cathlapotle hammerstones, which helped identify production methods and loci at the sites. A more comprehensive report detailing the full ground stone analysis from the Meier and Cathlapotle sites still needs to be completed (Ames et al. 2017:449-451). While these studies contributed to understanding the types of ground stone and the use of such implements by Indigenous populations in the Lower Columbia, most Pacific Northwest archaeologists have not examined technological aspects of ground stone, including manufacturing strategies and use wear.

\section{The Relationship between Ground Stone Production and Food Gathering/Processing}

Previous research established a relationship between investments in ground stone production and changing subsistence strategies, particularly in relation to the use of plant materials. Adams (1999:475-477) suggests that analysis of ground stone tools played a significant role in elucidating subsistence strategies in the New and Old World, specifically through the identification of processing domesticated and non-domesticated plant resources. In the American Southwest, manos and metates are identified as processing implements for both small seeds, and maize (Adams 1999:479-482). In the same region, Buonasera (2012: 21-23) argues that increased investment in ground stone technology suggests an increased reliance on specific plant resources that she identified through ground stone lipid analyses. In eastern North America, Kristen Gremillion discussed the relationship between mortars and pestles for processing small seeds and 
grains, suggesting that high investments in tool manufacture and processing labor did not compete with other productive tasks (Gremillion 2004: 228-229). The presence of seeds and acorns in association with ground stone mortars and pestles can provide information about changes in subsistence patterns, the distribution of plant food availability, and changes in subsistence labor levels (Buonasera 2013:190-192). These examples of ground stone tools and their association with plant materials reveal a strong relationship between plant resources and the tools used to process them, as well as a strong reliance on the procurement and processing of plants for subsistence.

Ethnographic sources from the Lower Columbia describe ground stone tools being used for a variety of tasks including carving associated with canoe manufacture, timber harvesting and splitting associated with plank house construction (Spier and Sapir 1930), vegetal processing (Lewis 1964:156-158; Lewis and Clark 1893:673-675, 928930; Gahr 2013:73-75), and fish harvesting and processing (Spier and Sapir 1930; Ray 1938). Specific reference to ground stone tools in the ethnographic record of the Lower Columbia is rare when compared to reference to flaked lithic tools. Consequently, I supplemented Lower Columbia research with literature that generalizes the Pacific Northwest when necessary. To supplement the dearth of direct mention of ground stone tools, I also examined records of activities that would have used ground stone tools to inform on past tool manufacture and use. For example, in Wishram Ethnography, which documents Spier and Sapir's experiences and observations in The Dalles-Celilo area, the authors noted the use of ground stone tools for manufacturing canoes (Spier and Sapir 1930:187-188). In addition to ground stone tools used in canoe manufacture, ground 
stone tools in the form of net weights were documented in descriptions of fishing throughout the Lower Columbia (Spier and Sapir 1930:176; Ray 1938:108). Ground stone tools were also used to produce dried and pounded salmon meal and to transform various roots into pulp for making thin and oblong cakes (Lee and Frost 1968:181). Ethnographic and Archaeological Information on Lower Columbia Ground Stone Tool Manufacture

Spier and Sapir's Wishram informant, Mrs. Teio, described the characteristics and manufacturing process of ground stone bowls by stating:

Stone bowls were made of granite. The hollow was made first since the stone would withstand hard pecking while the stone was still a solid block. When the hollow was completed, the exterior was dressed. Large bowls of this type were used for cooking by the familiar process of dropping hot stones into the food (Spier and Sapir 1930:190).

Additionally, Mrs. Teio described the qualities of pestles and their manufacture in detail:

Stone pestles were 12-14 inches long, round in section, tapering from a three inch diameter at the bottom to half that at the top. The lower face was somewhat convex. The upper end was sometimes ornamented by shaping it to resemble a nose, for example. These were made of common or black granite (gabro? [sic]), the latter being better material. The stone was placed on a layer of dry dirt, four or five inches thick, to serve as a cushion and prevent it breaking during the pecking process. It was lightly tapped with a sharp-edged fragment of granite, turning it the while to give it cylindrical form. Hollows were fashioned by continuous pecking at one spot (Spier and Sapir 1930:189).

Mrs. Teio described a "pecking" technique, and discussed the use of a "sharpedged fragment of granite" in the reduction process, which may be referencing the use of a cobble chopper. Cobble choppers are defined as hand-held tools made from cobble (64-254 $\mathrm{mm}$ [2.5-10 in]) and pebble-sized stones (less than $64 \mathrm{~mm}$ [2.5 in]), which are manufactured by the removal of one or more flakes by direct percussion (Roulette 1989:4). Early studies of cobble choppers hypothesized that different chopper shapes and 
sizes represented specific typologies related to function (Borden 1968:61), however, subsequent research suggests that different forms are likely attributed to material type, the original shape of the cobble, and repeated resharpening events (Haley 1996:51-53; Roulette 1989:4-5; Hayden and Nelson 1981:888). I conducted a records review to establish if there are other accounts of using cobble choppers in ground stone production. Few have hypothesized that cobble choppers were used in ground stone manufacture (Roulette 1989:35-36) and even fewer have experimentally used cobble choppers in ground stone replications.

I located one account of a contemporary Mayan population using cobble choppers to produce ground stone bowls. Ethnoarchaeological research conducted in the Mayan Highlands of Malacatancito, Guatemala, revealed the use of fine-grained basalt and metamorphic stone cobble choppers to produce manos and metates made of vesicular basalt. In addition to witnessing the reduction process, Hayden and Nelson observed discarded exhausted choppers at quarry locations along the river and at workshop sites adjacent to occupied homes. The choppers were classed in three size categories. The largest were used for roughing out a block of vesicular basalt at the quarry location, weighed approximately 2 kilograms $(\mathrm{kg})$ (4.4 pounds [lb]), and were mostly used with two hands. Choppers weighing approximately $1 \mathrm{~kg}(2.2 \mathrm{lb})$ were classed in the second size class and were used with one hand for later-stage reduction and shaping. The smallest size class included choppers weighing approximately .5 kg $(1.1 \mathrm{lb})$; tools in this class were used for final shaping stages of ground stone. Hayden and Nelson note that the flaked portion of the chopper was driven directly into the subject piece to remove 
material. Once the chopper edge was too blunt to be effective, tool makers removed flakes to resharpen the working edge. The authors concluded that variations in chopper form were not attributed to intentional shaping, but rather, were caused by episodes of rejuvenation. Variations in wear occurred between the larger size classes and the smallest size class, as the smaller choppers featured pronounced edge-rounding due to using the edge as an abrader as well as a pecking tool. The abrading finishing technique often caused a degree of edge-rounding that caused the negative flake scars on the choppers to no longer be visible. Not only did this article detail the reduction process, Hayden and Nelson also described raw material selection for the cobble choppers. Knowing the choppers had to withstand considerable force from impact blows on the vesicular basalt, the stone workers selected dense and fine-grained basalt for chopper manufacture. They examined potential chopper materials for flaws and often tested cobbles before reduction. Cobbles were discarded after minimal use if deemed unsuitable after a few attempts (Hayden and Nelson 1981:885-896). Despite regional differences between the Mayan Highlands and the Lower Columbia, Hayden and Nelson's work shows the effectiveness of cobble choppers in ground stone manufacture and the skill and knowledge required in the raw material selection and reduction process.

Ground stone tools represent a diverse and important part of the tool kit in the Lower Columbia, yet little is known about tool manufacture, use, and how these artifacts may reflect changes in subsistence strategies and resource use over time.

Archaeological Investigations at Site 35CO2

Archaeologists have conducted a limited number of large-scale archaeological excavations in the study region. As a result, there are few local ground stone collections 
that have been professionally excavated. As previously mentioned, the majority of local ground stone is in private legacy collections. Though lacking archaeological context, private ground stone artifact collections have much to offer regarding the identification of site-specific resource procurement and processing activities, artifact functions through use wear and residue analyses, and artifact life histories. I analyzed ground stone artifacts from a private artifact collection originating from site $35 \mathrm{CO} 2$, the Rylander collection.

The ground stone artifacts analyzed from site $35 \mathrm{CO} 2$ are part of a collection from the homesteading family, the Rylanders. The Rylander $35 \mathrm{CO} 2$ collection contains over 60 individual ground stone artifacts, including mauls, pestles, bowls, abraders, perforated and banded net weights, adze blades, and stone sculptures (Table 1). Artifacts were collected between 1909 and 1946 at site 35CO2 during farming activity.

Emory Strong briefly described site 35CO2 in Stone Age on the Columbia in 1959 (Strong 1959) and Richard Pettigrew formally recorded the site with the Oregon State Historic Preservation Office in 1973 (Pettigrew 1973). However, much of what is known about site $35 \mathrm{CO} 2$, is a result of excavations conducted by OAS, an avocational archaeology interest group, in 1960, 1962, and 1963. Excavation blocks were laid out beginning approximately 30.48 meters $(\mathrm{m})(100$ feet $[\mathrm{ft}])$ from the edge of the river bank and were excavated in $1.5-\mathrm{m}(5-\mathrm{ft})$ blocks and 30.5-centimeter $(\mathrm{cm})(12$-inch [in]) levels. In total, 1,032, $1.5 \times 1.5 \mathrm{~m}$ units were excavated. Level record sheets detailing soil changes and encountered features were completed for each excavated level. Unit floors were also drawn if a feature was encountered and excavation walls were profiled once an 
entire row of units was completed. Artifacts recovered during OAS excavations were collected and bagged with provenience information (Jones 1972). After the excavations were completed, artifacts were intended to be classified then returned to the individual who paid to excavate the block. Classification workshops were hosted by OAS. If unable to attend, excavators could request classification documents and send information to the OAS secretary (Screenings 1963).

In 2015, OAS members Dan Stueber and David Minnick relocated OAS site records from the $35 \mathrm{CO} 2$ excavations. Available records include artifact classifications, drawings, and descriptions; unit floor drawings; profile sketches and soil descriptions; site maps; and a handwritten preliminary report authored by Emory Strong. I reviewed the $35 \mathrm{CO} 2 \mathrm{OAS}$ documents as part of my background review, which suggest between 20 and 30 percent of excavators classified and recorded their finds (Table 1). Though approximately 70 to 80 percent of the artifact frequency data are missing from the OAS excavation records, available records indicate an abundance of ground stone artifacts. The sizeable and diverse artifact assemblage suggests that site 35CO2 was a substantial occupation site with many specialized activities occurring at the locale, including resource processing with ground stone tools, wood working, and the manufacture, use, and maintenance of flaked lithic tools. Due to the collection of artifacts by OAS members at site $35 \mathrm{CO} 2$, artifacts are located in scattered private collections and are unavailable for analysis. All ground stone analysis detailed in this thesis was conducted on the assemblage collected by the homesteading family, the Rylanders (Table 1). Despite the informal artifact collection by the Rylanders at site $35 \mathrm{CO} 2$, the assemblage 
has the potential to provide valuable information on local ground stone technology. It is not possible, however, to extrapolate from my analysis in much detail about the larger, unavailable, groundstone assemblage given the differences in collection strategies and lack of information available for a large portion of the OAS effort at $35 \mathrm{CO} 2$.

Table 1. Recorded ground stone totals from OAS excavations by year and Rylander collection totals. These totals represent only a fraction of the ground stone likely recovered from the site. Only the Rylander collection was available for my analysis.

\begin{tabular}{lccccc}
\multicolumn{1}{c}{ Tool Type } & $\mathbf{1 9 6 0}$ & $\mathbf{1 9 6 2}$ & $\mathbf{1 9 6 3}$ & Total & Rylander Collection \\
\hline Abraders & 32 & 48 & 57 & 137 & 1 \\
\hline Adzes & 8 & 9 & 13 & 30 & 6 \\
\hline Bowls \& Mortars & 13 & 11 & 12 & 36 & 8 \\
\hline Mauls \& Pestles & 50 & 31 & 35 & 116 & 19 \\
\hline Net Weights & 58 & 62 & 62 & 182 & 13 \\
\hline Other & 0 & 0 & 0 & 0 & 15 \\
\hline Total & & & & $\mathbf{5 0 1}$ & $\mathbf{6 2}$
\end{tabular}

\section{Experimental Archaeology}

With limited ethnographic information on ground stone tool manufacture and use

in the Lower Columbia, we must rely on archaeological examples and experimental replications to clarify regional site use, tool manufacture and maintenance, and resource procurement and processing strategies. Experimental archaeology is defined as the "fabrication of materials, behaviors, or both in order to observe one or more processes involved in the production, use, discard, deterioration, or recovery of material culture" (Skibo 1992:18). This approach aims to systematically test hypotheses, while replicating conditions and activities, to ultimately develop data-based observations that help interpret and explain past systems. The ultimate goal of experimental archaeology is not just to replicate a particular technology, but to learn about the sequence of events and build a 
body of knowledge around the entire manufacturing process that can be used to help interpret the past (Schiffer and Skibo 1987: 595-597).

Binford suggests that while the archaeological record is static, living systems must be examined to connect present observations to past inference. For experimental archaeology to be a viable means of analysis, we must operate under the assumption that contemporary observations can be applied to past living systems (Binford 1983:417-419). Gould explains that observations of present processes are a good foundation to understand and explain past events (Gould 1977:150). This inferential process is important, as we can isolate causal relationships from outcomes in a contemporary setting, and examine archaeological objects and infer the acting factors that impacted the object prior to it entering the archaeological record. These isolated "causes" and relationships can take the form of "signature patterns" or attributes that can be observed both in experimental replications and in the archaeological record. These diagnostic attributes can be assumed to show a correlation between actions and outcomes in the present and past, rather than a coincidence (Binford 1983: 417-419).

Past experimental archaeological research has been criticized for lacking a theoretical foundation, not adhering to scientific experimental procedures, and lacking archaeological applicability (Outram 2008:1-5; Flores 2012:64, 198-203). However, recent research has developed foundational principles, such as emphasis on sound scientific methods, clear research designs, and theoretical contextualization, to legitimize experimental archaeology (Marsh and Ferguson 2010:1-5). With rigorous attention to 
these principles, experimental archaeology will increase our understanding of the archaeological record and past human behaviors.

The first accounts of experimental archaeology being applied to lithic studies was reported in the late 1860s when Sven Nilsson and Sir John Evans used their personal flintknapping experiences to help explain how artifacts in the archaeological record were made and used. Nilsson did not attempt to replicate artifacts, but instead was able to draw conclusions from knapping flints for his rifle, while Evans replicated English handaxes to prove that they were produced with only stone implements. Nilsson and Evans' groundbreaking work with experimental knapping led to increased scientific exploration in lithic studies (Johnson 1978:337-338). Experimental flintknapping studies continued to evolve and notable knappers Don Crabtree and Errett Callahan introduced the importance of not only the product of experimental knapping, but the process of flintknapping, emphasizing reduction stages and techniques (Crabtree 1967: 60-63; Callahan 2000: 1-5, 25-35). When applied to lithic studies, Flenniken defines replication in experimental archaeology as reproducing stone tools using archaeological objects as controls, using the same raw materials and reduction tools as past tool manufacturers, while employing similar traditional or aboriginal reduction techniques (Flenniken 1975:2). Experimental archaeology has played a significant role in understanding the mechanics of flaked lithic production and use (Collins 1975:15-24; Crabtree 1975:105113; Callahan 2000: 1-5; Flenniken 1981:1-12). Experimental archaeology can inform on material selection and preference, production strategies, tool use, and can be extended 
to interpret human behavior associated with tool manufacture and use (Crabtree 1975:105-113).

Despite the potential for exploring and evaluating production and use similar to flaked lithic research, experimental archaeology focusing on ground stone tool production and use is limited. Notable contributions have explored manufacturing mechanics, macro and microscopic use wear patterns, raw material selection, and residue analysis, most of which focus on replicating ground stone tools from the North American Southwest (Adams et al. 2015; 1-5, 15-18; Adams 2014:129-137; Adams 2002: 62-65; Adams 1999: 475-498; Adams 1989:261-270; Buonasera 2015:335-344; Buonasera 2012:19-21, 31-35; Osborne 1998:116-122; O’Brien 1994:22-50; Squitieri and Eitam 2016:1-9). Despite the geographic difference, experimental ground stone replications conducted in the North American Southwest are applicable to the Lower Columbia, as major principles relating to manufacturing strategies, design theory, tool efficiency, and use wear are not defined by geography. Additionally, experimental ground stone replications, regardless of study area, offer valuable insight into experimental research design and methods.

Adams has contributed substantially to experimental ground stone literature, detailing manufacturing and use strategies, as well as innovative analysis methods. While Adams has been involved in numerous experimental ground stone replication studies (Adams et al. 2015; 1-5, 15-18; Adams 2014:129-137; Adams 2002: 62-65; Adams 1999: 475-498; Adams 1989:261-270), key components that are present throughout her research include the combination of archaeological data and 
ethnoarchaeological studies, the application of tribology, or the study of friction and wear patterns, to aid in interpreting use wear on ground stone tools, and the use of macro and microscopic magnification for analysis and documentation of use wear. Despite the rise in influential experimental ground stone research, Adams states the approach lacks standardization in methods of analysis and terminology. In an effort to remedy this inconsistency, Adams has made her research transparent and accessible. While drawing from tribology research, Adams outlined four classes of wear mechanisms, including adhesive wear, fatigue wear, abrasive wear, and tribochemical wear (Figure 2). Adams describes adhesive wear as the occurrence of movement when two surfaces come into contact with each other, creating molecular interactions that are broken as one surface moves across the other. Adhesive wear is often seen where tools are heavily handled due to the adherence of skin oils on the tool surface even when no other wear is visible. Fatigue wear results from the stress of movement applied on surfaces in contact with one another, which causes the crushing and collapse of grains with higher elevations than the surrounding surface. Fatigue wear is visible on ground stone tools as cracks, step fractures, pitting, and may have the appearance of frosted glass. Abrasive wear is caused by the movement of loosened material, which may have been dislodged through adhesive and fatigue wear. These loose particles become an abrasive agent and cause surface damage that is visible as striations and gouges on the higher elevation grains on the tool surface. The harder or more durable grains on one surface work against the softer material of the other working surface. Striations can be examined to assess directionality of applied force. Adhesive wear, fatigue wear, and abrasive wear work interactively and 
create chemical interactions between grains on the tool surface and processed materials, which is called tribochemical wear. Adams labels these interactions as reaction products, which are oxides and other films that build up on the working surface. These may be visible as a sheen or polish on tool surfaces (Adams 2002:28-32; Adams 2014:129-137).

By recognizing wear patterns in experimental replications with controlled processing activities, we have the opportunity to examine unmodified surfaces, interactions between working surfaces and processed materials, as well as tool efficiency, breakage patterns, and tool recycling (Adams 2014:133-137). Adams suggests that a standardization of methods and vocabulary in experimental ground stone replications and analysis will not only eliminate the need for new jargon and duplicate studies, it will allow researchers the opportunity to explore new hypotheses and widen replications to include various material types and a wider array of resources to process (Adams 2014:136-137).

While previous experimental ground stone research has contributed greatly to the discipline, more research is needed to address raw material use, manufacturing strategies, and tool use and recycling specific to Pacific Northwest archaeology to help illuminate past behaviors surrounding resource procurement and use. 


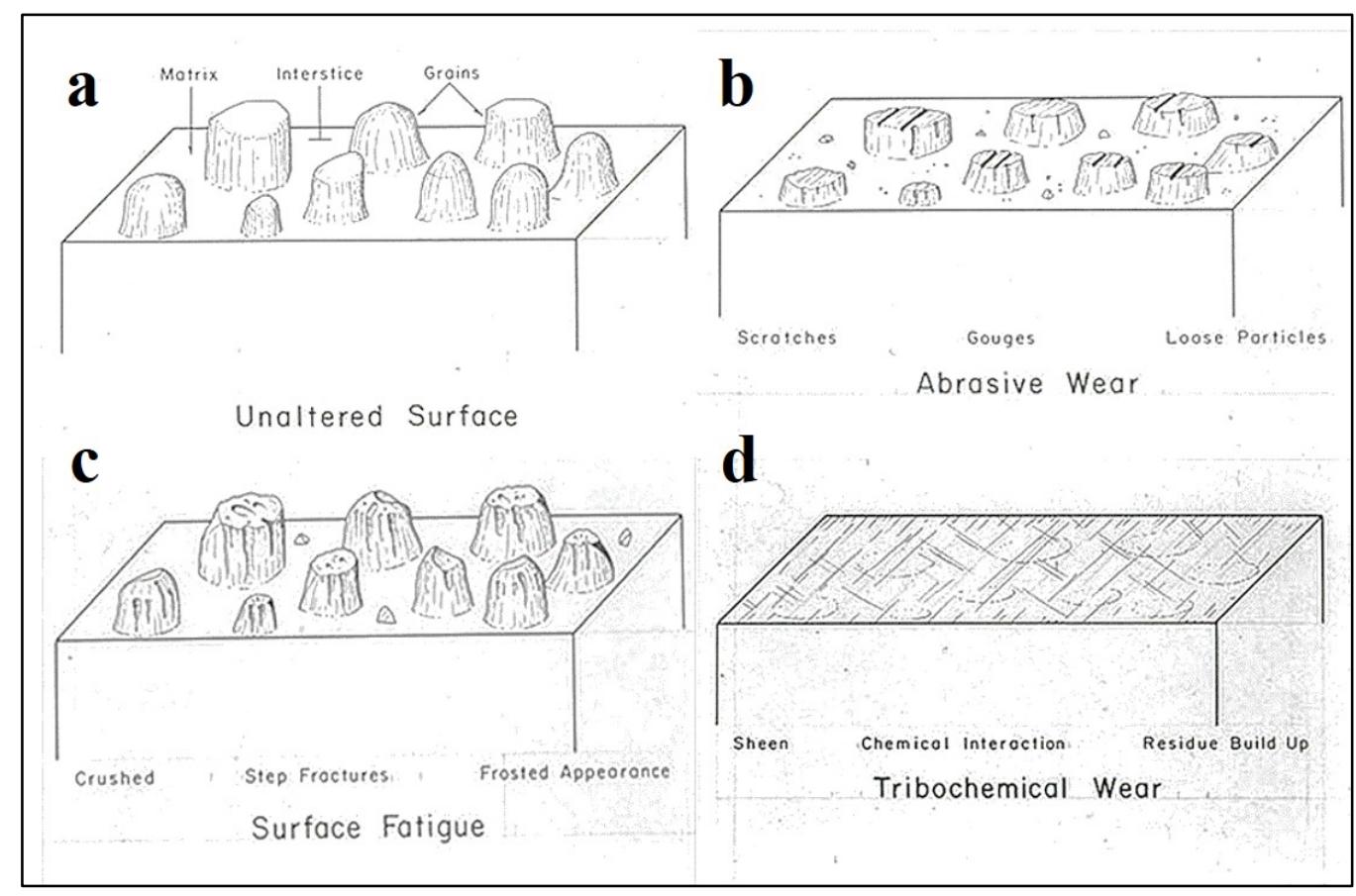

Figure 2. Line drawings of ground stone wear. (a) Microscopic view of an unaltered stone surface; (b) Microscopic view of abrasive wear; (c) Microscopic view of surface fatigue; (d) Microscopic view of tribochemical wear. Images adapted from Adams (2002). 


\section{Chapter III: Research Methods}

There are five stages to my thesis research: 1) preliminary analysis of a sample of the $35 \mathrm{CO} 2$ Rylander ground stone artifacts to identify raw material types and examine possible manufacturing attributes, 2) experimental replication and analysis of replicates, 3) experimental processing and subsequent use wear analysis of replicates, 4) analysis of ground stone artifacts from the 35CO2 Rylander collection, and 5) residue analysis of a sub-sample of ground stone artifacts from the 35CO2 Rylander collection. In this chapter I summarize my approach to each of these methods of analysis.

Preliminary Analysis of 35CO2 Ground Stone Artifacts

Traditionally, ground stone analyses consist of using form to determine function, in addition to recording the implement's weight and a few other attribute descriptions. Analysis that only relies on a form equals function model misses other potential tool uses, manufacturing, and use attributes. Adams (2002:5-7) suggests that we can explore higher-level research questions regarding ground stone through more holistic technological analyses. Adams (2002) promotes a fine-grained empirical, experimental, and methodological approach that I adopted in my analysis. I used clarifying terminology in artifact attribute descriptions and type definitions to facilitate the comparability of ground stone artifacts between sites and across time.

My analysis entailed taking measurements to record artifact weight, length, width, thickness, and circumference. Ground stone terminology, anatomy, and measuring strategies were adapted from Adams (2002 and 2014), Dubreuil and Savage (2014), and Banning (2000). Using categories adapted and defined by Adams (2002) and Pettigrew (1981), I conducted a preliminary classification of 35CO2 artifacts. In addition to the 
abovementioned measurements, my analysis detailed raw material type, tool condition, texture on used and non-used surfaces, grain morphology (e.g. rounded, crushed, leveled) tool design, the presence or absence of residues or staining, and the presence or absence of evidence of tool recycling (Table 2). Adams (2002:23) defines a recycled tool as a tool that was designed for a primary activity, then is employed in a different context that may have physically altered the item.

Furthermore, I recorded attributes that I associated with manufacturing, which included flake scars, and linear gouges with v-shaped cross sections, which I hypothesized as remnant chopper scars. When existing definitions appeared too subjective or not regionally appropriate, I elaborated or edited these definitions to make them more suitable.

Additionally, I examined and tested existing ground stone definitions and classification systems to identify inadequate metrics and subjective classifications. While following Adams' (2002) analytical methods, I found assigning codes for various attributes too limiting for tools with such dynamic wear. Additionally, the use of codes for attributes such as level of sharpness, damage, and usability, is subjective and I was not confident that the categories were mutually exclusive or that my results could be replicated by another researcher. Based on this preliminary analysis, in addition to knowledge of factors important in technological choice, and the local ethnographic record, I developed hypotheses, expectations, and analysis methods to address my research questions (Table 3). 
Table 2. Ground stone attributes, descriptions, interpretations, and representative photographs.

\begin{tabular}{|c|c|c|c|}
\hline Attribute & Description of Expression & Interpretation of Attribute & Image of Attribute \\
\hline Grain Crushing & $\begin{array}{l}\text { Visible as crushed or collapsed } \\
\text { asperities, gouging, step } \\
\text { fractures are common. }\end{array}$ & $\begin{array}{l}\text { Manufacture through pecking, } \\
\text { processing of hard materials, may also } \\
\text { represent post-depositional damage. }\end{array}$ & \\
\hline Grain Leveling & $\begin{array}{l}\text { Visible as flattened or plateaud } \\
\text { asperities, striations may be } \\
\text { visible on flattened grain } \\
\text { surfaces. }\end{array}$ & $\begin{array}{l}\text { Wear associated with processing using } \\
\text { directional force, may also be associated } \\
\text { with tool manufacture with directional } \\
\text { force and the use of an abrasive agent. }\end{array}$ & \\
\hline Grain Rounding & $\begin{array}{l}\text { Visible as domed or rounded } \\
\text { asperities. }\end{array}$ & $\begin{array}{l}\text { Processing of soft, pliable materials, may } \\
\text { also represent natural wear in an alluvial } \\
\text { setting. }\end{array}$ & \\
\hline Polish & $\begin{array}{l}\text { Visible as a sheen, reflective } \\
\text { under additional light. }\end{array}$ & $\begin{array}{l}\text { Heavy use, accumulation of processed } \\
\text { materials, including fats and oils. }\end{array}$ & \\
\hline
\end{tabular}


Table 3. Summary of research questions, hypotheses, expectations, and means of analyses.

\begin{tabular}{|c|c|c|c|}
\hline Research Question & Hypothesis & Expectations & Method of Analysis \\
\hline $\begin{array}{l}\text { - What are the manufacturing } \\
\text { time investments for ground } \\
\text { stone tools? } \\
\text { - Is there a relationship } \\
\text { between investment in } \\
\text { production and rates of } \\
\text { recycling? }\end{array}$ & $\begin{array}{l}\text { - Ground stone tools require } \\
\text { high manufacturing time } \\
\text { investments. As a result, tools } \\
\text { will be rejuvenated and broken } \\
\text { tools will be recycled. }\end{array}$ & $\begin{array}{l}\text { - A fine-grained and hard raw material will } \\
\text { require more manufacturing time } \\
\text { investment than a coarse-grained and softer } \\
\text { raw material. } \\
\text { - Ground stone tools will be rejuvenated } \\
\text { and/or recycled when possible due to the } \\
\text { high investment already put in. }\end{array}$ & $\begin{array}{l}\text { - Experimental replication of } \\
\text { high time investment and low } \\
\text { time investment/expedient } \\
\text { pieces. } \\
\text { - Examine rates of rejuvenation } \\
\text { and recycling in archaeological } \\
\text { assemblages. }\end{array}$ \\
\hline $\begin{array}{l}\text { How does raw material } \\
\text { selection relate to the } \\
\text { manufacture of specific tool } \\
\text { types? }\end{array}$ & $\begin{array}{l}\text { - Different material types will } \\
\text { be used depending on the } \\
\text { intended function of the tool. }\end{array}$ & $\begin{array}{l}\text { - Materials which rank higher on the Mohs } \\
\text { scale of mineral hardness will be } \\
\text { differentially selected for tools that require } \\
\text { low porosity and high durability. } \\
\text { - Materials which rank lower on the Mohs } \\
\text { scale will be differentially selected for tasks } \\
\text { that require porosity or for ease in } \\
\text { manufacturing. }\end{array}$ & $\begin{array}{l}\text { - Determine rank of raw } \\
\text { materials on Mohs scale for } \\
\text { archaeological and } \\
\text { experimental assemblages. }\end{array}$ \\
\hline $\begin{array}{l}\text { - Does the manufacturing } \\
\text { wear (grain structure on the } \\
\text { tool surface) vary depending } \\
\text { on manufacturing strategies? } \\
\text { - How so? }\end{array}$ & $\begin{array}{l}\text { - Microscopic manufacturing } \\
\text { wear will differ depending on } \\
\text { manufacturing strategy. }\end{array}$ & $\begin{array}{l}\text { - Pecking and pounding will cause step } \\
\text { fractures and crushing of the surface grains. } \\
\text { - Grinding will cause rounding and polishing } \\
\text { of surface grains. }\end{array}$ & $\begin{array}{l}\text { - Experimental replication and } \\
\text { analysis of manufacturing wear } \\
\text { will be documented. }\end{array}$ \\
\hline $\begin{array}{l}\text { - Does the use wear on the } \\
\text { tool surface vary depending } \\
\text { on tool use? } \\
\text { - How so? }\end{array}$ & $\begin{array}{l}\text { Microscopic use-wear will } \\
\text { differ depending on tool use. }\end{array}$ & $\begin{array}{l}\text { - Pounding soft vegetal material will cause } \\
\text { crushing of the grains in the use area. } \\
\text { - Grinding denser materials will cause the } \\
\text { sheering of grains and more polished } \\
\text { surfaces. } \\
\text { - Abrasive wear will cause striations and will } \\
\text { loosen surface grain particles, which } \\
\text { become part of the abrading process. }\end{array}$ & $\begin{array}{l}\text { - Experimental use and analysis } \\
\text { of use wear. Use wear will be } \\
\text { photographically documented. } \\
\text { - Blood residue analysis and } \\
\text { possibly starch and phytolith } \\
\text { analyses will be conducted and } \\
\text { results documented. }\end{array}$ \\
\hline
\end{tabular}




\section{Experimental Tool Replication}

Raw Material Selection

I gathered raw materials similar to those found in the $35 \mathrm{CO} 2$ Rylander collection in the Columbia River Gorge at two different locations. I targeted large (between 15 and $25 \mathrm{~cm}$ (5.9 and $9.8 \mathrm{in}$ ) in diameter) andesite alluvial cobbles from the Sandy River Delta in Troutdale, Oregon, and collected five suitable pieces eroding from the shoreline, being sure none of the selected cobbles were artifacts (Figure 3). Andesite cobbles and boulders are common in this area, as the material travels down the Sandy River from its source on Mount Hood (Scott et al. 1997:1-2). In addition to the workability of the material, I selected andesite for the experimental replications, as multiple net weights from the $35 \mathrm{CO} 2$ Rylander collection are manufactured from andesite. Additionally, beginning the reductions with material that is close in shape to the targeted replication saved time and energy in removing excess material. Due to the various lines of evidence (archaeological, ethnohistoric, contemporary ethnographic, and experimental) suggesting cobble chopper use in ground stone manufacture, I decided to experiment with this reduction strategy in my replications. 


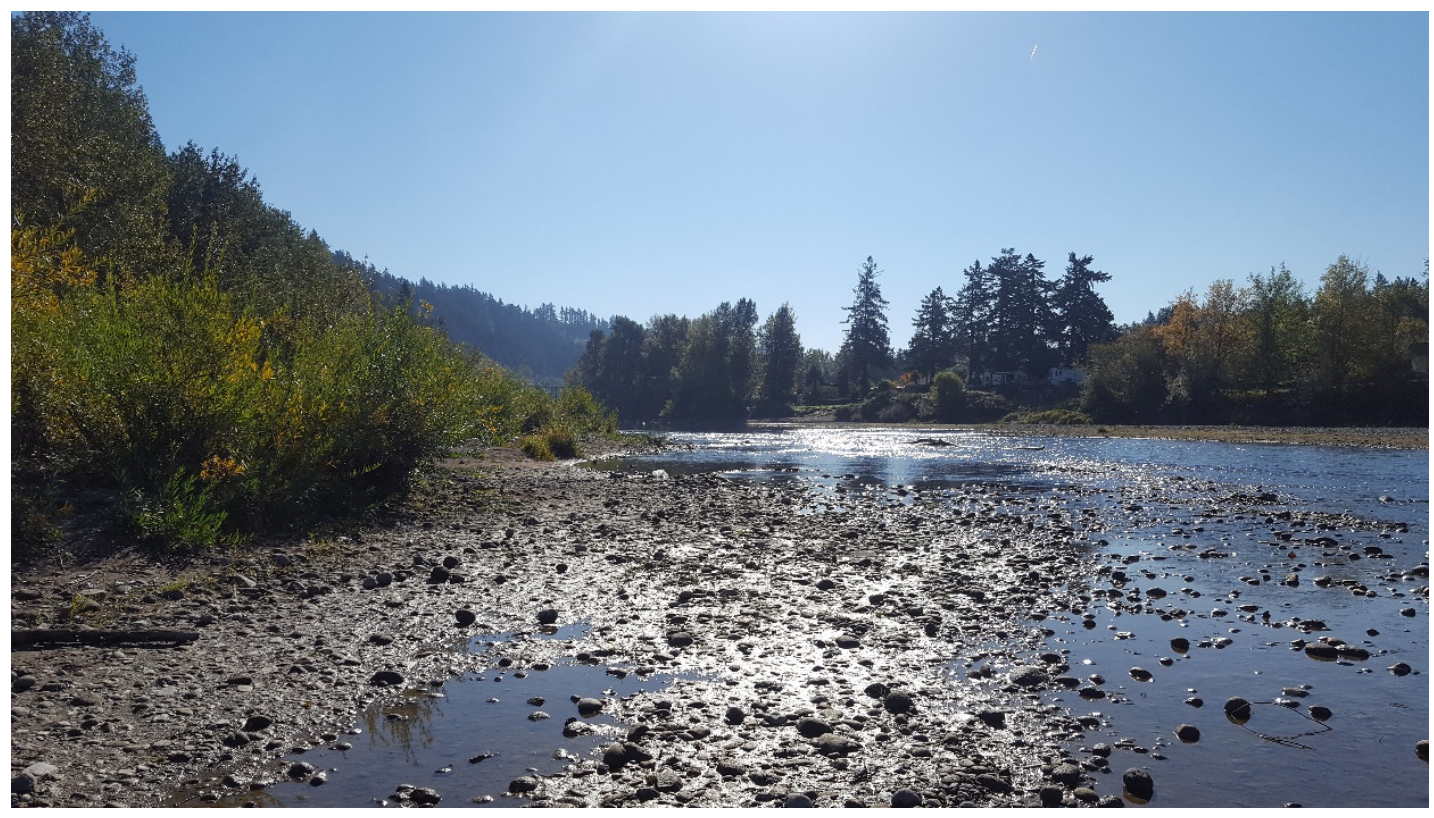

Figure 3. Raw material collection site: Sandy River Delta, Troutdale, Oregon.

I collected small to medium-sized (10-12 cm [3.9-4.7 in in diameter]) alluvial cobbles for chopper manufacturing from large piles of dredge material adjacent to the Columbia River near Rufus, Oregon (Figure 4). I selected cobbles that fit comfortably in my hand and had at least one thin margin from which flakes could be removed, avoiding cobbles with visible seams, bedding planes, or other material flaws that would compromise integrity or flake-ability. There are no choppers in the 35CO2 Rylander collection, so I based my targeted size on previous experimental experiences and familiarity with cobble choppers in local archaeological assemblages. I had previously only worked with quartzite cobble choppers and I wanted to experiment with other material types. So, in addition to quartzite, I also collected fine-grained volcanic and granite cobbles.

I also gathered cobbles to be used as hammerstones from the dredge piles. I targeted cobbles that fit comfortably in my hand, had considerable heft, and were either 
quartzite, fine-grained volcanic, or granite in composition. Finally, I targeted materials that would be suitable for manufacturing mauls and pestles. I selected oblong cobbles, ideally with a natural shape that mimicked the desired finished shape and that fit comfortably in my hand.

Once collected, I selected the best pieces for each replication tool category based on raw material composition and morphology. I created a pre-replication analysis form (Appendix B) and conducted the analysis on all selected materials prior to modification, which consisted of taking length, width, and thickness, circumference, and weight measurements. In addition to these metrics, I also noted material type and examined the texture and topography at no magnification, low magnification (up to 45x magnification), and high magnification (45x to $100 \mathrm{x}$ magnification). I sketched and photographed the materials as a whole, then photographed multiple surfaces using a Zeis Stemi 2000 CS Trinocular Zoom microscope.

Once replications were underway, it became clear that some of the cobbles I collected were not suitable for chopper manufacture due to shape, material type, or material flaws. Also, I had previously underestimated the relatively short lifespan of choppers when used on hard materials. I returned to the dredge disposal piles in Rufus, Oregon and collected additional cobbles. I only collected quartzite cobbles, as these proved to be the easiest to flake and the most durable. I was more selective regarding cobble shape, thickness, and did not collect any with visible flaws. 


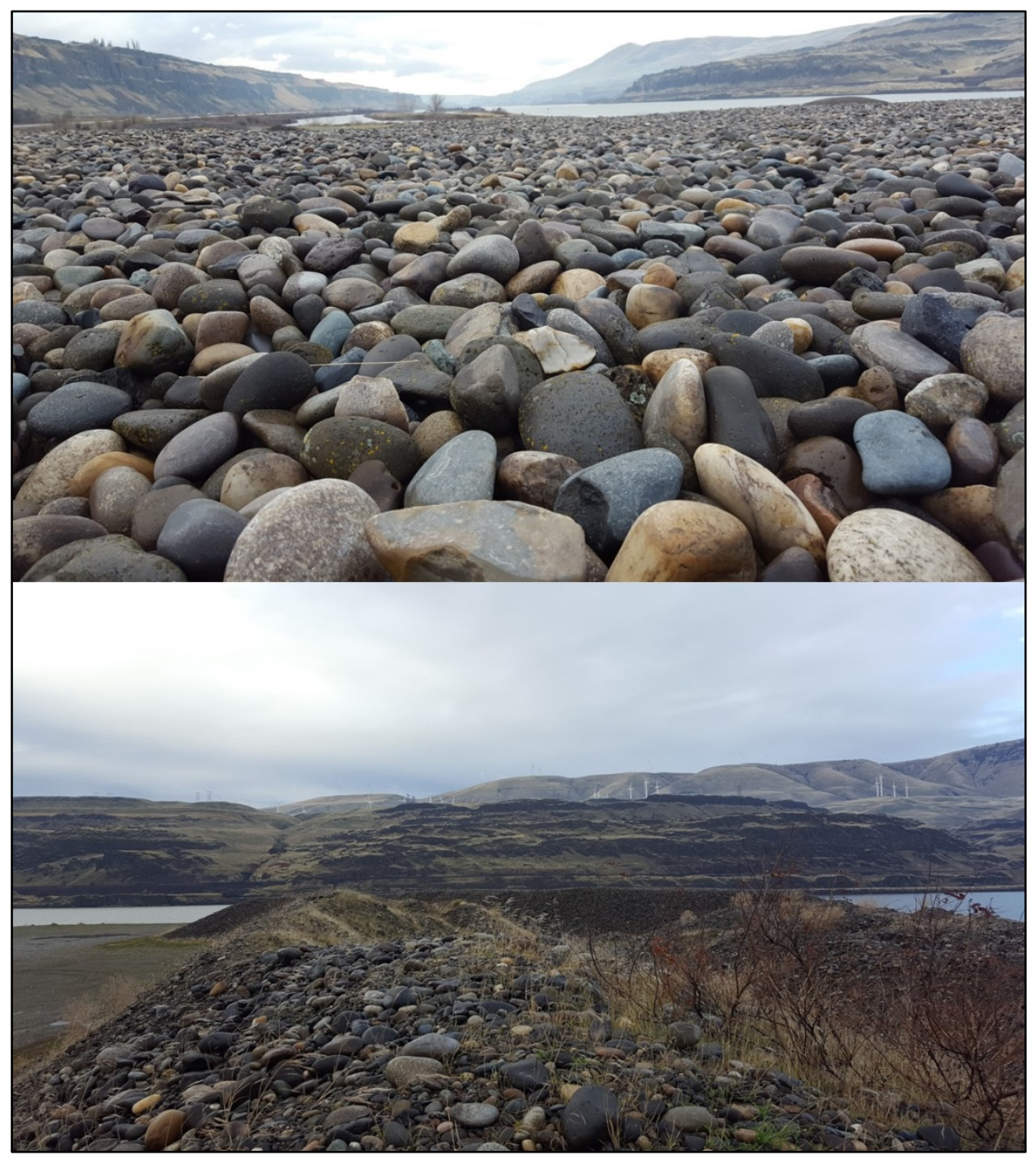

Figure 4. Raw material collection site: Dredge pile adjacent to the Columbia River, Rufus, Oregon.

Cobble Chopper Manufacture (KPM-12, KPM-13, KPM-16 through KPM-18, and KPM20 through KPM-40)

I began the replications with the production of unifacial cobble choppers using a hard-hammer percussion technique, which targets edges on the cobbles that are generally thin and less than 90 degrees. I timed each production and took notes on technique and observations regarding the workability of the material. 
A substantial amount of force was required to remove the first flake in all reductions, though the subsequent flakes detached quite easily. On average, four flakes were removed from each cobble chopper to achieve a sharp tool edge. I collected and photographed the choppers after production and before use. Additionally, I collected all debitage after each reduction session and separated it by reduction phase. The analysis of the debitage was not in the scope of this project, though future analyses will likely provide useful information to compare to debitage from local archaeological assemblages.

One chopper (KPM-13) fractured and broke during manufacture and the remaining portions could not be salvaged; I photographed the fragments and did not use them further. I used choppers in reductions until the edge was blunt and too dulled to effectively and efficiently remove material from the subject piece. At this point, I photographed the chopper prior to attempting to sharpen the tool. I rejuvenated cobble choppers by unifacially removing flakes from the used tool edge using a hard-hammer percussion technique until a sharp edge was achieved. Throughout cobble chopper use, small flakes were dislodged from the previously unflaked side of the cobble, almost creating a self-sharpening edge. On average, I used each cobble chopper for one hour until it needed to be resharpened. Generally, each cobble chopper could undergo two cycles of resharpening before I considered the chopper exhausted, which occurred when the worked edge was too blunt to easily to remove additional flakes. Often, the chopper was so worn at this stage, negative flake scars were no longer visible on either side of the 
chopper. At this point, I photographed and analyzed the chopper and it was no longer used.

\section{Banded and Notched Net Weight (KPM-8)}

I modeled my net weight replication after tool $35 \mathrm{CO} 2-446$ from the $35 \mathrm{CO} 2$ Rylander collection, which represents the style most common in the Rylander collection (Figure 5).

Initially, I scored a line around the short axis of the andesite cobble, so as to have a line to follow when pecking the groove. I held the subject piece (KPM-8) with my left, non-dominant, hand and operated the chopper with my right (dominant) hand, rotating and adjusting the subject piece as the reduction progressed. As the material was easy to work, a light amount of force was used when striking the subject piece with the chopper. Subsequently, I pecked a notch, which ran perpendicular to the pecked groove. I then pecked both ends of the cobble until they were flattened, an attribute which I observed in the 35CO2 Rylander banded and notched net weights. I used a broad flake scar on the chopper in a grinding motion to further smooth and remove loose debris from the pecked net weight ends. I collected all debitage from the reduction, which was predominantly fine dust from the net weight (KPM-8), in addition to small flakes from the cobble chopper (KPM-12) used in the reduction. 


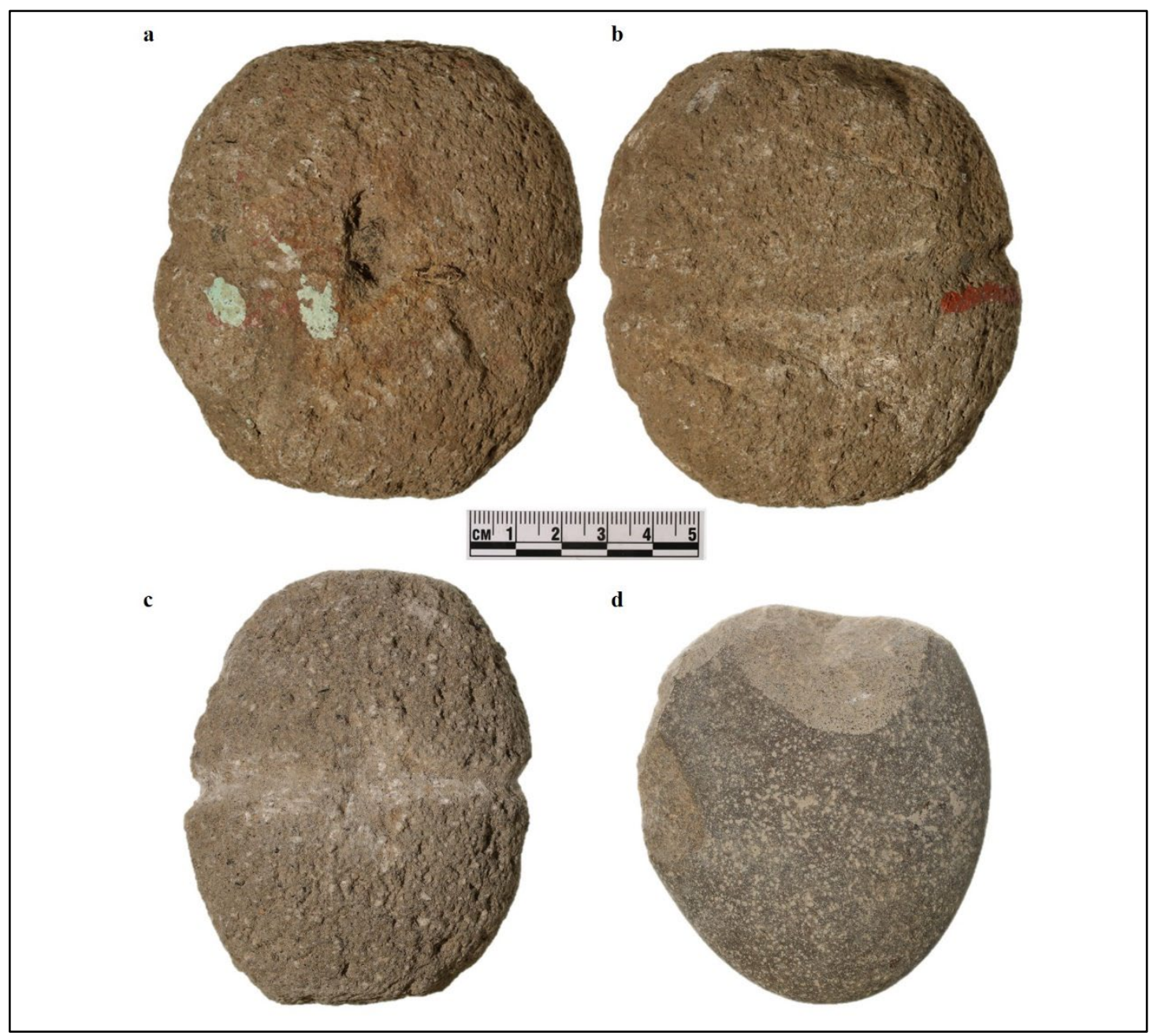

Figure 5. (a) and (b) Net weight 35CO2-446; (c) replication net weight KPM-8, which was modeled after 35CO2-446; (d) chopper KPM-12, which was used in the production of KPM8 .

\section{Maul Manufacture (KPM-3)}

I selected a large, elongated granite cobble (KPM-3) for the maul replication,

which was modelled after tools in the 35CO2 Rylander collection $(35 \mathrm{CO} 2-453,461,467$, and 468) (Figure 6). While many of the mauls in the Rylander collection are broken, maul 35CO2-467 (Figure 6) represents a complete tool form. The complete maul was helpful to reference when examining tool breaks and discussing tool rejuvenation and recycling. I began the reduction process by flattening the convex base of the subject 
piece by striking it with chopper KPM-17. I held the subject piece against my thigh, using my left hand to support the cobble; this helped support the entire cobble and prevented grip fatigue. More striking force was required compared to the net weight reduction, as the granite was substantially harder than the andesite used for the net weight. Various angles of pecking strokes were used with an emphasis on the sharpest edge of the chopper. I was constantly turning and adjusting the position of the subject piece. I found it more effective, meaning more material was removed, to concentrate pecking on one area to create a low spot, then working from the low spot outwards. I also used a grinding motion, using a broad and flat flake scar on the chopper, to remove loose material and slightly smooth the base of the tool. One goal in the reduction was to preserve as much weight in the base of the tool as possible, which would help make the maul an effective striking tool. I considered this initial phase complete when the base of KPM-3 featured a wide and slightly convex striking surface that resembled the base of numerous mauls in the $35 \mathrm{CO} 2$ Rylander collection; production took one hour.

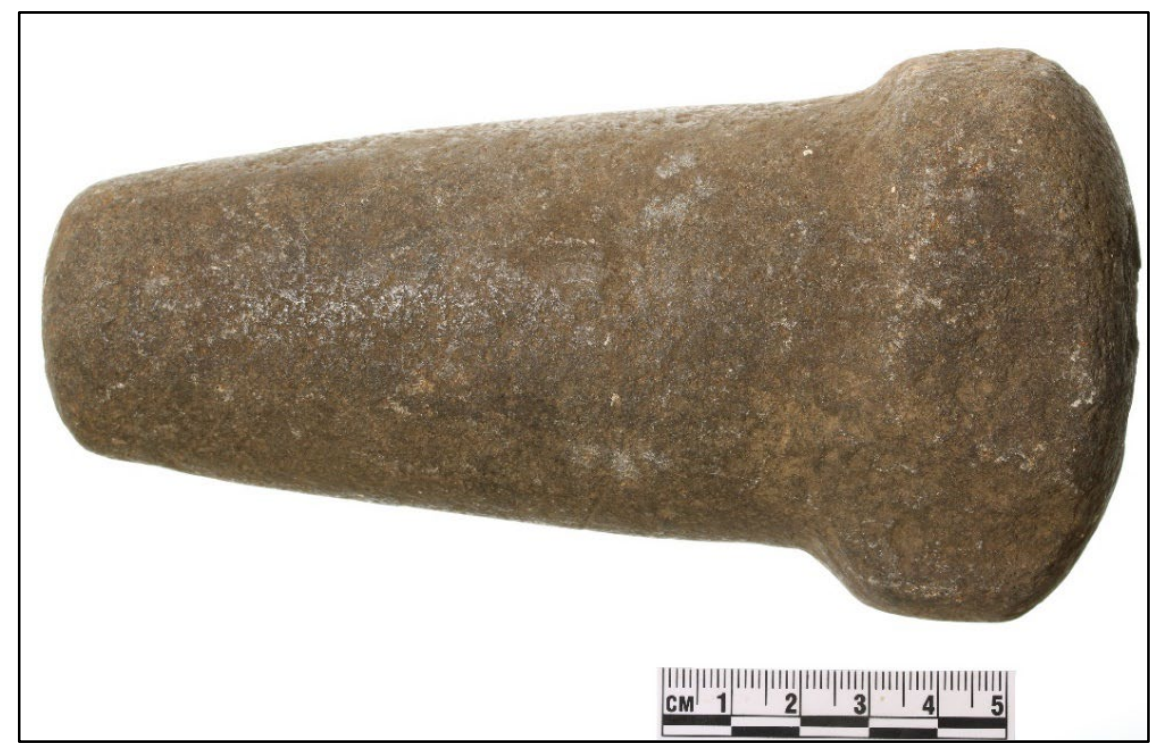

Figure 6. Maul 35CO2-467, after which replication KPM-3 is modeled. 35 
To help control reduction volume and increase comparability between reduction phases, I completed each subsequent reduction in one hour segments. Limiting reduction sessions to one hour also helped mitigate grip and upper body muscle fatigue. I then worked on creating a groove that traveled around the shortest axis of the subject piece, which is where the tool user's hand would be positioned, at the approximate mid-point on the cobble shaft. Prior to the reduction, I incised a line around the maul where I would be removing material so I had a visual path to follow. I did this by grinding the chopper edge along the surface of the maul in the desired location. I continued by pecking, using consistent, steady, and forceful motions, until a consistently shallow groove was pecked around the circumference of the subject piece. Next, I removed material from the shaft of the cobble to create a hand grip similar to mauls from the $35 \mathrm{CO} 2$ Rylander collection. At the suggestion of Dr. John Fagan, I pecked v-shaped grooves that ran parallel to the long axis of the cobble approximately $.5 \mathrm{~cm}(.20 \mathrm{in})$ apart (Figure 7). Subsequently, I removed the remaining ridges between the pecked troughs by pecking more aggressively into the base of the ridge. I held the chopper at approximately 45 degrees to the subject piece. This technique was effective, as the material removed from the ridges dislodged from the subject piece in larger fragments than when freely pecking the subject piece. I repeated this technique around the entire perimeter of the tool until all ridges were removed, then additional troughs were pecked to begin the process again. While this method was effective at removing material from the subject piece, the strategy wore chopper edges quickly and precision pecking, which was necessary when deepening the vertical grooves, was difficult. While many $35 \mathrm{CO} 2$ Rylander mauls with intact proximal 
ends feature a stylistic finish, I decided to leave the proximal end unmodified to conserve time. Additionally, since my use wear study focused on pestle and bowl attributes, I left the maul in a mid-stage of manufacture. The remaining reduction work on the maul would use the same techniques already employed, so I felt confident that I would not be missing any additional reduction attributes. During the entirety of reductions on the maul, small flakes from the chopper were dislodged, helping to self-sharpen the used chopper edge.

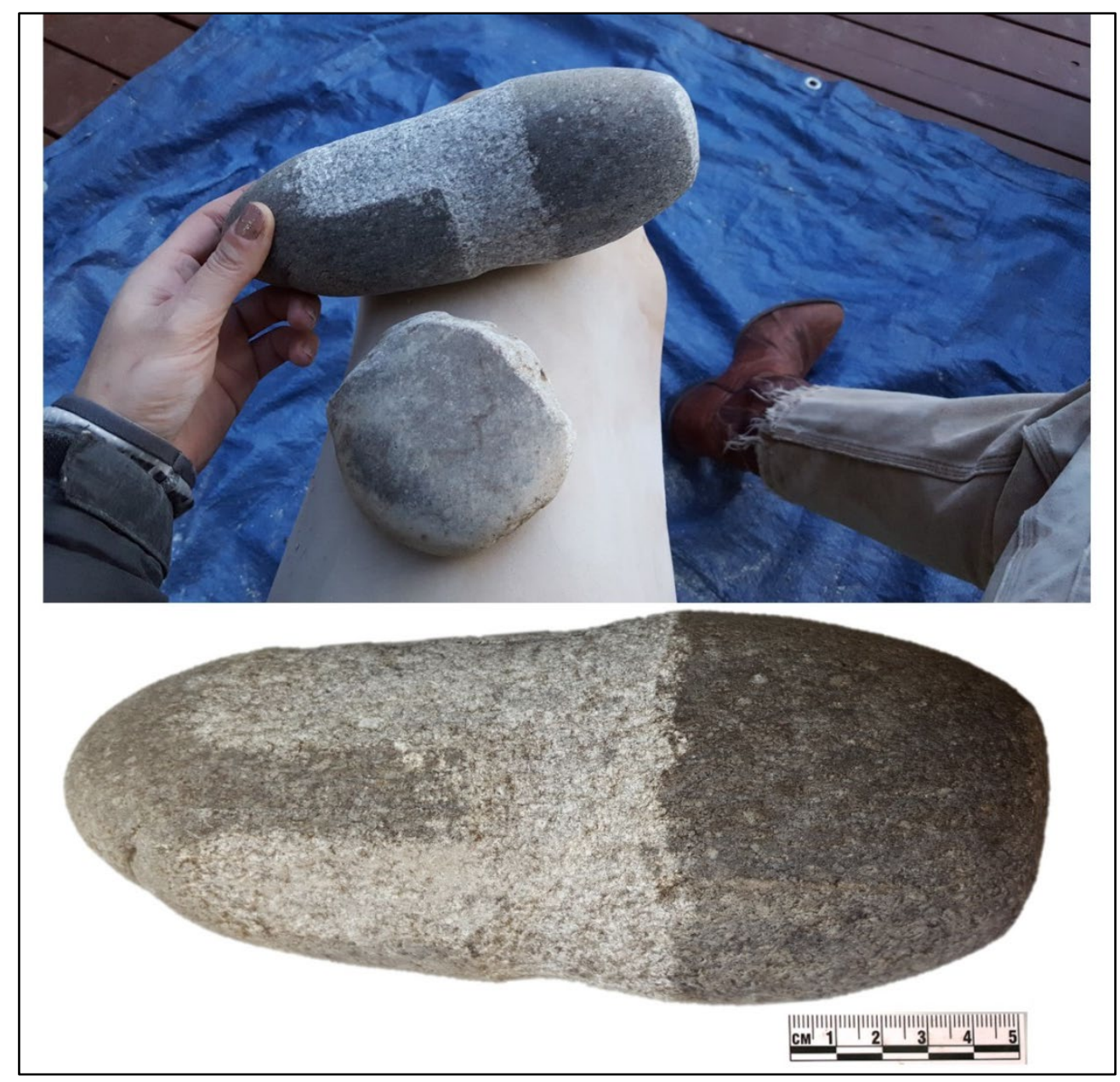

Figure 7. In progress reductions of maul KPM-3, showing pecked grooves in maul shaft. 


\section{Bowl Manufacture (KPM-19 and KPM-1)}

I began the bowl manufacturing process by selecting a bowl from the $35 \mathrm{CO} 2$ Rylander collection (35CO2-488) after which I modelled my replication (Figure 8). I selected bowl 35CO2-488 due to its complete form and the size of the basin, knowing I wanted to use the replicated bowl in the subsequent use study. A granite alluvial cobble (KPM-19) collected by Dr. John Fagan from the Columbia River near The Dalles, was used for the bowl replication. I first selected the face of the cobble that was slightly concave to be the working surface, or the basin of the bowl. The base of the bowl is slightly convex, but sits fairly flat without the need for modification. Using the sharp edge of the chopper, I scored a line to follow where I would subsequently peck

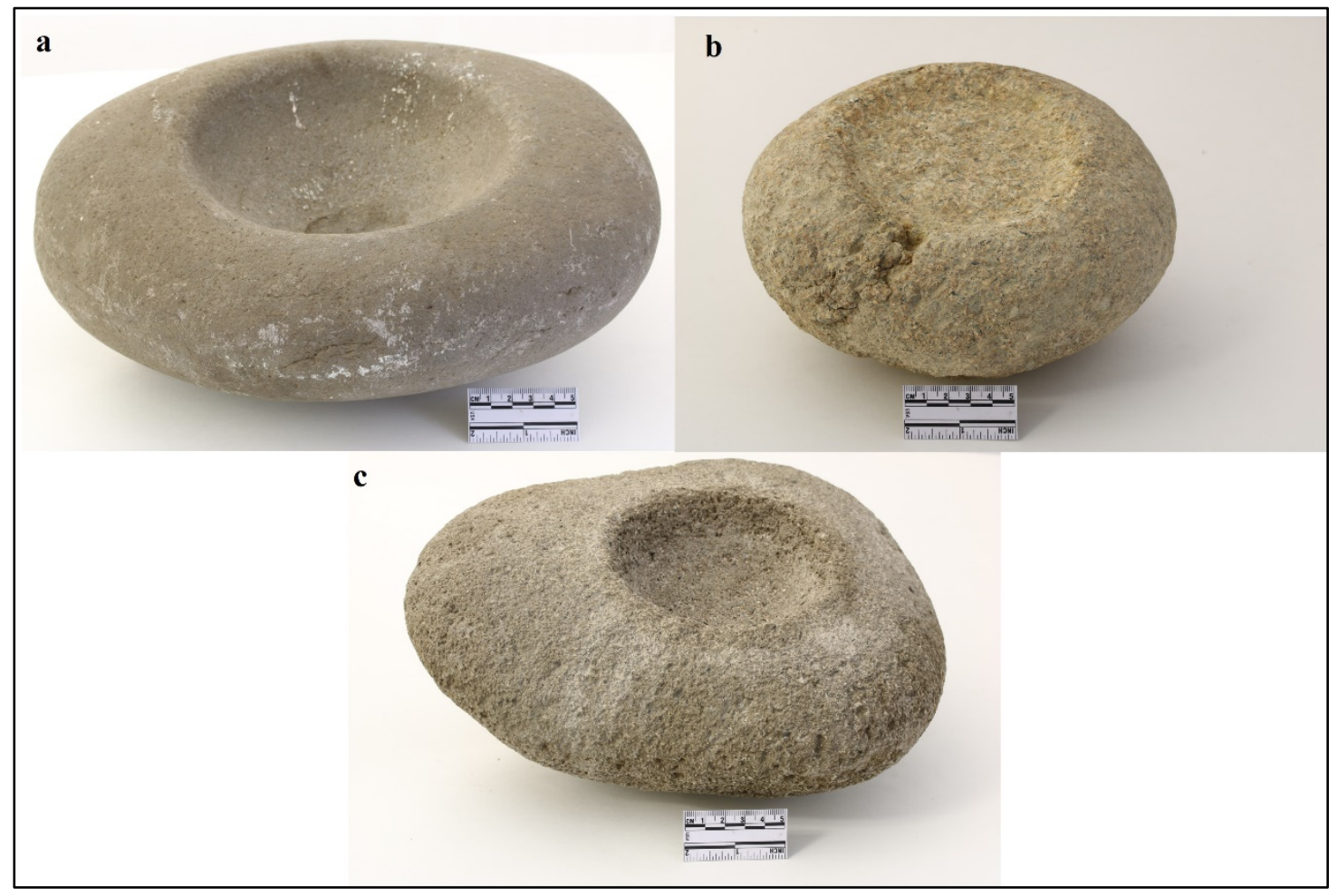

Figure 8. (a) bowl 35CO2-488, which bowl replications were based; (b) replicated bowl KPM19; (c) replicated bowl KPM-1. Scale is five $\mathrm{cm}$. 
a groove to begin removing material to create a basin. Then, I pecked a groove approximately $2.5 \mathrm{~cm}$ ( 1 in) from the rim of the subject piece (KPM-19), creating a ring that would be the extent of pecking for the basin, meaning all reductions would be taking place within the pecked ring (Photo 1, Appendix J). Pecking took a substantial amount of force, as the granite material was very hard. For the duration of the bowl reduction, I placed the bowl on the ground, which I cushioned with a folded leather pad. Most of the debitage from the reduction was in the form of dust, though the hardness of the granite cobble caused many flakes to detach from the cobble choppers used in the reduction process. I removed the portion interior to the pecked groove by holding the subject piece on its side to attack the base of the steep angle that was created by the pecked groove. I constantly rotated the chopper to use the sharpest edge on the tool. I worked from one edge of the bowl to the other, which helped maintain a steep ledge that moved across the subject piece. Attacking the base of the ledge effectively removed large pieces of the interior. Once I reached the other edge of the groove and the interior was pecked to a uniform depth, I pecked another ring around the periphery of the basin in the same manner described above and continued removing the portion within the grooved ring. After four one-hour reduction sessions and little progress, I altered my strategy by wetting the subject piece with water before pecking. I observed this technique on the website of avocational flintknapper, Larry Kinsella (Kinsella 2008). Kinsella stated that the wetting technique helped to identify individual pecking strikes, as the pecked area would appear dry and the non-pecked area would still appear wet. Though he did not note a difference in efficiency, I experienced a dramatic difference in the amount of 
material that was removed when the subject piece was wetted throughout the reduction session when compared to the subject piece being dry. In addition to increased reduction efficiency, the use of water helped control airborne dust. I poured water onto the subject piece, which would puddle in the basin and slowly settle into the pores of the material. I continued the pecking as described above, pecking an outer ring, then removing the interior. In one hour of reduction with water, I was able to remove approximately the equivalent of two hours of reduction without the aid of water. I continued to use water for all subsequent reductions. It is unclear why the use of water dramatically increased the reduction efficiency; my hypotheses include:

- The water and debitage create a paste that acts as an abrasive agent, helping to remove additional material.

- The water helps clear debris from subject material interstices and fissures, leaving unsupported micro fractures to easily break.

After 10 1-hour reduction sessions, I terminated reduction on KPM-19 when a crack formed on the exterior of the bowl. I selected KPM-1, an andesite alluvial cobble, which I collected from the Sandy River Delta, for the next bowl replication. I began the reduction by selecting the working surface, which was the flattest surface, thus minimizing the amount of material that would need to be removed. Next, I incised a ring that was approximately in the center of the cobble, ensuring the basin would be centered on the thickest portion of the subject piece. I saturated the working surface of the subject piece with water at this point. As with the previous bowl, I pecked a groove, outlining the extent of the basin. The material was substantially softer than the granite cobble (KPM-19) used for the previous bowl attempt, so the pecking strikes required much less 
force. Once the groove was pecked, I removed the material on the interior of the groove, adding water to KPM-1 when it had fully absorbed into the pores of the stone.

\section{Pestle Manufacture (KPM-4)}

I selected an elongated fine-grained volcanic alluvial cobble (KPM-4) collected from dredge piles near Rufus, Oregon, for the pestle replication, which was roughly modeled after pestle (35CO2-463) from the 35C02 Rylander collection (Figure 9). I selected cobble KPM-4 for the reduction due to its size and shape closely matching pestles in the $35 \mathrm{CO} 2$ Rylander collection prior to modification, which made the reduction more efficient. Before beginning the reduction, I examined the cobble to determine how I would orient the tool. I selected the end with the largest circumference to be the distal end, or working surface. Additionally, the cobble was most comfortable to grip when oriented this way. My goal was to flatten the base, or distal end, of the cobble without removing too much material. As the cobble was already a comfortable fit in my grip, I did not remove material from the shaft. Despite stylistic or decorative finishes on the proximal, or non-working, end of the pestle being common in the Lower Columbia, I left the proximal end unmodified to increase reduction efficiency. I held the subject piece (KPM-4) horizontally, or on its long axis, on a piece of leather on the ground with my left hand and used my right hand to peck the distal end of the cobble with a cobble chopper, focusing blows on one margin of the base, and moving across what would become the base of the pestle. The force of the blows caused the subject piece to move away from the chopper on the piece of leather which held debitage, causing shallow striations running along the long axis of the tool to form. Keeping the subject piece stationary, I constantly changed the angle and position of the chopper to use the sharpest edge. I 
refrained from holding the subject piece on end, or on the short axis, to try to fully support the cobble and prevent a mid-shaft break. As the use of water in the bowl reductions increased replication efficiency, I used water in the pestle reductions, pouring water over the surface I was reducing throughout the process. As before, the water mixed with the material that was removed from the subject piece, creating an abrasive paste.

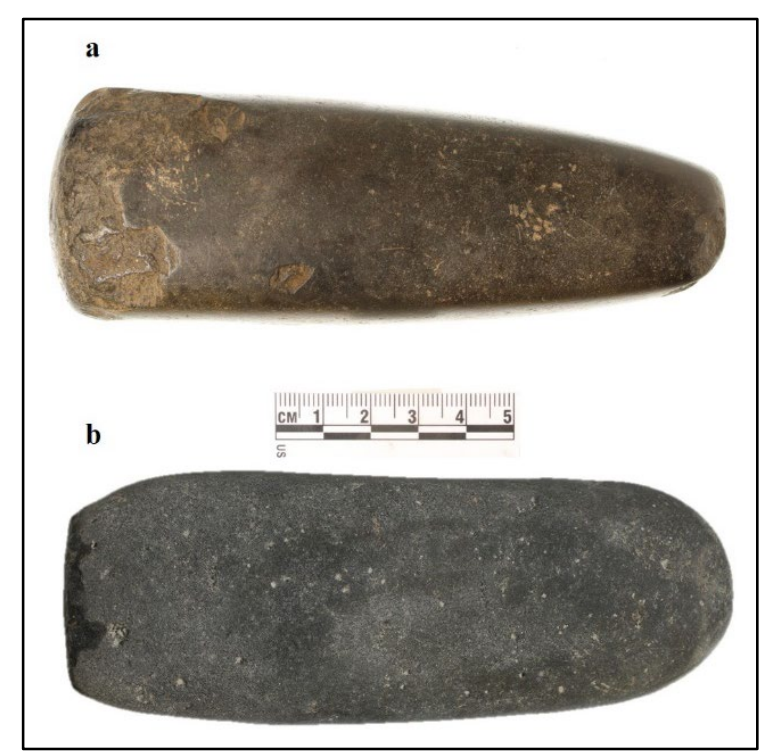

Figure 9. (a) pestle 35CO2-463 after which replications were modeled; (b) pestle replication KPM-4.

The pecking required a substantial amount of force, as the subject piece material is fine-grained and hard. The cortex of the cobble featured air pockets, or vesicles, which were shallow and sparsely dispersed over the cobble surface. I encountered one of these vesicles on the interior of the cobble as I was reducing the cobble. There was what appeared to be iron staining within the interior vesicle. Once this area was pecked, more material was dislodged from the air pocket compared to the surrounding area, as it appeared the air pocket had undergone weathering. This created a circular gouge in the 
base of the pestle. I continued to peck the base of the pestle to the approximate depth as the weathered vesicle before considering the replication complete.

\section{Post Manufacture Analysis}

After manufacture, I photographed and took length, width, thickness, and weight measurements of all the tool replicates. I examined all tools first without magnification, then at low magnification (up to $45 \mathrm{X}$ magnification), and at high magnification (45 to 100X magnification) to fully explore the impacts of manufacturing and use on the implement. All low and high magnification analyses used a Zeis Stemi 2000 CS Trinocular Zoom microscope. In addition to grain morphology (rounded, flattened, crushed), I described the material matrix, asperities, and interstices to examine use wear.

In order to objectively discuss raw material hardness and its relation to raw material selection and tool durability, I ranked the raw material hardness using the Mohs scale of mineral hardness (Broz et al. 2006:139-142). I performed the test on experimentally produced tools with material types similar to those encountered in the archaeological assemblage, so as to not damage artifacts in the analysis process.

\section{Experimental Use and Analysis}

I used replicated tools in two phases: one that mimicked the use of ground stone tools to process hard materials, such as cracking and shelling hazelnuts, and one that mimicked the processing of soft materials, such as hazelnuts.

I selected hazelnuts due to their importance to Indigenous communities in the region; they were often pounded and the flour made into cakes which could be stored or traded (Lewis and Clark 1893:673-675; Lewis 1964:156-158; Gass 1904:215-216). Given the shell and meat, hazelnuts represent two different processing materials (hard 
and soft), which gave me the opportunity to examine the tools for distinctive use wear attributes specific to the types of materials being processed. Additionally, the hazelnut meat can serve as a proxy for the processing of other soft materials, such as acorns and other nuts, various roots, and wapato, all of which have been documented as being processed using ground stone tools in the Lower Columbia River Valley (Lewis 1964:156-158; Lewis and Clark 1893:673-675, 928-930; Gahr 2013:73-75).

Phase I: Cracking and Shelling Hazelnuts

I cracked and shelled hazelnuts for five 2-hour sessions during Phase I, processing an approximate total of 1,500 hazelnuts. During the cracking and shelling, I held the bowl in my lap and used my right hand, to control the pestle (Figure 10). I placed approximately seven to 10 hazelnuts in the bowl reservoir with the pointed end facing upward then used the worked, or distal, end of the pestle to strike each shell on the point. The impact created large cracks that radiated toward the base of the shell and generally each shell required only one pestle strike to expose the kernel without fracturing the kernel. After cracking each shell, I used my hands to remove the shell pieces, which I kept separate from the kernels. I later processed the hazelnut kernels in Phase II. Occasionally I would come across a blank, which is a shell without a kernel, or a rotten kernel within a shell; the rotten material was discarded. Any remaining shell fragments were scooped out by hand. During the cracking and shelling process, deep gouges were created in the basin of the bowl and at each cleanout between batches, very fine-grained material from the bowl was scooped out with shell fragments. 


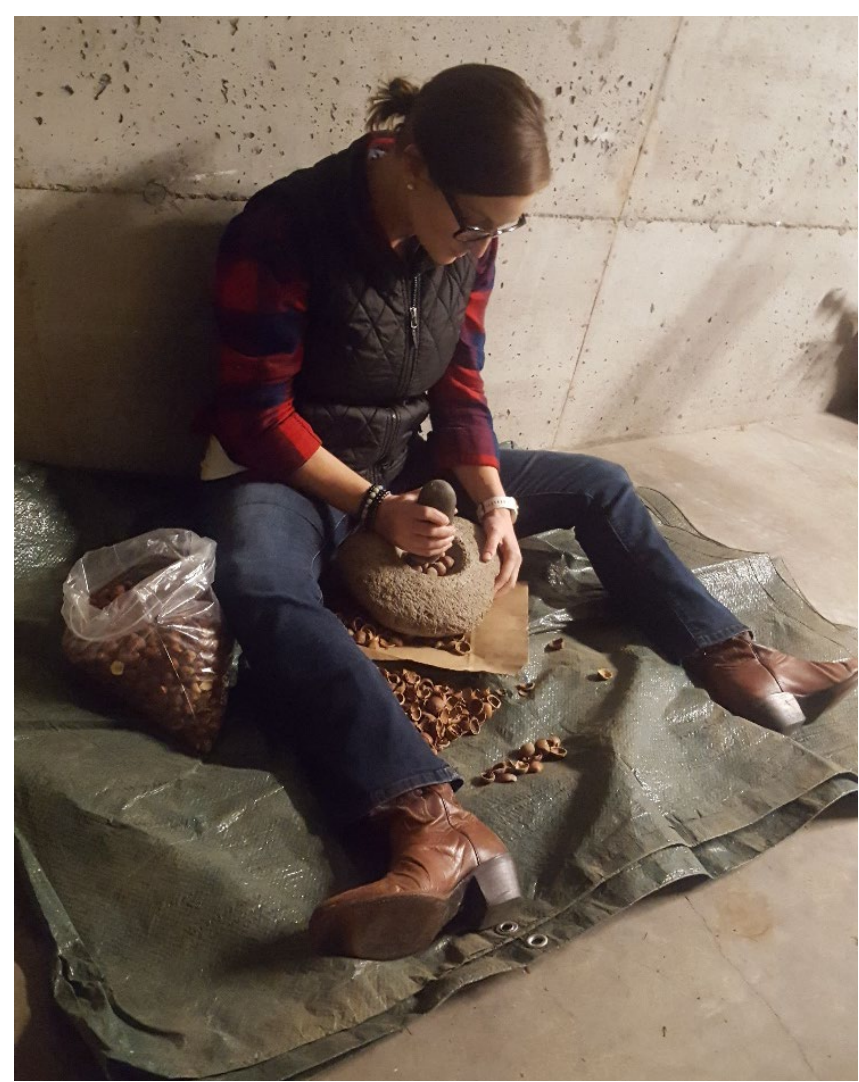

Figure 10. Shelling hazelnuts during Phase I of the experimental use wear study.

\section{Phase II: Processing Hazelnut Meat}

During Phase II I processed the kernel meat from the previously cracked and shelled hazelnuts for five 2-hour sessions. As with Phase I, I held the bowl in my lap while sitting cross-legged and used my right hand to control the pestle. I placed approximately 10 to 15 hazelnuts in the basin at one time and first used a pounding motion, then grinding motion to break down the kernels until a coarse meal was produced, which took approximately 10 minutes per batch. Once the desired coarseness was achieved, I scooped the meal out by hand, noticing that very fine-grained material from the bowl was mixed in with the hazelnut meal. 


\section{Phase I and II Post-Use Analysis}

After each phase of use, I photographed and took length, width, thickness, and weight measurements of the bowl and pestle. I examined the tools first without magnification, then at low magnification, and at high magnification. In addition to grain morphology (rounded, flattened, crushed), I described the material matrix, asperities, and interstices to examine use wear.

\section{Analysis of $35 \mathrm{CO} 2$ Rylander Ground Stone}

My analysis entailed recording the weight, length, width, and thickness for each artifact, in addition to recording a narrative description of attributes and interpretations associated with tool manufacture, use, and maintenance strategies. My descriptions reference microphotographs taken throughout the analysis to help clarify attribute descriptions and attribute interpretations are kept separate from descriptions. All analyses were conducted at low and high magnification, noting texture on used and nonused surfaces, manufacture and recycling attributes and general grain morphology and texture. Additionally, I recorded the presence of residues and staining.

I compared the wear patterns observed on the experimental tools from the use wear study to ground stone artifacts from the $35 \mathrm{CO} 2$ Rylander collection. This process allowed me to hypothesize about manufacturing strategies and uses of the archaeological tools by comparing them to manufacturing wear and use wear attributes on known reductions.

\section{Protein Residue Analysis Methods}

Funds awarded through the OAS Roy Jones Scholarship were used to conduct protein residue analysis on five ground stone artifacts from the 35CO2 Rylander 
collection to further explore animal resource use and processing in the region. Protein residue analysis was conducted by Archaeological Investigations Northwest, Inc. (AINW) in Portland, Oregon using the cross-over immunoelectrophoresis technique. Detailed methods and results of the residue analysis are presented in Appendix I and discussed in the Results chapter. 


\section{Chapter IV: Results}

In this chapter I present the results of the preliminary analysis of a sample of 35CO2 Rylander ground stone artifacts, then I transition to discuss the results of the experimental replications by tool type. I detail the analysis of the replications prior to the use wear study and after each phase of the processing exercise. Finally, I summarize the results of the analysis of the full ground stone assemblage from the $35 \mathrm{CO} 2$ Rylander collection and discuss the results of the protein residue analysis, which was conducted on select ground stone tools from the $35 \mathrm{CO} 2$ Rylander collection.

\section{Preliminary Analysis of the 35CO2 Rylander Collection}

I conducted my preliminary analysis on 19 ground stone artifacts from the $35 \mathrm{CO} 2$ Rylander collection, which can be classed in traditionally established and commonly used maul and pestle categories (Table 4).

A goal of my study was to develop a method for empirically identifying tool recycling. A preliminary analysis of mauls and pestles from the 35CO2 Rylander collection revealed heavy tool recycling and reuse after breakage (Table 4). For example, a tool that featured maul attributes was broken at the mid-shaft point and was rejuvenated to function as a pestle (Figure 11). These observations were addressed by creating a category of 'original tool form,' which represents the original intended tool function, and 'current tool form,' which represents the tool form when the artifact entered the archaeological record. All of the recycled tools in the Rylander collection were manufactured from a fine-grained volcanic tool stone. 
Table 4. Preliminary analysis of 35CO2 Rylander mauls and pestles.

\begin{tabular}{cccc} 
Artifact & \multicolumn{2}{c}{ Classification } & Raw Material \\
Number & $\begin{array}{c}\text { Current Tool } \\
\text { Form }\end{array}$ & $\begin{array}{c}\text { Original Tool } \\
\text { Form }\end{array}$ & Type \\
\hline 35CO2-453 & Maul & Maul & UM \\
\hline 35CO2-454 & Maul & Maul & FGV \\
\hline 35CO2-455 & Pestle & Pestle & FGV \\
\hline 35CO2-456 & Maul & Maul & FGV \\
\hline 35CO2-457 & Pestle & Pestle & Quartzite \\
\hline 35CO2-458 & Pestle & Maul & FGV \\
\hline 35CO2-459 & Pestle & Maul & FGV \\
\hline 35CO2-460 & Pestle & Maul & FGV \\
\hline 35CO2-461 & Maul & Maul & FGV \\
\hline 35CO2-463 & Pestle & Pestle & FGV \\
\hline 35CO2-464 & Maul/Pestle & Maul/Pestle & FGV \\
\hline 35CO2-465 & Maul & Maul & FGV \\
\hline 35CO2-466 & Maul/Pestle & Maul/Pestle & FGV \\
\hline 35CO2-467 & Maul & Maul & FGV \\
\hline 35CO2-468 & Maul & Maul & FGV \\
\hline 35CO2-469 & Maul & Maul & FGV \\
\hline 35CO2-470 & Pestle & Maul & FGV \\
\hline 35CO2-471 & Pestle & Pestle & FGV \\
\hline 35C02-491 & Pestle/Anvil & Pestle/Anvil & FGV \\
\hline (Unidentified metamorphic), FGV (Fine-grained volcanic)
\end{tabular}

I identified several attributes I thought were related to tool recycling and rejuvenation in my preliminary analysis of the Rylander collection. Specifically:

- Grain rounding over a previously broken surface.

- Polish traveling over a previously broken surface.

- Negative flake scars traveling over a break.

- Manufacturing attributes, including grain crushing, faceting, and remnant chopper scars on previously broken surfaces. 
While I did not rejuvenate a broken tool in my replication and use studies, I identified manufacturing attributes, including grain crushing, remnant chopper scars, and negative flake scars on the replicated pestle. These attributes were consistent with rejuvenation and recycling attributes on the Rylander tools. Additionally, the use wear attributes I recorded on the replicated pestle, which included grain rounding and polish over manufacturing attributes, were consistent with wear patterns on the recycled tools in the Rylander collection.

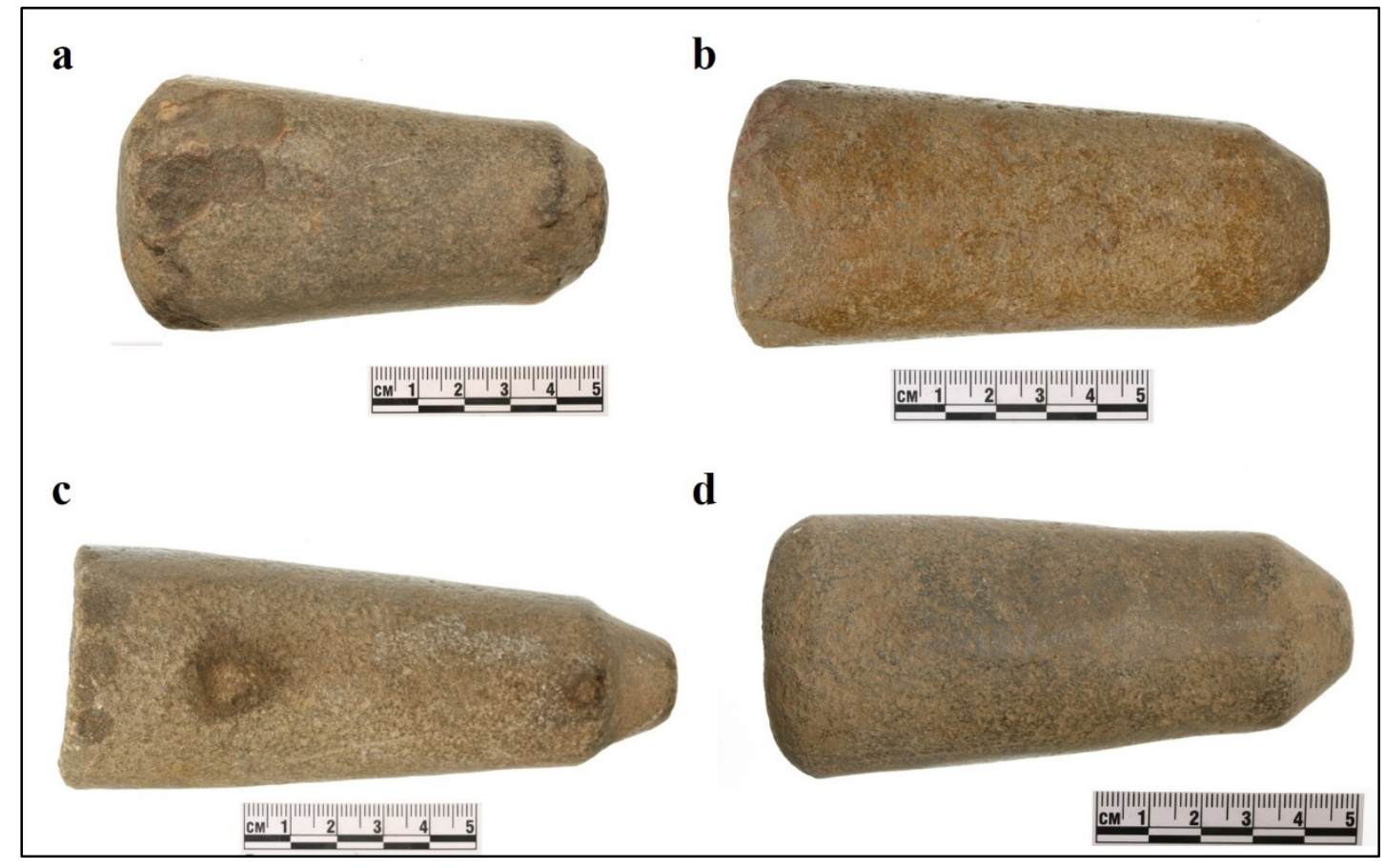

Figure 11. Evidence of tool recycling. Note edge rounding and negative flake scars on the distal ends of the tools. (a) Tool 35CO2-458; (b) Tool 35CO2-459; (c) Tool 35CO2-460; (d) Tool 35CO2-470.

During the preliminary analysis of the $35 \mathrm{CO} 2$ Rylander assemblage, I examined tools for manufacturing attributes. I identified short, linear gouge marks with v-shaped cross sections on the distal ends of two banded net weights and the exterior of one stone 
bowl (Figure 12). I interpreted these gouges as remnant chopper scars from manufacturing, which helped influence my decision to use cobble choppers in my replications; see the Analysis of $35 \mathrm{CO} 2$ Rylander Ground Stone Artifacts section within the Results chapter for more discussion.

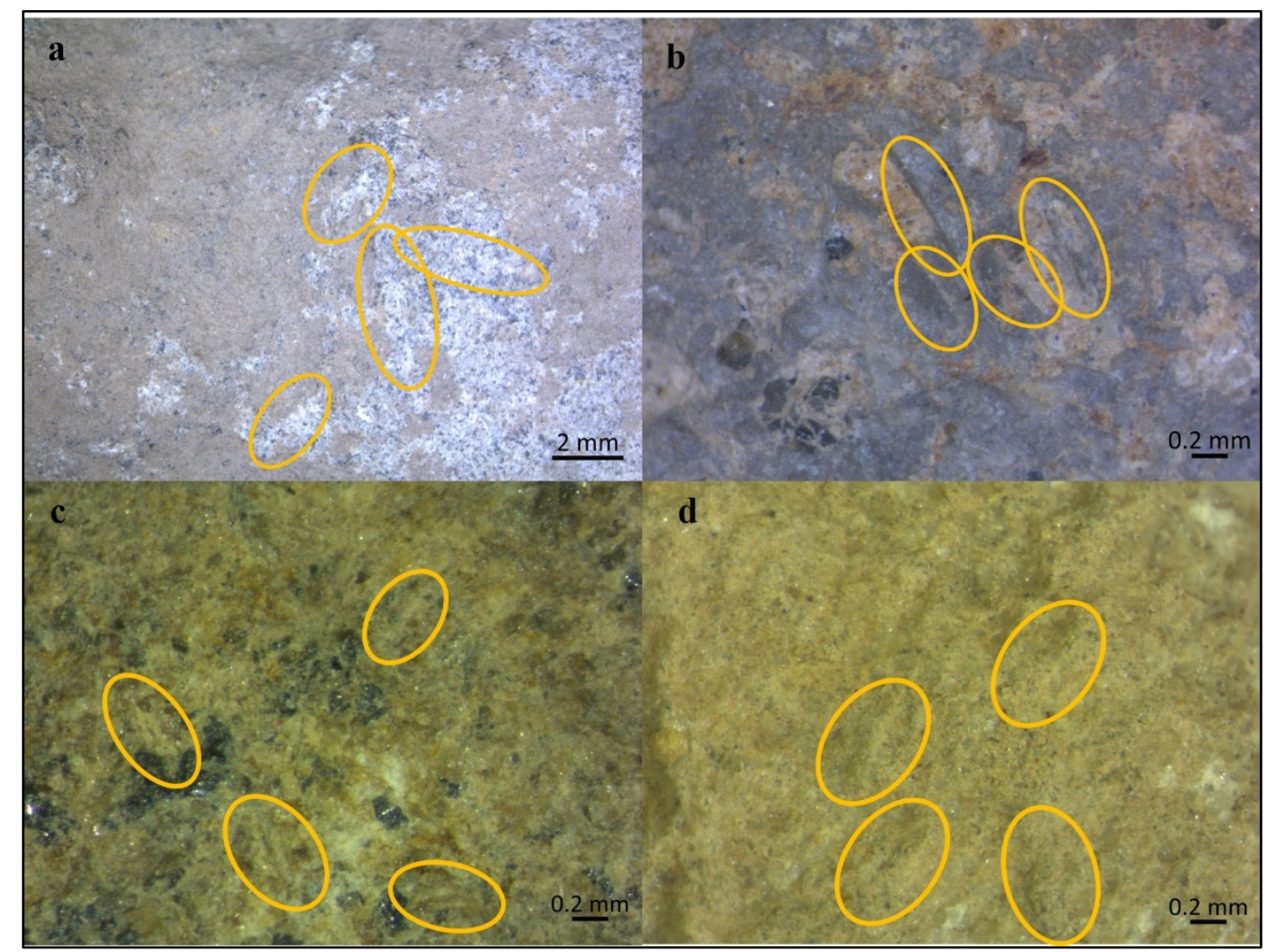

Figure 12. Photomicrograph of remnant chopper scars. Orange ovals mark chopper gouges. (a) 35CO2-441, 6.3x; (b) 35CO2-452, 31.5x; (c) 35CO2-482, 31.5x; (d) $35 \mathrm{CO} 2-485,31.5 \mathrm{x}$.

\section{Experimental Replications}

I conducted experimental tool replications to inform on various elements in ground stone tool manufacture and use, including raw material selection, reduction strategies, manufacturing investments, tool use, rejuvenation, breakage, and recycling. To assess these aspects of tool manufacture and use, I reproduced a banded and notched 
net weight, a bowl, a pestle, and a maul; I also produced the cobble choppers used for ground stone manufacture (Tables 5 and 6 ).

Table 5. Summary of experimental replication materials, manufacture time, and used cobble choppers.

\begin{tabular}{lcccc}
$\begin{array}{c}\text { Tool } \\
\text { Number }\end{array}$ & $\begin{array}{c}\text { Replication } \\
\text { Target }\end{array}$ & $\begin{array}{c}\text { Material } \\
\text { Type }\end{array}$ & $\begin{array}{c}\text { Manufacture Time } \\
\text { (H:M:S) }\end{array}$ & $\begin{array}{c}\text { Number of } \\
\text { Choppers Used }\end{array}$ \\
\hline KPM-1 & Bowl & Andesite & $2: 00: 00$ & 2 \\
\hline KPM-3 & Maul & Granite & $5: 00: 00$ & 3 \\
\hline KPM-4 & Pestle & FGV & $4: 00: 00$ & 4 \\
\hline KPM-8 & Net Weight & Andesite & $0: 32: 00$ & 1 \\
\hline KPM-14 & Hammerstone & Granite & $0: 00$ & $\mathrm{n} / \mathrm{a}$
\end{tabular}

To objectively assess the hardness of the selected raw materials, I used the Mohs scale to assign numerical values to the tool stone used in the experimental replications prior to modification (Table 6; Figure 13). The granite and fine-grained volcanic materials were the hardest tool stones used in the replications and were the most time consuming to work. 
Table 6. Mohs scale determination of experimentally produced tools.

\begin{tabular}{|c|c|c|c|}
\hline Tool & $\begin{array}{c}\text { Targeted } \\
\text { Replication }\end{array}$ & $\begin{array}{c}\text { Raw Material } \\
\text { Type }\end{array}$ & $\begin{array}{c}\text { Mohs Scale } \\
\text { Value }\end{array}$ \\
\hline KPM-1 & Bowl & Andesite & 3.5 \\
\hline KPM-3 & Maul & Granite & 8.5 \\
\hline KPM-4 & Pestle & FGV & 7.5 \\
\hline KPM-8 & Net Weight & Andesite & 3.5 \\
\hline KPM-12 & Chopper & Quartzite & 7.5 \\
\hline KPM-13 & Chopper & FGV & 7.5 \\
\hline KPM-14 & Hammerstone & Granite & 8.5 \\
\hline KPM-16 & Chopper & Quartzite & 7.5 \\
\hline KPM-17 & Chopper & Quartzite & 7.5 \\
\hline KPM-18 & Chopper & Quartzite & 7.5 \\
\hline KPM-19 & Bowl & Granite & 7.5 \\
\hline KPM-20 & Chopper & Quartzite & 7.5 \\
\hline KPM-21 & Chopper & Quartzite & 7.5 \\
\hline KPM-22 & Chopper & Granite & 7.5 \\
\hline KPM-23 & Chopper & Granite & 6.5 \\
\hline KPM-24 & Chopper & Quartzite & 7.5 \\
\hline KPM-25 & Chopper & Quartzite & 7.5 \\
\hline KРM-26 & Chopper & Quartzite & 7.5 \\
\hline KPM-27 & Chopper & Granite & 6.5 \\
\hline KPM-28 & Chopper & Quartzite & 6.5 \\
\hline KPM-29 & Chopper & Quartzite & 7.5 \\
\hline KPM-30 & Chopper & Quartzite & 7.5 \\
\hline KPM-31 & Chopper & Quartzite & 7.5 \\
\hline KPM-32 & Chopper & Quartzite & 7.5 \\
\hline KPM-33 & Chopper & Quartzite & 6.5 \\
\hline KPM-34 & Chopper & Quartzite & 7.5 \\
\hline KPM-35 & Chopper & Quartzite & 7.5 \\
\hline KPM-36 & Chopper & Quartzite & 7.5 \\
\hline KPM-37 & Chopper & Quartzite & 6.5 \\
\hline KPM-38 & Chopper & Quartzite & 7.5 \\
\hline KPM-39 & Chopper & Quartzite & 6.5 \\
\hline KPM-40 & Chopper & FGV & 7.5 \\
\hline
\end{tabular}




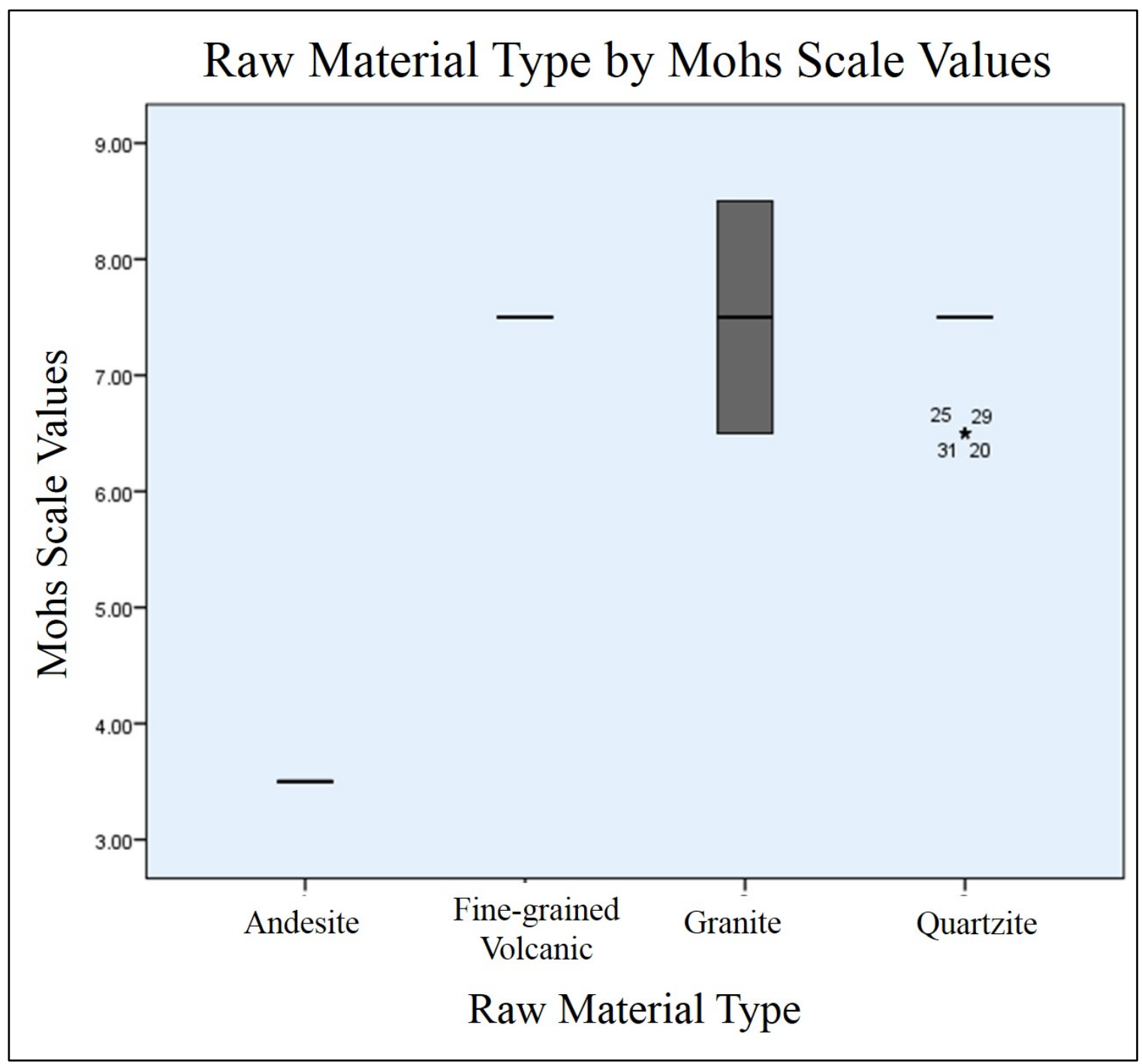

Figure 13. Mohs scale values of raw materials used in experimental replications.

Cobble Chopper Manufacture (KPM-12, KPM-13, KPM-16 through KPM-18, and KPM20 through KPM-40)

I produced 26 cobble choppers. Though hammerstone KPM-14 was used on all chopper productions, I noted very little damage, which is visible as minor pitting (Figure 14). On average, each cobble chopper took two minutes and 10 seconds to produce (Table 7). The quartzite cobble choppers took an average of two minutes and 25 seconds to manufacture, while the granite took two minutes and nine seconds, and the finegrained volcanic took just 46 seconds to produce (Table 7; Figure 15 ). On average, the 
quartzite is a softer tool stone than the granite and fine-grained volcanic tool stone, though the quartzite cobble choppers took longer on average to produce (Figure 13). This may be attributed to the thickness of the cobbles. The fine-grained volcanic cobbles had an average thickness of $28.64 \mathrm{~mm}$, while the granite choppers had an average thickness of $38.63 \mathrm{~mm}$, and the quartzite cobbles had an average thickness of $36.71 \mathrm{~mm}$. The thinner cobbles were generally faster to work, though this does not account for the difference between the granite and quartzite cobbles. Testing the choppers with the Mohs scale revealed that while most of the quartzite cobbles (17) ranked at 7.5, four ranked at 6.5 (Figure 13). While I took material hardness into account, I did not explore material brittleness. The fine-grained volcanic and granite may be more brittle and easier to fracture than the quartzite. A One-Way ANOVA resulted in a significance value of 0.347 $(\mathrm{F}=1.10, \mathrm{p}=0.347)$, which is above the .05 level of significance. Therefore, there is not a statistically significant difference in the mean length of production time by material type (Figure 15; Table 8). T-tests show a significant difference between the Mohs values and material type when comparing andesite to granite $(\mathrm{t}=-6.0, \mathrm{p}=0.001)$ and andesite to quartzite $(\mathrm{t}=-13.110, \mathrm{p}=0.000)$. A t-test could not be conducted between andesite and fine-grained volcanic, as the standard deviation of both groups is zero. 


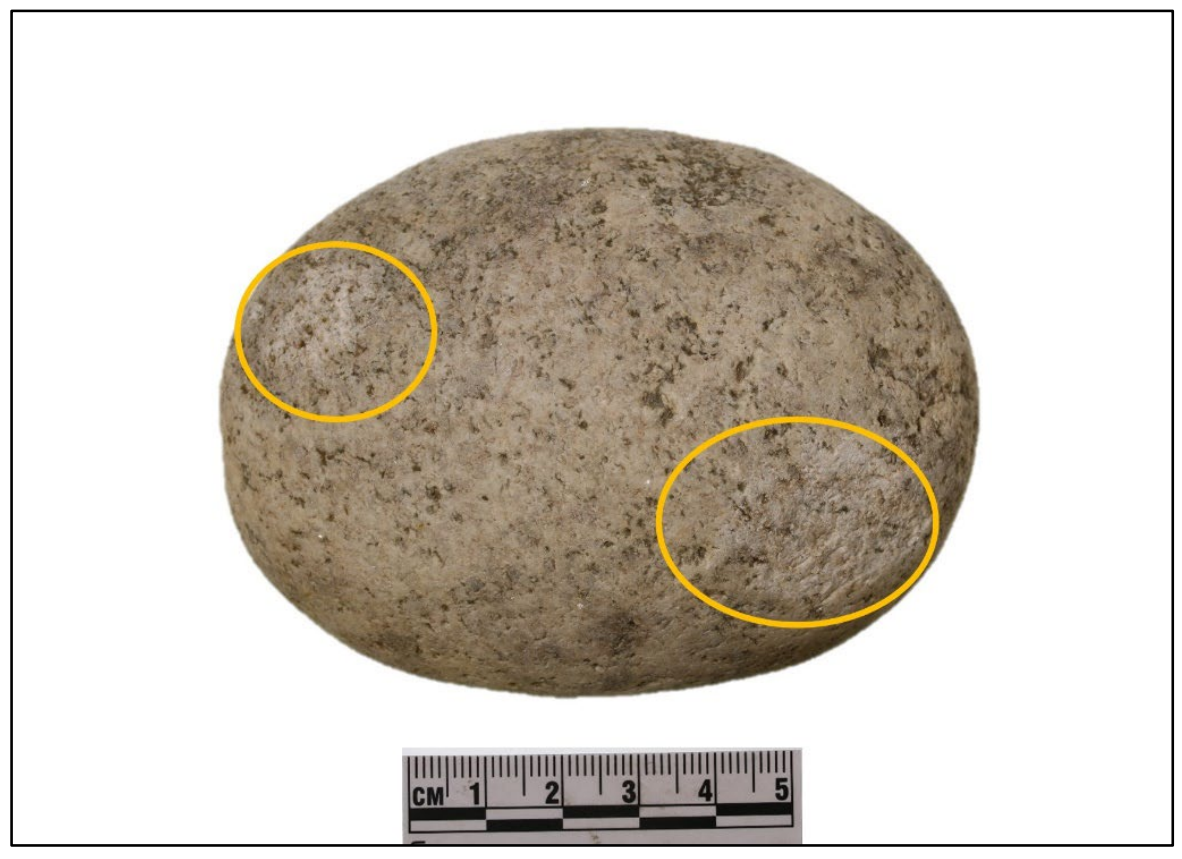

Figure 14. Hammerstone KPM-14 with visible use wear circled in orange. 
Table 7. Cobble chopper replications and manufacture times.

\begin{tabular}{|c|c|c|}
\hline Tool & Raw Material & $\begin{array}{l}\text { Manufacture Time } \\
\text { (Min:Sec) }\end{array}$ \\
\hline KPM-12 & Quartzite & $1: 32$ \\
\hline KPM-13 & FGV & $0: 25$ \\
\hline KPM-16 & Quartzite & $6: 02$ \\
\hline KРM-17 & Quartzite & $1: 45$ \\
\hline KPM-18 & Quartzite & 4:03 \\
\hline KPM-20 & Quartzite & $5: 25$ \\
\hline KРM-21 & Quartzite & $2: 24$ \\
\hline KPM-22 & Granite & $3: 02$ \\
\hline KPM-23 & Granite & $1: 45$ \\
\hline KРM-24 & Quartzite & $3: 59$ \\
\hline KРM-25 & Quartzite & $3: 4$ \\
\hline KРM-26 & Quartzite & $0: 35$ \\
\hline KРM-27 & Granite & $1: 42$ \\
\hline KРM-28 & Quartzite & $3: 25$ \\
\hline КРМ-29 & Quartzite & $1: 55$ \\
\hline KРM-30 & Quartzite & $1: 18$ \\
\hline KPM-31 & Quartzite & $2: 45$ \\
\hline KPM-32 & Quartzite & $1: 22$ \\
\hline KPM-33 & Quartzite & $1: 31$ \\
\hline KPM-34 & Quartzite & $0: 45$ \\
\hline KPM-35 & Quartzite & $1: 05$ \\
\hline KPM-36 & Quartzite & $1: 47$ \\
\hline KРM-37 & Quartzite & 2:03 \\
\hline KPM-38 & Quartzite & $2: 43$ \\
\hline КРM-39 & Quartzite & $1: 31$ \\
\hline KPM-40 & FGV & $1: 07$ \\
\hline $\begin{array}{l}\text { Average } \\
\text { Time }\end{array}$ & & $2: 10$ \\
\hline
\end{tabular}




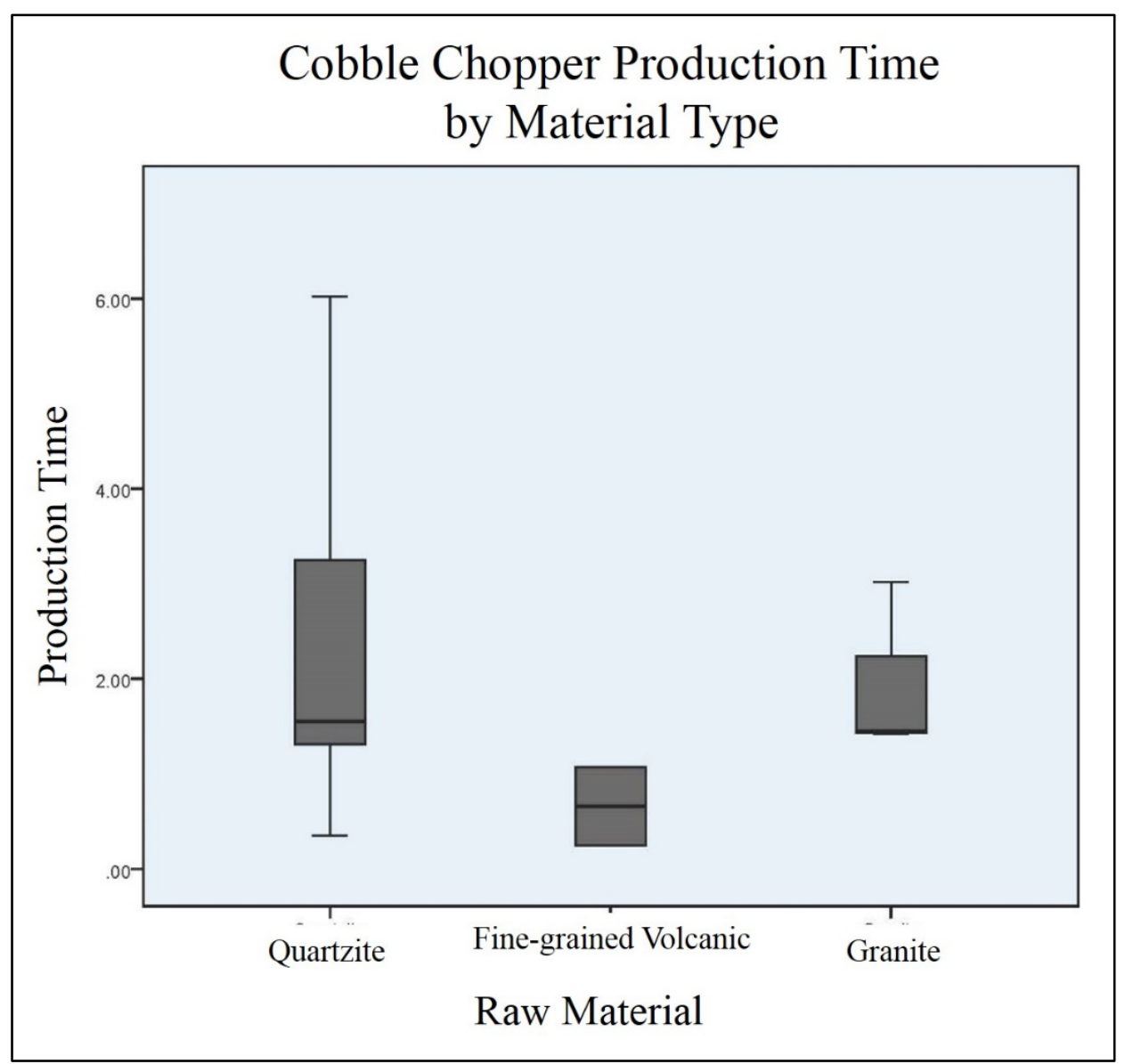

Figure 15. Box plot showing the range in cobble chopper production time by material type.

Table 8. Mean and standard deviation of cobble chopper production time by material type.

\begin{tabular}{cccc}
$\begin{array}{c}\text { Raw } \\
\text { Material }\end{array}$ & N & Mean (M:S) & Std. Deviation \\
\hline Quartzite & 21 & $2: 24$ & $1: 52$ \\
\hline FGV & 2 & $0: 66$ & 0.58 \\
\hline Granite & 3 & $1: 96$ & $0: 92$ \\
\hline Total & 26 & $2: 09$ & $1: 45$
\end{tabular}




\section{Banded and Notched Net Weight Manufacture (KPM-8)}

The net weight (KPM-8) took 32 minutes to produce and caused little damage to the cobble chopper (KPM-12).

\section{Maul Manufacture (KPM-3)}

In total, I spent five hours on the maul reduction, which was split into five onehour sessions. I estimate another 15 hours of reduction would be necessary to finish the tool. Choppers KPM-16, KPM-17, and KPM-25 were used in the reductions. In total, I used KPM-17 for three 1-hour reduction sessions and I resharpened the chopper after sessions one and two. I considered KPM-17 exhausted after the maul replication. I used choppers KPM-16 and KPM-25 each for an hour of the maul replication. After the reduction was halted, I photographed the in-progress maul (KPM-3) in addition to the cobble choppers used in the reduction (KPM-17 and KPM-25) (Figure 16). 


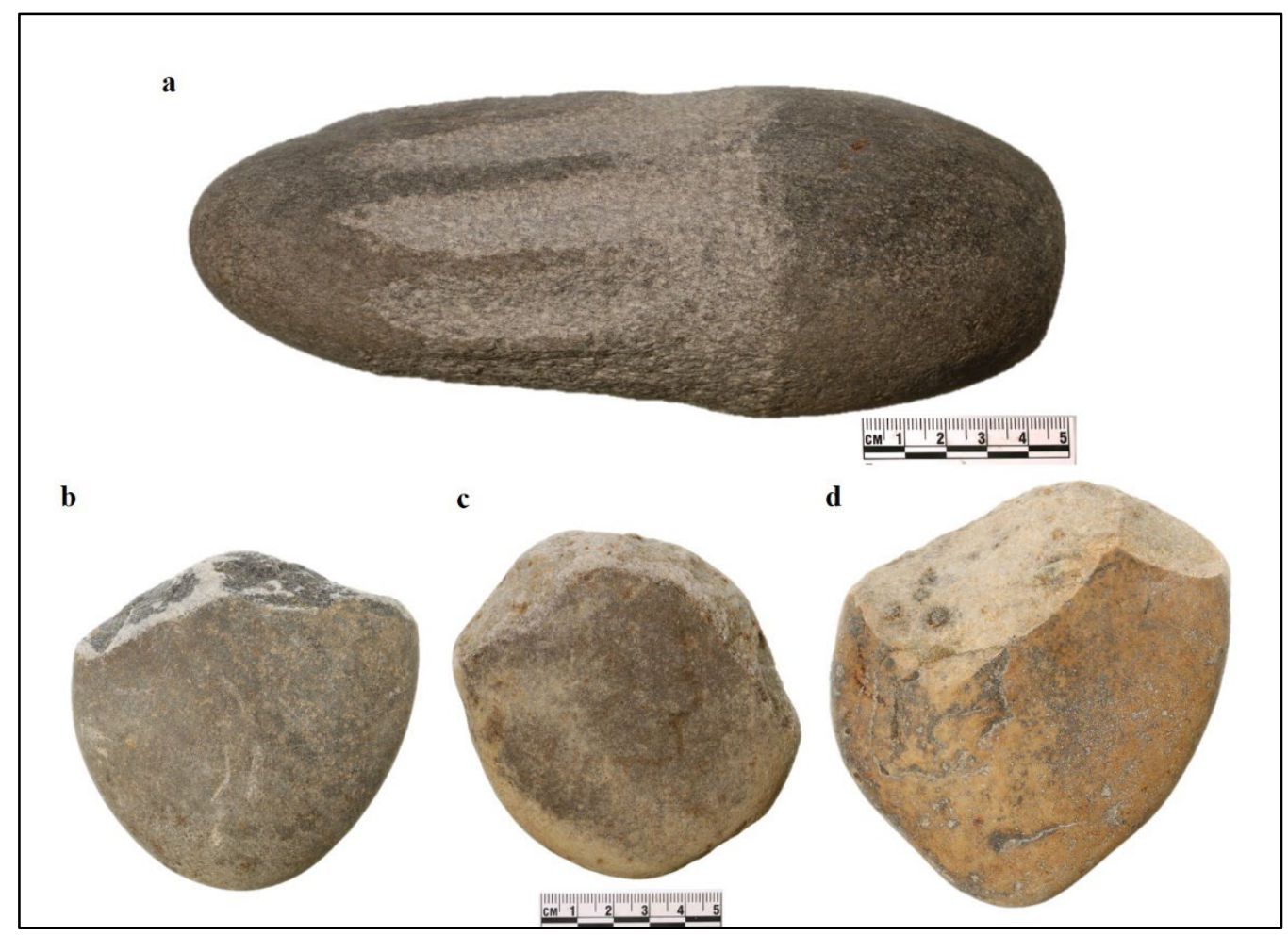

Figure 16. Replicated maul and choppers used in reduction. (a) Maul KPM-3 at the end of replications; (b) Chopper KPM-16; (c) Chopper KPM-17; (d) Chopper KPM-25.

\section{Bowl Manufacture (KPM-19 and KPM-1)}

After 10 1-hour reduction sessions on bowl KPM-19, an indirect percussion blow

caused a large flake to be unintentionally removed from the rim of the bowl. This kind of damage is visible on artifacts from the $35 \mathrm{CO} 2$ Rylander collection (35CO2-482 and 35CO2-487). Reductions briefly continued, though I discontinued pecking in the area of the flake removal. Despite avoidance, a crack became visible at the site of the flake removal and appeared to be spreading into the basin, as well as into the cortex (unmodified exterior of bowl) of the cobble. The crack appeared to follow a natural seam within the material. As granules continued to loosen and fall away from the crack, I discontinued reductions on KPM-19. In total, six cobble choppers were used in the reduction of KPM-19, including, KPM-18, KPM-20, KPM-21, KPM-22, KPM-24, and 
KPM-32. I used chopper KPM-18 for one hour before resharpening, however, due to poor durability, I did not continue using KPM-18 for the bowl replication. I used chopper KPM-20 for one hour and considered it exhausted, as the working edge was too blunt to remove flakes during rejuvenation attempts. Chopper KPM-21 was used for one hour before resharpening, then used for another hour before being considered exhausted, due to the blunt working edge. I used chopper KPM-22 for a total of three hours, and resharpened the chopper between two of the three sessions. Chopper KPM-22 was much larger than the other cobble choppers, and had a larger working edge, which contributed to its long use-life. However, the large size made the chopper difficult to handle for a long period of time, and although the chopper was not exhausted, it was no longer used in reductions. I used chopper KPM-32 for three one-hour reduction sessions, resharpening after the first two one-hour sessions. I considered the chopper exhausted after the third hour of use. I used chopper KPM-24 for the last one-hour session of reductions on bowl KPM-19.

I considered the bowl complete once the basin was uniform in depth and appeared deep enough for processing in the use wear phase of my project, which was approximately $3.6 \mathrm{~cm}$ (1.4 in) deep and took two 1-hour sessions to complete. As the material was soft, only two cobble choppers (KPM-26 and KPM-28) were used in the reduction.

I recorded detailed notes describing reduction techniques and general observations for each reduction session. Additionally, I collected all debitage after each reduction session and kept the debitage in separate labeled artifact bags. The cobble 
choppers (KPM-26 and KPM-28) and bowl (KPM-1) were photographed after the reduction was completed (Photos 14-17). All of the tools underwent a macro and micro analysis in the subsequent replication analysis project phase.

\section{Pestle Manufacture (KPM-4)}

After five one-hour reduction sessions, I considered the pestle complete. In total, I used four choppers in the reduction (KPM-12, and KPM-29 through KPM-31). Chopper KPM-12, made from a durable quartzite cobble was used for two 1-hour reduction sessions, while KPM-29, KPM-30, and KPM-31 were each used for 1 hour.

\section{Post-Manufacturing Analysis}

Choppers (KPM-12, KPM-13, KPM-16 through KPM-18, KPM-20 through KPM-40) I produced 26 unifacial cobble choppers, 15 of which were used in the ground stone replications. One chopper (KPM-13) broke during manufacture and was not used. Ten choppers (KPM-23, KPM-27, and KPM-33 through KPM-40) were produced, but not used by the time I completed reductions. Of the 15 choppers that were used in reductions, I considered 12 exhausted at the end of the reductions. I divided the choppers into three categories to fully explore how attributes changed with use: not used, used, and exhausted. Generally, the surface was smooth with minor pitting over the cobble. Moderate polish, low elevation differences, and round interstices with conical cross sections were also common attributes of the unmodified cobbles (Photo 26, Appendix J). The modified edge of cobble choppers that were not used in subsequent tool replications exhibited sharp and faceted grains, which were highly reflective under magnification and added light. Interstices were deep and irregular in shape, contributing to the variability in the grain surface elevations. Additionally, all the negative flake scars from manufacture 
were visible and fissures and grain crushing were visible at points of impact between the cobble and the hammerstone (Photo 27, Appendix J).

The choppers that were used, but not considered exhausted, featured predominantly crushed and collapsed grains with some faceting. Though not exhausted, the tool edge was slightly rounded and negative flake scars were visible on the working edge of the chopper (Photo 28, Appendix J). I noted a limited amount of polish, which had the appearance of frosted glass, on the used edge, which may be attributed to the abrasive paste that was created with debitage and applied water during the reductions. There is less elevation difference when compared to the non-used choppers and the interstices were generally round with conical cross sections (Photo 29, Appendix J).

The exhausted choppers had edges that were too blunt to rejuvenate by removing additional flakes. Damage was often so severe, previous flake scars were not recognizable. Despite using the choppers to primarily perform pecking motions, many of the edges appear to have ground surfaces from heavy edge damage (Photo 30, Appendix $\mathrm{J})$, however, under increased magnification, the grains were crushed and collapsed and faceted edges were highly reflective. Where negative flake scars were still visible, some grinding was visible on the broad, flat surfaces, which created rounded grains and polish with a frosted glass appearance. Very fine-grained material was also visibly trapped within interstices (Photo 31, Appendix J). The exhausted cobble choppers could be confused with hammerstones in analysis; future research on regional lithic assemblages should take this possibility into consideration. 
To summarize, the wear on cobble choppers used for groundstone manufacture is very different than what is expected for hammerstones used to produce flaked lithics. While we see grain crushing and faceting on cobble choppers used in ground stone tool manufacture and hammerstones used in flaked lithic reduction, the wear on cobble choppers will likely be focused along the cobble edge (Figure 17). A hammerstone will likely have wear in the form of facets on multiple surfaces (Figure 14). Additionally, cobble choppers tend to be manufactured from disk-shaped cobbles, while hammerstones are often more globular in form.

Collections that contain ground stone tools should be examined to determine if cobble choppers were misidentified as hammerstones, which would help explore ground stone manufacturing strategies at different sites.

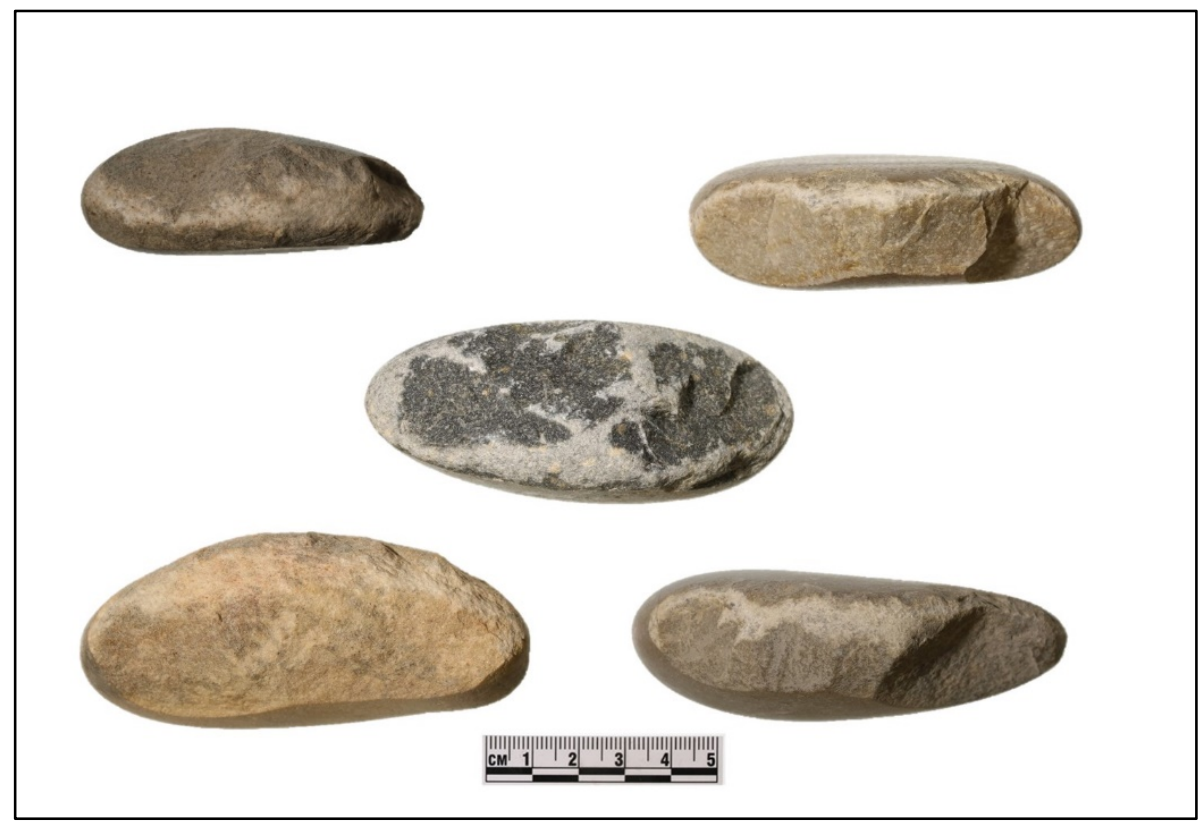

Figure 17. Use wear on cobble choppers used in experimental ground stone tool replications. 


\section{Hammerstone (KPM-14)}

Though hammerstone KPM-14 was the only hammerstone used in the manufacture of all 26 cobble choppers, little damage was evident without magnification. Prior to being used, the cobble featured a smooth surface with minor pitting, rounded grains, and round interstices with conical cross sections. The use wear that is present is visible as concentrations of pitting on both ends of the oblong granite cobble (Photo 32, Appendix J). I noted that there were four areas with the most dominant use wear; these areas became flattened and have a rough texture with dominant grain crushing. Additionally, grain faceting was visible and highly reflective under magnification and additional light. Very fine-grained material was also trapped in the irregularly shaped interstices, which was visible only under high magnification.

\section{Net Weight (KPM-8)}

Prior to modification, KPM-8, an andesite cobble, featured a rough texture, with large mostly round vesicles and great topographic surface variability. The interstices were deep, causing steep asperities that were rounded at their peaks. The cobble surface also featured a light amount of polish over most of the cobble, which had the appearance of frosted glass (Photo 33, Appendix J). Once modified, the analysis revealed faceted and reflective grains, steep, and narrow asperities. Grain crushing was also evident (Photo 34, Appendix J). Very fine-grained material was trapped in many of the interstices at the reduction sites (Photo 34, Appendix J).

\section{$\underline{\text { Maul (KPM-3) }}$}

Subject piece KPM-3, a granite cobble, featured a generally smooth surface, with shallow pitting and a superficial crack running along what appeared to be a bedding 
plane. The interstices were irregular in shape, but fairly shallow, creating little topographic variability of the cobble surface (Photo 35, Appendix J). I recorded a moderate amount of polish, which had the appearance of frosted glass, over much of the cobble. A slight depression near the crack featured grain crushing and faceting, which was highly reflective (Photo 36, Appendix J). The post-modification analysis revealed a rough surface with great elevation differences between asperities and interstices. Grain crushing and faceting were prominent and interstices were irregular in shape, bordered by steep asperities. Chopper scars were visible at reduction sites, which appeared as short, linear gouges with v-shaped cross sections (Photo 37, Appendix J).

\section{Bowls (KPM-19 and KPM-1)}

When examined without magnification, the unmodified surface of KPM-1, an andesite cobble, featured a rough surface with great elevation differences between asperities and interstices. Despite the rough surface and prominent pores on the cortex, the surface was generally homogenous. The interstices were generally irregular in shape and the depths varied greatly. Under low magnification, I noted that the majority of the cortex had visible grain rounding on asperities, though some grain faceting was visible on more durable grain inclusions. I recorded more extensive grain rounding under high magnification than was visible at low magnification (Photo 38, Appendix J).

Additionally, some areas featured polish on asperities, which had the appearance of frosted glass. As with the low magnification, some grain inclusions in the matrix featured more faceted surfaces, which visibly reflected light when viewed under magnification. The interstices maintained their irregular shape under high magnification, but I was able to discern a somewhat conical cross section in many of the concavities. A 
fine-grained material was visible within the bases of some of the interstices. This material was likely from the depositional environment in which the cobble was collected.

I conducted a subsequent analysis of the same region on cobble KPM-1 after completing the reductions. Without magnification, the surface appeared rough with great elevation differences between asperities and interstices, which were generally irregularlyshaped (Photo 39, Appendix J). When viewed with low magnification, the basin of the bowl featured a rough surface with visible sharp grain edges, and irregularly shaped interstices, some of which had semi-conical cross sections. Many short, linear gouge marks were visible, which appeared at various angles- sometimes parallel, and often intersecting. Upon analysis with higher magnification, I recorded additional linear gouge marks with v-shaped cross sections (Photo 40, Appendix J). The asperities were very steep and sharp, with no visible rounding or polish within the basin. Additionally, many fine-grained particles were visible in the interstices.

When I examined KPM-19 prior to modification, the cortex featured a rough and uneven texture. I noted great elevation differences between the asperities and interstices. A low-magnification analysis revealed generally rounded grains with prominent polish, which had the appearance of frosted glass. Though some were irregular in shape, the interstices were mostly round with a conical cross section. When I viewed the unmodified surface at high magnification, the polish was more evident and I was able to identify a few areas that exhibited grain crushing, which was visible as collapsed asperities with faceting that was reflective under additional applied lighting. 
I analyzed the modified portion of KPM-19, that overlapped the location of the previous analysis prior to modification, which is now the basin and walls of the manufactured bowl. I did not complete the reduction on KPM-19 due to a crack that propagated from the rim of the basin down the exterior of the bowl. When viewed without magnification, I noted a rough texture and crushed grains, but far less topographic variability when compared to the cortex, or unmodified surface (Photo 41, Appendix J). Under low magnification, I identified short, linear gouge marks, which were likely from cobble chopper strikes. Under high magnification, I recorded a vshaped cross section in the linear gouge marks (Photo 42, Appendix J). The grains were mostly crushed and faceted with highly reflective surfaces. I noted very little grain rounding and a small amount of polish, which had the appearance of frosted glass. The grain rounding and polish may be attributed to the abrasive action of the reduction debris and water wearing the asperities.

\section{Pestle (KPM-4)}

Prior to modification, KPM-4 featured a smooth surface with shallow vesicles over the entire cobble surface. Under low magnification, the vesicles appeared to be conical in cross section. Without magnification, I noted a slight polish covering the cobble, which was likely attributed to water action. Sparse and shallow pitting was visible over the cobble surface, which may be due to damage sustained through natural transport processes. The polish that was visible without magnification had the appearance of frosted glass under low magnification. Under high magnification, I noted grain rounding on asperities. In addition to the vesicles, I recorded many small concavities, many of which were irregular in shape and featured conical cross sections. 
These concavities were generally shallow with infrequent areas of deeper depressions. The polish noted earlier was visible as a frosted glass-type of sheen (Photo 43, Appendix J).

At low magnification on the modified (distal) end of the pestle, I noted small negative flake scars along the outside edge of the worked surface. These flake scars traveled up the shaft of the tool and are the result of pecking during tool manufacture (Photo 44, Appendix J). I identified many short, linear gouges at varying angles over the entire worked surface, which were v-shaped in cross section (Photo 45, Appendix J). These gouges were the result of chopper strikes during manufacture. The modified surface also featured steep and sharp ridges over the entire worked surface, as well as deep and irregularly shaped gouges that also had irregularly shaped cross sections. A natural seam in the material was also visible. A weathered vesicle, which was exposed during manufacture, widened and material was removed leaving a square gouge (Photo 46, Appendix J). Thin and shallow linear striations running along the long axis of the unmodified shaft were visible. These were caused by the pestle moving against reduction debris during the tool manufacture, as was detailed during the manufacturing methods section.

To summarize, I observed the following experimental tool manufacturing use wear attributes on each tool type:

- Hammerstone: faceting at impact locations, concentrated pitting and crushed grains, irregularly shaped interstices. 
- Cobble Choppers: faceted grains at the location of negative flake scars, deep and irregularly shaped interstices, grain crushing present.

- Banded and Notched Net Weight: asperities are steep and narrow, fine-grained material is trapped in interstices from reduction, irregularly shaped interstices, grain crushing, visible remnant chopper scars.

- Maul: great elevation differences between asperities and interstices, grain crushing and faceting is present, irregularly shaped interstices, and remnant chopper scars.

- Bowl: rough surface, great elevation differences between asperities and interstices, irregularly shaped interstices, remnant chopper scars, grain crushing and faceting, steep and sharp asperities.

- Pestle: small negative flake scars on the distal end of the tool, remnant chopper scars, grain crushing and faceting, irregularly shaped interstices, steep asperities, and great elevation differences between asperities and interstices.

\section{Experimental Tool Processing and Use Wear Analysis}

I conducted experimental tool processing activities to explore tool use and attributes associated with such use. I divided the use wear study into two phases: Phase I focused on processing dense and sharp materials and Phase II focused on processing soft materials. During Phase I and Phase II, I used KPM-1, the andesite bowl, and KPM-4, the fine-grained volcanic pestle, both of which were manufactured in the abovementioned replication study. 
Phase I: Processing Hard and Sharp Materials Use Wear Results

After the shelling and cracking activities using KPM-1 and KPM-4, I conducted a low and high-magnification analysis and took microphotographs to capture attributes associated with the experimental processing. Additionally, I recorded the weight and basin depth on KPM-1 and the weight and length of KPM-4 in order to track the loss of material from the processing.

The surface of the basin of bowl KPM-1 was rough with great elevation differences between the asperities and interstices and two main depressions were visible within the basin. The interstices were generally deep, irregularly shaped, and variably sized, bordered by steep and sharp asperities (Photo 47, Appendix J). Short, linear gouges with v-shaped cross sections were visible; these were previously interpreted as chopper scars from the manufacturing process (Photo 48, Appendix J). Under increased magnification, I recorded angular and faceted grains, which were highly reflective. Additionally, many fine shell fragments were lodged within interstices. I did not observe any polish within the basin. Prior to tool use, KPM-1 weighed $6591.41 \mathrm{~g}$ (232.51 ounces [oz]) and the basin was $33.69 \mathrm{~mm}$ (1.33 in) deep. After tool use, the bowl weighed $6579.18 \mathrm{~g}$, a difference of $12.23 \mathrm{~g}(.43 \mathrm{oz})$. The basin depth was variable after processing, at $39.59 \mathrm{~mm}$ (1.56 in) at the most shallow point, suggesting a loss of approximately 5.9 $\mathrm{mm}$ (.23 in) of material (Table 9).

Table 9. Phase I difference in basin depth and weight of bowl KPM-1.

\begin{tabular}{lcc} 
& Basin Depth $(\mathbf{m m})$ & Weight $(\mathbf{g})$ \\
\hline Before Phase I & 33.69 & 6591.41 \\
\hline After Phase I & 39.59 & 6579.18 \\
\hline Total Difference & 5.9 & 12.23 \\
& 71 &
\end{tabular}


Pestle KPM-4 exhibited a rough surface on the distal, or working end, of the tool. Additional negative flake scars appeared around the working margin of the pestle and gouging was evident on the base of the pestle in areas where previous weathering may have occurred through pores or vesicles on the cobble's cortex prior to modification (Photo 49, Appendix J). There was very little elevation difference between asperities and interstices. Under additional magnification, I noted that interstices were mostly round and conical in cross section and asperities are generally faceted, though some rounding was visible at the center, and most heavily used portion of the pestle base. A light amount of polish was visible and had a frosted glass appearance at this location as well (Photo 50, Appendix J). Additionally, fine fragments of hazelnut shell and fine grains from KPM-1 were visibly lodged in interstices on the base of KPM-4 (Photo 51, Appendix J). Prior to tool use, KPM-4 weighed $815.14 \mathrm{~g}(28.75 \mathrm{oz})$ and measured $155.56 \mathrm{~mm}$ (6.12 in) in length. After Phase I processing, KPM-4 weighed $815.02 \mathrm{~g}$ (28.74 oz), totaling a loss of .12 g (.004 oz). Pestle KPM-4 measured $155.31 \mathrm{~mm}(6.11$ in) in length after Phase I, a loss of .25 mm (.01 in) in length (Table 10).

Table 10. Phase I difference in tool length and weight of Pestle KPM-4.

\begin{tabular}{lcc} 
& Length $(\mathbf{m m})$ & Weight $(\mathbf{g})$ \\
\hline Before Phase I & 155.56 & 815.14 \\
\hline After Phase I & 155.31 & 815.02 \\
\hline Total Difference & .25 & .12
\end{tabular}




\section{Phase II: Processing Soft Materials Use Wear Results}

Prior to analysis, I soaked KPM-1 in water to loosen the remaining vegetal material and used a soft-bristled brush to remove hazelnut debris so the use wear attributes were visible. Following Phase II of tool use, KPM-1 exhibited a rough, uneven basin surface, with areas of deep gouging. The floor of the basin was oil stained, with staining that traveled up the basin walls and approximately $1 \mathrm{~cm}(.39 \mathrm{in})$ beyond the basin rim (Figure 18a). Hazelnut meat and husk material was still present in tool interstices within the basin. The interstices were deep, creating great elevation differences between asperities and interstices, and were generally irregularly-shaped and narrow with depth. Grains were mostly rounded and featured polish with a frosted glass appearance. Patches of grain faceting, which were highly reflective, were present, which may be the result of a combination of grinding and pounding to process the hazelnut kernels (Figure 18b). Prior to tool use in Phase II, KPM-1 weighed 6579.18 g (232.07 oz) and the basin was $39.59 \mathrm{~mm}$ (1.56 in) deep. After Phase II tool use, the bowl weighed $6577.68 \mathrm{~g}(232.02 \mathrm{oz})$, a difference of $1.5 \mathrm{~g}(.05 \mathrm{oz})$. The basin depth was variable after Phase II processing, at $42.55 \mathrm{~mm}$ (1.68 in) at the most shallow point, suggesting a loss of approximately $2.96 \mathrm{~mm}$ (.12 in) of material (Table11). 


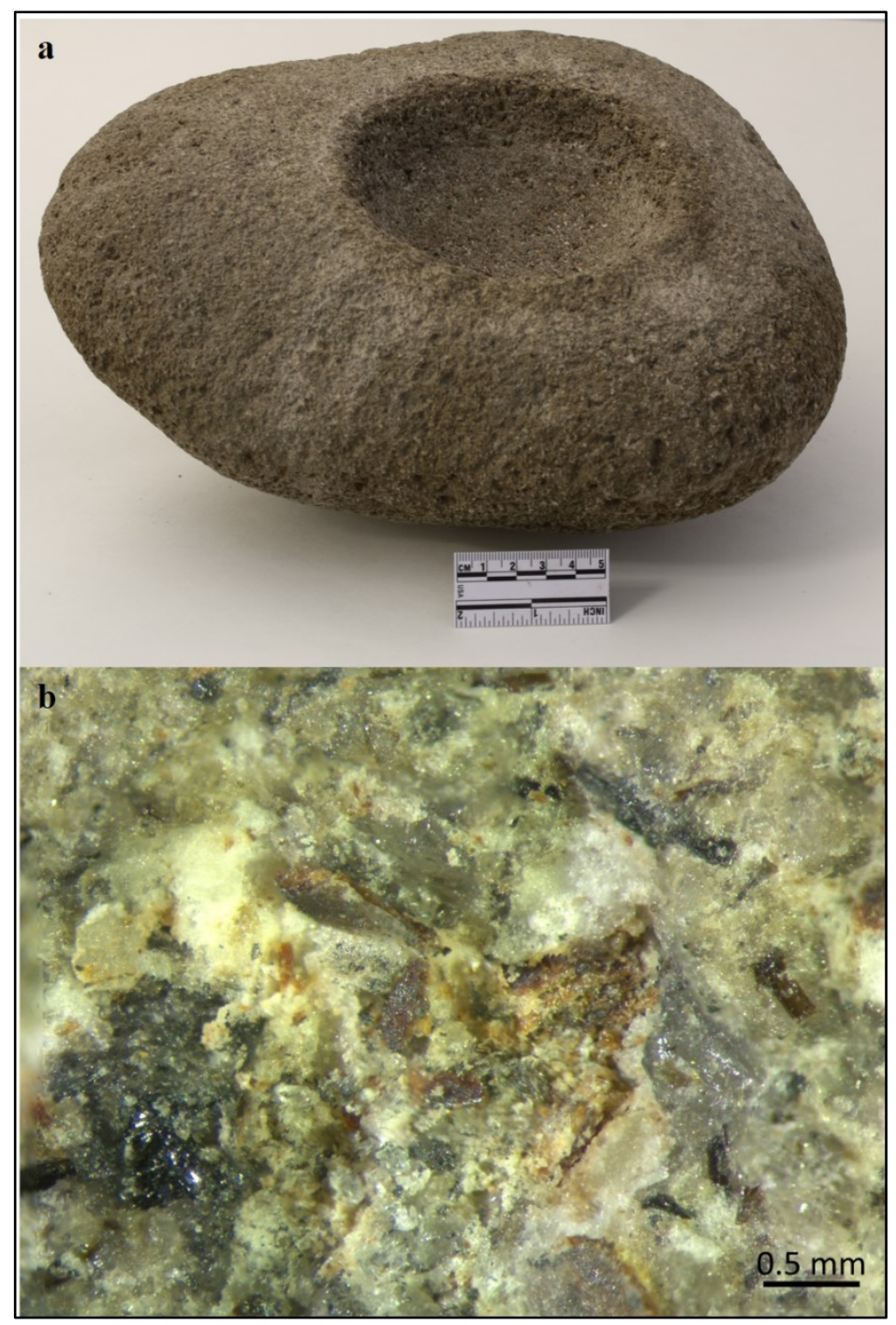

Figure 18. (a) Bowl KPM-1 after Phase II use wear showing oil staining within basin and around bowl rim; (b) photomicrograph of basin of KPM-1 showing rounded grains, polish, and remnant hazelnut husk in interstices.

Table 11. Phase II differences in basin depth and weight of bowl KPM-1.

\begin{tabular}{lcc} 
& Basin Depth $\mathbf{( m m )}$ & Weight $(\mathbf{g})$ \\
\hline Before Phase II & 39.59 & 6579.18 \\
\hline After Phase II & 42.55 & 6577.68 \\
\hline Total Difference & 2.96 & 1.5
\end{tabular}


Pestle KPM-4 featured a sheen and oil staining that was concentrated on the distal or working surface of the tool. There was a gap of approximately $15 \mathrm{~mm}(.59 \mathrm{in})$ in the oil staining on the distal end of the tool shaft, then there was a denser ring of oil staining that extended to approximately $35 \mathrm{~mm}$ (1.38 in) up the tool shaft. Variable oil staining was present above the dense ring of staining from handling the tool. The gap in the staining on the distal end of the shaft may be due to contact with the sides of the basin, which may have abraded the tool surface prior to the absorption of the oils (Photo 52, Appendix J). The interstices were mostly round with conical cross sections, though one gouged area featured a square-edged cavity. This was in an area that appeared to have been weathered through an existing vesicle in the natural cobble surface. Grains were rounded and featured polish with a frosted glass appearance (Photo 53, Appendix J). Prior to Phase II processing, KPM-4 weighed $815.02 \mathrm{~g}(28.749 \mathrm{oz})$ and measured 155.31 mm $(6.11 \mathrm{in})$ in length. After Phase II processing, KPM-4 weighed $815.06(28.750 \mathrm{oz})$, totaling a gain of $.04 \mathrm{~g}(.001 \mathrm{oz})$, which is likely attributed to the addition of hazelnut kernel lodged in the tool interstices (Photo 53, Appendix J). Pestle KPM-4 did not lose a measureable amount of material length after Phase II use and still measured $155.31 \mathrm{~mm}$ (6.11 in) in length (Table 12).

Table 12. Phase II difference in tool length and weight of pestle KPM-4.

\begin{tabular}{lcc} 
& Length $(\mathbf{m m})$ & Weight $(\mathbf{g})$ \\
\hline Before Phase II & 155.31 & 815.02 \\
\hline After Phase II & 155.31 & 815.06 \\
\hline Total Difference & 0 & +.04
\end{tabular}


I observed the following attributes in my analysis of the experimental tools:

Phase I: Processing Dense and Sharp Materials

Bowl: rough surface with great elevation differences between asperities and interstices, visible remnant chopper scars, irregularly shaped interstices, steep and sharp asperities, crushed and faceted grains.

Pestle: Rough surface on the distal end, additional flake scars present along the outer edge of the working surface, little elevation difference between asperities and interstices, some gouging visible, round interstices, faceted and rounded grains present, light polish present.

\section{Phase II: Processing Soft Materials}

Bowl: oil staining visible within basin and up basin walls and rim, great elevation differences between asperities and interstices, irregularly shaped interstices, both faceted and rounded grains present, polish present.

Pestle: staining and oil sheen that travels up shaft from distal end present, rounded grains and polish present, round interstices with conical cross sections.

I was able to associate specific attributes on the replicated ground stone tools with known activities. I could then examine the $35 \mathrm{CO} 2$ Rylander ground stone tools and hypothesize about tool manufacture and use by identifying attributes similar to those that resulted from my experimental replication and use studies.

\section{Analysis of 35CO2 Rylander Ground Stone Artifacts}

I conducted analysis on 62 ground stone artifacts from the $35 \mathrm{CO} 2$ Rylander collection, which were the only $35 \mathrm{CO} 2$ ground stone artifacts available for analysis at the time research was conducted. After a detailed macro and micro analysis, some tool designations and categories shifted, further supporting the need for detailed ground stone 
analyses. Artifacts were assigned to functional classes, which are defined in the glossary (Appendix A), based on attributes and use wear discussed in both regionally relevant and general ground stone reference resources. Of the 62 ground stone artifacts, I classified eight as bowls, five as pestles, eight as mauls, six as mauls/pestles, six as adzes, 13 as net weights, two as stone sculptures, one as a hammerstone, one as an abrader, and 12 as 'other,' which could not be easily assigned to one of these categories (Table 12). I created a maul/pestle category to capture tools that were too fragmented to differentiate between maul and pestle; these were mostly proximal end fragments. Additionally, the tools that were rejuvenated from mauls to pestles were lumped in the maul/pestle category in Table 12, but have been split in the analysis. When tools appeared to have more than one use, I categorized the artifacts by the primary tool use. Full artifact descriptions and analyses are located in Appendix H. I attempted to perform a Chi Square test to assess the significance of the relationship between raw materials and the manufactured tool type, however, the sample size was too small to state statistical significance (Table 13). 
Table 13. Ground stone artifacts by class and material type from the $35 \mathrm{CO} 2$ Rylander collection.

\begin{tabular}{lcccccc}
\multirow{1}{*}{$\begin{array}{c}\text { Raw } \\
\text { Material }\end{array}$} & Bowls & $\begin{array}{c}\text { Net } \\
\text { Weights }\end{array}$ & Pestles/Mauls & Adzes & Sculptures & Other \\
\cline { 2 - 7 } Andesite & 0 & 5 & 0 & 0 & 1 & 0 \\
\hline $\begin{array}{l}\text { Fine \& } \\
\text { Medium- }\end{array}$ & 7 & 8 & 16 & 1 & 1 & 10 \\
$\begin{array}{l}\text { Grained } \\
\text { Volcanic }\end{array}$ & & & & & & \\
\hline Quartzite & 0 & 0 & 2 & 0 & 0 & 1 \\
\hline Metamorphic & 0 & 0 & 1 & 5 & 0 & 3 \\
\hline Other & 1 & 0 & 0 & 0 & 0 & 0 \\
\hline Total & 8 & 13 & 19 & 6 & 2 & 14
\end{tabular}

The mauls were manufactured from both fine-grained volcanic tool stone, as well as an unidentified metamorphic (UM) material. Generally, the mauls featured rounded grains with conical interstices and polish on the shaft. Occasionally, I observed crushed grains on the shafts, which may represent remnant manufacturing attributes. Many of the mauls featured a 'nipple-top' style and either a flared or a stepped distal end, which is a regionally common maul style (Table 14) (Pettigrew 1981). Additionally, many of the mauls were broken at the shaft or distal end of the tools. The distal end of the tools often featured areas of both rounded and crushed and faceted grains, which is likely reflective of the material that the percussor was being used on (e.g. wood or stone)(Photo 54, Appendix J). I observed negative flake scars on the distal end of many of the mauls, as well as at fracture locations along the shaft (Photo 55, Appendix J) (Tables 15 and 16). 
Table 14. Mauls by material type, proximal, and distal styles.

\begin{tabular}{cccccc}
$\begin{array}{c}\text { Artifact } \\
\text { Number }\end{array}$ & $\begin{array}{c}\text { Original } \\
\text { Form }\end{array}$ & $\begin{array}{c}\text { Current } \\
\text { Form }\end{array}$ & $\begin{array}{c}\text { Material } \\
\text { Type }\end{array}$ & $\begin{array}{c}\text { Proximal } \\
\text { Style }\end{array}$ & $\begin{array}{c}\text { Distal } \\
\text { Style }\end{array}$ \\
\hline 35CO2-453 & Maul & Maul & UM & Rounded & Stepped \\
\hline 35CO2-454 & Maul & Maul & FGV & Nipple Top & n/a \\
\hline 35CO2-456 & Maul & Maul & FGV & Nipple Top & Flared \\
\hline 35CO2-458 & Maul & Pestle & FGV & Nipple Top & n/a \\
\hline 35CO2-459 & Maul & Pestle & FGV & Nipple Top & n/a \\
\hline 35CO2-460 & Maul & Pestle & FGV & Nipple Top & n/a \\
\hline 35CO2-461 & Maul & Maul & FGV & n/a & Stepped \\
\hline 35CO2-464 & Maul/Pestle & Maul/Pestle & FGV & Nipple Top & n/a \\
\hline 35CO2-465 & Maul & Maul & FGV & Nipple Top & n/a \\
\hline 35CO2-466 & Maul/Pestle & Maul/Pestle & FGV & Rounded & n/a \\
\hline 35CO2-467 & Maul & Maul & FGV & Rounded & Stepped \\
\hline 35CO2-468 & Maul & Maul & FGV & n/a & Stepped \\
\hline 35CO2-469 & Maul & Maul & FGV & n/a & Stepped \\
\hline 35CO2-470 & Maul & Pestle & FGV & Nipple Top & n/a \\
n/a indicates portion of tool is missing. & & & &
\end{tabular}

Table 15. Maul and pestle analysis attribute summary.

Mauls

Pestles

\begin{tabular}{lll}
\hline & $\begin{array}{l}\text { Rounded grains, conical } \\
\text { interstices, polish. Occasionally, } \\
\text { Proxhed grains present. }\end{array}$ & $\begin{array}{l}\text { Rounded grains, conical } \\
\text { interstices, polish. }\end{array}$ \\
\hline & $\begin{array}{l}\text { Rounded grains, conical } \\
\text { Rounded grains, conical } \\
\text { interstices, polish. Occasionally, } \\
\text { crushed grains present. }\end{array}$ & $\begin{array}{l}\text { Multiple use surfaces often } \\
\text { present. }\end{array}$ \\
\hline \multirow{2}{*}{ Distal End } & $\begin{array}{l}\text { Rounded and crushed grains, } \\
\text { negative flake scars. Many } \\
\text { heavily fractured distal ends. }\end{array}$ & $\begin{array}{l}\text { Rounded and crushed grains, } \\
\text { negative flake scars, polish. }\end{array}$
\end{tabular}


Table 16. Site $35 \mathrm{CO} 2$ Rylander maul analysis attribute summary by artifact. The ' $\mathrm{X}$ ' marks the presence of the given attribute; the blank cells represent the absence of the given attribute.

\section{Attributes}

\begin{tabular}{|c|c|c|c|c|c|c|c|c|c|}
\hline \multirow[b]{2}{*}{$\begin{array}{l}\text { Artifact } \\
\text { Number }\end{array}$} & \\
\hline & $\begin{array}{c}\text { Grain } \\
\text { rounding }\end{array}$ & $\begin{array}{c}\text { Grain } \\
\text { crushing }\end{array}$ & Polish & $\begin{array}{c}\text { Flake } \\
\text { scars } \\
\text { travelling } \\
\text { up from } \\
\text { distal end }\end{array}$ & $\begin{array}{c}\text { Remnant } \\
\text { chopper } \\
\text { scars }\end{array}$ & $\begin{array}{c}\text { Great } \\
\text { elevation } \\
\text { difference } \\
\text { between } \\
\text { asperities } \\
\text { and } \\
\text { interstices }\end{array}$ & $\begin{array}{c}\text { Little } \\
\text { elevation } \\
\text { difference } \\
\text { between } \\
\text { asperities } \\
\text { and } \\
\text { interstices }\end{array}$ & $\begin{array}{c}\text { Round } \\
\text { interstices }\end{array}$ & $\begin{array}{c}\text { Irregularly } \\
\text { shaped } \\
\text { interstices }\end{array}$ \\
\hline $35 \mathrm{CO} 2-453$ & $X$ & $X$ & $X$ & $\mathrm{X}$ & $\mathrm{X}$ & $X$ & $X$ & $X$ & $X$ \\
\hline $35 \mathrm{CO} 2-454$ & $X$ & $X$ & $X$ & & & $X$ & $X$ & $X$ & $X$ \\
\hline $35 \mathrm{CO} 2-456$ & $X$ & $X$ & $X$ & $X$ & & $X$ & $X$ & $X$ & $X$ \\
\hline $35 \mathrm{CO} 2-461$ & $X$ & $X$ & $X$ & $X$ & & $X$ & $\mathrm{X}$ & $X$ & $X$ \\
\hline $35 \mathrm{CO} 2-464$ & $X$ & & & & & $X$ & $X$ & $X$ & $X$ \\
\hline $35 \mathrm{CO} 2-465$ & $X$ & $X$ & & $X$ & & $X$ & $X$ & $X$ & \\
\hline $35 \mathrm{CO} 2-466$ & $X$ & $X$ & $\mathrm{X}$ & $\mathrm{X}$ & & $\mathrm{X}$ & $\mathrm{X}$ & $\mathrm{X}$ & $X$ \\
\hline $35 \mathrm{CO} 2-467$ & $X$ & $X$ & $X$ & $X$ & & $X$ & $X$ & $X$ & $X$ \\
\hline $35 \mathrm{CO} 2-468$ & $X$ & $X$ & $X$ & & & $X$ & $X$ & & $X$ \\
\hline $35 \mathrm{CO} 2-469$ & $\mathrm{X}$ & $\mathrm{X}$ & $\mathrm{X}$ & & & $\mathrm{X}$ & $\mathrm{X}$ & $\mathrm{X}$ & $\mathrm{X}$ \\
\hline
\end{tabular}


The pestles, which were manufactured from both quartzite and a fine-grained volcanic material, featured both grain rounding and crushing on the distal ends of the tools, likely attributed to different materials being processed (Photo 56, Appendix J). Additionally, the pestle shafts feature a high polish, rounded grains, and round interstices with conical cross sections (Photo 57, Appendix J). Many of the distal ends have negative flake scars travelling up toward the shaft (Table 17). I also recorded evidence of multiple use surfaces on pestles, including attributes associated with use as an anvil and heavy percussor (Figure 19). 
Table 17. Site $35 \mathrm{CO} 2$ Rylander collection pestle analysis attribute summary by artifact. The ' $\mathrm{X}$ ' marks the presence of the given attribute; the blank cells represent the absence of the given attribute.

\section{Attributes}

\begin{tabular}{|c|c|c|c|c|c|c|c|c|c|}
\hline $\begin{array}{l}\text { Artifact } \\
\text { Number }\end{array}$ & $\begin{array}{l}\text { Grain } \\
\text { rounding }\end{array}$ & $\begin{array}{c}\text { Grain } \\
\text { crushing }\end{array}$ & Polish & $\begin{array}{c}\text { Flake } \\
\text { scars } \\
\text { travelling } \\
\text { up shaft }\end{array}$ & $\begin{array}{c}\text { Remnant } \\
\text { chopper } \\
\text { scars }\end{array}$ & $\begin{array}{c}\text { Great } \\
\text { elevation } \\
\text { difference } \\
\text { between } \\
\text { asperities } \\
\text { and } \\
\text { interstices }\end{array}$ & $\begin{array}{c}\text { Little } \\
\text { elevation } \\
\text { difference } \\
\text { between } \\
\text { asperities } \\
\text { and } \\
\text { interstices }\end{array}$ & $\begin{array}{c}\text { Round } \\
\text { interstices }\end{array}$ & $\begin{array}{c}\text { Irregularly } \\
\text { shaped } \\
\text { interstices }\end{array}$ \\
\hline
\end{tabular}

\begin{tabular}{|c|c|c|c|c|c|c|c|c|c|}
\hline $35 \mathrm{CO} 2-441$ & $\mathrm{X}$ & $\mathrm{X}$ & & $\mathrm{X}$ & $\mathrm{X}$ & $\mathrm{X}$ & & & $\mathrm{X}$ \\
\hline $35 \mathrm{CO} 2-455$ & $\mathrm{X}$ & $\mathrm{X}$ & $\mathrm{X}$ & $\mathrm{X}$ & & $X$ & $\mathrm{X}$ & $\mathrm{X}$ & $\mathrm{X}$ \\
\hline $35 \mathrm{CO} 2-457$ & $\mathrm{X}$ & $\mathrm{X}$ & & $\mathrm{X}$ & & $\mathrm{X}$ & $\mathrm{X}$ & $\mathrm{X}$ & $X$ \\
\hline $35 \mathrm{CO} 2-458$ & $\mathrm{X}$ & $\mathrm{X}$ & $\mathrm{X}$ & $\mathrm{X}$ & & $\mathrm{X}$ & $\mathrm{X}$ & $\mathrm{X}$ & \\
\hline $35 \mathrm{CO} 2-459$ & $\mathrm{X}$ & $\mathrm{X}$ & $\mathrm{X}$ & $\mathrm{X}$ & & $\mathrm{X}$ & $X$ & & $X$ \\
\hline $35 \mathrm{CO} 2-460$ & $\mathrm{X}$ & $\mathrm{X}$ & $\mathrm{X}$ & $\mathrm{X}$ & & $\mathrm{X}$ & $X$ & $X$ & $X$ \\
\hline $35 \mathrm{CO} 2-463$ & $\mathrm{X}$ & $\mathrm{X}$ & $\mathrm{X}$ & $\mathrm{X}$ & & $\mathrm{X}$ & $X$ & $X$ & $\mathrm{X}$ \\
\hline $35 \mathrm{CO} 2-464$ & $\mathrm{X}$ & & & & & $\mathrm{X}$ & $X$ & $X$ & $X$ \\
\hline $35 \mathrm{CO} 2-466$ & $\mathrm{X}$ & $\mathrm{X}$ & $\mathrm{X}$ & $\mathrm{X}$ & & $\mathrm{X}$ & $X$ & $X$ & $X$ \\
\hline $35 \mathrm{CO} 2-470$ & $\mathrm{X}$ & $\mathrm{X}$ & $\mathrm{X}$ & $\mathrm{X}$ & $\mathrm{X}$ & $\mathrm{X}$ & $X$ & $X$ & $\mathrm{X}$ \\
\hline $35 \mathrm{CO} 2-471$ & $\mathrm{X}$ & $\mathrm{X}$ & $\mathrm{X}$ & $\mathrm{X}$ & & $\mathrm{X}$ & $X$ & $X$ & $\mathrm{X}$ \\
\hline $35 \mathrm{CO} 2-476$ & $\mathrm{X}$ & $\mathrm{X}$ & $X$ & & $X$ & $\mathrm{X}$ & $X$ & $X$ & $\mathrm{X}$ \\
\hline $35 \mathrm{CO} 2-491$ & $\mathrm{X}$ & $\mathrm{X}$ & $\mathrm{X}$ & $\mathrm{X}$ & & $\mathrm{X}$ & $\mathrm{X}$ & $\mathrm{X}$ & $\mathrm{X}$ \\
\hline
\end{tabular}




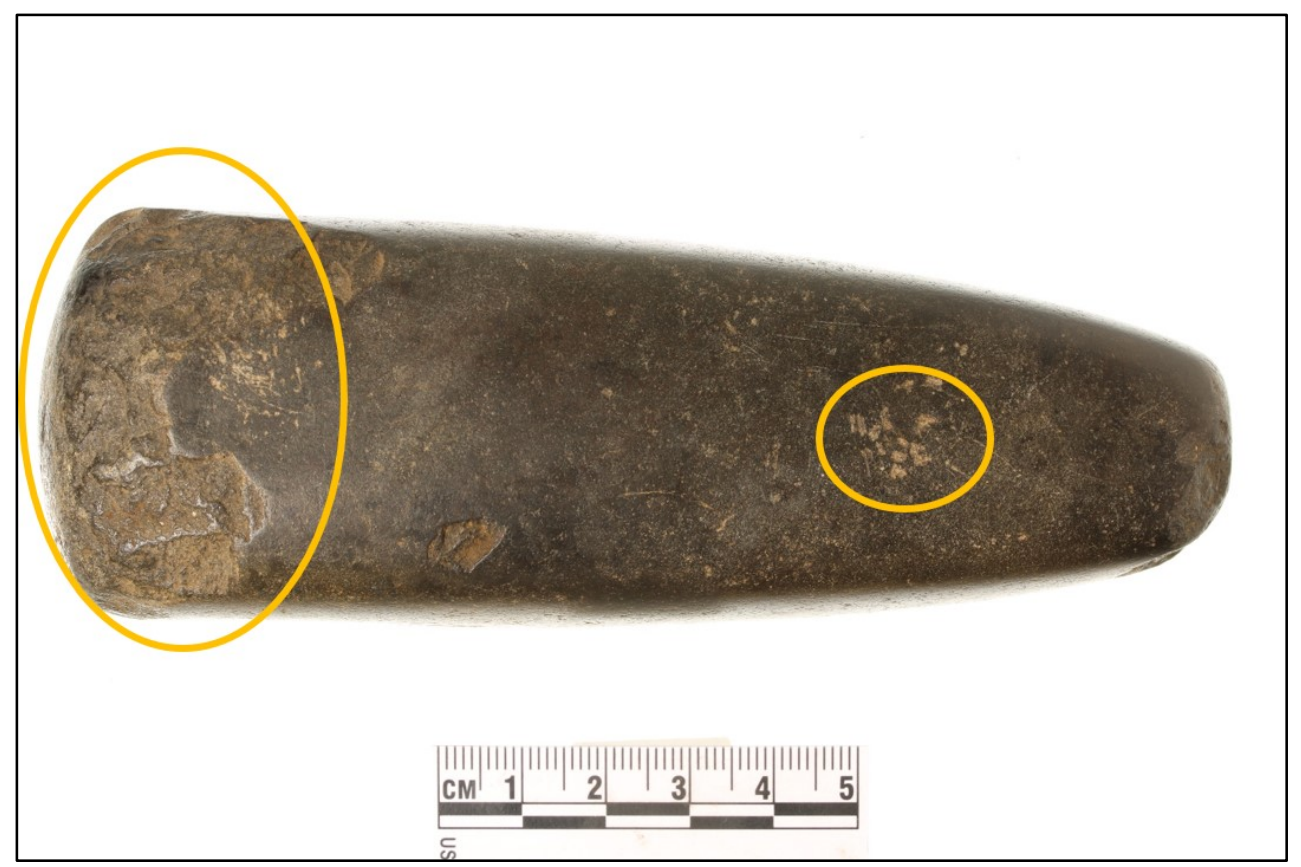

Figure 19. Pestle 35CO2-463 showing flake scars travelling up tool shaft from distal end, in addition to anvil wear on tool shaft.

The bowls ranged greatly in size from small bowls (440.19 $\mathrm{g}[15.53 \mathrm{oz}])$ that may have been used for pigment processing or oil lamps to much larger bowls weighing 13.56 $\mathrm{kg}$ (29.89 lb) (Appendix E, Tables 26 and 27). Tool stone includes a fine-grained volcanic material and mudstone. All of the bowls appear to be manufactured from alluvial cobbles, some of which have been modified on the base to create a flat area to allow the piece to independently sit level. Unmodified areas featured grain rounding, round interstices with conical cross sections, little elevation difference between asperities and interstices, and a light polish (Photo 58, Appendix J). I observed grain rounding, more prominent polish, little difference between asperities and interstices, and irregularly shaped interstices on the basin floor, while the basin walls featured both rounded and crushed grains, irregularly shaped interstices, and greater differences between asperities 
and interstices (Photo 59, Appendix J). Bowls that have a flattened base exhibited grain crushing and faceting, great elevation differences between asperities and interstices, irregularly shaped interstices, and no polish (Photo 60, Appendix J) (Tables 18 and 19). Additionally, two of the bowls (35CO2-482 and 35CO2-487) featured negative flake scars surrounding the rim of the bowl (Figure 20).

Table 18. Site 35CO2 Rylander collection bowl analysis attribute summary.

Bowls

Natural Surface Rounded grains, round interstices with conical cross sections, light polish. Little elevation difference between asperities and interstices.

Basin Rounded and crushed grains, irregularly-shaped interstices, variable elevation differences in interstices and asperities. Polish present.

Base

Grain crushing, great elevation differences between asperities and interstices, irregularly shaped interstices. 
Table 19. Site 35CO2 Rylander collection bowl analysis attribute summary by artifact. The ' $\mathrm{X}$ ' marks the presence of the given attribute; the blank cells represent the absence of the given attribute.

Attributes

\begin{tabular}{|c|c|c|c|}
\hline $\begin{array}{c}\text { Great } \\
\text { elevation } \\
\text { difference } \\
\text { between } \\
\text { asperities } \\
\text { and } \\
\text { interstices }\end{array}$ & $\begin{array}{c}\text { Little } \\
\text { elevation } \\
\text { difference } \\
\text { between } \\
\text { asperities } \\
\text { and } \\
\text { interstices }\end{array}$ & $\begin{array}{c}\text { Round } \\
\text { interstices }\end{array}$ & $\begin{array}{c}\text { Irregularly } \\
\text { shaped } \\
\text { interstices }\end{array}$ \\
\hline$X$ & $X$ & & $X$ \\
\hline$X$ & & $X$ & $X$ \\
\hline$X$ & $X$ & $X$ & $X$ \\
\hline$X$ & $X$ & $X$ & $X$ \\
\hline$X$ & $X$ & $X$ & $X$ \\
\hline$X$ & $X$ & & $X$ \\
\hline$X$ & $X$ & $X$ & $X$ \\
\hline$X$ & $X$ & $X$ & $X$ \\
\hline
\end{tabular}




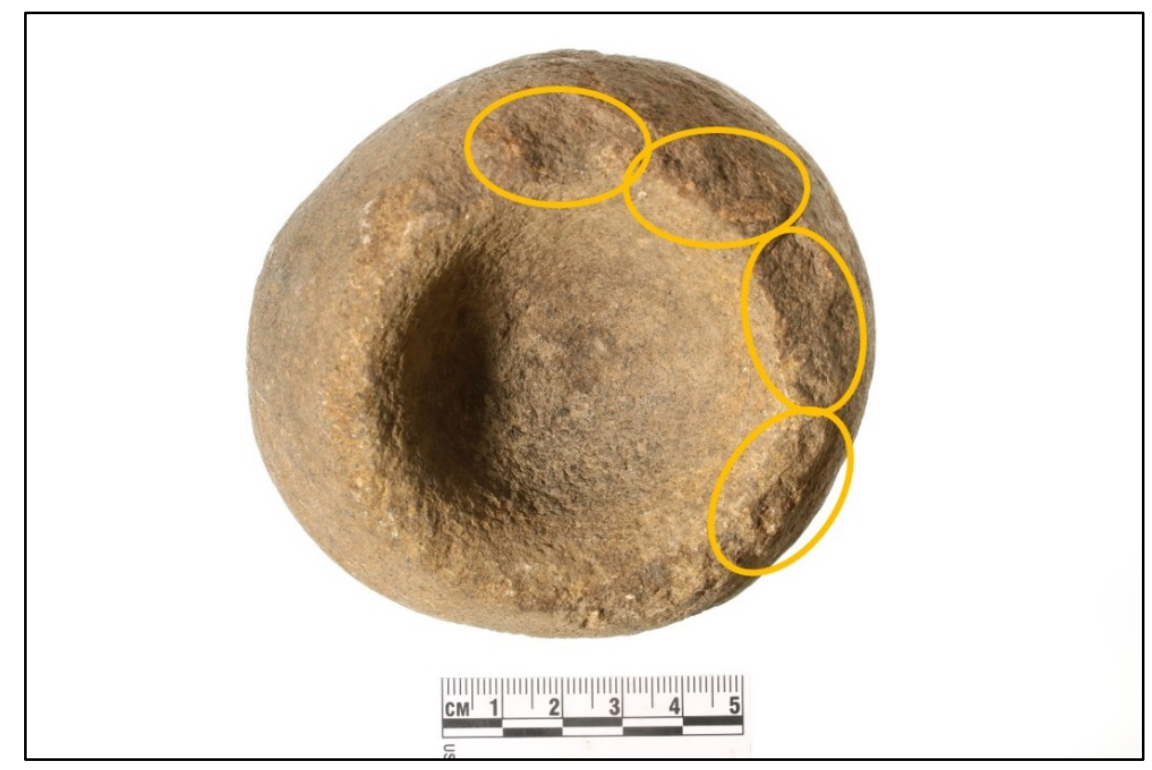

Figure 20. Bowl 35CO2-482 showing negative flake scars around the bowl rim.

The net weights, which were manufactured from a fine-grained volcanic material, andesite, and vesicular basalt, can be classed as banded, notched, and perforated (Table 20). Many of the notches, bands, and perforations have polish, which may be due to the wear from cordage being wrapped around or through the tools during use (Figure 21). All of the tools appear to be manufactured from alluvial cobbles. Areas with modification featured grain crushing and faceting with great elevation differences between asperities and interstices, and irregularly shaped interstices (Photo 61, Appendix J). As previously stated, I observed polish on many of grooves, notches, and perforations, in addition to some grain rounding in these areas. Generally, the unmodified areas had a rough surface with rounded grains, both round and irregularly shaped interstices, and a light polish (Tables 21 and 22) (Photo 62, Appendix J). 
Table 20. Site $35 \mathrm{CO} 2$ Rylander collection net weight styles and material type.

\begin{tabular}{|c|c|c|}
\hline $\begin{array}{l}\text { Artifact } \\
\text { Number }\end{array}$ & Tool Type & $\begin{array}{c}\text { Material } \\
\text { Type }\end{array}$ \\
\hline $35 \mathrm{CO} 2-438$ & Perforated Net Weight & Andesite \\
\hline $35 \mathrm{CO} 2-439$ & Perforated Net Weight & FGV \\
\hline $35 \mathrm{CO} 2-440$ & Perforated Net Weight & $\begin{array}{c}\text { Vesicular } \\
\text { Basalt }\end{array}$ \\
\hline $35 \mathrm{CO} 2-443$ & Notched Net Weight & FGV \\
\hline $35 \mathrm{CO} 2-444$ & Banded \& Notched Net Weight & FGV \\
\hline $35 \mathrm{CO} 2-445$ & Banded \& Notched Net Weight & FGV \\
\hline $35 \mathrm{CO} 2-446$ & Banded \& Notched Net Weight & Andesite \\
\hline $35 \mathrm{CO} 2-447$ & Banded \& Notched Net Weight & Andesite \\
\hline $35 \mathrm{CO} 2-448$ & Banded \& Notched Net Weight & FGV \\
\hline $35 \mathrm{CO} 2-449$ & Banded \& Notched Net Weight & Andesite \\
\hline $35 \mathrm{CO} 2-450$ & Banded Net Weight & FGV \\
\hline $35 \mathrm{CO} 2-451$ & Banded \& Notched Net Weight & FGV \\
\hline $35 \mathrm{CO} 2-472$ & Perforated Net Weight & Andesite \\
\hline
\end{tabular}




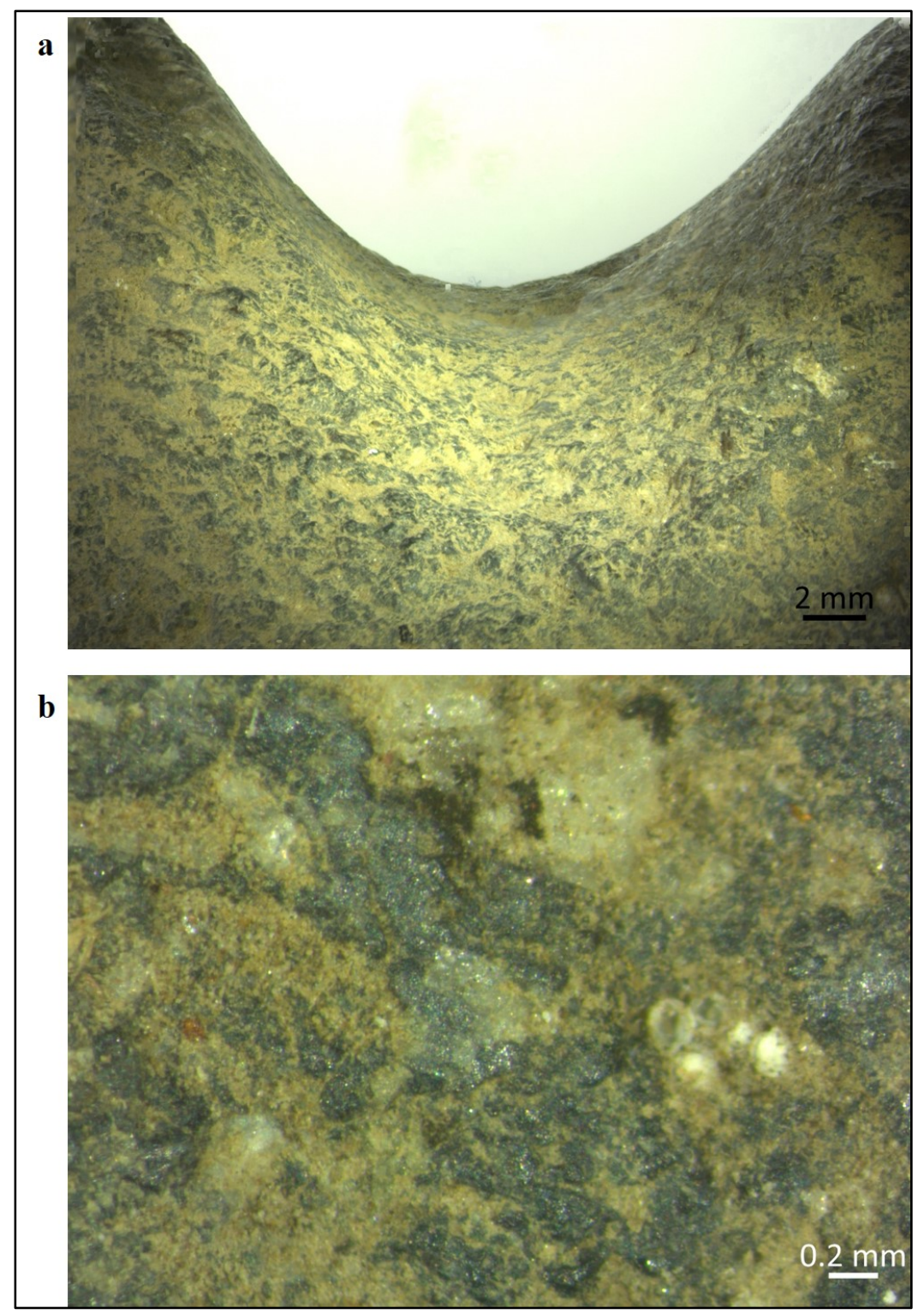

Figure 21. Photomicrograph of net weight $35 \mathrm{CO} 2-443$ showing grain rounding and polish at notch, (a) $4.095 \mathrm{x}$, (b) $31.5 \mathrm{x}$. 
Table 21. Site 35CO2 Rylander collection net weight analysis attribute summary.

\section{Net Weights}

Natural Surface Rough surface with rounded grains, light polish present, round and irregularly shaped interstices.

Grain crushing, great elevation differences between

Modified Surface interstices and asperities, irregularly shaped interstices. Polish and rounding present at many notches, perforations, and grooves. 
Table 22. Site $35 \mathrm{CO} 2$ Rylander collection net weight analysis attribute summary by artifact. The ' $\mathrm{X}$ ' marks the presence of the given attribute; the blank cells represent the absence of the given attribute.

\section{Attributes}

\section{Great Little}

elevation elevation

difference difference

between between

asperities asperities

and and

Artifact Grain Grain

Number rounding crushing Polish interstices

interstices

Round $\begin{gathered}\text { Irregularly } \\ \text { shaped }\end{gathered}$

\begin{tabular}{cccccccc} 
Number & rounding & crushing & Polish & interstices & interstices & interstices & interstices \\
\hline $35 \mathrm{CO} 2-438$ & $\mathrm{X}$ & & $\mathrm{X}$ & $\mathrm{X}$ & & $\mathrm{X}$ & $\mathrm{X}$ \\
\hline $35 \mathrm{CO} 2-439$ & $\mathrm{X}$ & & $\mathrm{X}$ & $\mathrm{X}$ & $\mathrm{X}$ & $\mathrm{X}$ & \\
\hline $35 \mathrm{CO} 2-440$ & $\mathrm{X}$ & $\mathrm{X}$ & $\mathrm{X}$ & $\mathrm{X}$ & & $\mathrm{X}$ & \\
\hline $35 \mathrm{CO} 2-443$ & $\mathrm{X}$ & & $\mathrm{X}$ & $\mathrm{X}$ & & $\mathrm{X}$ & $\mathrm{X}$ \\
\hline $35 \mathrm{CO} 2-444$ & $\mathrm{X}$ & & $\mathrm{X}$ & $\mathrm{X}$ & $\mathrm{X}$ & $\mathrm{X}$ & \\
\hline $35 \mathrm{CO} 2-445$ & $\mathrm{X}$ & $\mathrm{X}$ & $\mathrm{X}$ & $\mathrm{X}$ & $\mathrm{X}$ & $\mathrm{X}$ & $\mathrm{X}$ \\
\hline $35 \mathrm{CO} 2-446$ & $\mathrm{X}$ & $\mathrm{X}$ & & $\mathrm{X}$ & & $\mathrm{X}$ & $\mathrm{X}$ \\
\hline $35 \mathrm{CO} 2-447$ & $\mathrm{X}$ & $\mathrm{X}$ & & $\mathrm{X}$ & $\mathrm{X}$ & $\mathrm{X}$ & \\
\hline $35 \mathrm{CO} 2-448$ & $\mathrm{X}$ & $\mathrm{X}$ & $\mathrm{X}$ & $\mathrm{X}$ & & $\mathrm{X}$ & \\
\hline $35 \mathrm{CO} 2-449$ & $\mathrm{X}$ & $\mathrm{X}$ & $\mathrm{X}$ & $\mathrm{X}$ & & $\mathrm{X}$ & $\mathrm{X}$ \\
\hline $35 \mathrm{CO} 2-450$ & $\mathrm{X}$ & $\mathrm{X}$ & $\mathrm{X}$ & $\mathrm{X}$ & & $\mathrm{X}$ & $\mathrm{X}$ \\
\hline $35 \mathrm{CO} 2-451$ & $\mathrm{X}$ & $\mathrm{X}$ & $\mathrm{X}$ & $\mathrm{X}$ & $\mathrm{X}$ & $\mathrm{X}$ & \\
\hline $35 \mathrm{CO} 2-472$ & $\mathrm{X}$ & $\mathrm{X}$ & & $\mathrm{X}$ & & & $\mathrm{X}$
\end{tabular}


Analysis of the adzes, which were manufactured from a fine-grained volcanic material, an unidentified metamorphic material, and nephrite, revealed leveled asperities with very little elevation difference between asperities and interstices, and both round and irregularly shaped interstices over the entire tool surfaces. I recorded a high polish and shallow striations over the entire tool surface, in addition to damage at the bit end of the tool, including pitting, gouging, and negative flake scars (Photos 63 and 64, Appendix J). Additionally, all of the tools appeared to have been resharpened and linear facets that run parallel to the bit are visible and appear to be associated with sharpening and shaping the bit (Tables 23 and 24; Photo 65, Appendix J).

Table 23. Site $35 \mathrm{CO} 2$ Rylander collection adze analysis attribute summary.

\begin{tabular}{ll} 
& \multicolumn{1}{c}{ Adzes } \\
\hline \multirow{3}{*}{ Body of Tool } & $\begin{array}{l}\text { Little elevation differences between asperities and } \\
\text { interstices, leveled asperities, round and irregularly } \\
\text { shaped interstices. }\end{array}$ \\
\cline { 2 - 2 } & $\begin{array}{l}\text { High polish and shallow striations cover entire tool } \\
\text { surface. }\end{array}$ \\
\hline \multirow{2}{*}{ Bit End } & $\begin{array}{l}\text { Facets from shaping and sharpening, negative flake scars } \\
\text { and gouging from use. }\end{array}$
\end{tabular}


Table 24. Site 35CO2 Rylander collection adze analysis attribute summary by artifact. The ' $\mathrm{X}$ ' marks the presence of the given attribute; the blank cells represent the absence of the given attribute.

\section{Attributes}

\begin{tabular}{|c|c|c|c|c|c|c|c|c|c|}
\hline \multirow[b]{2}{*}{$\begin{array}{l}\text { Artifact } \\
\text { Number }\end{array}$} & \\
\hline & $\begin{array}{c}\text { High } \\
\text { polish }\end{array}$ & $\begin{array}{c}\text { Shallow } \\
\text { striatio } \\
\text { ns }\end{array}$ & $\begin{array}{c}\text { Groove } \\
\text { on poll- } \\
\text { end of } \\
\text { tool }\end{array}$ & $\begin{array}{c}\text { Facets } \\
\text { parallel } \\
\text { to bit }\end{array}$ & $\begin{array}{l}\text { Gouging/ } \\
\text { flake } \\
\text { scars on } \\
\text { bit }\end{array}$ & $\begin{array}{l}\text { Little elevation } \\
\text { difference } \\
\text { between } \\
\text { asperities and } \\
\text { interstices }\end{array}$ & $\begin{array}{c}\text { Leveled } \\
\text { asperities }\end{array}$ & $\begin{array}{c}\text { Round } \\
\text { interstices }\end{array}$ & $\begin{array}{c}\text { Irregularly } \\
\text {-shaped } \\
\text { interstices }\end{array}$ \\
\hline $35 \mathrm{CO} 2-427$ & $\mathrm{X}$ & $\mathrm{X}$ & $\mathrm{X}$ & & $\mathrm{X}$ & $\mathrm{X}$ & $\mathrm{X}$ & & $\mathrm{X}$ \\
\hline $35 \mathrm{CO} 2-428$ & $X$ & $X$ & & $X$ & $X$ & $X$ & $X$ & & $X$ \\
\hline $35 \mathrm{CO} 2-429$ & $X$ & $\mathrm{X}$ & & & $\mathrm{X}$ & & $\mathrm{X}$ & & $\mathrm{X}$ \\
\hline $35 \mathrm{CO} 2-430$ & $\mathrm{X}$ & $\mathrm{X}$ & & & $\mathrm{X}$ & & $\mathrm{X}$ & & $\mathrm{X}$ \\
\hline $35 \mathrm{CO} 2-431$ & $X$ & $X$ & & & $X$ & & $X$ & & $X$ \\
\hline $35 \mathrm{CO} 2-462$ & $\mathrm{X}$ & & & & $\mathrm{X}$ & $\mathrm{X}$ & & $\mathrm{X}$ & $\mathrm{X}$ \\
\hline
\end{tabular}




\section{Protein Residue Analysis Results}

I selected two pestles and three bowls to submit for protein residue analysis; all

five artifacts subjected to protein analysis featured heavy use wear and staining, and thus were considered good candidates for achieving a positive reaction. Antisera of species appropriate for the Lower Columbia River region were tested, including deer, bear, duck, trout, and rabbit. Due to funding constraints, the bear antiserum was tested on only two artifacts, 35CO2-485 and 35CO2-486, both of which are small bowls. I hypothesized that the small bowls may have been used as oil lamps and oil from bear fat used as lamp fuel. The antiserum is specific to at least the taxonomic level of family, meaning the rabbit antiserum reacts with proteins from family Leporidae, which includes species of rabbit and jackrabbit. The trout antiserum reacts with the subfamily Salmoninae, which includes salmon, steelhead, rainbow trout, and char. Deer antiserum reacts with family Cervidae, which includes white-tail and mule deer, elk, moose, and caribou. Duck antiserum reacts with family Anatidae, which includes swans, geese, and ducks. The bear antiserum reacts with family Ursidae, which includes black bear, brown bear, and grizzly bear (Appendix I).

Pestle 35CO2-463 tested positive for rabbit, pestle 35CO2-457 and bowls 35CO2485 and 35CO2-488 all tested positive for trout, confirming ground stone tools at site $35 \mathrm{CO} 2$ were used not only for vegetal processing, but also for processing faunal resources. Bowl 35CO2-486 did not have a reaction with any of the selected antisera. None of the artifacts had a positive response to the duck, deer, and bear antisera (Table 25). 
Table 25. Protein residue analysis results for select $35 \mathrm{CO} 2$ Rylander collection artifacts.

\begin{tabular}{llc} 
Artifact Number & Tool Type & Residue Results \\
\hline $35 \mathrm{CO} 2-457$ & Pestle & Trout \\
\hline $35 \mathrm{CO} 2-463$ & Pestle & Rabbit \\
\hline $35 \mathrm{CO} 2-485$ & Bowl & Trout \\
\hline $35 \mathrm{CO} 2-486$ & Bowl & $\mathrm{x}$ \\
\hline $35 \mathrm{CO} 2-488$ & Bowl & Trout
\end{tabular}




\section{Chapter V: Discussion and Conclusions}

Despite the regional importance of ground stone technology, it is analyzed in

coarse detail. To address the lack of detailed regional ground stone analysis, I conducted experimental replication and use studies to answer questions regarding time investments, raw material selection, and tool manufacture and use strategies. The questions guiding this research were:

- What are the manufacturing time investments for ground stone and how do these impact tool lifespan and recycling?

- Can evidence of tool recycling be identified? If so, how?

- What were ground stone tools used for and how were they maintained?

- What were the ground stone tools from the 35CO2 Rylander assemblage used for?

\section{Observations and Trends}

\section{$\underline{\text { Raw Material and Time Investments }}$}

The raw material selected for the experimental reductions and use wear exercises were chosen to inform on available tool stone in the region, raw material properties, and the necessity of extensive knowledge of raw material properties by Indigenous tool makers.

Different raw materials and behaviors regarding fracture mechanics quickly became apparent during the first phases of gathering tool stone for manufacturing cobble choppers. Even the tools required to manufacture ground stone tools have ideal attributes, including a hard material type, such as quartzite, flakeable margins, and a lack of weathering, or exposed seams. Ideal attributes and material types vary depending on the targeted tool manufacture. For example, soft tool stone such as andesite requires less time and effort to reduce, however, because of material softness, the tool's lifespan is 
reduced. Artifacts manufactured from andesite in the 35CO2 Rylander collection include banded and notched net weights, perforated net weights, and mobile stone sculptures, all artifacts that are not subject to heavy percussion or grinding activities. Conversely, tools that were primarily used for heavy percussion and grinding, such as pestles, mauls, bowls, choppers, and adzes, were typically manufactured from hard tool stones including quartzite, granite, various metamorphic rocks, and fine-grained volcanics, including basalt. Though the manufacturing time and skill level required for these tool stones is greater than the softer tool stones, the longevity of the tools is far greater.

Recognizing ideal tool stone attributes was advantageous for Indigenous tool makers, since tool stone impacts manufacturing efficiency and tool lifespan. Additionally, knowledge of ideal tool stone would be important when gathering raw materials from source locations far from tool manufacturing sites. It is likely Indigenous tool makers tested raw materials prior to transporting the materials for manufacture and left materials that were considered unfit for reductions.

In addition to manufacturing investments and tool longevity, the tool stone also impacts the efficacy of the tool itself. While a bowl can quickly be manufactured from an andesite cobble, as was done for the experimental replication phase of my study (KPM-1), use of the andesite bowl to process hazelnut meat resulted in a substantial amount of the tool stone debris being mixed with the food resource. This not only shortens the lifespan of the bowl, but also compromises the quality of the processed food resource. I attempted to perform a Chi Square test to assess the significance of the 
relationship between raw materials and the manufactured tool type, however, the sample size was too small to state statistical significance (Table 13).

There was likely a lot of variability in the lifespan of cobble choppers as well, depending on the availability of raw materials. For example, I used choppers until edges were substantially ground and blunt, as I had a finite supply of collected cobbles. However, if suitable cobbles were readily available, cobble choppers could have been discarded at initial signs of ineffectiveness or reduction inefficiency.

Though differential raw material hardness was immediately observable in the experimental reductions, using a standard may be helpful in making meaningful and objective comparisons between material types. The andesite used for the bowl and net weight replications (KPM-1 and KPM-8), rated a 3.5 on the Mohs scale, which is much softer than the granite I used for the bowl and net weight replications (KPM-19 and KPM-3). This difference is not surprising, nor is the required hardness of the choppers used in the reductions. The hardness of the cobbles ranged from a 5.5 to a 7.5 , which dramatically impacted the suitability of the cobbles as choppers. However, I noted different ratings between the same material types for both granite and quartzite cobbles (Table 6). This variability may be attributed to differential weathering, differences in grain structure, or the variability of inclusions. Gerberich et al. (2015:2681-2683) suggest the Mohs scale may not be a valuable tool to assess mineral hardness because of material variability in plasticity, elasticity, and fracture mechanics. However, without access to surface energy and plastic surface displacement values, the Mohs scale may still 
serve as an appropriate metric in a full suite of analysis methods in discussing raw material in ground stone reduction and use.

I hypothesized that if a tool breaks after a substantial amount of work has already been invested, it is more likely to be rejuvenated or recycled into another tool in an effort to salvage the investment. My use wear analysis of experimentally produced tools identified several attributes associated with rejuvenation and recycling. These include negative flake scars, grain crushing, faceting, and polish over broken surfaces, which are indicative of reshaping and use of the broken surface. Many of the tools from the $35 \mathrm{CO} 2$ Rylander collection appear to have been recycled after breaking. In all cases, the broken tools appear to have been originally manufactured as mauls, then broken, and subsequently recycled into pestles (Table 4). As hypothesized, the recycled and rejuvenated tools were manufactured from a fine-grained volcanic tool stone, which would have required increased manufacturing time and energy investments due to the mineral hardness (Table 6). The durability of the tool stone, however, makes the broken tools appropriate candidates for rejuvenation and recycling when possible.

While the adzes from the 35CO2 Rylander collection do not feature evidence of recycling, all of the adzes appear to have been resharpened, and one adze was resharpened to the point of exhaustion. It is reasonable to expect that a tool manufactured from nephrite, a durable and tough tool stone that likely required high time and skill investments, would have been used as long as the tool could still be rejuvenated and remain effective. In addition to the desirable tool stone qualities, nephrite was valuable due to its rarity in the region. The closest nephrite sources are located in western British 
Columbia, making the tool stone a valuable trade item (Morin 2015:12-14). While bowls manufactured from fine-grained volcanic material would have had a high manufacturing time investment, depending on the location of fractures, bowls may not have been able to be repurposed. It is likely, however, that the processing surface of bowls would have been rejuvenated or 'roughened' to create sharp asperities that were important in sheering and breaking up organic materials, such as nuts and grains, if that was the intended tool use and design.

\section{Manufacturing and Use Wear Attributes}

Through the experimental replication and use wear studies, I concluded that certain attributes can be tied to specific manufacturing strategies. Generally, crushed and faceted grains, irregularly shaped interstices, and great elevation differences are attributes that result from ground stone reduction using a cobble chopper with pecking motions. When the ground stone tools were shaped using either a negative flake scar or the dulled edge of a cobble chopper and a grinding motion, I recorded rounded grains, both round and irregularly shaped interstices, and less elevation difference between asperities and interstices.

Processing hazelnuts allowed me to examine ground stone attributes associated with processing both hard and soft materials. Shelling the hazelnuts, which simulated the processing of hard materials, produced faceted and crushed asperities with irregularly shaped interstices that featured great elevation differences between asperities and interstices on KPM-1, the bowl used in the processing. The pestle used in the processing, KPM-4, featured faceted grains, round interstices, little elevation difference between asperities and interstices, and a light amount of polish. The second phase of the use study 
consisted of processing the hazelnut kernels, which represented the processing of soft materials. Bowl KPM-1 featured mostly rounded grains, though faceted grains were also present. The interstices were irregularly shaped with great elevation differences between asperities and interstices. Polish was also present. Pestle KPM-4 featured polished rounded grains, round interstices with conical cross sections. Though this particular experiment shows a distinctive relationship between attributes and the material being processed, additional research that examines more raw material types and materials being processed is necessary to fully explore this relationship.

\section{Ground Stone Use at the $35 \mathrm{CO} 2$ site}

My final research question addressed the use of ground stone tools at the $35 \mathrm{CO} 2$ site, based on my analysis of the Rylander collection. To begin exploring this question I examined records from the $\mathrm{OAS}$ excavations at site $35 \mathrm{CO} 2$ for contextual information that addressed what kinds of activities were taking place at the site.

Excavations conducted by $\mathrm{OAS}$ at site $35 \mathrm{CO} 2$ recovered evidence of the presence of large plank houses and cremation pits, in addition to food processing and cooking areas. Though the OAS excavations and Rylander collection did not produce debitage from either flaked lithics or ground stone production, it is likely tool maintenance was also occurring at the site, and the lack of tool manufacturing debris may be attributed to collector bias. The 35CO2 Rylander ground stone collection represents a diverse set of activities, including fishing, food processing, tool maintenance, wood working, and artistic expression. This set of tools helps support the designation of site $35 \mathrm{CO} 2$ as a regionally important village site on the Lower Columbia. Additionally, when compared with ground stone counts at nearby Cathlapotle and Meier archaeological sites, site 
$35 \mathrm{CO} 2$ 's abundance of ground stone artifacts suggests that $35 \mathrm{CO} 2$ was a village site, as heavy ground stone artifacts suggest sedentism.

A goal of the analysis was to identify how the tools were manufactured and used. I examined 62 ground stone artifacts from the $35 \mathrm{CO} 2$ Rylander collection. Examining the amount of tool recycling and rejuvenation after breaking or extended use suggested great time investment in ground stone tool technology. This was especially notable with the mauls, pestles, and adzes. Additionally, the extensive use wear and heavy polish on the mauls, pestles, adzes, and bowls is indicative of a long use life, which can also be tied to the amount of time invested in the manufacturing process. Many of the tools have attributes suggesting the tool had more than one use or was used to process different types of materials, which is expected. Using the experimental replications and use wear study to hypothesize about manufacturing strategies and tool use was challenging, as many of the Rylander tools have been used so extensively. This long use life caused most of the manufacturing attributes to be eliminated through subsequent wear. Additionally, it is unlikely a mortar and pestle would have been used to process only one resource, which helps explain combinations of attributes. Many of the mortars appear to have been rejuvenated, or had the basin 'roughened' to maintain processing efficiency, which also eliminated use wear prior to the rejuvenation. The analysis of the $35 \mathrm{CO} 2$ Rylander ground stone assemblage suggests the site occupants were extensively involved in fishing and woodworking activities by the abundance of net weights, mauls, and adzes. This is also supported by the even greater presence of these tool types recovered from the OAS excavations at site $35 \mathrm{CO} 2$ (Table 1), in addition to the recovery of multiple splitting 
wedges, plank fragments, and fish bone, which was identified as salmon and sturgeon in OAS excavation field notes. Additionally, the highly curated nature of the tools suggest at least some level of craft specialization at site $35 \mathrm{CO} 2$. The presence of tool recycling and the amount of use wear reflects the high investment in ground stone tool technology and likely indicates tools were used for generations. These technologies and associated activities are expected in a Lower Columbia village site, as they likely represent plank house construction, mass food harvesting and processing, and tool maintenance activities. While the artifact totals are unknown at site $35 \mathrm{CO} 2$ due to collecting activities and avocational excavations, the estimated totals from the OAS excavations alone suggest similar ground stone tool types as the nearby Cathlapotle and Meier sites, but greater quantities than both sites (Ames et al. 2017).

The protein residue analysis yielded positive reactions for the presence of rabbit and trout residues. While most ethnographic data and contemporary research focuses on ground stone tool use associated with plant materials, these results support the sparse ethnographic record for the use of ground stone tools to process regional faunal resources. The positive trout residue was expected, as pounded salmon meal was produced with ground stone pestles and bowls (Lee and Frost 1968:181). While the ethnographic record does not mention the use of ground stone tools to process rabbits, the positive reaction with rabbit antisera suggests other small mammals may have been procured and processed with ground stone tools.

Although the 35CO2 Rylander artifacts were not professionally collected and were not stored in a controlled setting, protein residue analysis was successful and further 
demonstrates the value of not only examining ground stone tools for protein residues, but demonstrates how valuable legacy collections can be in answering questions about regional resource use, tool use, and complex lifeways.

\section{Future Research}

While many questions regarding ground stone manufacture and use were addressed in this thesis, more research must be conducted to more adequately analyze ground stone tools and explore their manufacture, use, and overall role in the Pacific Northwest and around the world.

More experimental tool replication and use wear studies must be conducted to solidify attribute-to-activity relationships. Experimental work should be expanded to include more raw material types to further explore fracture mechanics and determine if attributes associated with a single activity differ by material type. More comparisons should also be made between ground stone use wear and naturally accumulated alluvial wear. Why do these types of wear mimic one another and how can we tell them apart? While time consuming, additional use wear experiments must be conducted to aid in hypothesizing how tools were used, broken, and recycled in the Lower Columbia. Most of the experimental ground stone tool replication and use wear studies are based on tools from the American Southwest, and therefore, cannot be adequately translated to represent tools from the Pacific Northwest.

Background research for this project also revealed a lack of information on manufacturing strategies for ground stone technology. The use of cobble chopper tools in ground stone reduction should be more seriously explored not only through experimental tool replication, but by examining archaeological assemblages. After being used to 
manufacture ground stone tools, cobble choppers and their rejuvenation flakes have very distinctive use wear. As previously stated, ground stone tools are rare in the archaeological record; recognizing debitage from ground stone manufacture may help identify ground stone technology without the actual tools being present. Furthermore, while I collected the debitage from the experimental ground stone replications, it was not in the scope of this project to conduct debitage analysis. The byproduct of ground stone tool manufacture contains detritus from both the subject piece, as well as chopper flakes. Along with chopper rejuvenation flakes, this debris likely features diagnostic wear that can be associated with ground stone manufacture. Petrographic analyses on ground stone debitage would also be helpful in identifying raw materials and exploring trends in preferred tool stone and tool stone sources. Can petrographic analyses identify variability within the same rock types and can this help detect more specific tool stone attributes that were being targeted for ground stone tool manufacture? Future research can use quantitative analyses with larger sample sizes to further explore the significance of the relationship between selected raw material and tool type.

Additionally, more research must be conducted on ground stone tools that were deposited at various stages of manufacture. Recognizing and researching these tools will help us better understand manufacturing strategies, as manufacturing-associated attributes are often over stamped by heavy use wear on tools with long use lives.

\section{Project Significance}

Ground stone technology, while inadequately addressed in ethnographic texts and understudied in archaeological research, can help explore resource use, site-specific activities, and human behavior through tool manufacture and use decisions. More 
detailed and objective analyses will make data more comparable within and across regions. Experimental replication and use studies are important in exploring tool manufacture and use strategies that may have been employed by past tool makers, in addition to helping understand the complexities of tool stone selection, tool rejuvenation and recycling. The experimental replication and use study resulted in a comparative collection that was integral in conducting the analysis on the $35 \mathrm{CO} 2$ Rylander ground stone collection. The comparative analysis not only tied specific manufacture and use strategies to attributes, it resulted in the creation of a shareable use wear data set. This data set, which is in the form of hundreds of photomicrographs of attributes and associated descriptions of manufacture and use wear strategies, will help objectively describe ground stone attributes. Objectively describing attributes and using standardized terminology will strengthen ground stone analysis methods and will make datasets between assemblages and across regions possible.

I explored time investment, raw material selection, and tool recycling through experimental replication and use studies. I determined that raw material selection is tied to the targeted tool manufacture. A tool that will be used for heavy grinding and percussion activities will likely be manufactured from a hard tool stone, such as finegrained volcanic or granite. While the time investment is higher for these material types, the lifespan of the tool is longer, and the tool is more likely to be rejuvenated and recycled upon breaking. Net weights and stone sculptures, which do not require the durability of a hard tool stone, will often be manufactured from andesite or other soft tool stones, as they are much faster to work. 
The experimental replication study and analysis of the $35 \mathrm{CO} 2$ Rylander assemblage revealed the importance of the cobble chopper tool in ground stone manufacture. Not only were the cobble choppers efficient in ground stone reduction, remnant chopper scars were visible on multiple tools from the Rylander assemblage, further supporting the use of cobble choppers in ground stone tool manufacture. The cobble choppers used in the experimental tool replications had very distinctive use wear, including blunt edges, heavy battering, and grain crushing. It is likely that cobble chopper tools have been miscataloged in archaeological assemblages as hammerstones. Reexamining attributes on items cataloged as hammerstones, in addition to looking for remnant chopper scars on ground stone tools, will help us further explore this specialized use of cobble choppers for ground stone tool manufacture.

My research shows the value in conducting protein residue analysis on ground stone tools to evaluate the faunal resources that were processed. The protein residue analysis resulted in positive results, even as the tools from the $35 \mathrm{CO} 2$ Rylander collection were not archaeologically excavated, nor were they stored in a controlled setting. This example helps demonstrate that proteins can remain intact within the interstices of ground stone tools and successfully extracted and identified. While pollen analysis is often conducted on ground stone tools, protein residue analysis must also be considered a valid technique in identifying ground stone tool uses, and further verifying their use in processing both vegetal and faunal resources.

The 35CO2 Rylander collection analysis is significant in exploring the role of ground stone tools and understanding how this technology was used by communities in 
the region. The analysis (both attribute and protein residue analysis) of the $35 \mathrm{CO} 2$ Rylander collection exhibits the significance and research value of artifacts in private collections. As the ethnographic record for the region fails to adequately describe ground stone tool manufacture and use, remaining ground stone artifacts, many of which are contained in private collections, offer a means to explore how these tools helped communities thrive in the Lower Columbia. 


\section{References Cited}

Adams, Jenny L.

2014 Ground Stone Use-Wear Analysis: A Review of Terminology and

Experimental Methods. Journal of Archaeological Science 48:129-138.

2002 Ground Stone Analysis, pp. 83-224. The University of Utah Press, Salt Lake City, Utah.

1999 Refocusing the Role of Food-Grinding Tools as Correlates for Subsistence Strategies in the U.S. Southwest. American Antiquity 64(3):475-498.

1994 The Development of Prehistoric Grinding Technology in the Point of Pines Area, East-Central Arizona. Doctoral Dissertation, Department of Anthropology, University of Arizona, Tucson.

1989 Experimental Replication of the Use of Ground Stone Tools. Kiva 54(3):261271.

Adams, Jenny L., Joyce Skeldon Rychener, and Allen J. Denoyer

2015 Las Capas Archaeological Project: Ground Stone and Maize Processing

Experiments. Desert Archaeology, Inc. Report No. 2014-02.

Ames, Kenneth M., William Gardner O'Kearny, and Cameron M. Smith 2017 Postscript to Lithic Technology: Pecked and Ground Stone. In Lithic

Technology, Projectile Points, Osseous Artifacts, and Artifact Classifications of the Cathlapotle and Meier Archaeological Sites, Lower Columbia River, edited by Kenneth M. Ames and Katie Henry. Wapato Valley Project Archaeological Report \#11, Cultural Resources Series Number 19. Cultural Resources Team, U.S. Fish and Wildlife Service, Region I, Portland, Oregon.

Ames, Kenneth M., Cameron M. Smith, and Alexander Bourdeau 2008 Large Domestic Pits on the Northwest Coast of North America. Journal of Field Archaeology 33(1):3-18.

Ames, Kenneth M. and Herbert D.G. Maschner

1999 Peoples of the Northwest Coast: their Archaeology and Prehistory. Thames and Hudson Ltd, London.

Banning, E.B.

2000 The Archaeologist's Laboratory: the Analysis of Archaeological Data. Kluwer Academic/Plenum Publishers, New York. 
Binford, Lewis R.

1983 Working at Archaeology. Academic Press, New York.

Borden, Charles E.

1968 A Late Pleistocene Pebble Tool Industry of Southwestern British Columbia. In Early Man of Western North America, edited by Cynthia Irwin-Williams. Eastern New Mexico University Contributions in Anthropology 1(4):55-69.

Boyd, Robert Thomas

1999 The Coming of the Spirit of Pestilence: Introduced Infectious Diseases and Population Decline among Northwest Coast Indians, 1774-1874. UBC Press, Vancouver, and University of Washington Press, Seattle.

Bright, Jason, Andrew Ugan, and Lori Hunsaker 2002 The Effects of Handling Time on Subsistence Technology. World Archaeology 34(1):164-181.

Broz, Margaret E., Robert F. Cook, and Donna L. Whitney

2006 Microhardness, Toughness, and Modulus of Mohs Scale Minerals. American Mineralogist 91:135-142.

Buonasera, Tammy Y.

2015 Modeling the costs and benefits of manufacturing expedient milling tools. Journal of Archaeological Science 57:335-344.

Buonasera, Tammy Y.

2013 More than Acorns and Small Seeds: A Diachronic Analysis of Mortuary Associated Ground Stone from the South San Francisco Bay Area. Journal of Anthropological Archaeology 32:190-211.

2012 Expanding Archaeological Approaches to Ground Stone: Modeling Manufacturing Costs, Analyzing Absorbed Organic Residues, and Exploring Social Dimensions of Milling Tools. Doctoral Dissertation, School of Anthropology, University of Arizona, Tucson.

Callahan, Errett

2000 The Basics of Biface Knapping in the Eastern Fluted Point Tradition: A Manual for Flintknappers and Lithic Analysts. Reprinted from Archaeology of Eastern North America (7). Piltdown Productions, Lynchburg.

Collins, Michael B.

1975 Lithic Technology as a Means of Processual Inference. In Lithic Technology: Making and Using Stone Tools, edited by Earl Swanson. Mouton, The Hague. 
Crabtree, Don E.

1975 Comments on Lithic Technology and Experimental Archaeology. In Lithic

Technology: Making and Using Stone Tools, edited by Earl Swanson. Mouton, The Hague.

1967 Notes on Experiments in Flintknapping: Tools Used For Making Flaked Stone Artifacts. Tebiwa 9(1):60-73.

Croes, Dale R., John L. Fagan, and Maureen Newman Zehendner 2007 Testing the National Historic Landmark Wet Site 35MU4, the Sunken Village Archaeological Site, Multnomah County, Oregon. Department of Anthropology, South Puget Sound Community College, Olympia, Washington, and Archaeological Investigations Northwest Inc., Portland Oregon. Report No. 4. Prepared for Sauvie Island Drainage Improvement Company, Portland, Oregon.

Dubreuil, Laure and Daniel Savage

2014 Ground Stones: A Synthesis of the Use-Wear Approach. Journal of Archaeological Science 48:139-153.

Dunnell, Robert C. and Charlotte Beck

1979 The Caples Site, 45-SA-5, Skamania County, Washington. University of Washington Office of Public Archaeology. Submitted to the U.S. Army Corps of Engineers, Portland District.

Ellis, David V.

2013 Cultural Geography of the Lower Columbia. In Chinookan Peoples of the Lower Columbia, edited by Robert T. Boyd, Kenneth M. Ames, and Tony A. Johnson. University of Washington Press, Seattle and London.

Franklin, Jerry F. and C.T. Dyrness

1973 Natural Vegetation of Oregon and Washington. Pacific Northwest Forest and Range Experiment Station, U.S. Forest Service, Portland, Oregon.

Flenniken, John J.

1981 Replicative Systems Analysis: A Model Applied to the Vein Quartz Artifacts from the Hoko River Site. Laboratory of Anthropology Reports of Investigations 59, Washington State University, Pullman.

Flores, Jodi R.

2012 Experimental Archaeology: An Ethnography of its Perceived Value and Impact in Archaeological Research. Doctoral Dissertation, Department of Archaeology, University of Exeter, Exeter. 
Gahr, D. Ann Trieu

2013 Ethnobiology: Nonfishing Subsistence and Production. In Chinookan Peoples of the Lower Columbia, edited by Robert T. Boyd, Kenneth M. Ames, and Tony A. Johnson. University of Washington Press, Seattle and London.

Gass, Patrick

1904 Gass' Journal of the Lewis and Clark Expedition. A.C. McClurg \& Co., Chicago.

Gerberich, William W., Roberto Ballarini, Eric D. Hintsala, Maneesh Mishra, Jean

Francois Molinari, and Izabela Szlufarska

2015 Toward Demystifying the Mohs Hardness Scale. Journal of the American Ceramic Society 98(9):2681-2688.

General Land Office (GLO)

1854 Plat of Township No. 4 North, Range No. 1 West, Willamette Meridian.

Microfiche on file, U.S. Bureau of Land Management, Oregon State Office, Portland.

1866 Plat of Township No. 4 North, Range No. 1 West, Willamette Meridian.

Microfiche on file, U.S. Bureau of Land Management, Oregon State Office, Portland.

Gould, Stephen J.

1981 Ever Since Darwin: Reflections in Natural History. Norton, New York.

Gremillion, Kristen J.

2004 Seed Processing and the Origins of Food Production in Eastern North America. American Antiquity 69(2):215-233.

Hayden, Brian and Margaret Nelson

1981 The Use of Chipped Lithic Material the Contemporary Maya Highlands. American Antiquity 46(4):885-898.

Hajda, Yvonne

1984 Regional Social Organization in the Greater Lower Columbia, 1792-1830.

Doctoral Dissertation, School of Anthropology, University of Washington, Seattle.

Hajda, Yvonne and Elizabeth A. Sobel

2013 Lower Columbia Trade and Exchange Systems. In Chinookan Peoples of the Lower Columbia, edited by Robert T. Boyd, Kenneth M. Ames, and Tony A. Johnson. University of Washington Press, Seattle and London. 
Haley, Shawn

1996 The Pasika Complex Revisited. In Early Human Occupation in British

Columbia, edited by Roy L. Carlson and Luke Dalla Bona. University of British

Columbia Press, Vancouver.

Johnson, L. Lewis

1978 A History of Flintknapping Experimentation. Current Anthropology 19(2):337372.

Jones, Roy

1972 Wappato Indians of the Lower Columbia River Valley. Privately published, Portland.

Kinsella, Larry

2008 How to Make a Stone Axe/Celt. Electronic document, http://www.flintknapper.com, Accessed January 9, 2018.

Lee, Daniel and Joseph Frost

1968 Ten Years in Oregon. Ye Galleon Press, Fairfield.

Lewis, Albert Buell

1964 Tribes of the Columbia Valley and the Coast of Washington and Oregon. In Memoirs of the American Anthropological Association. Kraus Reprint Corporation, New York.

Lewis, Meriwether and William Clark

1893 Down the Columbia to Tidewater. The Columbia from Sandy River to The

Dalles. In The History of the Lewis and Clark Expedition, edited by Elliot Coues.

Dover Publications, Inc., New York.

Marsh, Erik J. and Jeffrey R. Ferguson

2010 Introduction. In Designing Experimental Research in Archaeology: Examining Technology through Production and Use, edited by Jeffrey R. Ferguson.

University Press of Colorado, Boulder.

Matrazzo, Donna

2012 Sauvie Island Historical Facts. Electronic document, http://sauvieisland.org/visitor-information/history/, accessed May 28, 2015.

Morin, Jesse

2015 Nephrite/Jade: The Prominent Celt Stone of the Pacific Northwest. In Toolstone Geography of the Pacific Northwest, edited by Terry L. Ozbun and Ron L. Adams. Archaeology Press, Simon Fraser University, Burnaby. 
O’Brien, Patrick K.

1994 An Experimental Study of Ground Stone Use-Wear. Master's thesis,

Department of Anthropology, University of Arizona, Tucson.

Osborne, Richard H.

1998 The Experimental Replication of a Stone Mortar. Lithic Technology 23(2):116123.

Outram, Alan K.

2008 Introduction to Experimental Archaeology. World Archaeology 40(1):1-6.

Peterson, Marilyn Sargent

1978 Mobile Stone Sculpture of the Lower Columbia. Master's thesis, Department of Anthropology, Portland State University, Portland.

Pettigrew, Richard M.

1981 A Prehistoric Culture Sequence in the Portland Basin of the Lower Columbia

Valley. University of Oregon Anthropological Papers No. 22, Eugene.

1973 Site form of 35CO2. On file, State Historic Preservation Office, Salem, Oregon.

Ray, Verne F.

1938 Lower Chinook Ethnographic Notes. University of Washington Press, Seattle.

Roulette Jr., Billy Ray

1989 Cobble Chopper Sites in Northwest Washington and Southwest British

Columbia: A New Interpretation. Master's thesis, Western Washington University, Bellingham.

Ruby, Robert H., and John A. John A. Brown

1976 The Chinook Indians: Traders of the Lower Columbia River, p 5-8. University of Oklahoma Press, Norman.

Saleeby, Becky Margaret

1983 Prehistoric Settlement Patterns in the Portland Basin of the Lower Columbia

River: Ethnohistoric, Archaeological, and Biogeographic Perspectives.

Unpublished Ph.D. dissertation, Department of Anthropology, University of Oregon, Eugene.

Schiffer, Michael B and James M. Skibo

1987 Theory and experiment in the Study of Technological Change. Current Anthropology 28(5):595-622. 
Scott, William E.,

1997 Geologic History of Mount Hood Volcano, Oregon- A Field-Trip Guide. U.S.

Department of the Interior U.S. Geological Survey, Open-File Report 97-263,

Portland, Oregon.

Screenings (Portland, Oregon)

1963 Decker Site Classification. Screenings 12(11):1.

Silverstein, Michael

1990 Chinookans of the Lower Columbia. In Northwest Coast, edited by Wayne

Suttles, p 538. Handbook of North American Indians, Vol. 7, William C.

Sturtevant, general editor. Smithsonian Institution, Washington, D.C.

Skibo, James M.

1992 Ethnoarchaeology, Experimental Archaeology and Inference Building in

Ceramic Research. Archaeologia Polona 30:27-38.

Spencer, Omar C.

1950 The Story of Sauvies Island. Binfords \& Mort, Portland, Oregon.

Spier, Leslie and Edward Sapir

1930 Wishram Ethnography. University of Washington Press, Seattle.

Strong, Emory M.

1959 Stone Age on the Columbia. Binfords \& Mort, Portland, Oregon.

Stryd, Anoud

1983 Prehistoric Mobile Art from the Mid-Fraser and Thomson River Areas. In Indian Art Traditions of the Northwest Coast, edited by Roy L. Carlson.

Archaeology Press, Simon Fraser University, Burnaby.

Squitieri, Andrea and David Eitam

2016 An Experimental Approach to Ground Stone Tool Manufacture. Journal of Lithic Studies 3(3):1-12.

Warner, George and Irene Warner

1975 Trojan III, 35CO1: Archaeological Report Covering the Third and Final Season of Salvage Excavation of the Trojan Site. Oregon Archaeological Society, Report No. 7, Portland, Oregon.

Wolf, John W.

1994 The Spatial Distribution of Ground Stone Tools as a Marker of Status

Differentials in a Chinookan Plank House on the Lower Columbia River. Master's thesis, Department of Anthropology, Portland State University, Portland. 
Zenk, Henry, Yvonne Hajda, and Robert Boyd 2016 Chinookan Villages of the Lower Columbia. Oregon Historical Quarterly 117(1):6-37. 


\section{Appendix A. Glossary of Terms}

Adze: An axe-like tool used primarily for woodworking. Tools feature a beveled or bifacial bit edge.

Anvil: Tool which provides base support for percussion activities. Wear patterns include striations, pitting, and gouges.

Asperities: Projections on a rock surface, which can be in the form of a single grain or a larger mass. Asperities can be described in terms such as crushed, faceted, rounded, and leveled.

Bifacially flaked: Material is removed from two opposing sides of an item.

Bowl: May also be referred to as mortars. Bowls and mortars are designed with a basin to contain materials for processing. Bowls and mortars may be additionally modified to make them sit flat.

Cobble chopper: Hand-held tools made from cobble (64-254 mm (2.5-10 in)) and pebble-sized stones (less than $64 \mathrm{~mm}$ (2.5 in)), which are manufactured by the removal of one or more flakes by direct percussion. Cobble choppers may be unifacially or bifacially flaked.

Crushed grains: Collapsed or heavily fractured asperities due to forces applied to the material surface. Higher elevations and weaker grains will be crushed that cannot sustain the load or force applied to the surface.

Distal: Tool edge or end most distant from user; often the primary use surface.

Exhausted: Item that is no longer usable due to wear or breakage. The item is also unable to be rejuvenated or recycled.

Experimental Archaeology: The replication of materials or processes to examine past behaviors and manufacture, use, and discard of material culture.

Ground stone: Any stone implement that is primarily manufactured through abrasion, polishing, pecking, or is used to primarily perform abrading, polishing, or pecking activities.

Hammerstone: A rock used as a percussor to primarily remove flakes from another material surface. Hammerstones often have more than one use surface.

Interstices: The spaces between asperities. Interstices can be described in terms of depth, plan view shaped and cross-section shape.

Maul/Pestle: Tool category used when an item cannot be differentiated between a maul and a pestle, which is often due to the item being broken. 
Maul: Oblong tool with a distal end that is substantially wider than the tool shaft and proximal end. Mauls vary greatly in style and complexity of design, but were primarily used for pounding stakes in the ground and driving wedges for splitting planks.

Modified surface: Rock surface that has been intentionally altered from its natural state.

Net weight: Tools used to keep fishing nets submerged and in place during use. Design or style varies within the Pacific Northwest, including banded, banded and notched, notched, and perforated. Banded net weights exhibit a groove that has been pecked around the short axis of the stone. Banded and notched net weights feature the grooved band in addition to a notch, which is pecked perpendicular to the groove on one or both sides of the tool. A notched net weight features notches that are pecked on opposite ends of the margins of the cobble. A perforated net weight features a hole that has been pecked through both sides of the cobble, creating a hole that passes through the rock. These modifications may feature polish caused by wear from lashing implements.

Unmodified surface: The natural rock surface, which may include cortex or the interior of a fractured rock.

Pestle: Oblong columnar or cylindrical tool primarily used for grinding, crushing, and pounding with a bowl or mortar. Though the distal end is often the primary use surface, the distal end and shaft may exhibit use wear.

Polish: Visible sheen on material surface. Polish may have the appearance of frosted glass, or have a more reflective surface.

Proximal: Tool edge or end closest to the user; often not the primary use surface.

Recycled tools: Tool that is modified to perform a different function than the tool was originally designed to perform.

Rejuvenation: The modification of a surface to increase the item's efficacy. Rejuvenation may be in the form of removing flakes from a cobble chopper to sharpen the edge, or pecking a basin to refresh and sharpen the use surface.

Striations: Surface scratches. Striations may be used to indicate directionality of tool use or shaping.

Topography: The physical features on the surface of the tool or raw material. Topography is often discussed in terms of grain elevations.

Tribochemical wear: wear caused by chemical reactions between films and oxides left by processes involving adhesive wear, abrasive wear, and fatigue wear.

Unifacially flaked: Material is removed from one surface of an implement. 
Use wear: The loss of surface material due to contact with another surface. The remaining surfaces display distinct characteristics at both macroscopic and microscopic levels. 
Appendix B. Replication Analysis Form

EXPERIMENTAL REPLICATION STUDY FORM

Identification Number:

Targeted Replication:

Material Type:

Form:

Source Location:

Pre-Experimental Replication

Weight:

Length:

Width:

Thickness:

Circumference:

Texture:

Low Magnification Analysis:

Surface Topography:

High Magnification Analysis:

Surface Topography: 


\section{Sketch:}

\section{Post-Experimental Replication}

Weight:

Length:

Width:

Thickness:

Circumference:

Texture:

\section{Low Magnification Analysis:}

Surface Topography:

\section{High Magnification Analysis:}

Surface Topography:

Sketch: 


\section{Appendix C. Site 35CO2 Artifact Catalog}

Table 26. Site $35 \mathrm{O} 2$ Rylander collection ground stone artifact catalog.

\begin{tabular}{|c|c|c|c|}
\hline $\begin{array}{c}\text { ARTIFACT } \\
\text { NUMBER }\end{array}$ & $\begin{array}{l}\text { ORIGINAL } \\
\text { FORM }\end{array}$ & $\begin{array}{l}\text { CURRENT } \\
\text { FORM }\end{array}$ & $\begin{array}{c}\text { RAW } \\
\text { MATERIAL } \\
\text { TYPE }\end{array}$ \\
\hline $35 \mathrm{CO} 2-425$ & Club & Club & Slate \\
\hline $35 \mathrm{CO} 2-426$ & $\begin{array}{l}\text { Horse-head } \\
\text { Handle }\end{array}$ & $\begin{array}{l}\text { Horse-head } \\
\text { Handle }\end{array}$ & FGV \\
\hline $35 \mathrm{CO} 2-427$ & Adze Blade & Adze Blade & Nephrite \\
\hline $35 \mathrm{CO} 2-428$ & Adze Blade & Adze Blade & UM \\
\hline $35 \mathrm{CO} 2-429$ & Adze Blade & Adze Blade & UM \\
\hline $35 \mathrm{CO} 2-430$ & Adze Blade & Adze Blade & $\mathrm{UM}$ \\
\hline $35 \mathrm{CO} 2-431$ & Adze Blade & Adze Blade & Nephrite \\
\hline $35 \mathrm{CO} 2-432$ & $\begin{array}{l}\text { Pipe Fragment } \\
\text { (Bowl) }\end{array}$ & $\begin{array}{l}\text { Pipe Fragment } \\
\text { (Bowl) }\end{array}$ & $\mathrm{UM}$ \\
\hline $35 \mathrm{CO} 2-438$ & $\begin{array}{c}\text { Perforated Net } \\
\text { Weight }\end{array}$ & $\begin{array}{c}\text { Perforated Net } \\
\text { Weight }\end{array}$ & Andesite \\
\hline $35 \mathrm{CO} 2-439$ & $\begin{array}{c}\text { Perforated Net } \\
\text { Weight }\end{array}$ & $\begin{array}{c}\text { Perforated Net } \\
\text { Weight }\end{array}$ & FGV \\
\hline $35 \mathrm{CO} 2-440$ & $\begin{array}{c}\text { Perforated Net } \\
\text { Weight }\end{array}$ & $\begin{array}{c}\text { Perforated Net } \\
\text { Weight }\end{array}$ & $\begin{array}{c}\text { Vesicular } \\
\text { basalt }\end{array}$ \\
\hline $35 \mathrm{CO} 2-441$ & $\begin{array}{l}\text { Multi Use- pestle } \\
\text { and abrader }\end{array}$ & $\begin{array}{l}\text { Multi Use- pestle } \\
\text { and abrader }\end{array}$ & FGV \\
\hline $35 \mathrm{CO} 2-442$ & Bowl Fragment & Bowl Fragment & FGV \\
\hline $35 \mathrm{CO} 2-443$ & $\begin{array}{c}\text { Notched Net } \\
\text { Weight }\end{array}$ & $\begin{array}{c}\text { Notched Net } \\
\text { Weight }\end{array}$ & FGV \\
\hline $35 \mathrm{CO} 2-444$ & $\begin{array}{c}\text { Banded \& } \\
\text { Notched Net } \\
\text { Weight }\end{array}$ & $\begin{array}{c}\text { Banded \& } \\
\text { Notched Net } \\
\text { Weight }\end{array}$ & FGV \\
\hline $35 \mathrm{CO} 2-445$ & $\begin{array}{c}\text { Banded \& } \\
\text { Notched Net } \\
\text { Weight }\end{array}$ & $\begin{array}{c}\text { Banded \& } \\
\text { Notched Net } \\
\text { Weight }\end{array}$ & FGV \\
\hline $35 \mathrm{CO} 2-446$ & $\begin{array}{c}\text { Banded \& } \\
\text { Notched Net } \\
\text { Weight }\end{array}$ & $\begin{array}{c}\text { Banded \& } \\
\text { Notched Net } \\
\text { Weight }\end{array}$ & Andesite \\
\hline
\end{tabular}




\begin{tabular}{|c|c|c|c|}
\hline $35 \mathrm{CO} 2-447$ & $\begin{array}{l}\text { Banded \& } \\
\text { Notched Net } \\
\text { Weight }\end{array}$ & $\begin{array}{c}\text { Banded \& } \\
\text { Notched Net } \\
\text { Weight }\end{array}$ & Andesite \\
\hline $35 \mathrm{CO} 2-448$ & $\begin{array}{c}\text { Banded \& } \\
\text { Notched Net } \\
\text { Weight }\end{array}$ & $\begin{array}{c}\text { Banded \& } \\
\text { Notched Net } \\
\text { Weight }\end{array}$ & FGV \\
\hline $35 \mathrm{CO} 2-449$ & $\begin{array}{c}\text { Banded \& } \\
\text { Notched Net } \\
\text { Weight }\end{array}$ & $\begin{array}{c}\text { Banded \& } \\
\text { Notched Net } \\
\text { Weight }\end{array}$ & Andesite \\
\hline $35 \mathrm{CO} 2-450$ & $\begin{array}{l}\text { Banded Net } \\
\text { Weight }\end{array}$ & $\begin{array}{c}\text { Banded Net } \\
\text { Weight }\end{array}$ & FGV \\
\hline $35 \mathrm{CO} 2-451$ & $\begin{array}{c}\text { Banded \& } \\
\text { Notched Net } \\
\text { Weight }\end{array}$ & $\begin{array}{c}\text { Banded \& } \\
\text { Notched Net } \\
\text { Weight }\end{array}$ & FGV \\
\hline $35 \mathrm{CO} 2-452$ & Bola Stone & Bola Stone & FGV \\
\hline $35 \mathrm{CO} 2-453$ & Maul & Maul & UM \\
\hline $35 \mathrm{CO} 2-454$ & Maul & Maul & FGV \\
\hline $35 \mathrm{CO} 2-455$ & Pestle & Pestle & FGV \\
\hline $35 \mathrm{CO} 2-456$ & Maul & Maul & FGV \\
\hline $35 \mathrm{CO} 2-457$ & Pestle & Pestle & Quartzite \\
\hline $35 \mathrm{CO} 2-458$ & Maul & Pestle & FGV \\
\hline $35 \mathrm{CO} 2-459$ & Maul & Pestle & FGV \\
\hline $35 \mathrm{CO} 2-460$ & Maul & Pestle & FGV \\
\hline $35 \mathrm{CO} 2-461$ & Maul & Maul & FGV \\
\hline $35 \mathrm{CO} 2-462$ & Adze & Adze & FGV \\
\hline $35 \mathrm{CO} 2-463$ & Pestle & Pestle & FGV \\
\hline $35 \mathrm{CO} 2-464$ & Maul/Pestle & Maul/Pestle & FGV \\
\hline $35 \mathrm{CO} 2-465$ & Maul & Maul & FGV \\
\hline $35 \mathrm{CO} 2-466$ & Maul/Pestle & Maul/Pestle & FGV \\
\hline $35 \mathrm{CO} 2-467$ & Maul & Maul & FGV \\
\hline $35 \mathrm{CO} 2-468$ & Maul & Maul & FGV \\
\hline $35 \mathrm{CO} 2-469$ & Maul & Maul & FGV \\
\hline $35 \mathrm{CO} 2-470$ & Maul & Pestle & FGV \\
\hline $35 \mathrm{CO} 2-471$ & Pestle & Pestle & FGV \\
\hline $35 \mathrm{CO} 2-472$ & $\begin{array}{c}\text { Perforated Net } \\
\text { Weight }\end{array}$ & $\begin{array}{c}\text { Perforated Net } \\
\text { Weight }\end{array}$ & Andesite \\
\hline $35 \mathrm{CO} 2-473$ & Unknown & Unknown & FGV \\
\hline $35 \mathrm{CO} 2-474$ & $\begin{array}{c}\text { Specialized } \\
\text { pecking tool }\end{array}$ & $\begin{array}{c}\text { Specialized } \\
\text { pecking tool }\end{array}$ & Quartzite \\
\hline $35 \mathrm{CO} 2-475$ & Unknown & Unknown & FGV \\
\hline $35 \mathrm{CO} 2-476$ & Pestle & Pestle & Quartzite \\
\hline
\end{tabular}




\begin{tabular}{|c|c|c|c|}
\hline $35 \mathrm{CO} 2-477$ & Hammerstone & Hammerstone & FGV \\
\hline $35 \mathrm{CO} 2-478$ & Manuport & Manuport & UM \\
\hline $35 \mathrm{CO} 2-479$ & Abrader & Abrader & $\begin{array}{c}\text { Vesicular } \\
\text { basalt }\end{array}$ \\
\hline $35 \mathrm{CO} 2-480$ & Unknown & Unknown & UM \\
\hline $35 \mathrm{CO} 2-481$ & Unknown & Unknown & FGV \\
\hline $35 \mathrm{CO} 2-482$ & Bowl & Bowl & FGV \\
\hline $35 \mathrm{CO} 2-483$ & Bowl & Bowl & Mudstone \\
\hline $35 \mathrm{CO} 2-484$ & Bowl & Bowl & FGV \\
\hline $35 \mathrm{CO} 2-485$ & Bowl & Bowl & FGV \\
\hline $35 \mathrm{CO} 2-486$ & Bowl & Bowl & Andesite \\
\hline $35 \mathrm{CO} 2-487$ & Bowl & Bowl & FGV \\
\hline $35 \mathrm{CO} 2-488$ & Bowl & Bowl & FGV \\
\hline $35 \mathrm{CO} 2-489$ & $\begin{array}{l}\text { Stone Sculpture } \\
\quad \text { (Sea Lion) }\end{array}$ & $\begin{array}{l}\text { Stone Sculpture } \\
\quad \text { (Sea Lion) }\end{array}$ & Andesite \\
\hline $35 \mathrm{CO} 2-490$ & Stone Sculpture & Stone Sculpture & $\begin{array}{c}\text { Vesicular } \\
\text { basalt }\end{array}$ \\
\hline $35 \mathrm{CO} 2-491$ & $\begin{array}{l}\text { Multi Use-anvil, } \\
\text { hammerstone, } \\
\text { pestle }\end{array}$ & $\begin{array}{l}\text { Multi Use-anvil, } \\
\text { hammerstone, } \\
\text { pestle }\end{array}$ & FGV \\
\hline
\end{tabular}




\section{Appendix D. Site 35CO2 Artifact Analysis Form}

Site:

\section{Collection:}

\section{Artifact Number:}

\section{Original Utilization:}

\section{Last Stage of Utilization:}

\section{Raw Material Classification:}

\section{Fabric:}

Isotropic (randomly oriented grains)

Linear (grains oriented in a single direction)

Planar (with parallel or foliated surfaces)

Plano-linear (linear in orientation)

\section{Texture}

Properties of Granularity

-Aphanitic Granular Structure (grains too small to be detected without the aid of a microscope) Ex: FGV (Basalt)

-Porphyritic-aphanitic Granular Structure (phenocrysts are visible to the unaided eye, but the matrix consists of an aphanitic structure) Ex: MGV (Andesite, dacite)

-Phaneritic (phenocrysts exhibit a grain size that is large enough to be identified with the unaided eye, crystals are approximately equal in size)

-Vesicular (many cavities or vesicles present, may discuss in terms of porosity), note regularity of vesicles and interstices

\section{Low Magnification Analysis:}

Surface Topography: Flat, sinuous, rounded, rugged, uneven, regular, irregular, are there any exposed interior material surfaces? How do these differ from exterior surfaces?

Wear Traces: Use wear vs. manufacturing wear, look at changes in larger grainsdescribe gauging, sheering, abrasions, pitting, etc. Describe asperities and interstices. Note distribution of wear- sparse, covering, and concentrated. Note density of wear- separated, adjacent, connected, orientation of wear (pits created from grain removal or linear traces) 
Microfractures: incl. scars, step fractures, flake removals, and crushing or breakage of grains, accumulation may result in a frosted appearance. Microfractures are common on tools manufactured through pecking Edge Rounding: Assoc. with processing soft materials, in which pliable materials penetrate into the interstices.

Leveling: Reduction in grain volume through reduction in grain summit, which is visible as grain faceting

Grain Removal: Removal of matrix material- strongly correlated with cohesion of raw material and hardness of minerals. Describe by shape of remnant pitting (irregular, circular, triangular), as well as depth of pitting.

Linear Traces: incl. scratches, striations, grooves. Describe direction, dimension, shape in profile ( $\mathrm{u}$ or v-shaped), continuous or intermittent, grouped or isolated.

Surface Reflectivity: identified as sheen or polish. Changes in reflectivity closely tied to the leveling of asperities- flatter grains have the ability to reflect greater quantities of light. Reflectivity can also be caused by tribochemical wear.

\section{High Magnification Analysis:}

Surface Topography: Flat, sinuous, rounded, rugged, uneven, regular or leveled, irregular, are there any exposed interior material surfaces? Do these vary across the surface of the tool? How do these differ from exterior surfaces?

Wear Traces: Use wear vs. manufacturing wear, look at changes in larger grains- describe gauging, sheering, abrasions, pitting, etc. Describe asperities and interstices. Note distribution of wear- sparse, covering, concentrated. Note density of wear- separated, adjacent, connected, orientation of wear (pits created from grain removal or linear traces)

Microfractures: incl. scars, step fractures, flake removals, and crushing or breakage of grains, accumulation may result in a frosted appearance. Microfractures are common on tools manufactured through pecking

Edge Rounding: Assoc. with processing soft materials, in which pliable materials penetrate into the interstices.

Leveling: Reduction in grain volume through reduction in grain summit, which is visible as grain faceting 
Grain Removal: Removal of matrix material- strongly correlated with cohesion of raw material and hardness of minerals. Describe by shape of remnant pitting (irregular, circular, triangular), as well as depth of pitting.

Linear Traces: incl. scratches, striations, grooves. Describe direction, dimension, shape in profile ( $\mathrm{u}$ or v-shaped), continuous or intermittent, grouped or isolated.

Surface Reflectivity: identified as sheen or polish. Changes in reflectivity closely tied to the leveling of asperites- flatter grains have the ability to reflect greater quantities of light. Reflectivity can also be caused by tribochemical wear.

Micropolish: Discuss density, distribution, orientation, and dimensions. Is the polish associated with the grain topography- leveling, rounding, or abraded areas? Also discuss the appearance in cross section (domed, irregular, flat) the texture (grainy or smooth), contours (sharp or diffuse), special features (pitting or striations). Also note brightness and opacity.

\section{Residue/Staining:}

Describe location. Are there residues adhering to tool grains? Are the grains themselves stained? At what magnification is residue/staining visible?

\section{Interpretation:}

Describe interpretation of manufacturing strategies, use, breakage, rejuvenation, recycling, etc.

\section{Artifact Sketch:}




\section{Appendix E. Artifact Measurements}

Table 27. Site $35 \mathrm{CO} 2$ Rylander collection artifact measurements.

\begin{tabular}{|c|c|c|c|c|}
\hline $\begin{array}{c}\text { ARTIFACT } \\
\text { NUMBER }\end{array}$ & $\begin{array}{l}\text { WEIGHT } \\
\text { (G) }\end{array}$ & $\begin{array}{c}\text { LENGTH } \\
\text { (MM) }\end{array}$ & $\begin{array}{l}\text { WIDTH } \\
\text { (MM) }\end{array}$ & $\begin{array}{c}\text { THICKNESS } \\
\text { (MM) }\end{array}$ \\
\hline $35 \mathrm{CO} 2-425$ & 430.11 & 248.23 & 64.22 & 24.57 \\
\hline $35 \mathrm{CO} 2-426$ & 79.42 & 64.49 & 43.76 & 17.65 \\
\hline $35 \mathrm{CO} 2-427$ & 116.75 & 91.43 & 41.42 & 18.62 \\
\hline $35 \mathrm{CO} 2-428$ & 17.15 & 33.01 & 36.84 & 10.19 \\
\hline $35 \mathrm{CO} 2-429$ & 59.83 & 61.67 & 38.29 & 15.91 \\
\hline $35 \mathrm{CO} 2-430$ & 71.27 & 66.96 & 43.17 & 13.96 \\
\hline $35 \mathrm{CO} 2-431$ & 81.49 & 83.24 & 43.96 & 12.28 \\
\hline $35 \mathrm{CO} 2-432$ & 5.05 & 23.51 & 20.57 & 10.3 \\
\hline $35 \mathrm{CO} 2-438$ & 89.11 & 68.82 & 50.62 & 23.09 \\
\hline $35 \mathrm{CO} 2-439$ & 394.53 & 99.1 & 93.2 & 31.69 \\
\hline $35 \mathrm{CO} 2-440$ & $1,060.69$ & 135.04 & 102.34 & 73.13 \\
\hline $35 \mathrm{CO} 2-441$ & 184.22 & 93.66 & 38.66 & 33.58 \\
\hline $35 \mathrm{CO} 2-442$ & $2,489.19$ & 168.34 & 196.64 & 61.87 \\
\hline $35 \mathrm{CO} 2-443$ & $2,731.92$ & 160.76 & 158.11 & 58.15 \\
\hline $35 \mathrm{CO} 2-444$ & $1,394.73$ & 121.19 & 105.77 & 79.53 \\
\hline $35 \mathrm{CO} 2-445$ & $1,172.54$ & 112.64 & 94.86 & 70.46 \\
\hline $35 \mathrm{CO} 2-446$ & 645.37 & 102.97 & 92.87 & 52.07 \\
\hline $35 \mathrm{CO} 2-447$ & 814.66 & 119.25 & 85.41 & 54.2 \\
\hline $35 \mathrm{CO} 2-448$ & $1,333.26$ & 115.13 & 106.36 & 69.38 \\
\hline $35 \mathrm{CO} 2-449$ & $1,302.43$ & 119.58 & 94.28 & 71.58 \\
\hline $35 \mathrm{CO} 2-450$ & $1,270.11$ & 110.27 & 103.51 & 68.49 \\
\hline $35 \mathrm{CO} 2-451$ & 649.32 & 90.26 & 80.07 & 67.06 \\
\hline $35 \mathrm{CO} 2-452$ & 159.49 & 61.36 & 48.67 & 41.04 \\
\hline $35 \mathrm{CO} 2-453$ & $1,221.77$ & 156.34 & 76.89 & 64.24 \\
\hline $35 \mathrm{CO} 2-454$ & 763.18 & 134.55 & 79.91 & 78.43 \\
\hline $35 \mathrm{CO} 2-455$ & 749.26 & 103.73 & 47.12 & 49.62 \\
\hline $35 \mathrm{CO} 2-456$ & $1,443.39$ & 160.22 & 91.47 & 89.52 \\
\hline $35 \mathrm{CO} 2-457$ & 954.81 & 126.72 & 74.61 & 78.3 \\
\hline $35 \mathrm{CO} 2-458$ & 493.16 & 115.91 & 61.58 & 63.34 \\
\hline $35 \mathrm{CO} 2-459$ & 703.92 & 133.89 & 64.69 & 50.03 \\
\hline $35 \mathrm{CO} 2-460$ & 498.04 & 120.01 & 54.89 & 47.41 \\
\hline $35 \mathrm{CO} 2-461$ & $1,203.55$ & 119.83 & 74.91 & 56.28 \\
\hline $35 \mathrm{CO} 2-462$ & 569.22 & 109.24 & 62.6 & 30.2 \\
\hline
\end{tabular}




\begin{tabular}{|c|c|c|c|c|}
\hline $35 \mathrm{CO} 2-463$ & 814.17 & 152.58 & 52.02 & 49.32 \\
\hline $35 \mathrm{CO} 2-464$ & 189.78 & 59.52 & 51.51 & 46.06 \\
\hline $35 \mathrm{CO} 2-465$ & 495.41 & 60.17 & 57.23 & 56.51 \\
\hline $35 \mathrm{CO} 2-466$ & 350.13 & 51.7 & 46.8 & 51.52 \\
\hline $35 \mathrm{CO} 2-467$ & $1,331.27$ & 167.83 & 88.19 & 69.49 \\
\hline $35 \mathrm{CO} 2-468$ & $1,138.43$ & 135.14 & 83.81 & 71.67 \\
\hline $35 \mathrm{CO} 2-469$ & $1,278.56$ & 110.63 & 77.01 & 64.44 \\
\hline $35 \mathrm{CO} 2-470$ & 481.74 & 117.7 & 52.72 & 51.48 \\
\hline $35 \mathrm{CO} 2-471$ & 465.33 & 113.92 & 56.02 & 55.37 \\
\hline $35 \mathrm{CO} 2-472$ & $1,942.13$ & 186.22 & 173.19 & 47.84 \\
\hline $35 \mathrm{CO} 2-473$ & 960.84 & 161.45 & 135.02 & 37.18 \\
\hline $35 \mathrm{CO} 2-474$ & 204.46 & 80.94 & 58.85 & 25.71 \\
\hline $35 \mathrm{CO} 2-475$ & $2,908.39$ & 192.13 & 153.65 & 36.81 \\
\hline $35 \mathrm{CO} 2-476$ & 424.83 & 119.24 & 57.8 & 42.66 \\
\hline $35 \mathrm{CO} 2-477$ & 608.79 & 139.43 & 69.22 & 46.51 \\
\hline $35 \mathrm{CO} 2-478$ & 323.11 & 156.12 & 42.69 & 25.74 \\
\hline $35 \mathrm{CO} 2-479$ & 174.24 & 98.16 & 47.68 & 31.8 \\
\hline $35 \mathrm{CO} 2-480$ & 109.75 & 60.94 & 57.02 & 27.2 \\
\hline $35 \mathrm{CO} 2-481$ & 8.42 & 37.33 & 19.93 & 5.01 \\
\hline $35 \mathrm{CO} 2-482$ & $1,728.39$ & 103.23 & 99.05 & 106.14 \\
\hline $35 \mathrm{CO} 2-483$ & 481.37 & 116.52 & 114.32 & 61.28 \\
\hline $35 \mathrm{CO} 2-484$ & 728.64 & 102.77 & 93.21 & 67.45 \\
\hline $35 \mathrm{CO} 2-485$ & 318.26 & 86.49 & 75.26 & 42.14 \\
\hline $35 \mathrm{CO} 2-486$ & 440.19 & 76.41 & 74.83 & 54.93 \\
\hline $35 \mathrm{CO} 2-487$ & $4,330.12$ & 211.1 & 145.27 & 135.64 \\
\hline $35 \mathrm{CO} 2-488$ & $13,560.22$ & 302.41 & 245.81 & 119.26 \\
\hline $35 \mathrm{CO} 2-489$ & $7,806.86$ & 275.66 & 142.25 & 101.84 \\
\hline $35 \mathrm{CO} 2-490$ & $18,052.47$ & 354.73 & 223.87 & 235.69 \\
\hline $35 \mathrm{CO} 2-491$ & $1,712.52$ & 245.61 & 79.55 & 55.25 \\
\hline
\end{tabular}

Table 28. Mean values of 35CO2 Rylander collection ground stone by tool type.

\begin{tabular}{lcccc} 
Tool Type & $\begin{array}{c}\text { Weight } \\
(\mathbf{g})\end{array}$ & $\begin{array}{c}\text { Length } \\
(\mathbf{m m})\end{array}$ & $\begin{array}{c}\text { Width } \\
(\mathbf{m m})\end{array}$ & $\begin{array}{c}\text { Thickness } \\
(\mathbf{m m})\end{array}$ \\
\hline Mauls & 941.55 & 115.59 & 72.77 & 64.82 \\
\hline Pestles & 617.07 & 119.55 & 56.77 & 51.84 \\
\hline Bowls & 3080.12 & 142.7 & 121.11 & 83.83 \\
\hline Net Weights & 1138.52 & 118.56 & 103.12 & 58.97 \\
\hline Adzes & 152.62 & 74.26 & 44.38 & 16.86 \\
\hline
\end{tabular}


Appendix F. Experimental Replication Pre-Modification Measurements

Table 29. Experimental replication pre-modification measurements.

\begin{tabular}{|c|c|c|c|c|c|c|}
\hline $\begin{array}{l}\text { Identification } \\
\text { Number }\end{array}$ & $\begin{array}{c}\text { Weight } \\
\text { (g) }\end{array}$ & $\begin{array}{c}\text { Length } \\
(\mathbf{m m})\end{array}$ & $\begin{array}{l}\text { Width } \\
(\mathbf{m m})\end{array}$ & $\begin{array}{l}\text { Thickness } \\
\text { (mm) }\end{array}$ & $\begin{array}{c}\text { Replication } \\
\text { Target }\end{array}$ & $\begin{array}{c}\text { Material } \\
\text { Type }\end{array}$ \\
\hline KPM-1 & $8,040.51$ & 291.18 & 215.15 & 117.21 & Bowl & Andesite \\
\hline KPM-3 & $2,780.04$ & 225.43 & 94.37 & 81.13 & Maul & Granite \\
\hline KPM-4 & 837.62 & 161.93 & 57.81 & 50.83 & Pestle & FGV \\
\hline KPM-8 & 532.11 & 111.43 & 82.48 & 54.81 & Net Weight & Andesite \\
\hline KPM-12 & 327.91 & 100.27 & 78.18 & 28.78 & Chopper & Quartzite \\
\hline KPM-13 & 428.26 & 102.66 & 102.11 & 24.41 & Chopper & FGV \\
\hline KPM-14 & 728.75 & 105.33 & 79.32 & 60.07 & Hammerstone & Granite \\
\hline KРM-16 & 715.44 & 122.41 & 95.64 & 41.91 & Chopper & Quartzite \\
\hline KPM-17 & 782.93 & 124.44 & 105.55 & 43.11 & Chopper & Quartzite \\
\hline KPM-18 & 453.28 & 108.74 & 78.06 & 32.55 & Chopper & Quartzite \\
\hline KPM-19 & $6,803.68$ & 206.49 & 177.83 & 123.85 & Bowl & Granite \\
\hline KPM-20 & 388.69 & 110.78 & 70.92 & 36.48 & Chopper & Quartzite \\
\hline KPM-21 & 567.23 & 116.93 & 84.95 & 41.87 & Chopper & Quartzite \\
\hline КРМ-22 & 833.6 & 128.87 & 106.41 & 41.93 & Chopper & Granite \\
\hline KРM-23 & 600.86 & 119.7 & 82.42 & 43.78 & Chopper & Granite \\
\hline KPM-24 & 672.17 & 118.36 & 93.01 & 42.33 & Chopper & Quartzite \\
\hline KPM-25 & 803.61 & 126.98 & 106.28 & 40.07 & Chopper & Quartzite \\
\hline КРМ-26 & 783.43 & 117.04 & 105.17 & 49.75 & Chopper & Quartzite \\
\hline KPM-27 & 361.54 & 97.69 & 82.8 & 30.17 & Chopper & Granite \\
\hline KРM-28 & 718.27 & 124.45 & 104.25 & 38.71 & Chopper & Quartzite \\
\hline КРМ-29 & 420.78 & 95.98 & 92.25 & 31.13 & Chopper & Quartzite \\
\hline KРM-30 & 606.32 & 111.27 & 104.46 & 37.64 & Chopper & Quartzite \\
\hline KPM-31 & 466.78 & 101.13 & 99.84 & 34.45 & Chopper & Quartzite \\
\hline KPM-32 & 389.91 & 94.89 & 86.09 & 32.31 & Chopper & Quartzite \\
\hline KРM-33 & 453.94 & 105.32 & 87.28 & 29.72 & Chopper & Quartzite \\
\hline KPM-34 & 509.55 & 105.64 & 87.08 & 39.77 & Chopper & Quartzite \\
\hline KPM-35 & 453.28 & 92.25 & 89.43 & 31.41 & Chopper & Quartzite \\
\hline KPM-36 & 503.21 & 94.28 & 85.68 & 34.19 & Chopper & Quartzite \\
\hline KРM-37 & 549.66 & 98.91 & 85.37 & 36.47 & Chopper & Quartzite \\
\hline KРM-38 & 606.35 & 107.84 & 84.22 & 33.5 & Chopper & Quartzite \\
\hline KPM-39 & 565.29 & 108.54 & 89.56 & 34.72 & Chopper & Quartzite \\
\hline KРM-40 & 475.91 & 108.99 & 85.35 & 92.86 & Chopper & FGV \\
\hline
\end{tabular}




\section{Appendix G. Experimental Replication Post-Modification Information}

Table 30. Experimental replication post-modification measurements.

\begin{tabular}{|c|c|c|c|c|c|c|}
\hline $\begin{array}{l}\text { Identification } \\
\text { Number }\end{array}$ & $\begin{array}{l}\text { Weight } \\
\text { (g) }\end{array}$ & $\begin{array}{c}\text { Length } \\
\text { (mm) }\end{array}$ & $\begin{array}{l}\text { Width } \\
\text { (mm) }\end{array}$ & $\begin{array}{l}\text { Thickness } \\
\text { (mm) }\end{array}$ & $\begin{array}{c}\text { Replication } \\
\text { Target }\end{array}$ & $\begin{array}{c}\text { Material } \\
\text { Type }\end{array}$ \\
\hline KPM-1 & 6591.41 & 291.18 & 215.15 & 117.21 & Bowl & Andesite \\
\hline KPM-3 & $2,780.04$ & 225.43 & 94.37 & 81.13 & Maul & Granite \\
\hline KPM-4 & 815.14 & 155.31 & 57.81 & 50.83 & Pestle & FGV \\
\hline КРM-8 & 490.24 & 103.51 & 77.48 & 49.79 & Net Weight & Andesite \\
\hline KPM-12 & 292.71 & 96.52 & 78.93 & 28.78 & Chopper & Quartzite \\
\hline KPM-13 & 320.93 & 89.68 & 102.11 & 24.41 & Chopper & FGV \\
\hline KPM-14 & 726.56 & 104.39 & 80.12 & 60.26 & Hammerstone & Granite \\
\hline KPM-16 & 434.04 & 107.31 & 95.64 & 41.91 & Chopper & Quartzite \\
\hline KPM-17 & 586.27 & 109.06 & 105.55 & 43.11 & Chopper & Quartzite \\
\hline KPM-18 & 339.68 & 94.95 & 78.06 & 32.55 & Chopper & Quartzite \\
\hline KPM-19 & $6,466.68$ & 206.48 & 177.78 & 123.85 & Bowl & Granite \\
\hline KPM-20 & 290.76 & 96.71 & 70.92 & 36.48 & Chopper & Quartzite \\
\hline KРM-21 & 425.19 & 101.97 & 84.95 & 41.87 & Chopper & Quartzite \\
\hline KPM-22 & 624.61 & 112.53 & 106.41 & 41.93 & Chopper & Granite \\
\hline KPM-23 & 449.78 & 104.63 & 82.42 & 43.78 & Chopper & Granite \\
\hline KРM-24 & 503.95 & 103.79 & 93.01 & 42.33 & Chopper & Quartzite \\
\hline KPM-25 & 602.09 & 110.23 & 106.28 & 40.07 & Chopper & Quartzite \\
\hline KPM-26 & 587.14 & 102.95 & 105.17 & 49.75 & Chopper & Quartzite \\
\hline КРM-27 & 311.63 & 80.46 & 82.8 & 30.17 & Chopper & Granite \\
\hline KРM-28 & 538.43 & 89.71 & 104.25 & 38.71 & Chopper & Quartzite \\
\hline КРM-29 & 314.82 & 83.48 & 92.25 & 31.13 & Chopper & Quartzite \\
\hline KPM-30 & 454.42 & 97.61 & 104.46 & 37.64 & Chopper & Quartzite \\
\hline KPM-31 & 349.31 & 88.86 & 99.84 & 34.45 & Chopper & Quartzite \\
\hline KPM-32 & 359.83 & 85.49 & 86.09 & 32.31 & Chopper & Quartzite \\
\hline KPM-33 & 387.11 & 96.09 & 87.28 & 29.72 & Chopper & Quartzite \\
\hline KPM-34 & 385.24 & 84.29 & 87.08 & 39.77 & Chopper & Quartzite \\
\hline KPM-35 & 339.75 & 81.18 & 89.43 & 31.41 & Chopper & Quartzite \\
\hline КРM-36 & 377.41 & 82.96 & 85.68 & 34.19 & Chopper & Quartzite \\
\hline KPM-37 & 411.58 & 86.13 & 85.37 & 36.47 & Chopper & Quartzite \\
\hline KРM-38 & 454.41 & 94.89 & 84.22 & 33.5 & Chopper & Quartzite \\
\hline КРM-39 & 423.69 & 94.97 & 89.56 & 34.72 & Chopper & Quartzite \\
\hline KPM-40 & 350.37 & 94.36 & 85.35 & 92.86 & Chopper & FGV \\
\hline
\end{tabular}




\section{Appendix H. Site 35CO2 Artifact Analysis Descriptions $35 \mathrm{CO} 2-425$}

Tool $35 \mathrm{CO} 2-425$ is made from a fine-grained volcanic material, is thin in cross section, and tapered on both ends (Photo 66, Appendix J). I classified the tool as a possible club, which may be considered a prestige item due the skill required to manufacture the item and the lack of use wear. Though the tool features evidence of heavy post-depositional damage, which appears to be attributed to plow activities, I noted the presence of heavy polish on the non-damaged tool surface, which has the appearance of frosted glass. Shallow pitting, short linear gouges, and very fine and shallow striations that generally travel diagonal to the long axis of the tool and are v-shaped in cross section are visible, and may be attributed to tool manufacture and shaping (Photo 67, Appendix J). The grain asperities are generally levelled, though grain crushing is visible at plow scar locations.

$35 \mathrm{CO} 2-426$

Tool 35CO2-426 is made from a fine-grained volcanic material and the tool type and function are undetermined. The tool is broken, but the remaining portion is shaped to resemble what appears to be a horse with features incised on both sides of the Figure (Photo 68, Appendix J). I recorded a high polish on both sides of the object, in addition to very fine striations that are $\mathrm{v}$-shaped in cross section and travel in various directions. The fine striations are likely attributed to fine tool shaping and polishing. The grains are rounded with very little elevation difference between interstices and asperities (Photos 69 and 70, Appendix J). While the mane and ear designs appear to have been incised with linear grinding motions, the eye features appear to have been completed using a twisting 
and grinding motion. The grains in this location are rounded and polished and have visible horizontal striations (Photo 71, Appendix J).

$35 \mathrm{CO} 2-427$

Tool $35 \mathrm{CO} 2-427$ is an adze manufactured from nephrite and features a highly polished and smooth surface (Photo 72, Appendix J). Under magnification, very fine striations that run parallel to the tool's long axis are visible, which may be attributed to fine tool shaping (Photo 73, Appendix J). I noted very little elevation differences between the asperities and interstices over most of the tool, though there is greater elevation difference at the groove that travels parallel to the tool's long axis. The asperities are flattened and the interstices are irregular in shape. Small negative flake scars and more concentrated striations are visible on the tool's bit edge, which may be attributed to use and re-sharpening (Photo 74, Appendix J).

$35 \mathrm{CO} 2-428$

Tool 35CO2-428 is an adze manufactured from an undetermined type of metamorphic material (Photo 75, Appendix J). The adze is smooth and highly polished, featuring multiple faceted surfaces from the poll to bit end of the tool. Additionally, I noted many fine striations on the tool that generally travel parallel to the long axis of the adze (Photo76, Appendix J). The faceting and striations are likely due to tool shaping and rejuvenation. The asperities are flattened and the interstices are generally shallow and irregularly shaped. The bit end of the tool has small negative flake scars, pitting, and fine striations, which may be attributed to tool use and re-sharpening (Photo 77, Appendix J). 
$35 \mathrm{CO} 2-429$

Tool 35CO2-429 is an adze manufactured from an unidentified metamorphic material that features fine striations travelling in various directions, which may be due to fine tool shaping (Photo 78, Appendix J). The tool is smooth and polished, but features heavy pitting at the poll end of the tool. Grains are leveled with irregularly shaped interstices. The bit end has many small negative flake scars and more concentrated fine striations that travel perpendicular to the bit edge. The flake scars and striations are likely due to tool use and re-sharpening.

$35 \mathrm{CO} 2-430$

Tool 35CO2-430 is an adze manufactured from an undetermined type of metamorphic material (Photo 79, Appendix J). The adze has a highly polished and smooth surface. There is damage to the poll end of the tool. I recorded many fine striations over the non-damaged portions of the tool, which travel in various directions. These striations may be attributed to fine tool shaping. Grain asperities are generally levelled on the non-damaged tool surfaces and are crushed at damage locations. Interstices on all tool surfaces are irregular in shape. The bit end of the tool is heavily damaged and features many small negative flake scars and concentrated fine striations, which are likely due to heavy tool use and previous episodes of re-sharpening. $35 \mathrm{CO} 2-431$

Tool 35CO2-431 is an adze manufactured from nephrite (Photo 80, Appendix J). The adze has a very smooth surface with a heavy polish. There is damage to the poll end and adjacent edge of the tool. I recorded many fine striations over the non-damaged portions of the tool, which travel in various directions. These striations may be attributed to fine tool shaping. The bit end of the tool features many small negative flake scars and 
concentrated fine striations, which may be due to tool use and re-sharpening. Grain asperities are generally levelled on the non-damaged tool surfaces and are crushed at damage locations. Interstices on all tool surfaces are irregular in shape.

$35 \mathrm{CO} 2-432$

Tool 35CO2-432 appears to be a pipe bowl manufactured from an undetermined metamorphic material (Photos 81 and 82, Appendix J). The pipe stem has been broken off. The bowl is highly polished, smooth, and features two holes that have been drilled through the material. I recorded many fine striations covering the entire tool surface that run in various directions, which may be attributed to fine tool shaping. The grain asperities are flattened on the top, or flattened portion, of the bowl, and are generally rounded on the remaining tool surfaces. There are horizontal tool striations within the pipe bowl and smaller holes, which may indicate that the bowl and smaller holes were completed using a downward grinding and twisting motion (Photo 83, Appendix J). I also recorded a small amount of undetermined residue on the flattened portion of the pipe bowl.

\section{$35 \mathrm{CO} 2-438$}

Tool 35CO2-438 is a perforated net weight manufactured from an andesite alluvial cobble (Photo 84, Appendix J). The cobble is flat in cross section, and features a conical depression on each side of the tool, which meet in the middle to create an hourglass shape. The tool has a rough surface texture with many visible vesicles, or pores. The grains that are on the exterior of the tool, or the non-perforated surface, feature grain rounding and the interstices are generally round with conical cross sections (Photo 85, Appendix J). There is a lot of elevation difference between asperities and interstices and 
a moderate amount of polish, which has the appearance of frosted glass. The walls of the perforation do not have a visible polish, and asperities are steep and sharp with highly reflective facets (Photo 86, Appendix J). Interstices are irregularly shaped. The center of the perforation, or the region where two conical depressions meet, features grain rounding and polish, which has the appearance of frosted glass. These attributes may be due to cordage running through the perforation and wearing on grains, causing rounding and polish. Small fibers are visible in the interstices. I recorded dark staining mostly on one side of the cobble that penetrates into the perforation.

$35 \mathrm{CO} 2-439$

Tool 35CO2-439 is a perforated net weight made of a fine-grained volcanic material (Photo 87, Appendix J). The cobble is generally flat with conical perforations on both sides of the cobble that meet in the middle, creating an hourglass shape. The exterior, or unmodified surface of the cobble, is generally flat and smooth with visible bedding planes and what appears to be post-depositional damage likely due to plow blade contact. There is little elevation difference between asperities and interstices and a moderate amount of polish present. The grains on the unmodified portion of the tool are rounded and the interstices are generally round with conical cross sections. The walls of the perforation, in contrast, have a rough texture and great elevation differences between interstices and asperities, with both faceted and crushed grains. The center of the perforation, or the area where the perforations on each side of the cobble meet, features grains that are rounded with a slight amount of polish, which may be due to wear from contact with cordage. Additionally, there is less elevation difference between asperities 
and interstices when compared to the walls of the perforation. Dark staining is present on both sides of the tool.

$35 \mathrm{CO} 2-440$

Tool 35CO2-440 is a perforated net weight manufactured from vesicular basalt (Photo 88, Appendix J). The perforation appears to have been completed by pecking a conical depression on both sides of the cobble at the thinnest cross section. The unmodified tool surface is smooth with many vesicles, which are round with conical cross sections. There is a light amount of polish on the unmodified cobble exterior and the grain asperities are rounded. The walls of the perforation also feature vesicles, but the polish is lacking. There is greater elevation difference between asperities and interstices in this region when compared to the unmodified surface and grains are generally faceted with some crushed asperities. Polish is present at the center of the perforation, or the area where the depressions from both sides of the cobble meet, which may be due to sustained wear from cordage running through the perforation (Photo 89, Appendix J).

\section{$35 \mathrm{CO} 2-441$}

Tool 35CO2-441 appears to have been a multi-purpose tool made from a finegrained volcanic material, whose attributes suggest use as a small pestle, as well as an abrader (Photo 90, Appendix J). Short, linear gouges with v-shaped cross sections, which I interpreted as chopper scars, are present at the narrow 'neck' portion of the tool. Grains in this region are mostly faceted, though some crushing is visible. Interstices are irregularly shaped. There is great elevation difference between asperities and interstices. The base of the tool features small negative flake scars that travel up the shaft of the tool. 
Grains on the tool base are mostly crushed, though there are areas where slight rounding is visible (Photo 91, Appendix J). One face of the tool is flattened and features many striations with v-shaped cross sections that travel parallel to the long axis of the tool (Photo 92, Appendix J). Grains in this region are mostly leveled, with some areas of crushing and interstices are irregularly shaped.

$35 \mathrm{CO} 2-442$

Tool 35CO2-442 is a rim fragment of a bowl made from a fine-grained volcanic material (Photo 93, Appendix J). The bowl appears to have been manufactured from a large alluvial cobble. The remaining tool portion features post-depositional damage, which appears to be due to contact with a plow blade. The surface of the rim exterior is weathered and pitted, but generally smooth with great elevation differences between asperities and interstices (Photo 94, Appendix J). The rim interior, or what would have been the basin wall of the bowl, is much smoother than the exterior, with less elevation difference between asperities and interstices. The asperities on the exterior are rounded and feature a light amount of polish and the interstices are round with conical cross sections. However, at areas of plow damage, the grains are crushed with no polish and greater elevation differences. The basin portion of the rim features grain rounding, irregularly shaped interstices, and polish that has a frosted glass appearance (Photo 95, Appendix J). There is a faint stain on the interior basin wall portion of the tool. $35 \mathrm{CO} 2-443$

Tool 35CO2-443 is a notched net weight manufactured from a fine-grained volcanic material (Photo 96, Appendix J). The tool features two v-shaped notches- one on each side of the broad, flat alluvial cobble. The unmodified tool surface is smooth with 
substantial pitting. The interstices are round with conical cross sections. Asperities are round and polished; the polish has a frosted glass appearance (Photo 97, Appendix J). The notched areas feature grain rounding and interstices that are irregularly shaped. The surface of the notches is smoother than the unmodified tool surfaces and features more polish than the unmodified areas (Photo 98, Appendix J), which may be due to wear from cordage wrapping during tool use.

\section{$35 \mathrm{CO} 2-444$}

Tool 35CO2-444 is a banded and notched net weight manufactured from a finegrained volcanic material (Photo 99, Appendix J). The tool features an oval notch on one side of the cobble, which runs perpendicular to a band that is u-shaped in cross section, which travels around the short axis of the tool. The net weight appears to have been manufactured from an alluvial cobble, with the notch and banding being the only areas of modification. The unmodified tool surface features grain rounding, round interstices with conical cross sections, and a few areas of light polish (Photo 100, Appendix J). I recorded great elevation differences between asperities and interstices. There are areas of post depositional damage, which appears to be attributed to plow blade contact; grains are generally crushed in these areas. The modified areas, which include the groove and notch, feature less elevation difference between asperities and interstices when compared to the unmodified surfaces. I recorded rounded grains within the groove and notch and more dominant polish that had the appearance of frosted glass, which may be attributed to repeated wear from cordage running through the tool groove (Photo 101, Appendix J). Iron staining was also visible within the groove (Photo 101, Appendix J). 


\section{$35 \mathrm{CO} 2-445$}

Tool $35 \mathrm{CO} 2-445$ is a banded and notched net weight manufactured from a finegrained volcanic material (Photo 102, Appendix J). The tool appears to have two grooves that run perpendicular to each other and a notch on one side of the cobble where the grooves intersect. The groove that follows the long axis of the cobble is more prominent than the groove following the short axis of the tool. It appears the tool is manufactured from an alluvial cobble, with the grooves and notching being the only modification. I recorded grain rounding, round interstices with conical cross sections, and minimal polish on the unmodified tool surfaces. The tool grooves and notching feature grain crushing, irregularly shaped interstices, greater elevation differences between asperities and interstices when compared to unmodified surfaces, and no visible polish. $35 \mathrm{CO} 2-446$

Tool 35CO2-446 is a banded and notched net weight manufactured from andesite (Photo 103, Appendix J). The tool surface is rough with vesicles covering the entire tool surface. There is a narrow v-shaped groove that runs along the short axis of the tool with a notch that is elongated and extends beyond the groove. The notch is oriented along the long axis of the tool. Additionally, both ends of the net weight are flattened. I recorded heavy post-depositional damage to the tool, which is likely due to plow damage. The unmodified portion of the tool features grain rounding and round interstices with conical cross sections and great elevation differences between interstices and asperities. The modified areas, which appear to be the groove, notch, and flattened ends, generally feature grain faceting and crushing, irregularly shaped interstices and a lack of polish. I 
noted a minimal amount of grain rounding within the groove, which may be due to wear associated with cordage being wrapped around the tool during use.

$35 \mathrm{CO} 2-447$

Tool 35CO2-447 is a banded and notched net weight made from andesite (Photo 104, Appendix J). The tool appears to be a minimally shaped alluvial cobble, with a shallow groove that follows the short axis of the tool, a notch on one side, and slightly flattened ends. I recorded heavy post-depositional damage, which is likely due to plow blade contact. The unmodified cobble surfaces are smooth with rounded grains and round interstices with conical cross sections, and low elevation differences between asperities and interstices. I noted greater elevation variability between asperities and interstices and irregularly shaped interstices on the modified tool surfaces. While the flattened ends only featured grain crushing and faceting, the groove and notch both feature grain faceting and rounding, which may be attributed to wear related to cordage being tied around the tool during use.

$35 \mathrm{CO} 2-448$

Tool 35CO2-448 is a banded and notched net weight manufactured from a finegrained volcanic material (Photo 105, Appendix J). The tool features a u-shaped groove that runs along the short axis of the tool with an oblong notch that intersects the groove, running along the long axis of the tool. The unmodified portion of the tool is smooth with grain rounding, round interstices with conical cross sections, and a light amount of polish, which is interrupted by areas that were likely plow damaged after deposition. The damaged areas have deep v-shaped linear gouges with crushed grains and no polish. I recorded both faceted and crushed grains on the flattened ends and within the groove, 
though the groove also has minimal grain rounding, which may be due to wear from cordage during use. The modified surfaces also had greater elevation differences between interstices and asperities with irregularly shaped interstices.

$35 \mathrm{CO} 2-449$

Tool 35CO2-449 is a banded and notched net weight manufactured from andesite (Photos 106 and 107, Appendix J). The tool appears to have been manufactured from an alluvial cobble, with modifications to create flattened ends, a u-shaped groove that travels along the short axis of the cobble, and a notch on one side of the tool that intersects and runs perpendicular to the groove. Deep v-shaped gouges, which are likely postdepositional plow scars are present. The unmodified surfaces feature grain rounding, round and irregularly shaped interstices, and a light amount of polish. While the flattened ends feature grain crushing and faceting, the groove and notch have grain rounding and a light amount of polish, which may be related to wear during tool use. There is a dark stain that has a light sheen when viewed with magnification on the tool that travels over the groove on the side opposite to the notch.

$35 \mathrm{CO} 2-450$

Tool $35 \mathrm{CO} 2-450$ is a banded net weight made from a fine-grained volcanic material (Photo 108, Appendix J). The tool appears to be heavily weathered with a rough surface. Both the modified and unmodified surfaces feature great elevation differences between asperities and interstice, with irregularly shaped interstices. The unmodified surfaces feature mostly rounded grains with conical cross sections, I observed some grain crushing, which is likely due to the weathered and damaged state of the tool. The flattened ends feature grain crushing and faceting, while the groove features mostly 
rounded grains and a light amount of polish, likely due to cordage being wrapped around the grooved portion of the tool.

$35 \mathrm{CO} 2-451$

Tool 35CO2-451 is a banded and notched net weight made from a fine-grained volcanic material (Photo 109, Appendix J). The tool appears to have been manufactured from an alluvial cobble, which was minimally shaped during manufacture. I identified the groove, which travels along the short axis of the cobble, and a notch that intersects the groove as the only tool modifications. The unmodified surfaces feature grain rounding, round interstices with conical cross sections, a light amount of polish, and little elevation difference between asperities and interstices. The notch and $\mathrm{u}$-shaped groove feature both grain faceting and rounding, but no polish. Areas with grain rounding may be due to wear from cordage contact during tool use. Additionally, the modified areas have greater elevation differences between interstices and asperities when compared to the unmodified surfaces.

$35 \mathrm{CO} 2-452$

Tool 35CO2-452 appears to be a bola stone, which is manufactured from a finegrained volcanic alluvial cobble (Photo 110, Appendix J). The tool features a shallow ushaped groove that travels along the long axis of the tool and appears to be the only modification on the cobble. The unmodified surface is rough and has rounded grains, great elevation differences between interstices and asperities, no visible polish, and both round and irregularly shaped interstices (Photo 111, Appendix J). What appears to be a plow scar cuts across the groove. I recorded grains that were mostly faceted, great elevation differences between asperities and interstices, and what appear to be remnant 
chopper scars within the groove (Photo 112, Appendix J). Additionally, there are areas within the groove that have rounded grains, which may be attributed to cordage running through the groove during tool use (Photo 113, Appendix J).

\section{$35 \mathrm{CO} 2-453$}

Tool 35CO2-453 is a maul made from an undetermined metamorphic material (Photo 114, Appendix J). The maul has a flared base, or distal end, and a 'nipple-top' proximal end. The distal end of the tool is broken, revealing the interior rock material. I recorded a light polish, which has the appearance of frosted glass under magnification, covering the shaft of the tool. Much of the shaft features deep pitting that has round and irregularly shaped interstices with great elevation differences between asperities and interstices. Additionally, rectangular gouges with v-shaped cross sections are visible on the tool shaft, which may be remnant scars from manufacturing. Post-depositional damage that appears to be attributed to plow damage is also visible on the tool shaft. The shaft features both rounded and crushed asperities. The 'nipple-top,' or proximal end features grain rounding, round interstices with conical cross sections, and less elevation difference when compared to the tool shaft. I noted grain crushing and faceting on the non-fractured portion of the distal end, or base, of the tool, in addition to little elevation difference between asperities and interstices. A large negative flake scar and many smaller flake scars that have grain rounding and a light polish traveling over the flake scar margins are present adjacent to the break, suggesting that the tool was used after the flake removal. What appears to be plant residue is present on the base of the tool (Photo 115, Appendix J). The interior surface of the tool, which is visible at the break on the distal end of the tool, features great elevation differences between asperities and 
interstices and faceted grains. It appears the tool may have been used with too much force or used on a material that was harder than the tool, which may have caused the fracture.

\section{$35 \mathrm{CO} 2-454$}

Tool $35 \mathrm{CO} 2-454$ is a maul manufactured from a fine-grained volcanic material that features a 'nipple-top' finish at the proximal end and a shaft that gradually flares out toward the base, which is broken off (Photo 116, Appendix J). The shaft is heavily pitted with round interstices and conical cross sections over the entire non-fractured portion of the tool. A high polish, which has the appearance of frosted glass is also visible on the shaft. Polish is present on the proximal end as well, but is less pronounced when compared to the polish present on the shaft. Asperities are rounded on both the shaft and proximal end, though the proximal end features more elevation variability between asperities and interstices than the shaft. The interior material surface, which is visible at the break, features jagged and faceted grains with great elevation differences between interstices and asperities. Interstices are irregularly shaped and there is no visible polish. Staining is visible on the tool shaft.

\section{$35 \mathrm{CO} 2-455$}

Tool $35 \mathrm{CO} 2-455$ is a pestle that may have also been used as a percussor, which is manufactured from a fine-grained volcanic material whose base, or distal end, is broken (Photo 117, Appendix J). Negative flake scars travel from the break location up the shaft toward the proximal end. The break edge features grain rounding and polish that travels over the edge of the break, suggesting the tool was used after the break. I noted great elevation differences between asperities and interstices and faceted grains on the interior 
material surface, which is exposed by the break in the shaft. The proximal end of the tool has rounded grains and a light polish in the center and heavy pitting, grain crushing, and negative flake scars, suggesting the proximal end may have been used as both a pestle and a percussor. Interstices are irregularly shaped with great elevation differences between asperities and interstices in this region. I recorded pitting on the tool shaft with round interstices and conical cross sections, in addition to little elevation differences between asperities and interstices. Asperities are rounded and feature a high polish. $35 \mathrm{CO} 2-456$

Tool 35CO2-456 is a maul manufactured from a fine-grained volcanic material (Photo 118, Appendix J). The tool is finely shaped, flares out at both the distal and proximal ends, and features a 'nipple-top' finish. From the shoulder at the proximal end to the tool base, the maul features a high polish, which is interrupted by plow scars. The proximal end also features heavy plow damage, which has exposed the interior of the tool stone. In contrast with the polished finish, the interior tool stone features a rough surface, faceted and crushed grains, irregularly shaped interstices, and great elevation differences between asperities and interstices. Both the shaft and the distal end feature a high polish, rounded grains, little elevation difference between asperities and interstices, and both round and irregularly shaped interstices. Small negative flake scars are also present around the flared distal lip of the tool, while the base features heavy pitting at the center of the flat face. The high polish and rounded grains suggests the tool was used on a soft material. 
$35 \mathrm{CO} 2-457$

Tool $35 \mathrm{CO} 2-457$ is a pestle manufactured from an alluvial quartzite cobble (Photo 119, Appendix J). Both ends of the tool are slightly rounded and convex, appearing to be the only areas modified during the tool manufacturing process. The tool appears to have been used on both the proximal and distal ends, though use wear is more prominent on the distal end, suggesting it was the primary use surface. I noted grain faceting, which is highly reflective under magnification and additional light, on both the proximal and distal ends with greater elevation differences between asperities and interstices when compared to the natural cobble surface. The distal end also features grain crushing and negative flake scars, which have grain rounding and crushing use wear traveling over the margins of the scars, suggesting the tool was used after the flakes were removed. Additionally, the tool features a surface that appears to be naturally more flat that the other cobble surfaces. The flattened surface features a reddish purple stain and concentrated gouge marks that are round and irregularly shaped and conical in cross section, suggesting the tool was also used as an anvil (Photo 120, Appendix J). The unmodified cobble surface is smooth with dispersed pitting that is generally round with conical cross sections and low elevation differences between asperities and interstices.

$35 \mathrm{CO} 2-458$

Tool 35O2-458 is manufactured from a fine-grained volcanic material and features a 'nipple-top' finish and a break across the tool shaft (Photo 121, Appendix J). It appears the tool was manufactured to be used as a maul based on the style of the proximal end, and the overall size and shape of the tool, but was broken and rejuvenated and recycled to be later used as a pestle. The shaft and proximal end have a smooth finish with dispersed 
pitting with round interstices and conical cross sections. The shaft features a heavy polish, while the widest ring of the proximal finish features a light polish. I noted grain rounding on the shaft and proximal end of the tool, however, the proximal end also features grain crushing and gouging. It is unclear if the damage to the proximal end is post-depositional or occurred during use. The distal end of the tool, which was broken and appears to have been reworked, has faceted and crushed grains over the break edge with great elevation differences between asperities and interstices, which are irregularly shaped. The center portion of the distal end is slightly convex and features grain rounding and a light polish. I recorded jagged and faceted asperities and great elevation differences between asperities and irregularly shaped interstices on the interior surface of the tool stone, which is visible in the negative flake scars along the distal end of the tool. $35 \mathrm{CO} 2-459$

Tool 35CO2-459 is manufactured from a fine-grained volcanic material and appears to have been manufactured as a maul and rejuvenated to be used as a pestle once broken (Photo 122, Appendix J). The shaft and tapered proximal end have a smooth surface with evenly distributed pitting and light polish. I recorded rounded grains and irregularly shaped interstices with little elevation difference between asperities and interstices on the shaft and proximal end; interstices are irregularly shaped (Photo123, Appendix J). Small negative flake scars are present at the break and travel up the shaft toward the proximal end (Photo 124, Appendix J). Isolated patches of dark staining are present on the tool shaft. The base of the tool has grain crushing and rounding that travels over the break, suggesting the tool was rejuvenated after the break. Interstices at the rejuvenation site are irregularly shaped and there are great differences in elevation of interstices and asperities. 
However, it does not appear the rejuvenation was complete and the tool does not appear to have been used as a pestle after the break and rejuvenation. The interior tool stone, which is visible at the break location features faceted grains, no polish, and great elevation differences between asperities and interstices. Interstices are irregularly shaped.

\section{$35 \mathrm{CO} 2-460$}

Tool 35CO2-460 is manufactured from a fine-grained volcanic material and was likely originally manufactured as a maul, but was rejuvenated to be used as a pestle after breaking (Photo 125, Appendix J). The tool is broken below the shaft, which features negative flake scars around the edge of the break at the base. I recorded both grain crushing and grain rounding over the edge of the break and edges of the margins of the flake scars, suggesting the tool was used after the flake removals and break occurred (Photo 126, Appendix J). The break also features great elevation differences between interstices and asperities with irregularly shaped interstices. Additionally, light staining and polish is visible on the broken surface, further supporting the hypothesis that the tool was repurposed after the break (Photo 127, Appendix J). The shaft and proximal end have evenly distributed pitting with a smooth surface and high polish. There is little elevation difference between the asperities and interstices and interstices are both round and irregularly shaped (Photo 128, Appendix J).

$35 \mathrm{CO} 2-461$

Tool 35CO2-461 is a maul manufactured from a fine-grained volcanic material (Photo 129, Appendix J). The maul is heavily damaged, missing the proximal end and a large portion of the distal end. I recorded a smooth surface with round and oval shaped 
interstices with conical cross sections and little elevation difference between asperities and interstices on the tool shaft. Additionally, the shaft has patches of light polish, which has the appearance of frosted glass. Where intact, the base features both faceted and rounded grains, with the rounded grains primarily occurring near the edges of the tool. There is little elevation difference between asperities and interstices and interstices are both round and irregular in shape. Additionally, the base features patches of light polish. Where fractured, the interior of the tool stone has many faceted grains with great elevation difference between interstices and asperities and no visible polish.

$35 \mathrm{CO} 2-462$

Tool 35CO2-462 is manufactured from a fine-grained volcanic material and may have been manufactured to be used as an adze (Photo 130, Appendix J). The tool is broken at mid-shaft and features a bit-like tapered end that is still intact. The entire nonfractured portion of the tool features evenly distributed pitting, which appears natural, and a polished surface, which is more pronounced at the bit end of the tool (Photo 131, Appendix J). A negative flake scar is present on the tapered portion of the bit end as well. The shaft, which is round in cross section, has rounded grains, low elevation differences between asperities and interstices, and irregularly shaped interstices. Additionally, the tool features more concentrated pitting on the tool shaft (Photo 132, Appendix J). Post-depositional damage, which appears to be attributed to plow activity, is present on the tool shaft. I recorded rounded grains, irregularly shaped interstices, and low elevation differences between on the asperities and interstices on the bit end of the tool as well. The interior of the tool stone, which is visible at the break, has sharp and 
faceted asperities, great elevation differences between asperities and interstices, and irregularly shaped interstices.

$35 \mathrm{CO} 2-463$

Tool $35 \mathrm{CO} 2-463$ is a pestle manufactured from a fine-grained volcanic material (Photo 133, Appendix J). Though the tool appears to have been primarily used as a pestle, the tool also has use wear that suggests the tool was used as a percussor, as well as an anvil. The tool is square in cross section and all tool surfaces feature polish, though the shaft is far more polished than the distal and proximal ends of the tool. There are areas of concentrated pitting and gouging with faceted and crushed asperities and irregularly shaped interstices, which may be attributed to using the flat shaft surfaces as an anvil (Photo 134, Appendix J). Both the distal and proximal ends have multiple negative flake scars, suggesting the tool was also used as a percussor. The negative flake scars have grain crushing and rounding, in addition to polish that travels over the margin of the scars, indicating the tool was used after the flakes were removed. The proximal and distal ends of the tool predominantly feature grain rounding with little elevation difference between asperities and interstices, which are both irregularly shaped and round with conical cross sections (Photo 135, Appendix J). I noted very little elevation difference, rounded grains, and round interstices with conical cross sections on the shaft where the tool was not used as an anvil.

$35 \mathrm{CO} 2-464$

Tool 35CO2-464 is the proximal end of what appears to be either a maul or pestle manufactured from a fine-grained volcanic material (Photo 136, Appendix J). The remaining fragment features the 'nipple-top' finish style. The non-fractured surface is 
smooth with rounded grains, little elevation difference between asperities and interstices, and interstices are generally round with conical cross sections. The interior of the tool stone, which is visible at the break below the proximal end, features a rough surface, great elevation differences between asperities and interstices, and irregularly shaped interstices.

$35 \mathrm{CO} 2-465$

Tool 35CO2-465 is a maul made of a fine-grained volcanic material (Photo 137, Appendix J). The tool is broken at the shaft, with the distal end missing. The shaft has a somewhat rough texture with what appears to be post-depositional damage attributed to plow contact. In non-damaged areas, the shaft features rounded grains and round interstices with conical cross sections. There is a moderate amount of elevation difference between asperities and interstices. The proximal end of the tool features both grain rounding and crushing and greater elevation differences between asperities and interstices, in addition to small step fractures and negative flake scars. It is unclear if this damage is post-depositional or associated with use. The interior of the tool, which is exposed at the break along the shaft, is rough with grain faceting and great elevation differences between asperities and interstices, which are irregularly shaped.

\section{$35 \mathrm{CO} 2-466$}

Tool 35CO2-466 is manufactured from a fine-grained volcanic material and appears to be the proximal end of either a maul or pestle; the distal end of the tool is broken and absent (Photo 138, Appendix J). The surface of the shaft and proximal end is somewhat rough with evenly distributed pitting over the entire non-fractured surface. There is a light polish, which has the appearance of frosted glass, covering the non-fractured tool 
surface (Photo 139, Appendix J). Grains are rounded and interstices are generally round with conical cross sections. There is a moderate amount of elevation difference between asperities and interstices. I recorded small negative flake scars on the proximal end, which tapers in from the shaft then slightly flares out. It is unclear if the damage to the proximal end is associated with use or occurred after deposition. The interior tool material, which is visible at the break of the distal end of the tool, features a rough surface with faceted grains, great elevation differences between asperities and interstices, and irregularly shaped interstices.

$35 \mathrm{CO} 2-467$

Tool $35 \mathrm{CO} 2-467$ is a maul manufactured from a fine-grained volcanic material (Photos 140 and 141, Appendix J). The tool is broken at the distal end and is missing approximately one third of the base. The tool generally has a rough texture with evenly distributed pitting over the non-fractured surface. I recorded a light polish, grain rounding, round interstices with conical cross sections, and a moderate amount of elevation difference between asperities and interstices on the tool shaft. What appear to be post-depositional plow scars are visible on the tool shaft. I recorded sharp and faceted asperities and great elevation differences between asperities and interstices on the proximal end of the tool. Interstices are irregularly shaped. The intact portion of the distal end of the tool features both grain rounding and crushing and a light amount of polish. A negative flake scar is present adjacent to the fracture, which may suggest the tool was used with too much force or on a material that was harder than the tool, causing the break. The interior of the stone, which is visible at the break on the distal end, has 
faceted grains, irregularly shaped interstices, and great elevation differences between asperities and interstices.

$35 \mathrm{CO} 2-468$

Tool 35CO2-468 is a maul made from a fine-grained volcanic material (Photos 142

and 143, Appendix J). The tool is broken and missing the proximal end and a portion of the distal end. Though the tool has what appear to be plow scars, the plow scars cut across the fractures on the tool, suggesting the plow damage did not cause the tool breaks. The remaining portion of the shaft features a light polish and little elevation difference between asperities and interstices. I recorded rounded grains and irregularly shaped interstices on the tool shaft as well. The proximal end and non-fractured portion of the distal end also feature rounded grains and irregularly shaped interstices. The tool stone interior, which is exposed at the break on the base, features sharp and steep asperities, great elevation differences between asperities and interstices, and angular and faceted grains, with some grain crushing.

$35 \mathrm{CO} 2-469$

Tool 35CO2-469, a fine-grained volcanic maul, is broken between 15 and $28 \mathrm{~mm}$ (.59 and $1.10 \mathrm{in}$ ) above the distal end, with a portion of the shaft and proximal end missing (Photos 144 and 145, Appendix J). Negative flake scars are present along the jagged edge of the break. Though what appear to be plow scars are present on the distal end of the tool, it is unknown whether or not the tool broke prior to deposition. The interior of the tool stone, which is visible at the break, features sharp and faceted grains, steep asperities, and great elevation differences between asperities and interstices (Photo 146, Appendix J). Excluding the break surface, the rest of the tool is highly polished 
with evenly distributed shallow pitting, which are both round and irregularly shaped (Photo 147, Appendix J). The grains on both the tool shaft and base are rounded. I recorded more polish on the base, or use surface, of the tool in addition to less elevation difference between asperities and interstices, when compared to the shaft of the tool. Interstices on the tool base are shallow and irregularly shaped (Photo 148, Appendix J). $35 \mathrm{CO} 2-470$

Tool 35CO2-470 is manufactured from a fine-grained volcanic material and was likely originally manufactured as a maul, but was rejuvenated to be used as a pestle after breaking (Photo 149, Appendix J). The tool is broken at the shaft, with negative flake scars travelling up the shaft from the break location. The edge of the tool at the break has been rounded and it appears the tool was used after the break, which resulted in the development of polish (Photo 150, Appendix J). Though the tool features polish on the rejuvenated distal end, it does not appear to have been used enough to lessen elevation differences between asperities and interstices. Excluding gouges that appear to be plow scars, the shaft features grain rounding, irregularly shaped interstices, and little elevation difference between asperities and interstices. Short, linear gouges with v-shaped cross sections are visible on the shaft, which may be remnant chopper scars from manufacturing (Photo 151, Appendix J). The base of the tool, or distal end, features greater elevation differences between asperities and interstices than the tool shaft. Additionally, the distal end features grain rounding and irregularly shaped interstices. I recorded a slight polish and shallow striations at the tapered proximal end of the tool (Photo 152, Appendix J). The presence of the polish may be attributed to handling and use, while the striations may be caused by abrading during the tool manufacturing 
process. Interstices at the proximal end are mostly round with conical cross sections and grains are rounded with little elevation differences between interstices and asperities. $35 \mathrm{CO} 2-471$

Tool $35 \mathrm{CO} 2-471$ is a pestle manufactured from a fine-grained volcanic material (Photo 153, Appendix J). The cross section of the tool is square and both the proximal and distal ends are broken. While the primary use of the tool appears to have been as a pestle, heavy concentrations of pitting and gouging on the broad, flat sides of the tool suggest use as an anvil as well (Photo 154, Appendix J). Excluding the areas of pitting, the shaft features heavy polish, grain rounding, and little elevation difference between asperities and interstices. Though the distal end of the pestle is broken and has negative flake scars traveling up the shaft, the tool has been rejuvenated and rounded at the site of the break. Additionally, the distal end features great elevation differences between asperities and interstices, areas of polish, and both grain rounding and crushing (Photo 155, Appendix J). The interior of the tool stone, which is exposed at the proximal end break, features sharp and faceted grains, irregularly shaped interstices, and great elevation differences between asperities and interstices.

$35 \mathrm{CO} 2-472$

Tool $35 \mathrm{CO} 2-472$ is a perforated net weight manufactured from andesite. The tool is disc-shaped and features a hole through the center which is conical from both sides of the tool, creating an hourglass shape (Photo 156, Appendix J). Both flat surfaces are rough in texture and feature great elevation differences between asperities and interstices. Grains are angular and faceted and interstices are irregularly shaped. The perforation features less elevation variability when compared to the flat tool surfaces. Additionally, 
grain rounding is prominent within the perforation, which may be associated with wear caused by cordage running through the center of the tool. The exterior tool edge features both faceted and crushed grains with great elevation differences between asperities and interstices. The faceted grains on the flat surfaces and tool edges may be attributed to shaping during the manufacturing process, while the grain crushing on the tool edge may be associated with battering during use.

\section{$35 \mathrm{CO} 2-473$}

Tool 35CO2-473 is a tool that features one flattened side and one convex side with rounded edges, and is made from a fine-grained volcanic material (Photo 157, Appendix J). The convex side features a trough that borders the convex portion and the lip that forms the rounded edge. The tool function is unknown. I recorded a heavy polish on the convex surface with grain rounding and little elevation difference between asperities and interstices (Photo 158, Appendix J). The aforementioned trough on the convex side of the tool does not feature a polish. These attributes are interrupted by concentrations of pitting and gouging, which are both round and irregularly shaped and may be associated with the tool being used as an anvil (Photo 159, Appendix J). The flat surface is also polished, but to a lesser degree than the convex tool surface. Additionally, the flat surface features little elevation difference between asperities and interstices and mostly rounded grains, though there are isolated areas where the grains are flattened. Shallow linear striations are visible, which have v-shaped cross sections (Photo 160, Appendix J). $35 \mathrm{CO} 2-474$

Tool 35CO2-474 is made from a quartzite alluvial cobble and may have been manufactured to be used as a specialized pecking tool (Photo 161, Appendix J). The tool 
is crescent-shaped and features negative flake scars along one edge of the tool, though the edge has been subsequently rounded (Photo 162, Appendix J). The periphery of the entire tool is pitted, though the tool is most heavily pitted at the location of the negative flake scars (Photo 163, Appendix J). Grains are both crushed and faceted at the flaked location with irregularly shaped interstices, and great elevation differences between asperities and interstices. The unmodified tool surface is smooth and polished with rounded grains, round interstices, and little elevation difference between asperities and interstices. It appears the entire cobble edge was used as a pecking tool, while the crescent shape may have been useful in shaping grooves that are common on mauls in the region.

\section{$35 \mathrm{CO} 2-475$}

Tool $35 \mathrm{CO} 2-475$ is manufactured from a fine-grained volcanic material and is generally square-shaped in plan-view and thin and rectangular in cross section (Photo 164, Appendix J). One side of the tool features a shallow, round concavity in the corner of the broad, flat surface (Photo 165, Appendix J). The function of the tool is unknown, though intersecting shallow linear striations and concentrated pitting and gouging suggest the tool may have been used as an anvil and grinding or cutting surface. Both flattened sides of the tool feature a light polish, with more prominent polish within the concavity. The areas of concentrated pitting and gouging feature grain crushing, irregularly shaped and steep interstices, and more elevation variability between interstices and asperities when compared to the surrounding tool surface. I recorded flattened grains and great elevation differences between interstices and asperities at the location of the shallow striations, suggesting the back and forth motion of grinding. The concavity, which had a 
higher level of polish than surrounding surfaces also features grain rounding and round interstices with conical cross sections and less elevation difference between asperities and interstices when compared to the surrounding used surfaces (Photo 166, Appendix J). $35 \mathrm{CO} 2-476$

Tool $35 \mathrm{CO} 2-476$ is a quartzite pestle that is minimally shaped and has little use wear (Photo 167, Appendix J). The cobble appears to be shaped along the shaft and at the distal end of the tool. Both faceted and crushed grains are present on the modified portion of the shaft (Photo 168, Appendix J). Additionally, irregularly shaped interstices, great elevation differences between asperities and interstices, and what appear to be chopper scars from manufacture are visible on the shaft. What appear to be plow scars are also visible on the shaft portion of the tool. The base, or distal end, of the tool features grain crushing and faceting, great elevation differences between asperities and interstices, irregularly shaped interstices, as well as negative flake scars, which are likely attributed to shaping during manufacture and light use wear (Photo 169, Appendix J). In contrast, the unmodified portion of the tool features a smooth and polished surface with rounded grains, little elevation difference between asperities and interstices, and round interstices with conical cross sections.

$35 \mathrm{CO} 2-477$

Tool $35 \mathrm{CO} 2-477$ is a hammerstone made from a fine-grained volcanic material (Photo 170, Appendix J). The unmodified portion of the alluvial cobble features evenly distributed shallow pitting, a smooth, polished surface, grain rounding, round interstices with conical cross sections, and little elevation difference between asperities and interstices. The region of the cobble used as a hammerstone features a large facet and 
dense pitting and grain crushing (Photo 171, Appendix J). Additionally, interstices are irregularly shaped and there is greater elevation differences between asperities and interstices when compared to the unmodified tool surface.

$35 \mathrm{CO} 2-478$

Item 35CO2-478 is a unmodified metamorphic alluvial cobble (Photo 172, Appendix

J). The item appears to be a similar tool stone that was used for adzes from the $35 \mathrm{CO} 2$ Rylander collection (35CO2-428 through 35CO2-431) and may have been acquired for that purpose.

35CO2-479

Tool 35CO2-479 is an abrader manufactured from vesicular basalt (Photos 173 and 174, Appendix J). The tool is rectangular with a v-shaped depression running along the long axis of the tool stone. I recorded linear gouging, grain crushing and faceting and great elevation differences between asperities and interstices within the modified portion of the tool (Photos 175 and 176, Appendix J). The unmodified portion of the tool features a light polish, grain rounding, irregularly shaped interstices and great elevation differences between asperities and interstices due to the vesicular nature of the tool stone. Heavy post-depositional damage, which appears to be plow scars, is present on the tool. What appears to be a pitch residue is also visible on the tool. $35 \mathrm{CO} 2-480$

Tool 35CO2-480 is manufactured from an unknown type of metamorphic material whose function is unknown, as the object is broken (Photo 177, Appendix J). The item is shaped and has a smooth and polished finish, rounded and leveled grains, round interstices with conical cross sections, and very little elevation difference between asperities and interstices. Many fine and shallow striations with v-shaped cross sections 
are visible and travel at many different angles across the modified tool surface (Photos 178 and 179, Appendix J). The interior of the tool stone, which is visible at the break location, features faceted grains, greater elevation differences between asperities and interstices when compared to the modified surface, and irregularly shaped interstices. $35 \mathrm{CO} 2-481$

Tool 35CO2-481 is made from a fine-grained volcanic material whose function is unknown (Photo 180, Appendix J). The piece is thin, shaped, and broken along one edge. The remaining portion of the item is rectangular with two grooves, creating three tangs on the side opposite the break. Shallow striations, which are v-shaped in cross section, cover both sides of the item and run along the long and short axis of the tool (Photos 181183, Appendix J). Grains are generally flattened on the tool surface, though grain rounding is present at the grooved tool edge. Additionally, the tool surface is highly polished, there is little elevation difference between asperities and interstices, and interstices are both round and irregularly shaped.

$35 \mathrm{CO} 2-482$

Tool 35CO2-482 is a bowl made from a fine-grained volcanic material (Photo 184, Appendix J). The exterior of the bowl appears to be modified in some areas, while other regions appear to be the natural material surface. Additionally, the base of the bowl is modified and features a slightly concave surface, which allows the bowl to independently sit flat. What appear to be plow scars are also present on the bowl exterior. Grains are generally round, interstices are round with conical cross sections, and there are great elevation differences between asperities and interstices on the unmodified portion of the bowl exterior. The area of the bowl exterior that appears to be modified is flattened and 
has a rougher texture than the surrounding surface. I recorded faceted grains, with crushing in some areas, great elevation differences between asperities and interstices, irregularly shaped interstices, and what appear to be scars from manufacturing (Photo 185, Appendix J). The rim features substantial damage in the form of numerous negative flake scars. I noted a high polish within the basin, or bowl interior, in addition to grain rounding, round interstices with conical cross sections, and great elevation differences between asperities and interstices (Photo 186, Appendix J). Dark staining is present within the basin. The tool may have been used as an oil lamp, due to its small size and shallow basin.

35CO2-483

Tool 35CO2-483 is a bowl manufactured from what appears to be a spherical concretion or mudstone cast (Photos 187 and 188, Appendix J). The tool stone is soft and the bowl has sustained substantial damage, which appears to be associated with plow damage (Photo 189, Appendix J). I recorded rounded grains, round and irregularly shaped interstices, and great elevation differences between interstices and asperities. Similar to the exterior, the basin features grain rounding and round and irregularly shaped interstices. However, the basin also features less elevation difference between asperities and interstices when compared to the exterior, and the interior also features a light polish (Photo 190, Appendix J).

$35 \mathrm{CO} 2-484$

Tool 35CO2-484 is a bowl manufactured from a fine-grained volcanic material (Photo 191, Appendix J). The bowl features a rough exterior, which appears to be minimally shaped, and is missing a large fragment, exposing the interior of the tool stone. 
I recorded sparse and evenly distributed pitting on the bowl exterior. Additionally, the exterior featured both rounded and faceted grains, round interstices with conical cross sections, and greater elevation differences between asperities and interstices when compared to the basin (Photo 192, Appendix J). Many small negative flake scars are present along the bowl rim. The basin walls are rougher than the bottom of the basin and feature great elevation differences, round and irregularly shaped interstices, and a combination of grain rounding and faceting. I noted rounded grains, round interstices with conical cross sections, less elevation difference between asperities and interstices when compared to the basin walls and bowl exterior, and polish on the floor of the basin (Photo 193, Appendix J). The interior of the tool stone, which is visible at the break, has a rough texture, faceted grains, irregularly shaped interstices, and great elevation differences between interstices and asperities. A ring of staining is visible on the basin wall.

$35 \mathrm{CO} 2-485$

Tool $35 \mathrm{CO} 2-485$ is a bowl manufactured from a fine-grained volcanic material (Photos 194 and 195, Appendix J). The bowl is small and features a flattened base and thin incised line along the outer edge of the bowl rim; black pigment was applied to the incised line. Damage to the rim appears to be post-depositional, as the negative flake scar does not feature the same weathering as the surrounding surface. The bowl exterior has a slightly rough texture, rounded grains, little elevation difference between asperities and interstices, round interstices with conical cross sections, and a light polish.

I recorded grain rounding, less elevation difference between asperities and interstices within the bowl basin when compared to the bowl exterior, round interstices 
with conical cross sections, and more prominent polish than the bowl exterior (Photo 196, Appendix J). The incised line around the bowl rim is shallow and varies between being $\mathrm{v}$-shaped and u-shaped in cross section. The applied pigment is shiny and highly reflective (Photo 197, Appendix J). Modification to the base of the bowl created a concave surface that features grain faceting and crushing, irregularly shaped interstices, great elevation differences between asperities and interstices and short, linear gouges with v-shaped cross sections, which may be remnant chopper scars from manufacturing (Photo 198, Appendix J).

$35 \mathrm{CO} 2-486$

Tool 35CO2-486 is a bowl manufactured from a fine-grained volcanic material (Photo 199, Appendix J). The small bowl features a rough texture on the bowl exterior with what appears to be plow scars and a flattened base, which allows the piece to sit flat. I recorded grain rounding, irregularly shaped interstices, great elevation differences between asperities and interstices, and a light polish on the exterior bowl surface and base. The bowl basin features both grain rounding and crushing, irregularly shaped interstices, and slightly greater elevation difference between asperities and interstices when compared with the bowl exterior and base. The basin features a more prominent polish when compared to the bowl exterior and also features visible staining at the floor of the basin.

$35 \mathrm{CO} 2-487$

Tool $35 \mathrm{CO} 2-487$ is a bowl manufactured from a fine-grained volcanic material (Photo 200, Appendix J). The bowl has sustained substantial damage to the exterior sides, rim, and bowl basin, which is likely attributed to plow damage. I recorded both 
grain rounding and faceting on the bowl exterior, in addition to irregularly shaped interstices, great elevation differences in interstices and asperities, and a slight polish. The basin features grain rounding and faceting, less elevation difference between asperities and interstices compared to the bowl exterior, round interstices with conical cross sections, and a more prominent polish when compared to the bowl exterior. Grain faceting within the basin may be attributed to rejuvenating the basin surface after use. The tool stone interior, which is visible at plow scar locations, features faceted and crushed grains, great elevation differences between asperities and interstices, and irregularly shaped interstices.

\section{$35 \mathrm{CO} 2-488$}

Tool $35 \mathrm{CO} 2-488$ is a bowl manufactured from a fine-grained volcanic material (Photo 201, Appendix J). The exterior of the bowl features evenly distributed shallow pitting and what appears to be post-depositional plow damage. Additionally, the exterior has grain rounding, little elevation difference between asperities and interstices when compared to the bowl basin, round interstices with conical cross sections, and polish that is more prominent on the exterior base of the bowl (Photo 202, Appendix J). The heavier polish on the exterior bowl base is likely due to the repeated contact with another surface beneath the bowl during use. The bowl interior, or basin, features both round and irregularly shaped interstices and greater elevation differences between asperities and interstices when compared to the bowl exterior. I recorded grain rounding on the basin walls and periphery of the floor of the basin, while heavy pitting, faceted grains, and crushed grains are more prominent in the center of the basin floor (Photo 203, Appendix J). A light polish is also present within the basin, but is more prominent on the basin 
walls and edges of the basin floor. This difference in grain morphology within the basin may be attributed to the use of the tool to process soft materials, which caused the grain rounding, and dense materials, which would have caused the gouging and grain crushing and faceting. Dark staining is also present within the basin and up the basin walls and rim of the bowl.

$35 \mathrm{CO} 2-489$

Tool $35 \mathrm{CO} 2-489$ is a zoomorphic mobile stone sculpture manufactured from andesite (Photos 204-207, Appendix J). The piece appears to be modeled after a seal or sea lion, which is a common motif in the region (Peterson 1979:210-213,215; Stryd 1983:147-148). Both crushed and faceted grains are present on the modified surface, along with irregularly shaped interstices, and great elevation differences between asperities and interstices. What appears to be a plow scar cuts across one side of the piece. The pecked grooves that form the motif are both u-shaped and v-shaped in cross section.

\section{$35 \mathrm{CO} 2-490$}

Tool 35CO2-490 is a mobile stone sculpture manufactured from vesicular basalt (Photos 208-213, Appendix J). Various geometric shapes are pecked into the material surface, including concentric circles and trapezoids with incised lines radiating from them. The 'top' of the sculpture is conical, while the base is sheared off, with the remaining portion of the sculpture missing. The surface has a rough texture and features both crushed and faceted grains, irregularly shaped interstices where previously round vesicles have been broken, and great elevation differences between asperities and 
interstices. The pecked grooves that create the designs are approximately $8.67 \mathrm{~mm}(.34$ in) deep and are both v-shaped and u-shaped in cross section.

$35 \mathrm{CO} 2-491$

Tool 35CO2-491 is manufactured from a fine-grained volcanic material and appears to have multiple uses, including a hammerstone, pestle, and anvil (Photos 214 and 215, Appendix J). The tool is in the form of an elongate alluvial cobble that features a high polish and shallow, evenly distributed pitting over the entire tool surface. One end of the tool is battered and fractured and may have been used as a percussor, while the other end is flattened and worn, likely from use as a pestle. The pestle use surface features rounded grains and little elevation difference between asperities and interstices (Photo 216). Additionally, the tool features two broad, flat surfaces that each feature concentrations of pitting and gouging, suggesting use as an anvil (Photo 217, Appendix J). The use wear on the pestle end features rounded grains, little elevation difference between asperities and interstices, and round interstices with conical cross sections. The broad and flat faces of the tool, which contain the anvil use wear feature both rounded and crushed grains, greater elevation differences when compared to the pestle surface, and irregularly shaped interstices. Where fractured, the tool features grain faceting and crushing, great elevation differences between asperities and interstices, and irregularly shaped interstices. It is unknown if the fracture occurred in association with the tool being used as a percussor, though damage on the tool is consistent with a fracture caused by using the tool on too dense of a material or improperly using the tool. 


\section{Appendix I. Protein Residue Analysis Results}

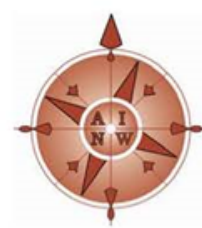

\section{Archaeological Investigations Northwest, Inc.}

3510 N.E. $122^{\text {nd }}$ Ave. - Portland, Oregon 97230

Phone (503) 761-6605 • Fax (503) 761-6620

Vancouver Phone (360) 696-7473 E-mail: ainweainw.com Web: www.ainw.com

August 6, 2018

Ms. Kelley Prince-Martinez

Staff Archaeologist

Archaeological Investigations Northwest, Inc.

3510 NE $122^{\text {nd }}$ Ave.

Portland, Oregon 97230

Re: Results of Protein Residue Analysis on five groundstone artifacts from site 35CO2

AINW Report No. 4086

Dear Ms. Prince-Martinez:

At your request, Archaeological Investigations Northwest, Inc. (AINW), analyzed five groundstone artifacts from the Rylander collection from site $35 \mathrm{CO} 2$. The analysis was done to identify possible protein residues using cross-over immunoelectrophoresis (CIEP). There were four positive reactions to two of the five chosen antisera.

The CIEP technique has been widely used in forensic laboratories to determine the origin of bloodstains as evidence in criminal investigations, and has been adapted for use in archaeology to detect protein residues on prehistoric artifacts. The CIEP technique is based on the immune (antigen-antibody) reaction. Extracts of protein residues from artifacts in an ammonia solution are tested against antisera from known animals. The solutions are placed on a gel substrate and exposed to an electric current which causes the proteins to flow together. An immune reaction between the extract and the antiserum causes a precipitate to form, which is visible after being stained.

The CIEP tests were conducted between August 2 and 4, 2018, by laboratory director Dr. Cam Walker. Extracts from the five groundstone artifacts were tested against bear, deer, rabbit, duck, and trout antisera. The bear antiserum was custom-produced by Triple J Farms for AINW. The deer antiserum was made by Bethyl Laboratories, Inc. The rabbit antiserum was manufactured by MP Biomedicals, LLC, and the duck antiserum produced by Biorbyt Laboratories, Inc. Finally, the trout antiserum was custom-produced for AINW by Cocalico Biologicals, Inc. A chart included with this report shows the antisera that were used in the tests and the species found to react with each antiserum.

Standard analysis procedures began by extracting residue from the five groundstone artifacts. The extracts were then placed singly into gels, and tested against the five antisera with the CIEP technique. In addition to the artifact extracts, positive and negative control sera were run with each gel. This was done to determine if there were any contaminants or extraneous proteins that may give false positive results. If an anomalous result such as an extract reacting with a negative control serum is obtained, the extract solution is mixed with an equal volume of a $1 \%$ solution of a non-ionic detergent to increase chemical bonding specificity, and is run through the CIEP process again. If a reaction still occurs 
Ms. Kelley Prince-Martinez

Results of Protein Residue Analysis on five groundstone artifacts from site $35 \mathrm{CO} 2$

AINW Report No. 3086

after the addition of the non-ionic detergent, any reactions of those specimens to the antiserum are discounted. None of the extracts analyzed for this project reacted with the negative control.

There was a single positive response to the rabbit antiserum from artifact $35 \mathrm{CO} 2-463$, a pestle. The rabbit antiserum responds to proteins from Family Leporidae, which includes species of rabbit and jackrabbit. There were three positive responses to the trout antiserum, from artifacts 35CO2-457 (a pestle), 35CO2-485 (a small bowl), and 35CO2-488 (a mortar). The trout antiserum reacts with proteins from Subfamily Salmoninae, which includes salmon, steelhead, rainbow trout, and char species. The positive results were confirmed by repeat analysis. The results of all tests are indicated on the attached chart.

The single negative result from testing against the selected antisera does not preclude the possibility of the artifact extract retaining residues from other animals. The liquid extracts obtained from the artifacts have been frozen for storage and will be retained for one year should you wish any additional tests. Please call or email us if you have any questions about the analysis or this report.

Sincerely,

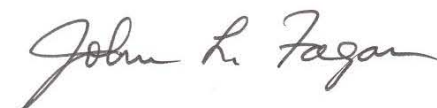

John L. Fagan, Ph.D., R.P.A.

President/Senior Archaeologist

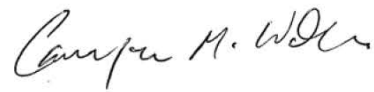

Cam Walker, Ph.D.

Supervising Archaeologist/

Laboratory Director

Attachments 
ARCHAEOLOGICAL INVESTIGATIONS NORTHWEST, INC.

PROTEIN RESIDUE ANALYSIS COMPARATIVE RESULTS

Project: Protein residue analysis on five groundstone artifacts from site $35 \mathrm{CO} 2$

\begin{tabular}{|c|c|c|c|c|c|c|c|c||}
\cline { 5 - 8 } & \multicolumn{3}{|c|}{ Antiserum } \\
\hline \hline RAL \# & SITE & CATALOG \# & $\begin{array}{c}\text { MATERIAL/ } \\
\text { TOOL TYPE }\end{array}$ & Bear & Deer & Duck & Rabbit & Trout \\
\hline 2 & $35 \mathrm{CO} 2$ & $35 \mathrm{CO} 2-457$ & Pestle & N/A & - & - & - & + \\
\hline 3 & $35 \mathrm{CO} 2$ & $35 \mathrm{CO} 2-463$ & Pestle & N/A & - & - & + & - \\
\hline 4 & $35 \mathrm{CO} 2$ & $35 \mathrm{CO} 2-486$ & Small bowl & - & - & - & - & - \\
\hline 5 & $35 \mathrm{CO} 2$ & $35 \mathrm{CO} 2-488$ & Small bowl & - & - & - & - & + \\
\hline GEL \# & & & Mortar & N/A & - & - & - & + \\
\hline \hline
\end{tabular}

Key: + = Positive; - = Negative 


\section{Archaeological Investigations Northwest, Inc.}

\section{AINW RESIDUE ANALYSIS LABORATORY ANTISERUM CHART}

\begin{tabular}{|c|c|c|c|}
\hline COMPANY & ANTISERUM & HOST & REACTS WITH \\
\hline \multirow{4}{*}{ BLI $^{*}$} & $\begin{array}{l}\text { BOTTLENOSE } \\
\text { DOLPHIN }\end{array}$ & rabbit & $\begin{array}{l}\text { Family Delphinidae: dolphins, less strongly with porpoises } \\
\text { and toothed whales }\end{array}$ \\
\hline & DEER & rabbit & $\begin{array}{l}\text { Family Cervidae: white-tail and mule deer, elk, moose, } \\
\text { caribou }\end{array}$ \\
\hline & FERRET & rabbit & $\begin{array}{l}\text { Family Mustelidae: ferret, otter, badger, mink, stoat, } \\
\text { wolverine, marten }\end{array}$ \\
\hline & WHITE WHALE & rabbit & Family Monodontidae: belugas and narwhals, porpoises \\
\hline $\mathrm{BYT}^{*}$ & DUCK & rabbit & Family Anatidae: swans, geese and ducks \\
\hline $\mathrm{CBI}^{*}$ & TROUT & rabbit & $\begin{array}{l}\text { Subfamily Salmoninae: salmon, steelhead, rainbow trout, } \\
\text { char }\end{array}$ \\
\hline \multirow{11}{*}{$\mathrm{MP}^{*}$} & BOVINE & rabbit & Family Bovidae: domestic cow, bison \\
\hline & CAT & goat & Family Felidae: cat, mountain lion, lynx, bobcat \\
\hline & CHICKEN & goat & $\begin{array}{l}\text { Order Galliformes, Order Anseriformes, Order } \\
\text { Columbiformes }\end{array}$ \\
\hline & DOG & rabbit & Family Canidae: domestic dog, coyote, wolf, fox \\
\hline & GOAT & rabbit & $\begin{array}{l}\text { Bovid Subfamilies Bovinae and Caprinae, less strongly with } \\
\text { cervids }\end{array}$ \\
\hline & GUINEA PIG & goat & Order Rodentia: guinea pig, porcupine, beaver \\
\hline & HORSE & goat & Family Equidae: horse, donkey, mule, extinct equids \\
\hline & MOUSE & goat & Order Rodentia: mice, rats \\
\hline & RABBIT & goat & Family Leporidae: rabbit, jackrabbit \\
\hline & RAT & goat & Order Rodentia: rats, mice, squirrels \\
\hline & SHEEP & rabbit & Genus Ovis: domestic sheep, bighorn sheep \\
\hline NIL* $^{*}$ & PIGEON & rabbit & Order Columbiformes: pigeons, doves \\
\hline SIGMA* & HUMAN & goat & Order Primates: humans, apes, monkeys \\
\hline \multirow{4}{*}{$\begin{array}{l}\text { Triple J Farms } \\
\text { (custom) }\end{array}$} & BEAR & goat & Family Ursidae: black bear, brown bear, grizzly \\
\hline & CAMEL & goat & Order Artiodactyla: camelids, bovids, cervids, antilocaprids \\
\hline & RHINO & goat & $\begin{array}{l}\text { Family Rhinocerotidae: white, black, Indian, Javan, } \\
\text { Sumatran, and extinct rhinoceros }\end{array}$ \\
\hline & $\begin{array}{l}\text { ASIAN } \\
\text { ELEPHANT }\end{array}$ & goat & $\begin{array}{l}\text { Asian and African elephants and extant and extinct members } \\
\text { of Order Proboscidea }\end{array}$ \\
\hline
\end{tabular}

"Notes: BLI = Bethyl Laboratories, Inc, BYT = Biorbyt Laboratories, Inc., CBI = Cocalico Biologicals, Inc., MP = MP Biomedicals, LLC, NIL = Nordic Immunological Laboratories, Sigma = Sigma-Aldrich Co., LLC. 


\title{
Archaeological Investigations Northwest, Inc.
}

\author{
AINW RESIDUE ANALYSIS LABORATORY \\ METHODS AND PROCEDURES
}

Blood protein residue analysis performed at the Archaeological Investigations Northwest, Inc. (AINW) Residue Analysis Laboratory uses the technique of cross-over immuno-electrophoresis (CIEP) to analyze protein residues extracted from the surface of stone artifacts and other objects. This technique has been widely used in forensic laboratories to determine the origin of bloodstains as evidence in criminal investigations, and has fairly recently been adapted for use in archaeology to detect protein residues on stone tools. The CIEP method used by the AINW Residue Analysis Laboratory is based on techniques developed by the Royal Canadian Mounted Police Serology Laboratory in Toronto, Ontario (Culliford 1971; Newman 1990; Williams 1990). The CIEP technique uses the immune (antibody-antigen) reaction, the principle that all animals produce immunoglobulin proteins (antibodies) that recognize and bind with foreign proteins (antigens) as part of the body's defense system. The ability of antibodies to precipitate antigens out of solution is the basis of CIEP analysis (Newman 1990:56). CIEP indicates the presence or absence of a particular antigen, and is not designed as a quantitative test. While other types of immunoassay have been used effectively to analyze blood protein residues under various conditions, the CIEP test is particularly suitable in that it is sensitive (able to detect protein in concentrations of about two parts per million), does not require expensive or bulky equipment, is relatively fast (about 48 hours per test), and can easily and efficiently accommodate multiple samples (Newman 1990:52).

\section{BLOOD PROTEIN RESIDUES}

Blood is composed of red and white blood cells and serum, which is composed of about 150 different proteins including albumin, alpha, and beta globulins. Immunoglobulins are large, $Y$-shaped proteins with antigen binding sites located on the $\mathrm{V}$ portion of the $\mathrm{Y}$. There are several immunoglobulin molecules of different weight, size, and function. The most common type (and the most pertinent for CIEP) is immunoglobulin $G(\operatorname{IgG})$. Other less common varieties are immunogobulin $A$ (IgA), immunoglobulin $D(\operatorname{IgD})$, immunoglobulin $E(\operatorname{IgE})$, and immunoglobulin $\mathrm{M}(\operatorname{Ig} M)$. Some of these proteins can survive in the environment in a nonfunctional but immunologically identifiable form for long periods of time by forming a "covalently cross-linked proteinaceous mass with a high molecular weight" (Marlar et al. 1995:30). This combination of protein, fatty tissues and soil particles is resistant to microbes and is markedly insoluble in water. It seems probable that porosity and surface roughness of the artifact also aids in the preservation of protein residues. Experiments by AINW and others have identified blood residues from mammoth, bison, musk ox, horse, caribou, bear, duck, and trout on Paleoindian artifacts that may be as old as 11,500 years (Forgeng 1998; Loy and Dixon 1998; Williams 1993). Other studies suggest that protein residues can survive in recognizable form for as long as 40,000 years (Prager et al. 1980).

Artifacts can be examined under a binocular microscope (at around $240 \mathrm{x}$ maximum magnification) to identify probable residues, as well as cells, hair and other tissues. Microscopic examination is not always effective as a screening technique as CIEP can still detect otherwise invisible residues. A common medical test for occult blood is sometimes effective when used to screen the extracted residue solution. However, the CEIP technique can detect residues in more dilute concentrations than is possible with the commonly available occult blood test. 


\section{Archaeological Investigations Northwest, Inc.}

\section{THE IMMUNE REACTION}

Immunological forensic tests owe their effectiveness to the antigen-antibody reaction, which allows very specific recognition and identification. Essentially, any molecule that can bind to an antibody is an antigen. For archaeological purposes, the antigen is an unknown protein adhering to an artifact after its use. Antigens are foreign proteins that, when introduced into the blood stream of an animal, stimulate the immune system of the animal to produce antibodies (most commonly IgG protein molecules) with specific binding sites that match corresponding sites on the foreign antigen. Polyclonal antibodies, which bind to multiple sites on the antigen and therefore have a high rate of successful matching to unknown proteins, are the most commonly used reactants in CIEP. The meeting of antigen and antibody forms a very strong bond between the two proteins. The visible line formed in a positive CIEP reaction occurs when an antigen with multiple binding sites matches a group of polyclonal antibodies, binds with them, and causes the proteins to precipitate out of solution (Marlar et al. 1995:28),

\section{ANTISERA}

The antisera used in AINW's CIEP analysis are obtained from commercial laboratories. A forensic antiserum is made by injecting a host animal, typically a goat or rabbit, with a protein solution obtained from another animal. The immune system of the host animal produces antibodies (mainly IgG) in reaction to the foreign antigen. Blood serum drawn from the host animal is purified and tested to determine the range of reactivity of the antiserum. The purified antiserum is then freeze-dried for storage and shipment. After receipt of a new lot of antiserum, the AINW laboratory routinely tests each antiserum against representative specimens from up to 32 different animal species.

\section{THE AINW RESIDUE ANALYSIS LABORATORY}

Ancient protein residues are often difficult to extract from the artifacts that have preserved them. The AINW Residue Analysis Laboratory uses a 5\% ammonia solution, which has been used for similar applications in forensic medicine (Dorrill and Whitehead 1979; Kind and Cleevely 1969). Ammonia is generally more effective in lifting old and partially denatured blood proteins than other solvents (Newman 1990). A small amount of the ammonia solution is applied to the artifact in a plastic tray, and the tray and artifact are placed in an ultrasonic bath (Branson 2200) for 30 minutes or longer. The artifact in solution is then placed on a mechanical rotator (Thermolyne Rotomix) for an additional ten minutes. Artifacts too large for the ultrasonic extraction may be placed on the rotator for 30 minutes or longer. Residues from soil samples can also be extracted using variations of these methods. The extraction solution is then drawn off and stored in an airtight microcentrifuge tube. The extracts are centrifuged to clarify the sample, refrigerated, and the CIEP test is run as soon as possible after extraction. The extracts may be frozen immediately if testing is to be delayed for more than one week.

AINW's CIEP method uses an agarose gel as a substrate. Standard analysis procedures begin with extracting residues from the artifacts with a 5\% ammonia solution. The artifact extracts are then placed singly into gels, and tested against the antisera selected for these tests with the CIEP technique. In addition to the artifact extracts, positive and negative control sera are run with each gel. This is done to determine if there are any contaminants or extraneous proteins that may give false positive results. If an 


\section{Archaeological Investigations Northwest, Inc.}

anomalous result such as an extract reacting with multiple antisera or to a negative control serum is obtained, the extract solution is mixed with an equal volume of a $1 \%$ solution of a non-ionic detergent to increase chemical bonding specificity, and is run through the CIEP process again. If a reaction still occurs after the addition of the non-ionic detergent, any reactions of those specimens to the antisera are discounted. Experiments at AINW have implicated plant pitch used in hafting prehistoric stone tools as a possible cause of some cross or non-specific reactions.

Electrophoresis is used to drive the antigens and antibodies together. The gel substrates are placed in acrylic electrophoresis tanks filled with barbital buffer solution, then attached to the regulated H.V. power source. The antibodies move toward the cathode because of the overall negative charge on the molecule, while the antigens move toward the anode. A precipitate is formed where the proteins meet and bond in the area between the wells, visible as a white line or arc (Culliford 1971). The gel is soaked overnight in saline to stabilize the reaction, then dried and stained with a standard protein stain as a permanent record of the CIEP results. The dried and stained gel is then backlit on a light table, and examined under magnification for the presence of precipitate lines, indicating positive reactions. After testing, the extracts are frozen and stored for one year in case additional testing is requested. 


\section{Archaeological Investigations Northwest, Inc.}

\section{HINTS FOR ARTIFACT COLLECTION AND TREATMENT FOR RESIDUE ANALYSIS}

For optimum results, the following suggestions are provided for archaeologists considering submitting artifacts for blood residue analysis (see also Marlar et al. 1995:36)

1. Handle artifacts as little as possible in the field. Avoid contamination by using latex gloves, the tip of a clean trowel, or other careful methods similar to the treatment of radiocarbon samples.

2. Do not brush off, spit clean, or wash the artifact. Since proteins are known to bind to soil particles, loss of adhering dirt may result in loss of blood antigen.

3. Place the artifact in a clean ziplock bag with as little loose dirt as possible.

4. Submit a small amount (about one tablespoon) of soil from the area adjacent to the artifact. As bacteria or animal excreta in the soil may cause false positive reactions, soil controls are useful for cross checking results from artifacts.

5. Positive results have been obtained from projectile points, scrapers, flake tools, debitage, bone, burned bone, fire-cracked rock, cobble tools, ground stone tools, and soil samples from features and general site contexts. Surface artifacts are also good candidates for residue preservation. Obsidian, CCS, and basalt artifacts are equally likely to preserve residues, although some more porous materials may contain more proteins.

6. When selecting the type of antisera for analysis, consider allowing for a broad range of testing supplemented by more specific testing of positive results (for example, testing positives for chicken against duck and pigeon to narrow the results). If an artifact tests negative for all of the selected antisera, it may still contain preserved residues from other species. 


\section{Archaeological Investigations Northwest, Inc.}

\section{REFERENCES}

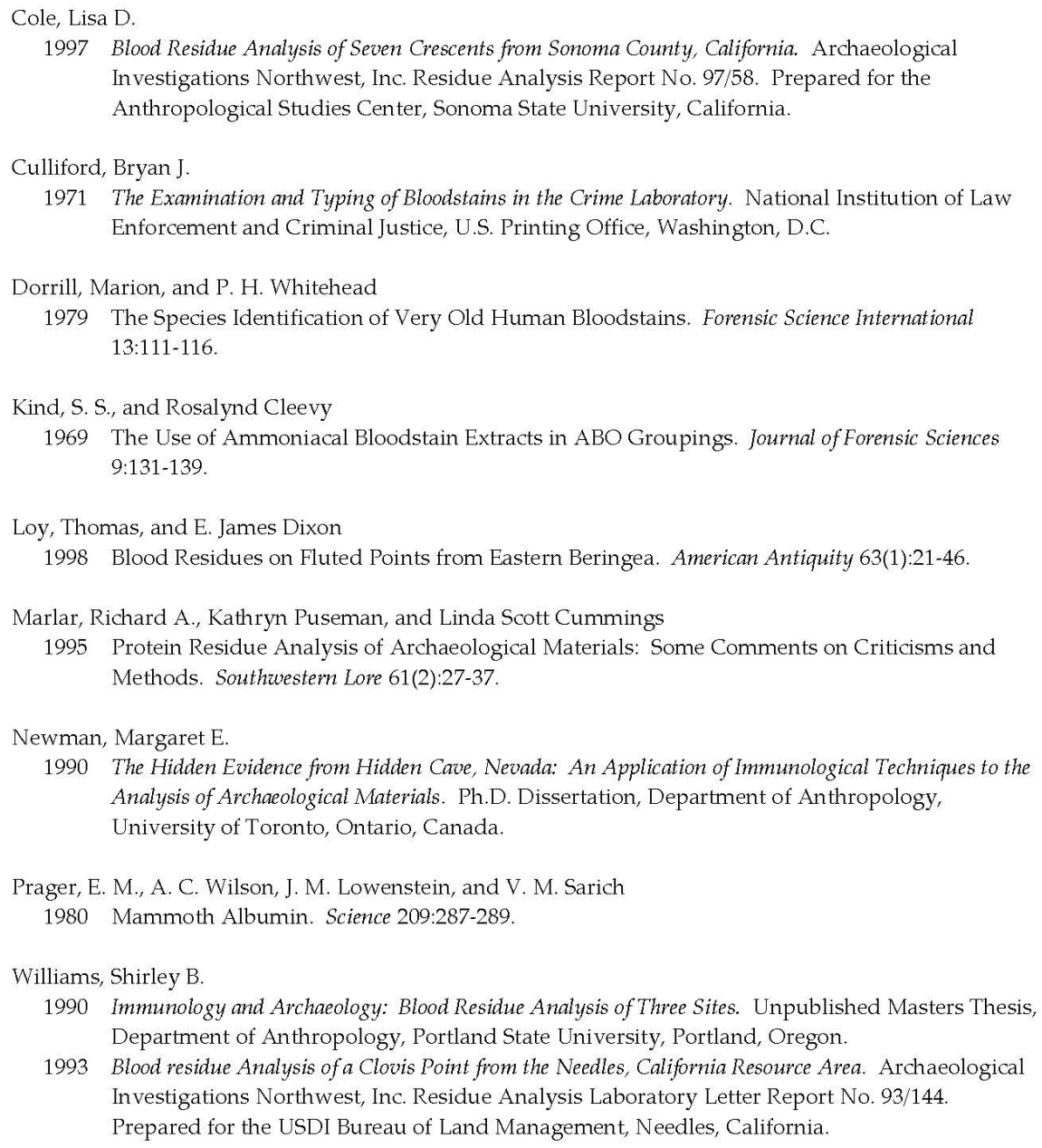




\section{Appendix J. Photographs}

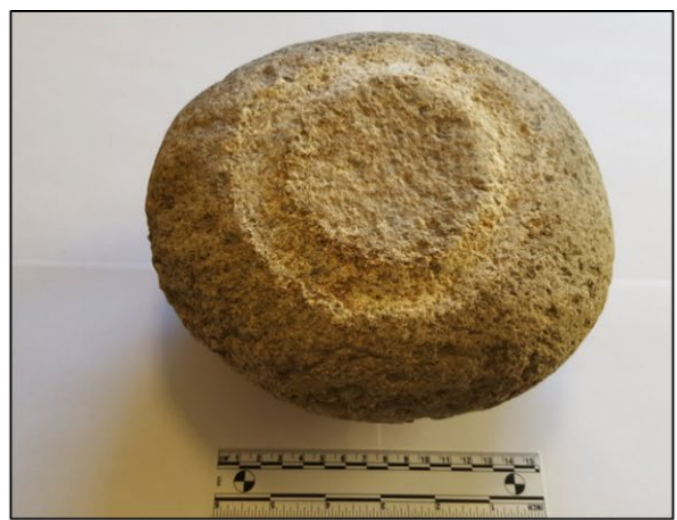

Photo 1. In-progress reduction of bowl KPM-19, showing pecked groove at bowl basin.
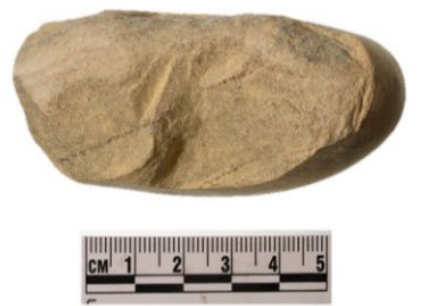

Photo 3. Cobble chopper KPM-18 utilized in the manufacture of bowl KPM-19, showing use wear on tool edge.

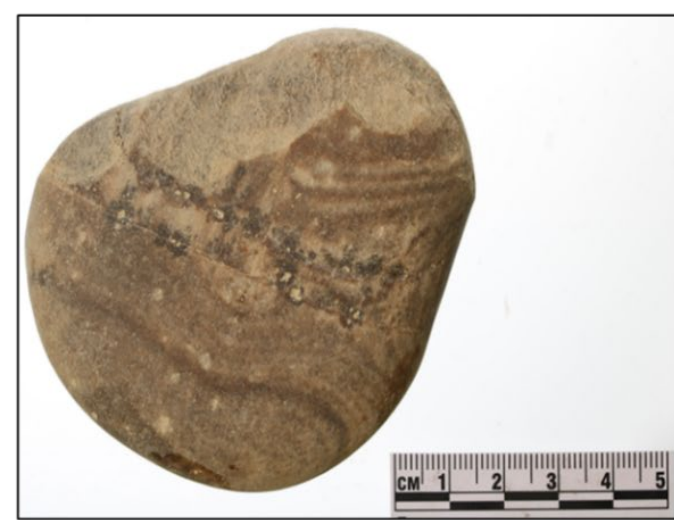

Photo 2. Cobble chopper KPM-18 utilized in the manufacture of bowl KPM-19.

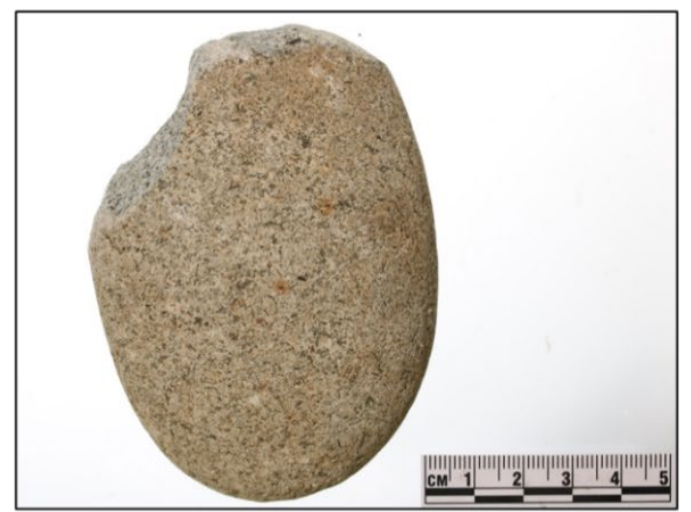

Photo 4. Cobble chopper KPM-20 utilized in the manufacture of bowl KPM-19. 


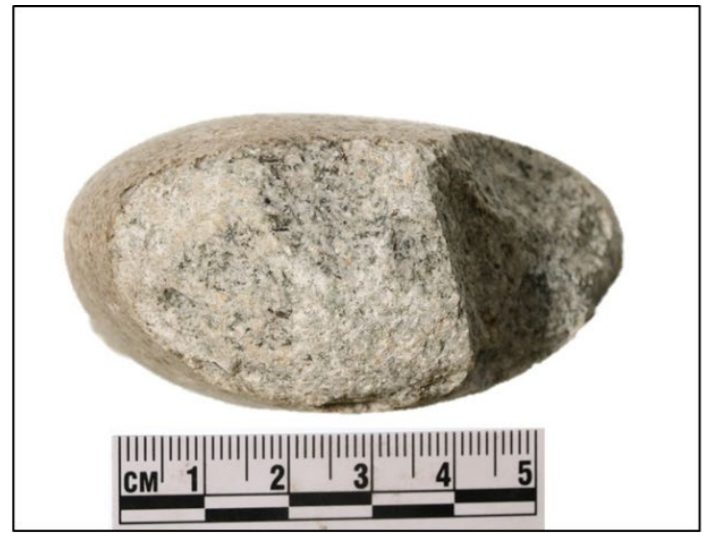

Photo 5. Cobble chopper KPM-20 utilized in the manufacture of bowl KPM-19, showing use wear on tool edge.

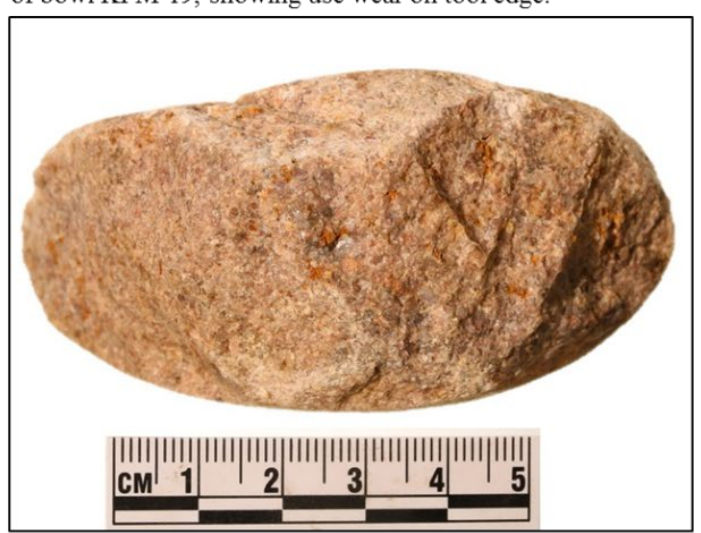

Photo 7. Cobble chopper KPM-21 utilized in the manufacture of bowl KPM-19, showing use wear on tool edge.

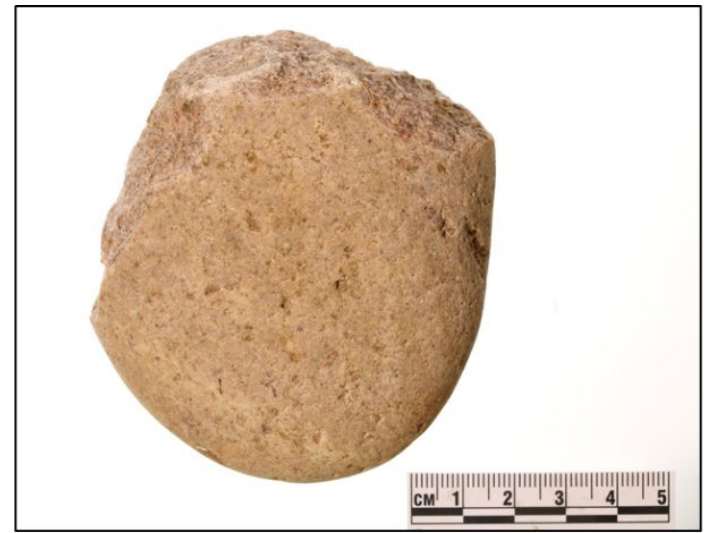

Photo 6. Cobble chopper KPM-21 utilized in the manufacture of bowl KPM-19.

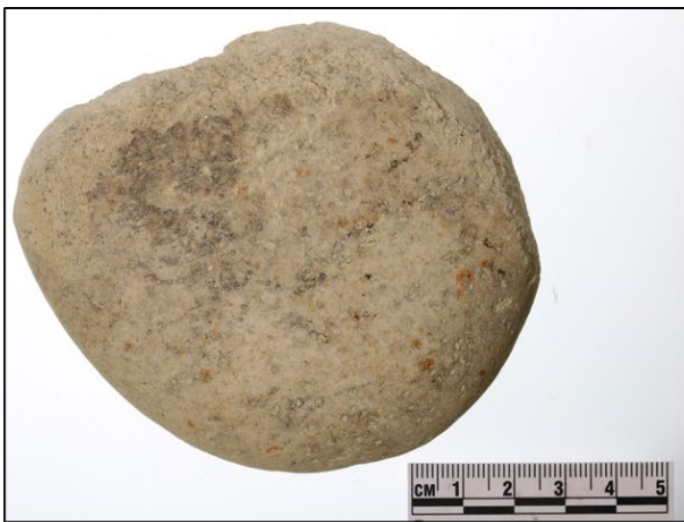

Photo 8. Cobble chopper KPM-22 utilized in the manufacture of bowl KPM-19. 


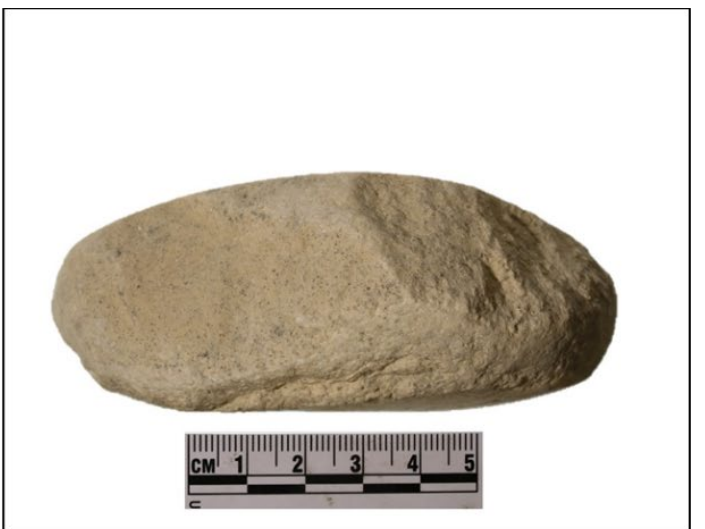

Photo 9. Cobble chopper KPM-22 utilized in the manufacture of bowl KPM-19, showing use wear on tool edge.

$\vec{\infty}$

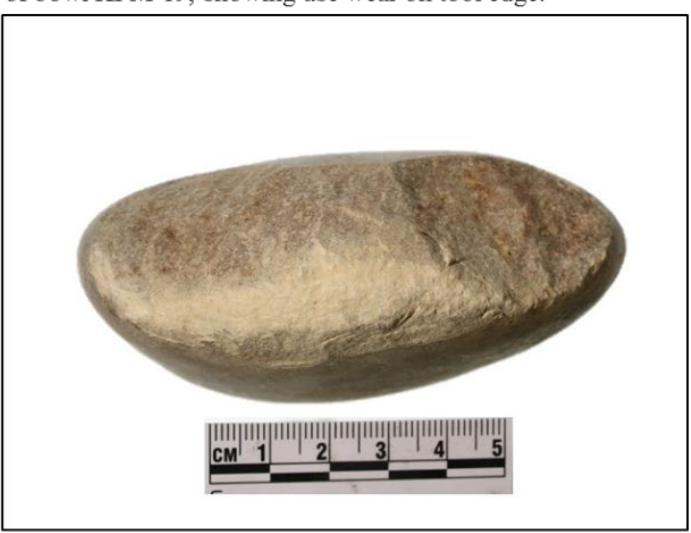

Photo 11. Cobble chopper KPM-24 utilized in the manufacture of bowl KPM-19, showing use wear on tool edge.

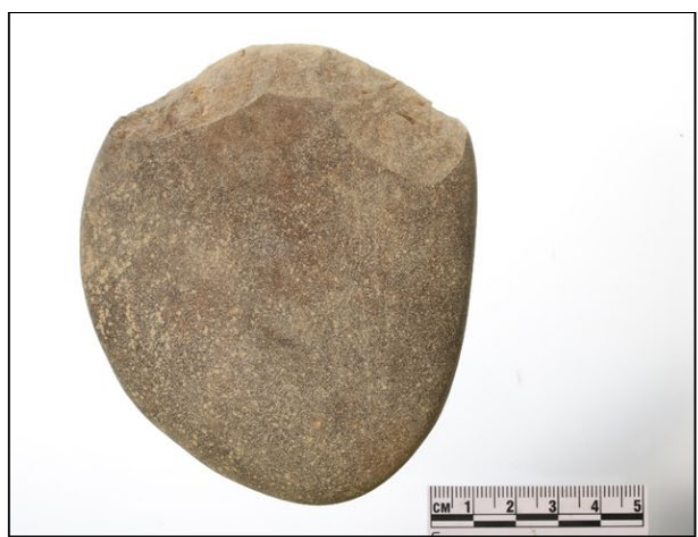

Photo 10. Cobble chopper KPM-24 utilized in the manufacture of bowl KPM-19.

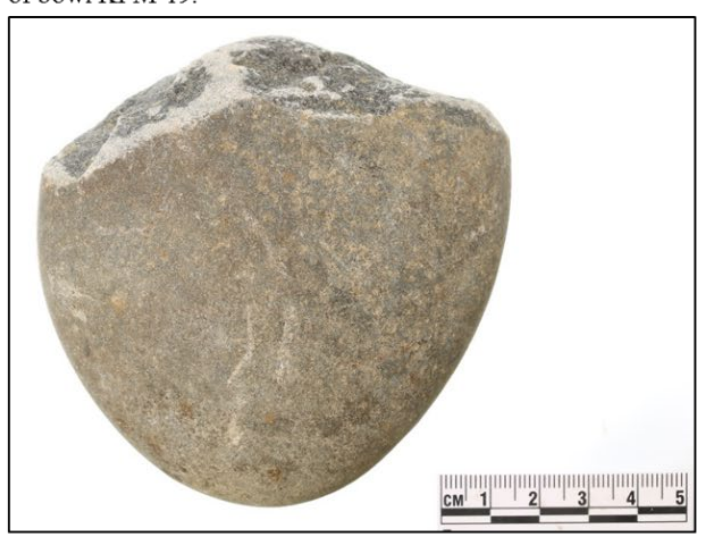

Photo 12. Cobble chopper KPM-32 utilized in the manufacture of bowl KPM-19. 


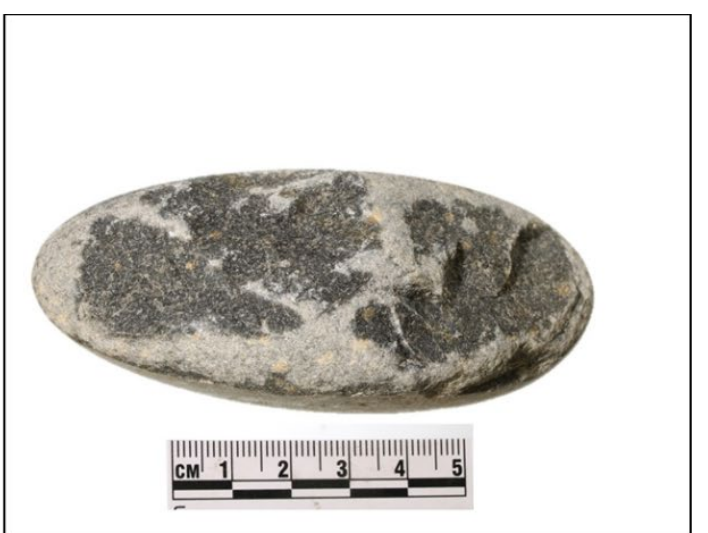

Photo 13. Cobble chopper KPM-32 utilized in the manufacture of bowl KPM-19, showing use wear on tool edge.

ㄱํำ

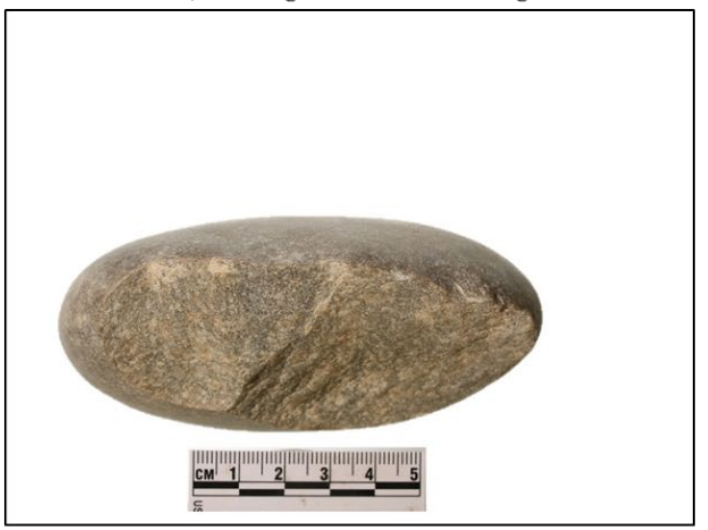

Photo 15. Cobble chopper KPM-26 utilized in the manufacture of bowl KPM-1, showing use wear on tool edge.

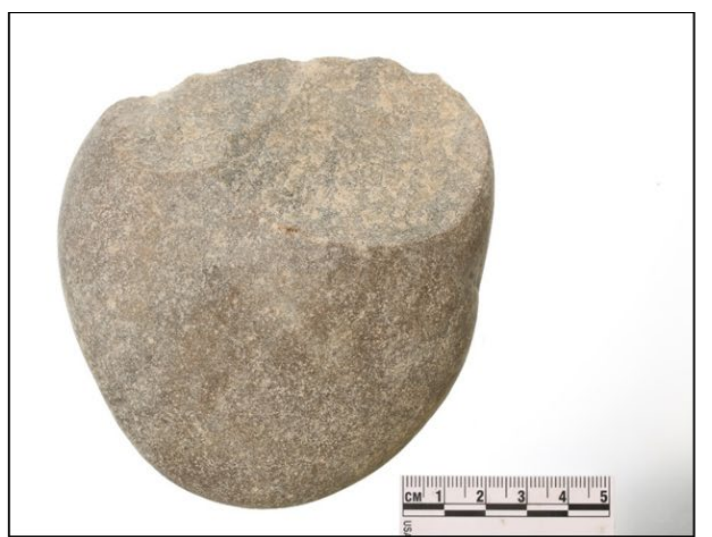

Photo 14. Cobble chopper KPM-26 utilized in the manufacture of bowl KPM-1.

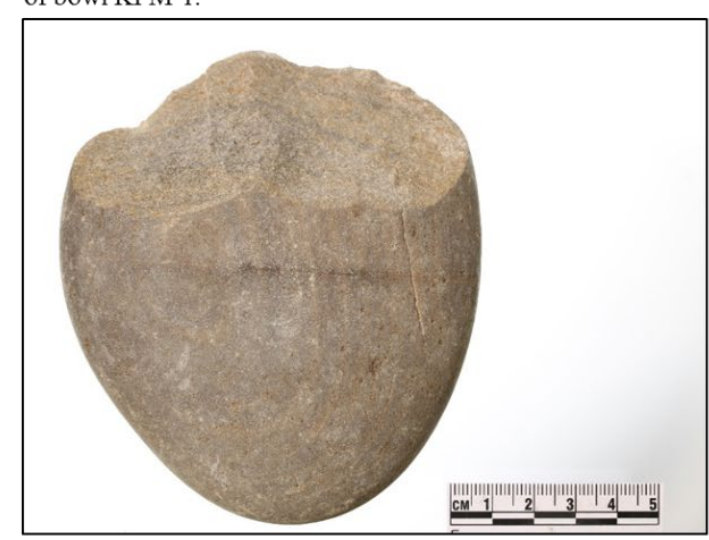

Photo 16. Cobble chopper KPM-28 utilized in the manufacture of bowl KPM-1. 


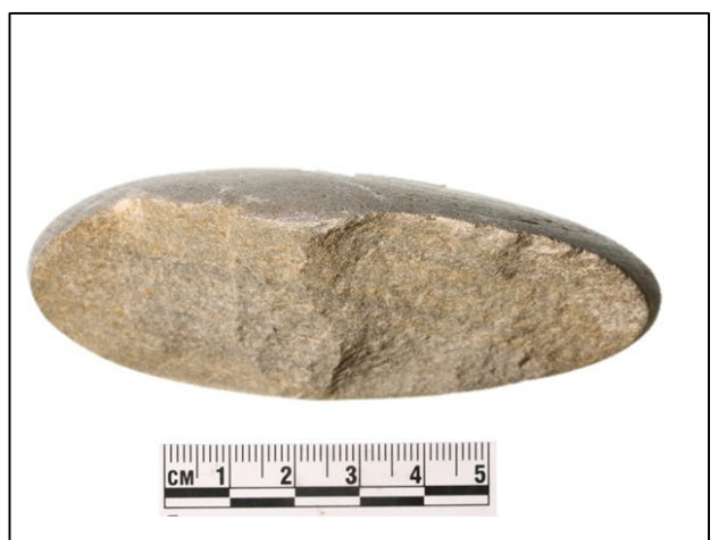

Photo 17. Cobble chopper KPM-28 utilized in the manufacture of bowl KPM-1, showing use wear on tool edge.

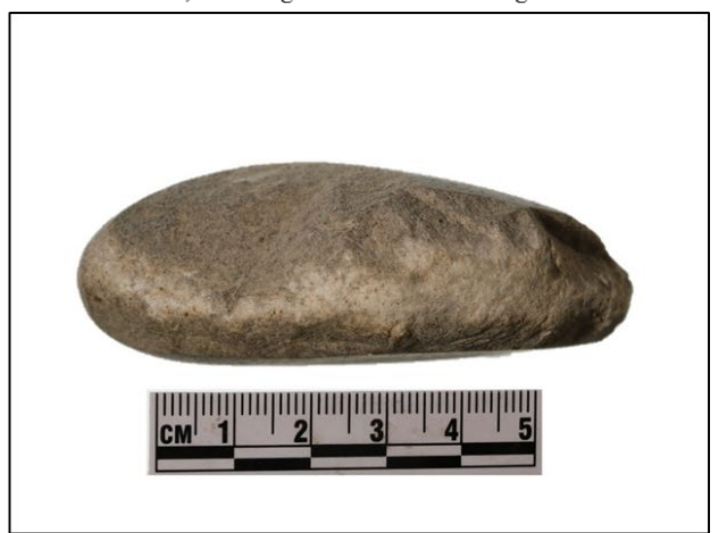

Photo 19. Cobble chopper KPM-12 utilized in the

manufacture of pestle KPM-4, showing use wear on tool edge.

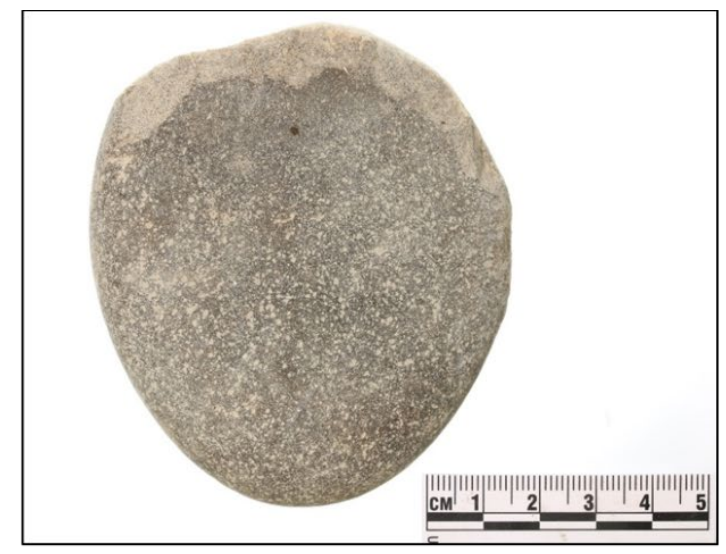

Photo 18. Cobble chopper KPM-12 utilized in the manufacture of pestle KPM-4.

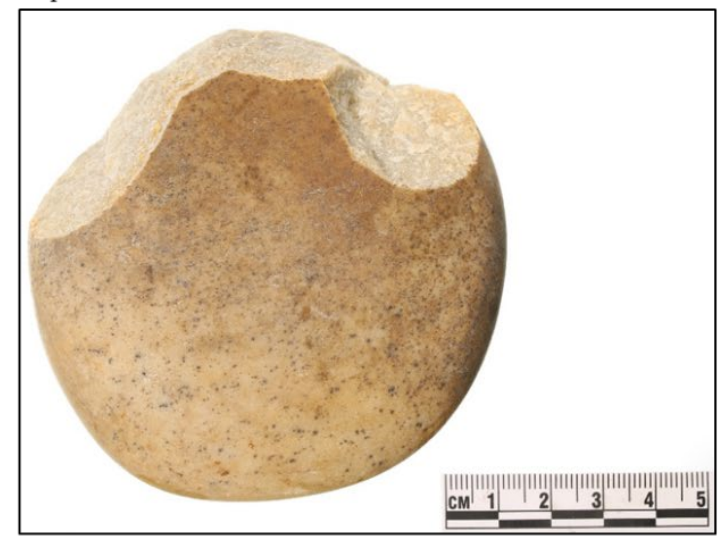

Photo 20. Cobble chopper KPM-29 utilized in the manufacture of pestle KPM-4. 


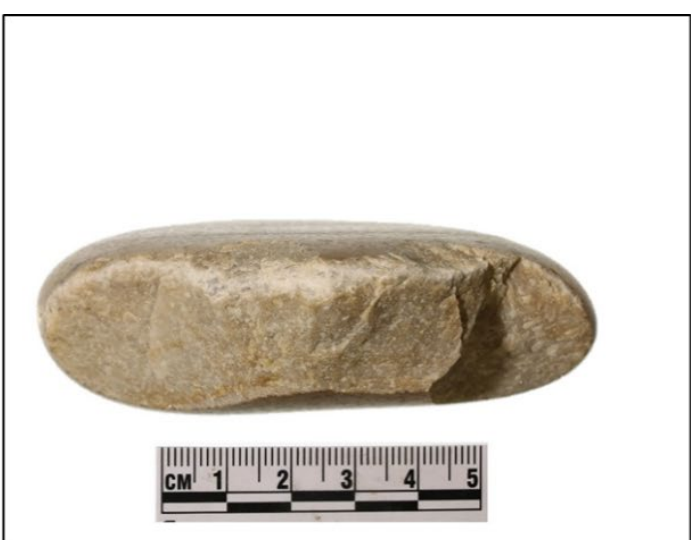

Photo 21. Cobble chopper KPM-29 utilized in the manufacture of pestle KPM-4, showing use wear on tool edge.

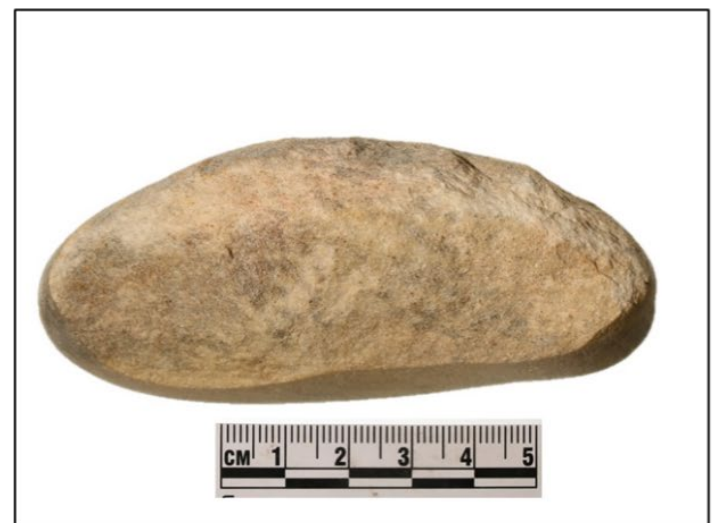

Photo 23. Cobble chopper KPM-30 utilized in the manufacture of pestle KPM-4, showing use wear on tool edge.

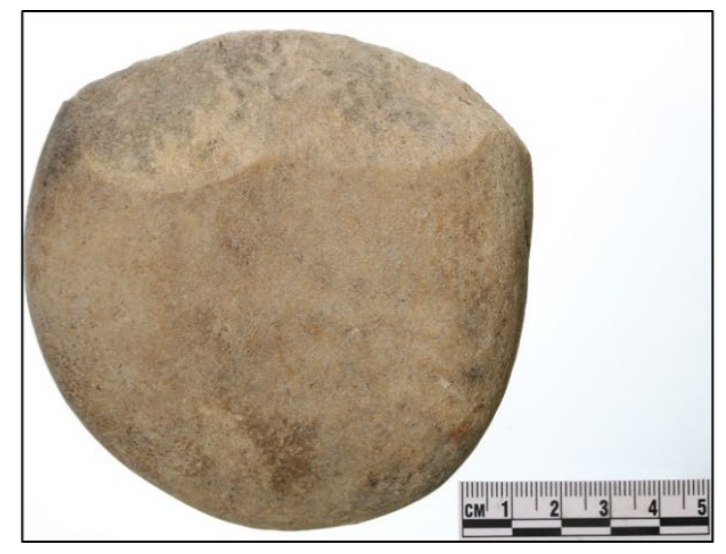

Photo 22. Cobble chopper KPM-30 utilized in the manufacture of pestle KPM-4.

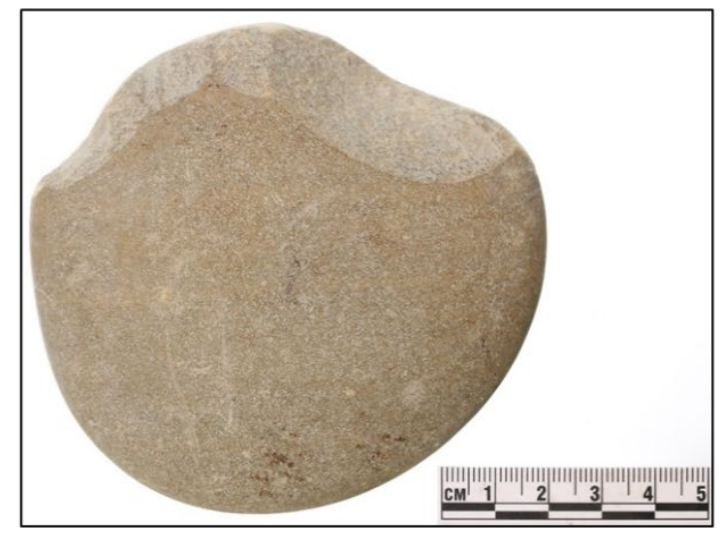

Photo 24. Cobble chopper KPM-31 utilized in the manufacture of pestle KPM-4. 


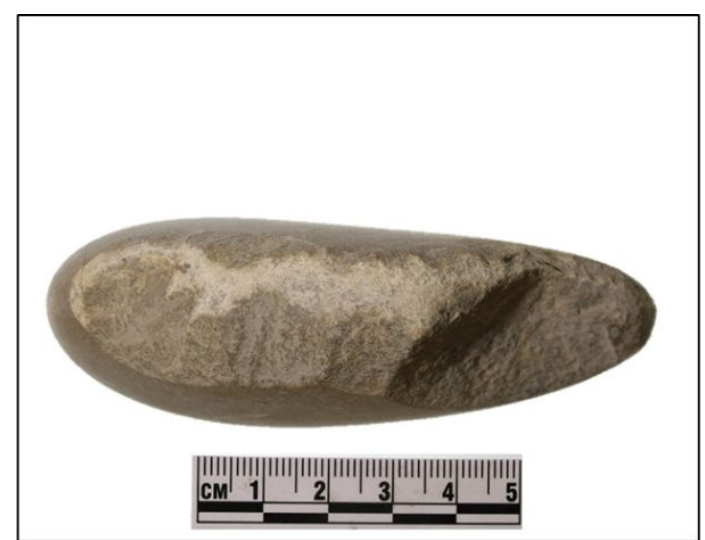

Photo 25. Cobble chopper KPM-31 utilized in the manufacture of pestle KPM-4, showing use wear on tool edge.

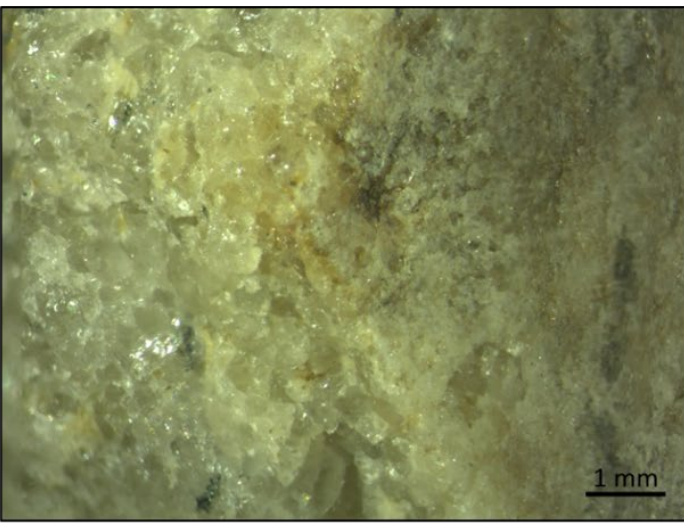

Photo 27. Photomicrograph of KPM-33 showing post-

modification attributes, 12.6x. KPM-33 was not utilized after manufacture.

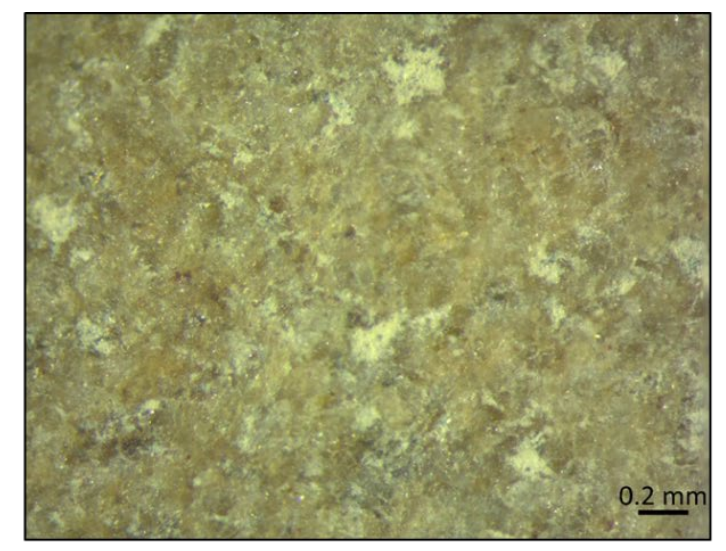

Photo 26. Photomicrograph of KPM-18 showing premodification attributes, $40 \mathrm{x}$.

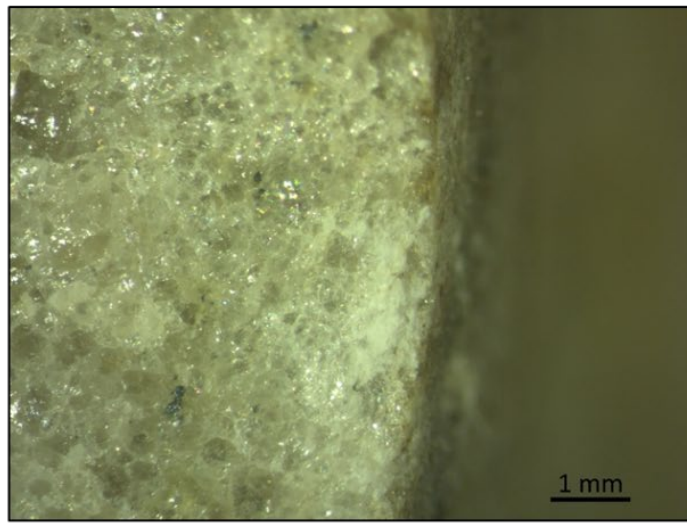

Photo 28. Photomicrograph of KPM-33 showing grain

crushing at the site of flake removal, 12.6x. 


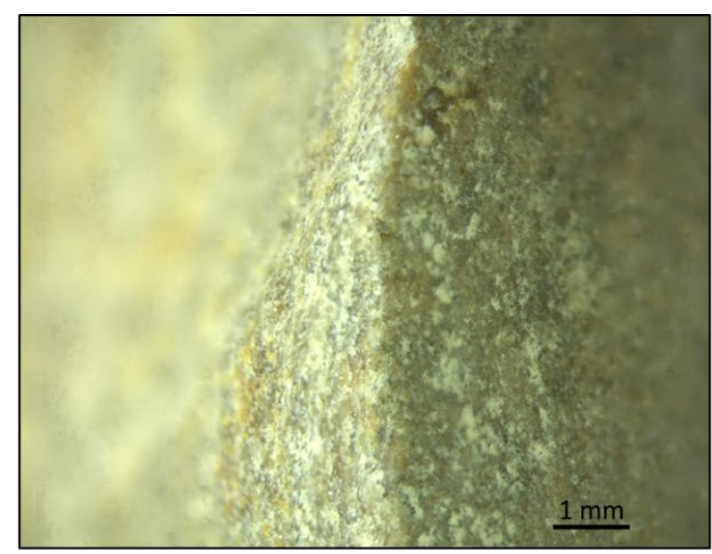

Photo 29. Photomicrograph of KPM-28 showing use wear attributes, $13 \mathrm{x}$.

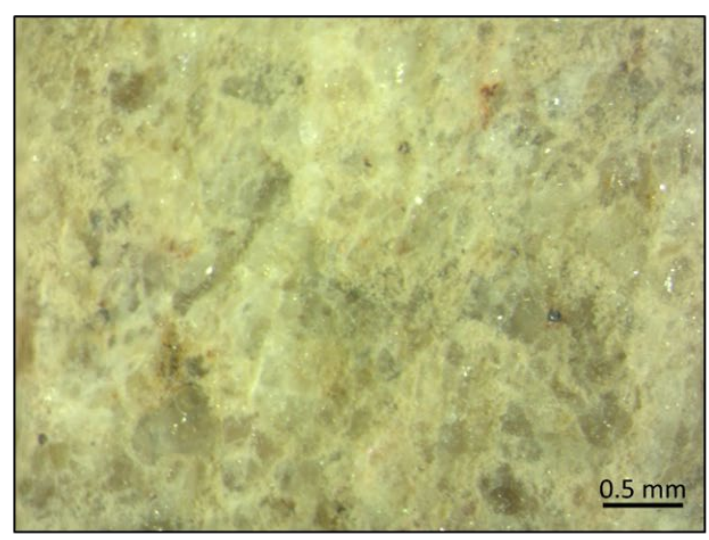

Photo 31. Photomicrograph of KPM-30 showing grain rounding and material trapped in interstices, $25.2 \mathrm{x}$.

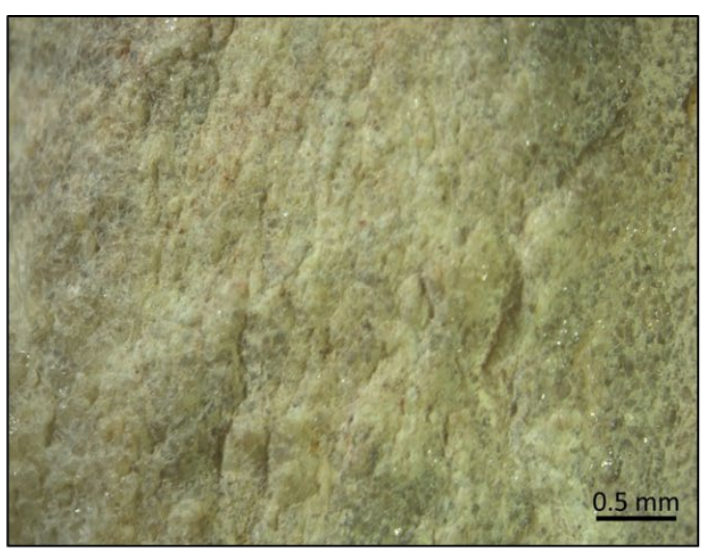

Photo 30. Photomicrograph of KPM-30 showing grain crushing at chopper edge and negative flake scars on the previously unflaked side $\mathrm{f}$ the cobble, $6.3 \mathrm{x}$.

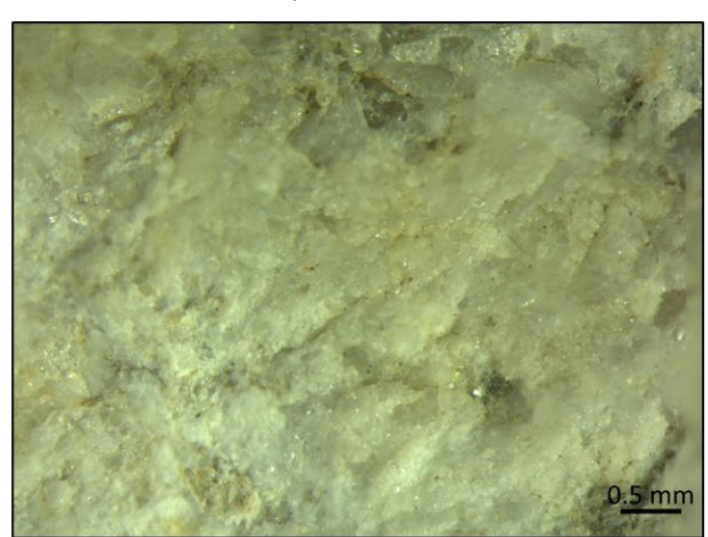

Photo 32. Photomicrograph of KPM-14 showing use wear at one of multiple locations on cobble, $20 \mathrm{x}$. 


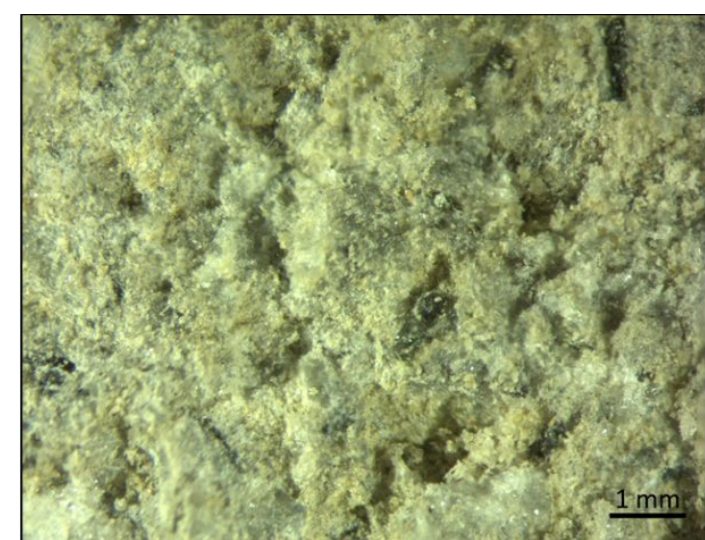

Photo 33. Photomicrograph of the pre-modification surface of KPM-8, 16x.

$\stackrel{\infty}{\perp}$

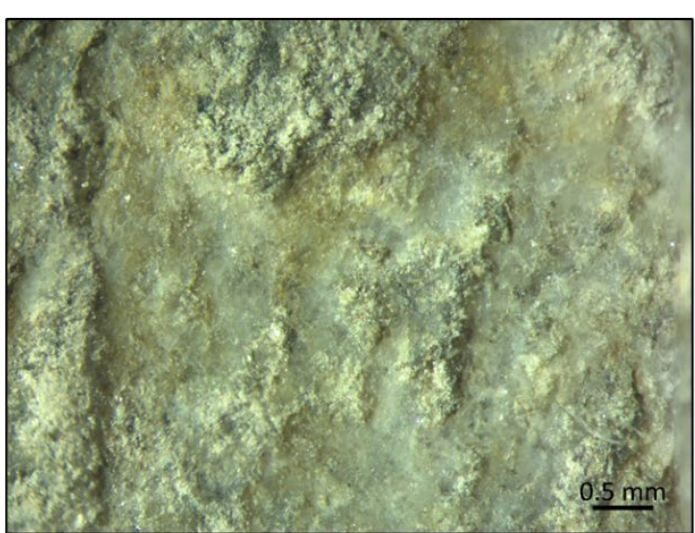

Photo 35. Photomicrograph of KPM-3 prior to modification, $20 \mathrm{x}$

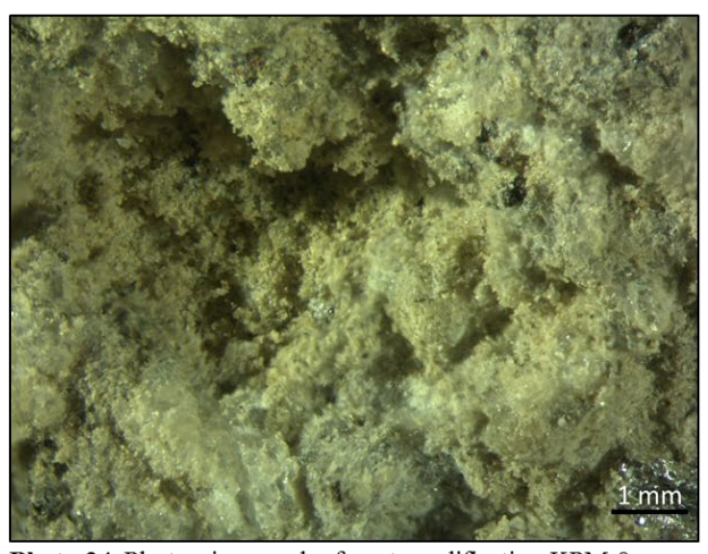

Photo 34. Photomicrograph of post-modification KPM-8 showing crushed grains and material trapped in interstices, $20 \mathrm{x}$.

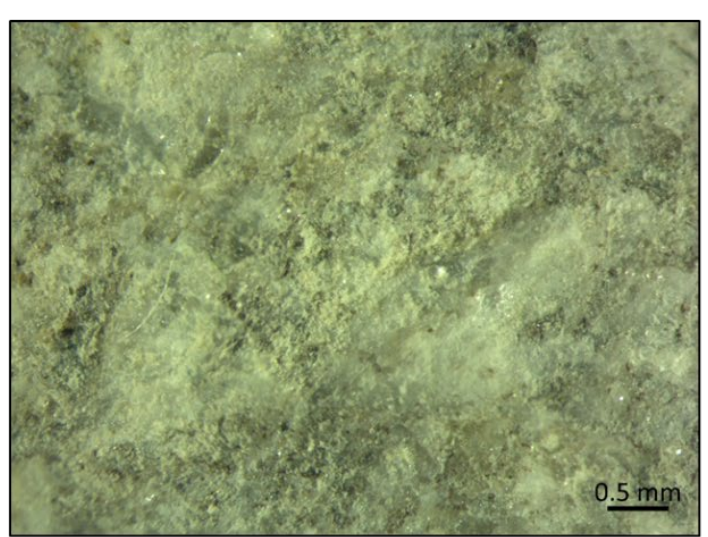

Photo 36. Photomicrograph of KPM-3 after manufacture showing crushed grains, 20x 


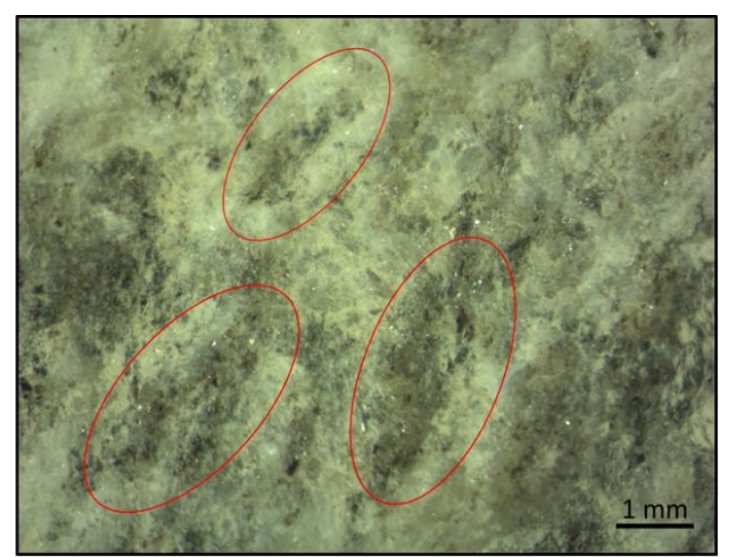

Photo 37. Photomicrograph of KPM-3 after manufacture showing remnant chopper scars, $12.6 \mathrm{x}$.

$\underset{\infty}{\infty}$

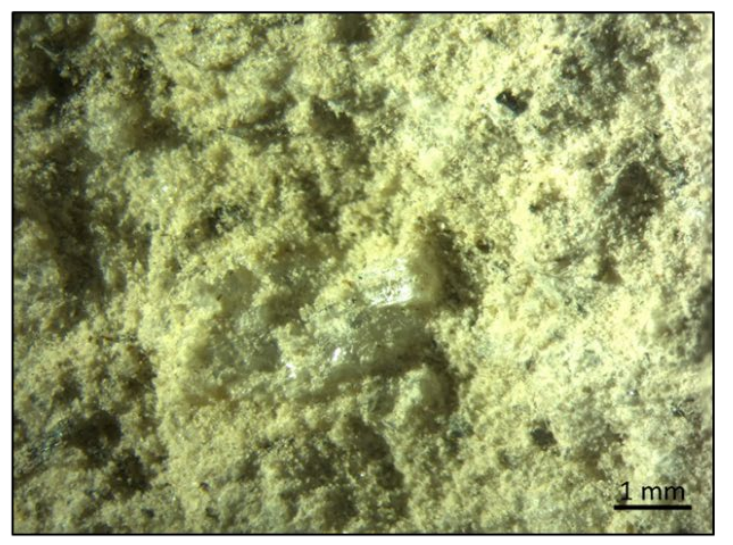

Photo 39. Photomicrograph of KPM-1 post modification showing grain crushing, 13x.

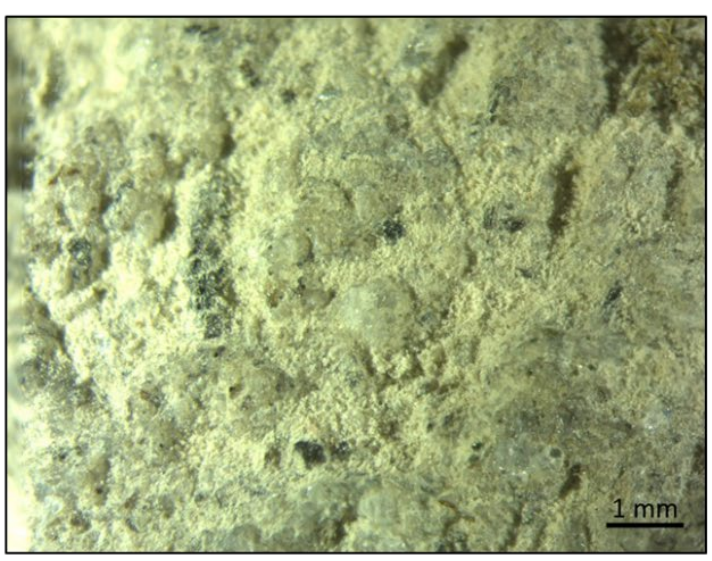

Photo 38. Photomicrograph of KPM-1 prior to modification,

$13 \mathrm{x}$.

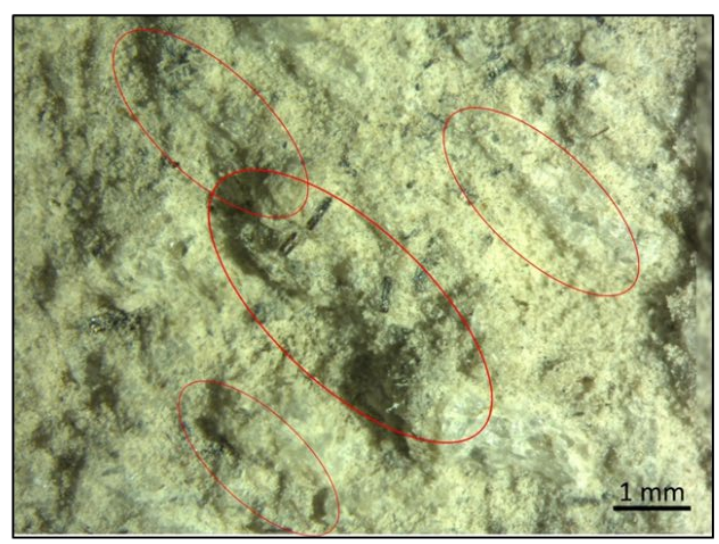

Photo 40. Photomicrograph of KPM-1 post modification showing remnant chopper scars, $13 \mathrm{x}$. 


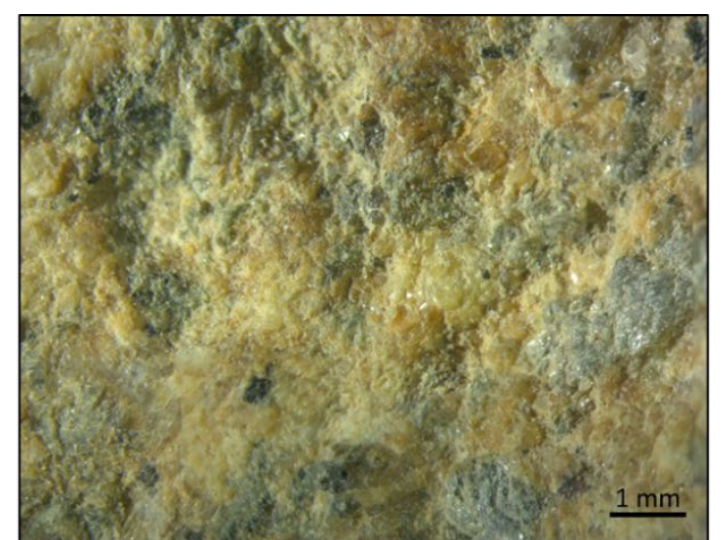

Photo 41. Photomicrograph of KPM-19 post modification showing sharp asperities and grain crushing, $13 \mathrm{x}$.

\section{$\ddot{\infty}$}

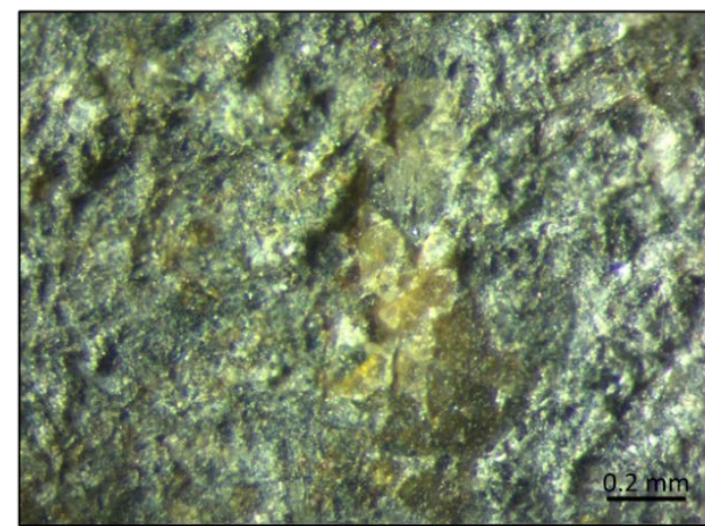

Photo 43. Photomicrograph of KPM-4 prior to modification showing polish and grain rounding, $64 \mathrm{x}$

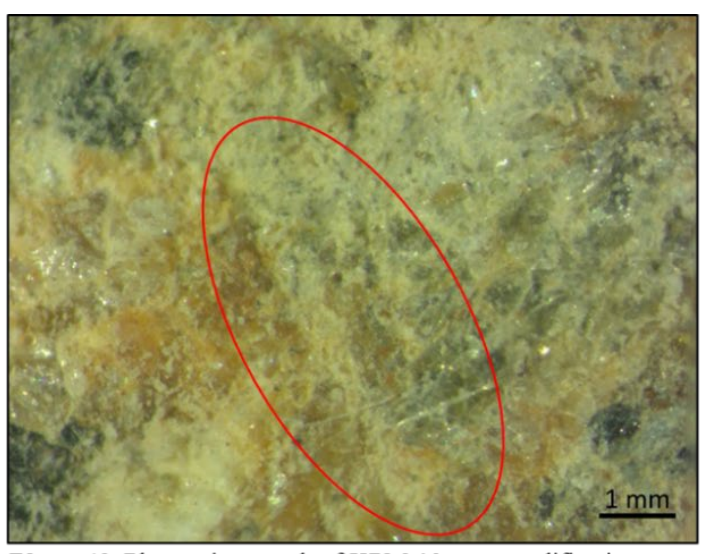

Photo 42. Photomicrograph of KPM-19 post modification showing remnant chopper scar, $31.5 \mathrm{x}$.

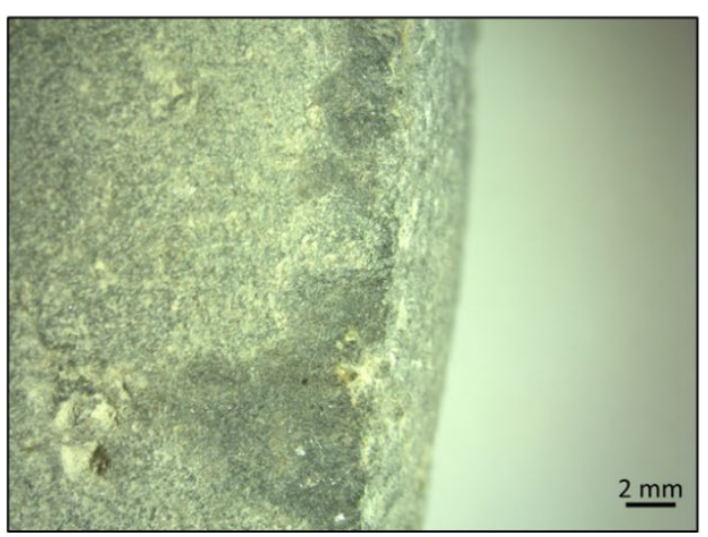

Photo 44. Photomicrograph of KPM-4 post modification

showing negative flake scars travelling up the shaft from the distal end, $4.095 \mathrm{x}$. 


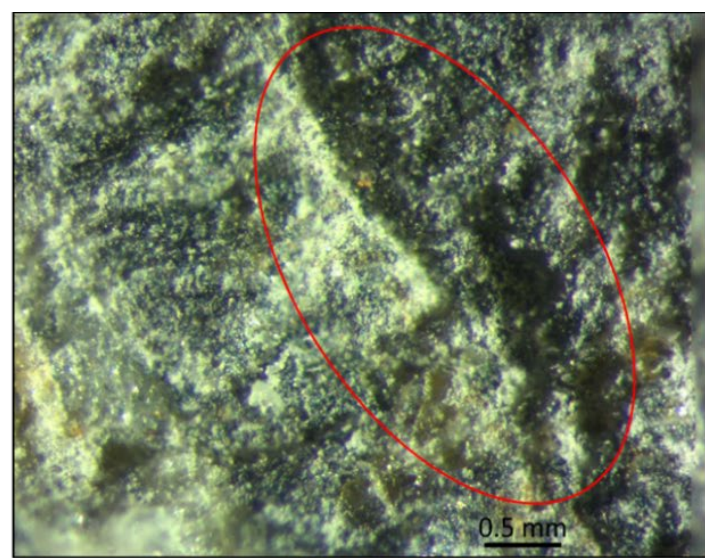

Photo 45. Photomicrograph of KPM-4 post modification showing remnant chopper scar, $64 \mathrm{x}$.

$\ddot{\infty}$

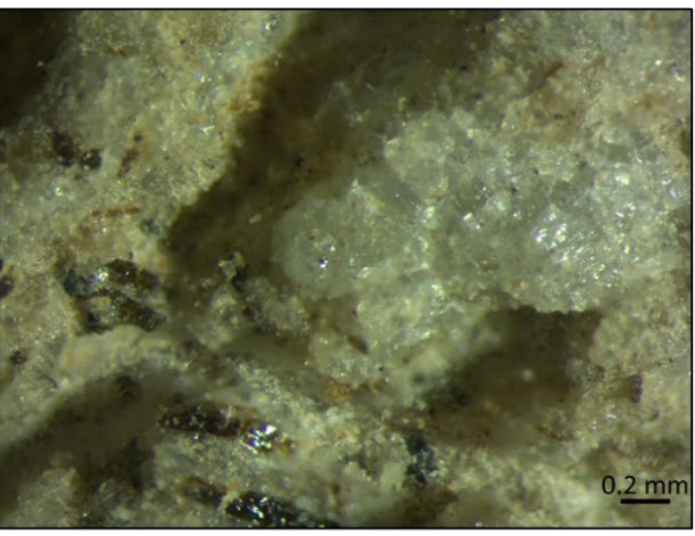

Photo 47. Photomicrograph of KPM-1 post Phase I use wear, showing steep asperites and grain crushing, $64 \mathrm{x}$.

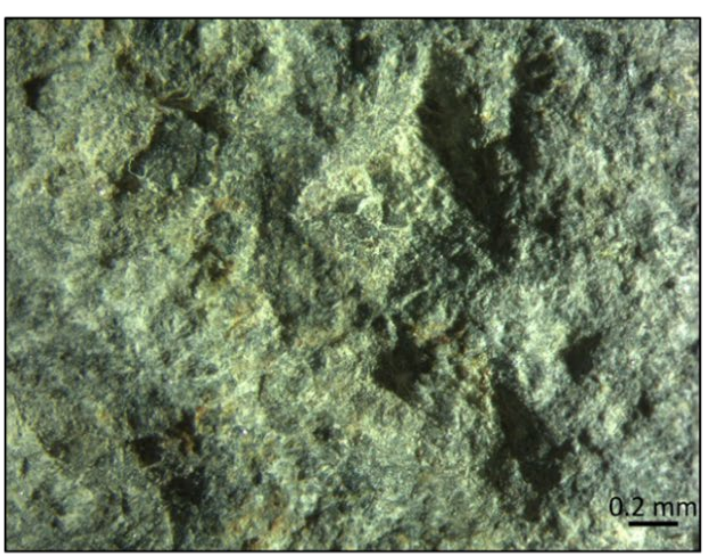

Photo 46. Photomicrograph of KPM-4 post modification showing sharp asperities and grain crushing, $13 \mathrm{x}$.

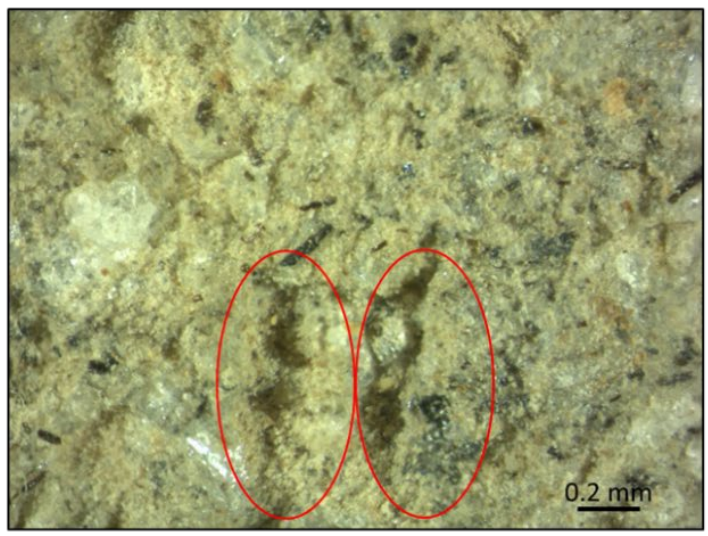

Photo 48. Photomicrograph of KPM-1 post Phase I use wear showing remnant chopper scars, $12.6 \mathrm{x}$. 


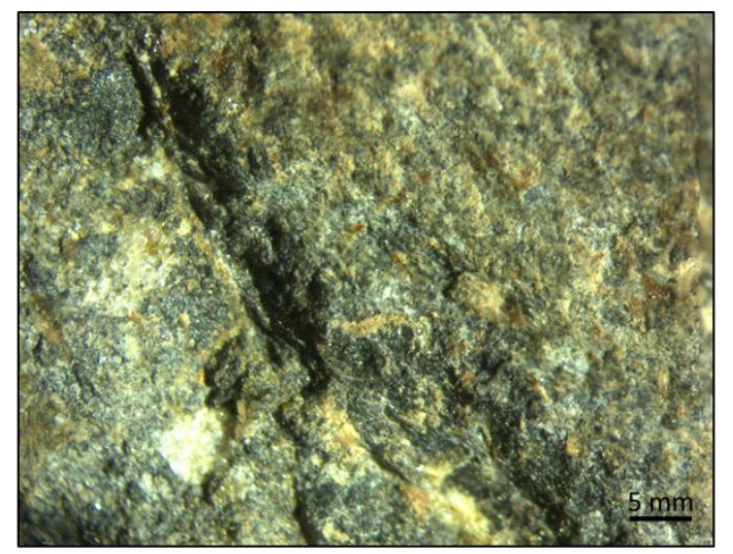

Photo 49. Photomicrograph of KPM-4 post Phase I use wear showing increased use wear at existing seam on distal end of pestle, $13 \mathrm{x}$.

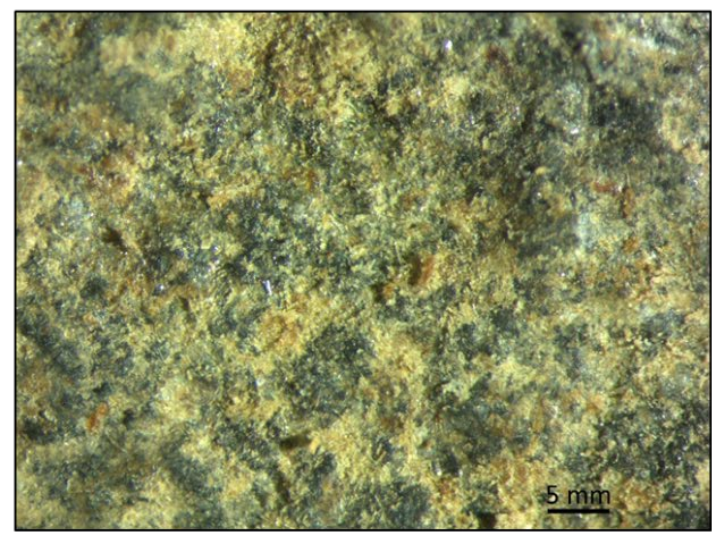

Photo 51. Photomicrograph of KPM-4 post Phase I use wear showing filbert husk material trapped in interstices, $25 \mathrm{x}$.

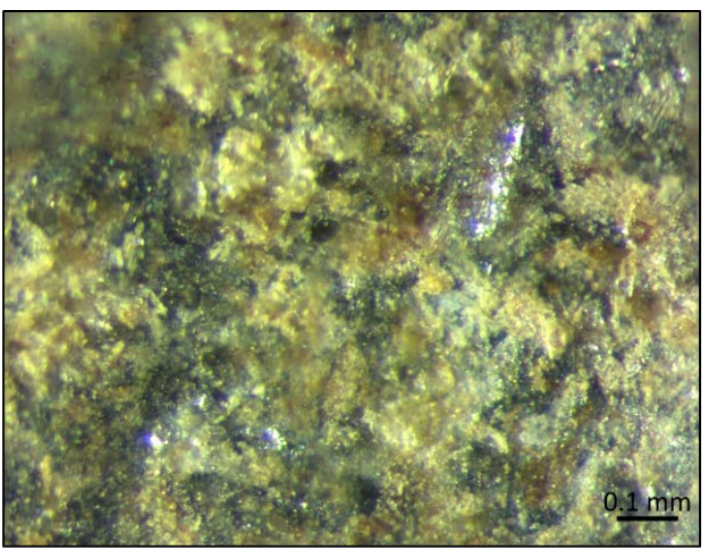

Photo 50. Photomicrograph of KPM-4 post Phase I use wear showing polish on asperities, $100 \mathrm{x}$.

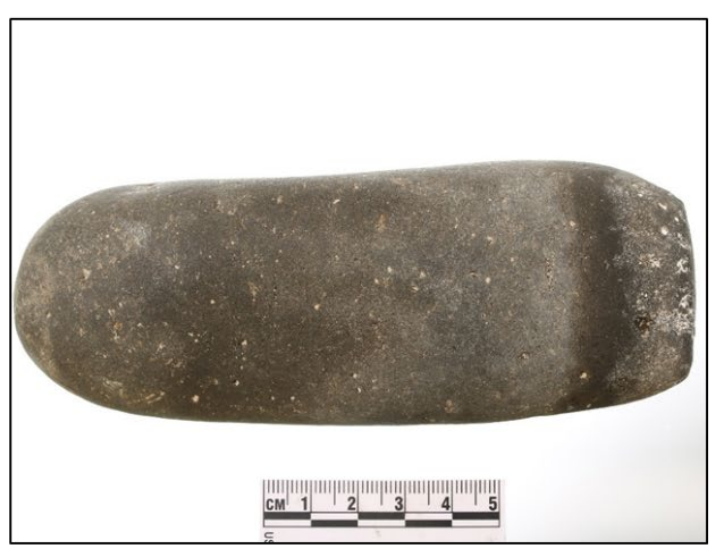

Photo 52. Pestle KPM-4 post Phase II use wear showing oil staining at distal end of tool. 


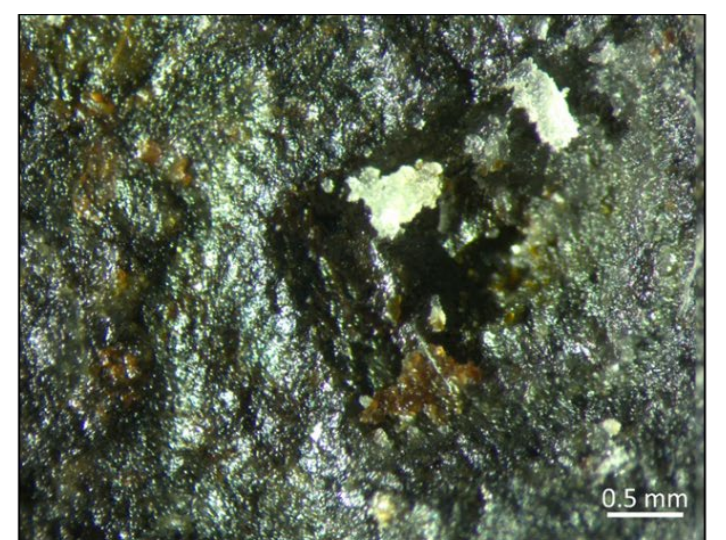

Photo 53. Photomicrograph of KPM-4 post Phase II use wear showing polish and oil staining, rounded grains, and remnant filbert kernel material, $25 \mathrm{x}$

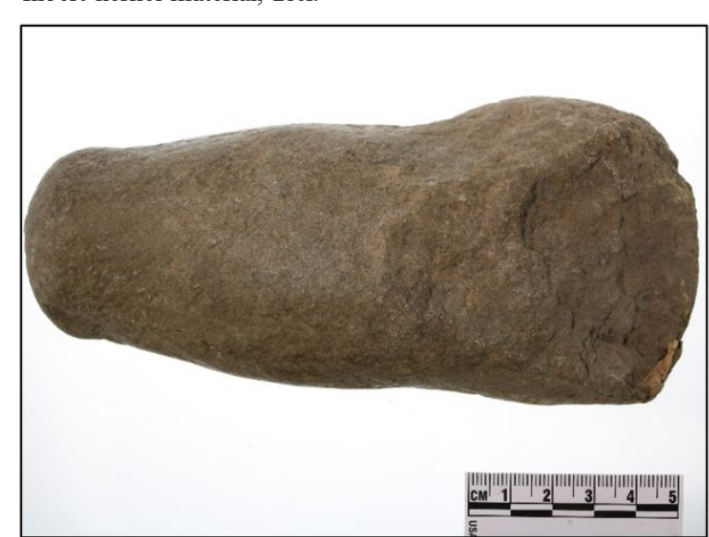

Photo 55. Maul 35CO2-453 showing a fracture along the distal end of the tool.

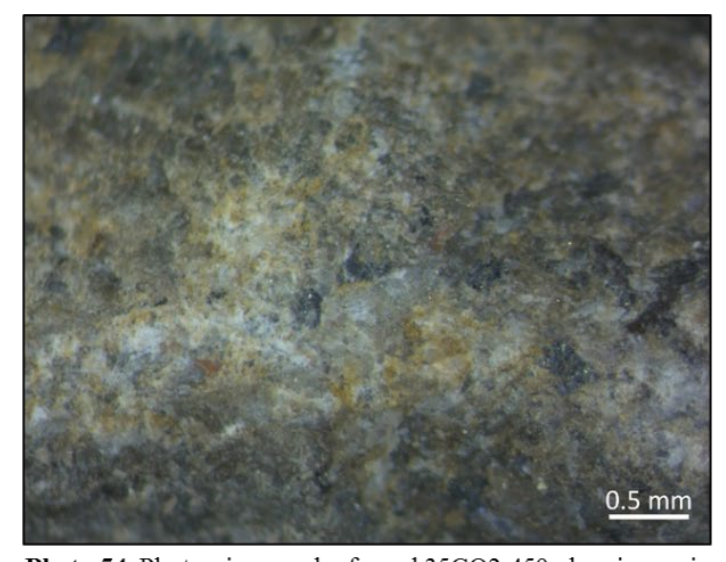

Photo 54. Photomicrograph of maul 35CO2-459 showing grain rounding and crushing on the distal end of the tool, $25.2 \mathrm{x}$.

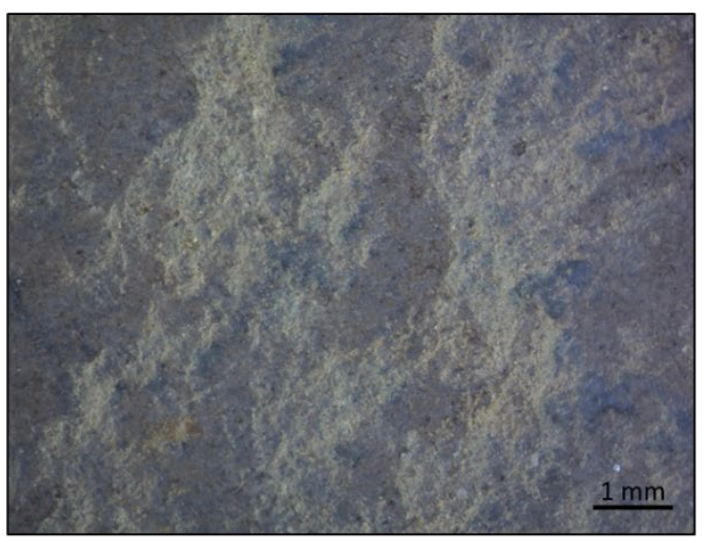

Photo 56. Photomicrograph of grain rounding and crushing in the distal end of pestle $35 \mathrm{CO} 2-470,12.6 \mathrm{x}$. 


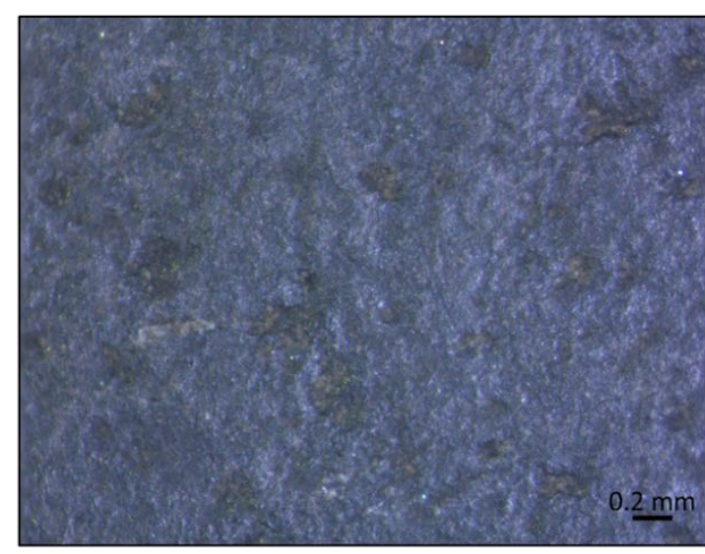

Photo 57. Photomicrograph of 35CO2-471 showing polish on the shaft of the tool, $31.5 \mathrm{x}$.

\section{$\varpi$}

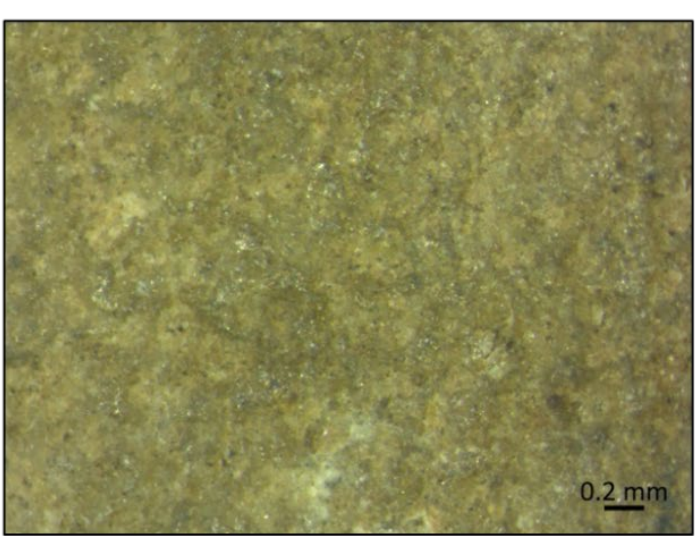

Photo 59. Photomicrograph of bowl 35CO2-485 showing grain rounding and polish within the bowl basin, $31.5 \mathrm{x}$

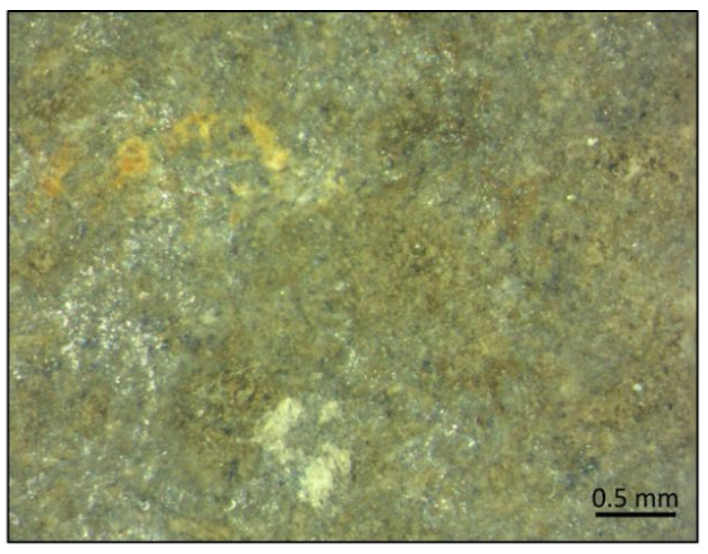

Photo 58. Photomicrograph of bowl 35CO2-488 showing grain rounding and polish on non-modified bowl exterior, $25.2 \mathrm{x}$.

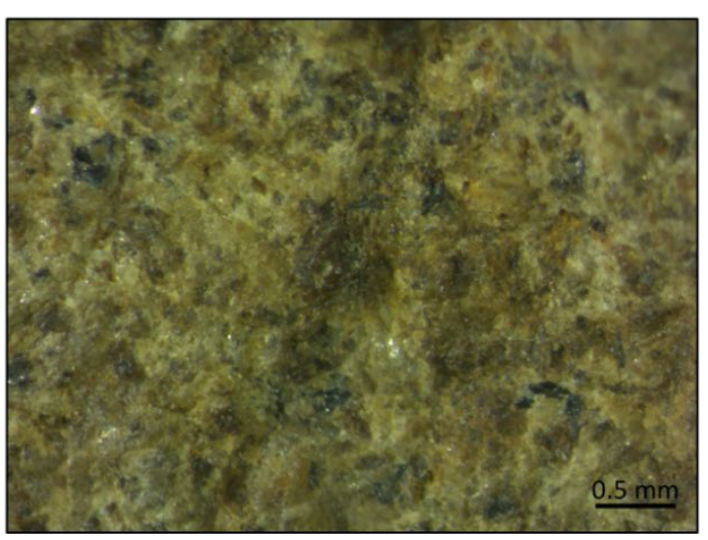

Photo 60. Photomicrograph of bowl 35CO2-482 showing sharp asperities and grain crushing on modified bowl base, $25.2 \mathrm{x}$. 


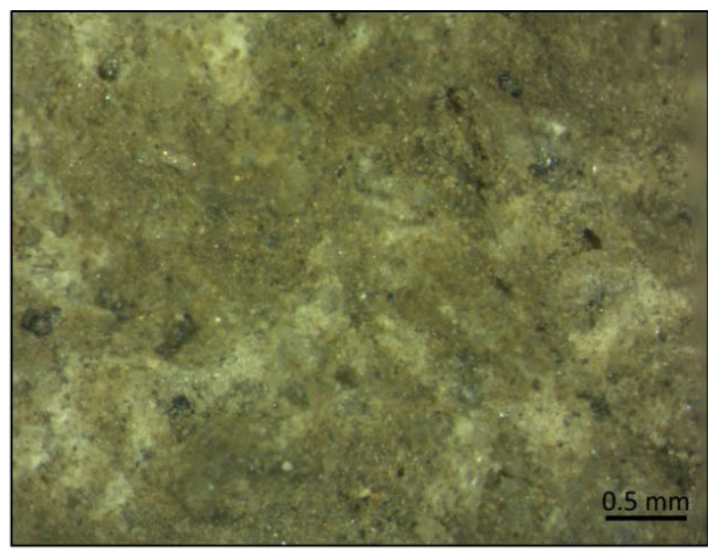

Photo 61. Photomicrograph of net weight 35CO2-438 showin sharp asperities and grain crushing at perforation, $25.2 \mathrm{x}$.

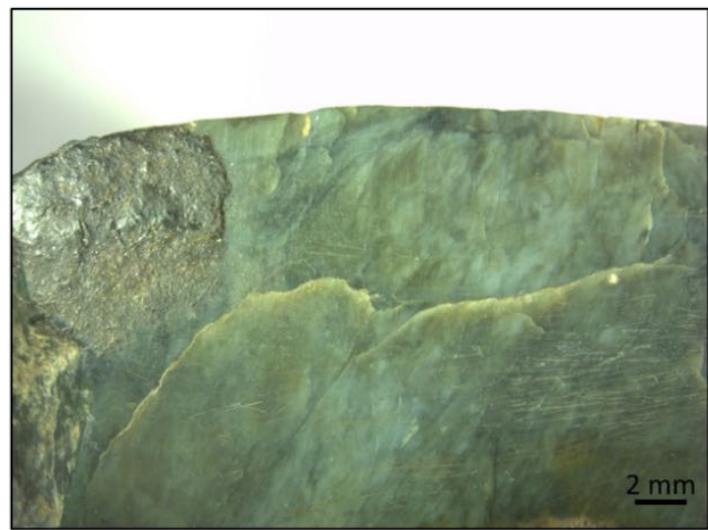

Photo 63. Photomicrograph of adze 35CO2-427 showing

negative flake scars and possible pitch residue on the bit end of the tool, 4.095x.

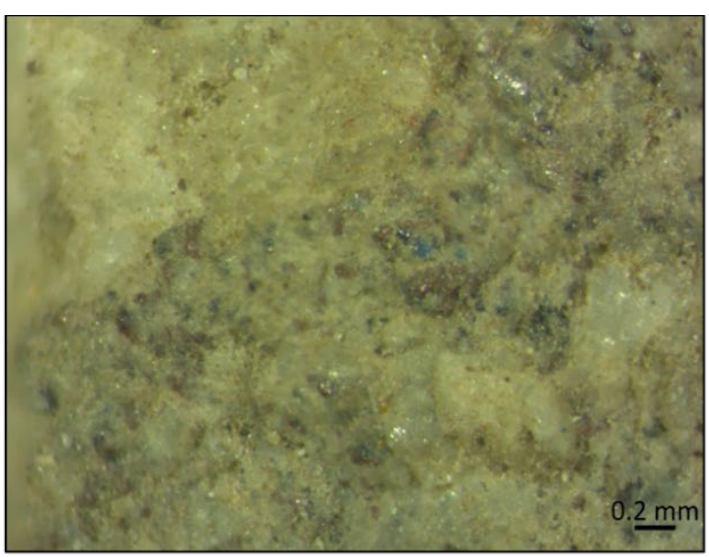

Photo 62. Photomicrograph of net weight 35CO2-444 showing grain rounding and polish in the non-modified surface, $31.5 \mathrm{x}$.

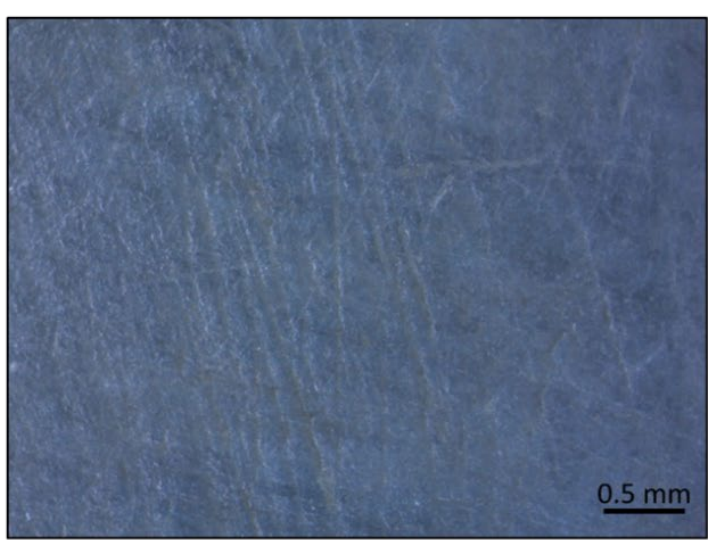

Photo 64. Photomicrograph of adze $35 \mathrm{CO} 2-427$ showing striations on the broad tool face, $25.2 \mathrm{x}$. 


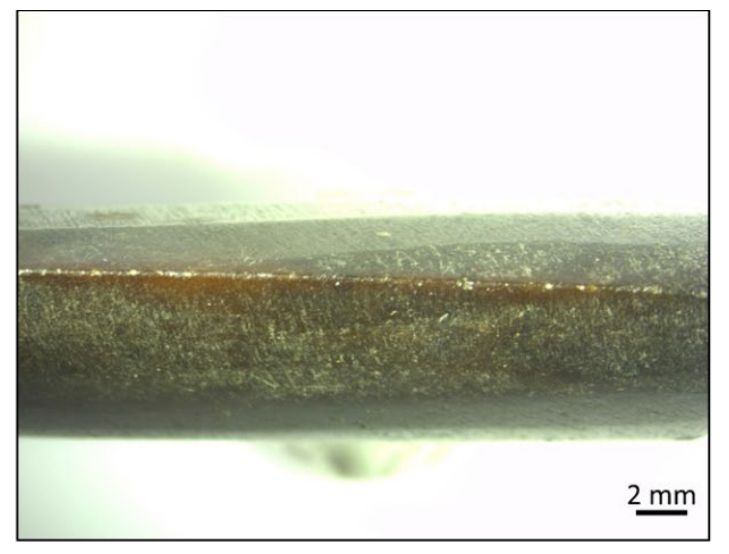

Photo 65. Photomicrograph of adze 35CO2-428 showing faceting on the bit end of the tool $4.095 \mathrm{x}$.

N

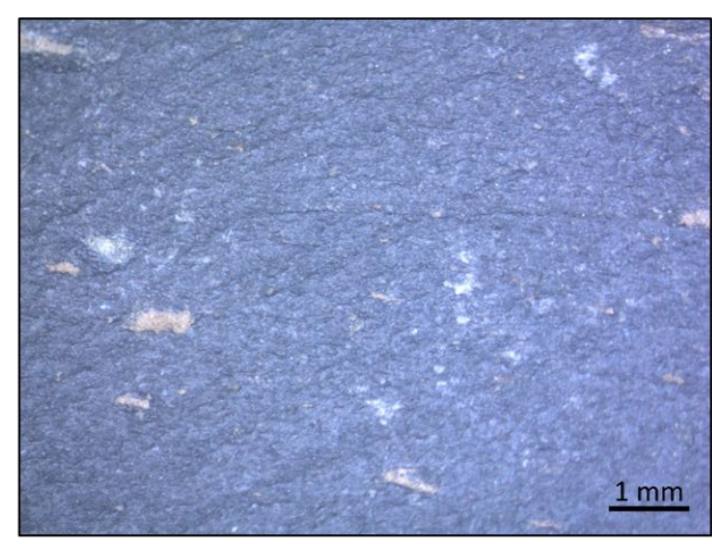

Photo 67. Photomicrograph of slate club 35CO2-425 showing striations and pitting, $12.6 \mathrm{x}$.

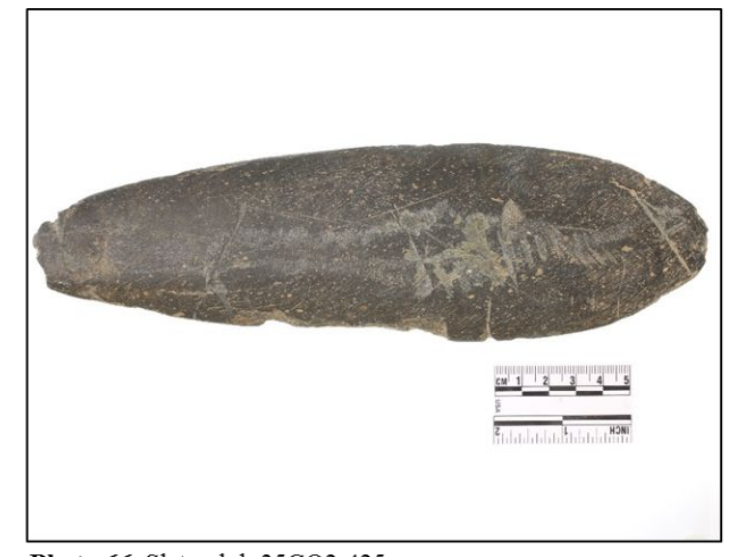

Photo 66. Slate club 35CO2-425.

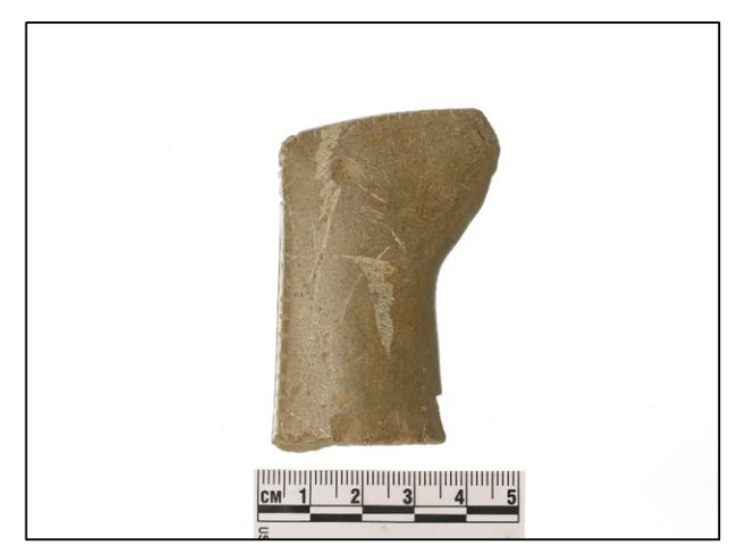

Photo 68. Carved horse figure 35CO2-426. 


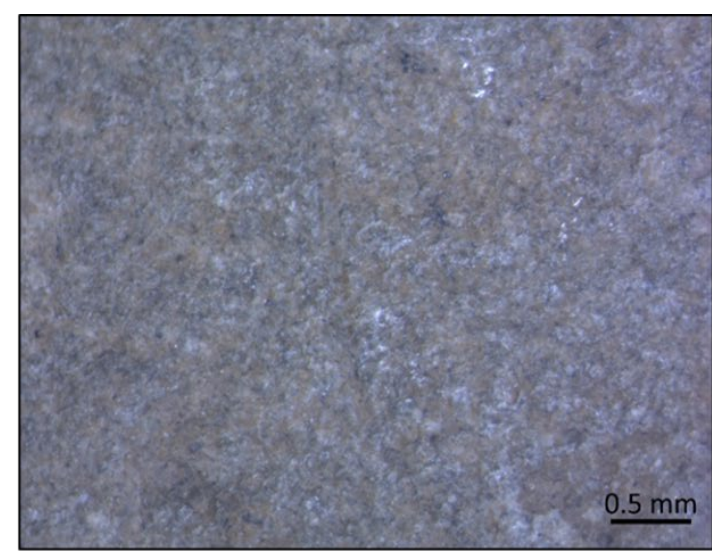

Photo 69. Photomicrograph of 35CO2-426 showing rounded grains and polish, $25.2 \mathrm{x}$

$\bar{\omega}$

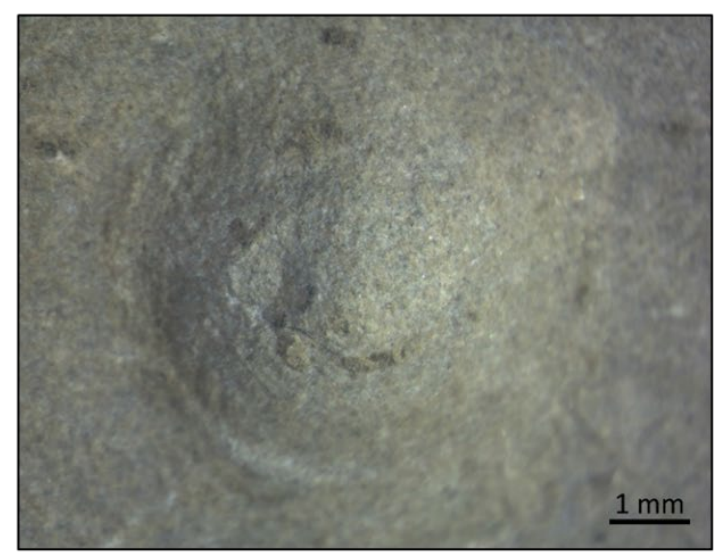

Photo 71. Photomicrograph of 35CO2-426 showing striations at eye, 12.6x.

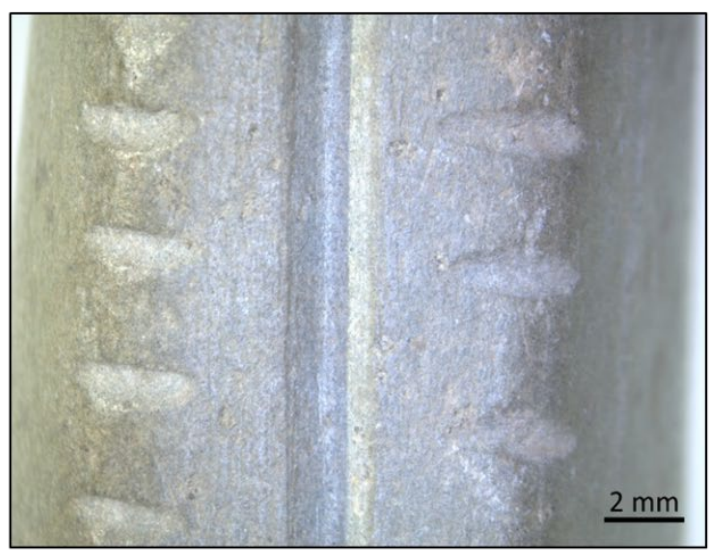

Photo 70. Photomicrograph of 35CO2-426 showing notching at mane, $6.3 \mathrm{x}$.

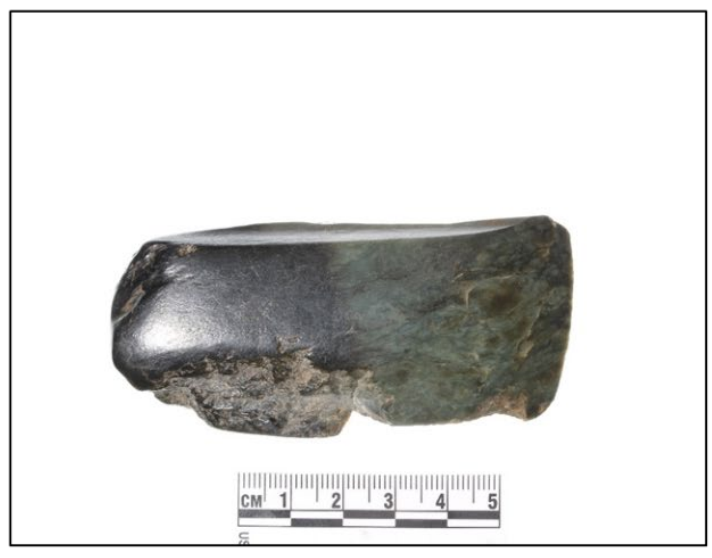

Photo 72. Adze 35CO2-427. 


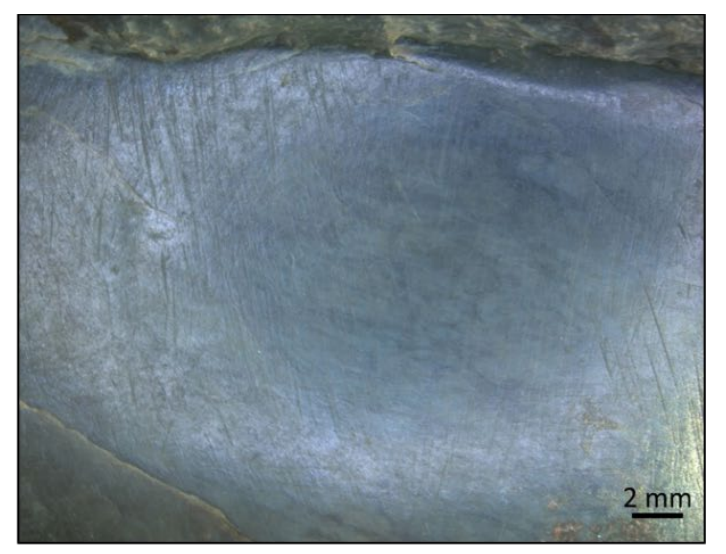

Photo 73. Photomicrograph of 35CO2-427 showing striations, $4.095 \mathrm{x}$.

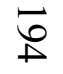

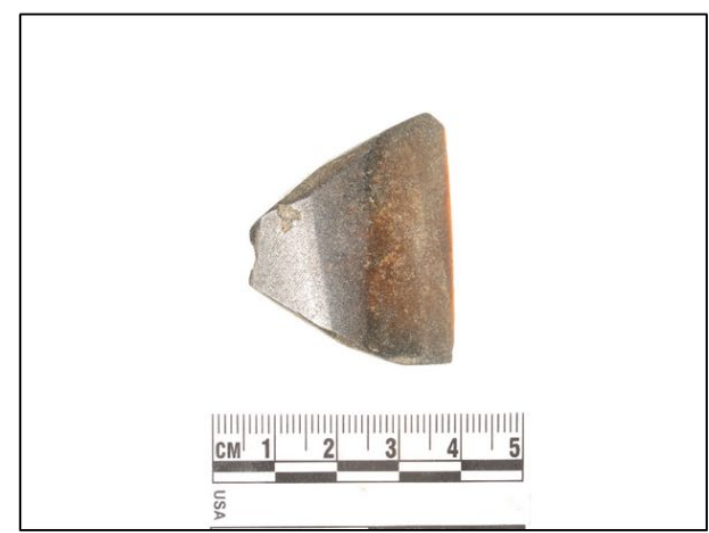

Photo 75. Adze 35CO2-428.

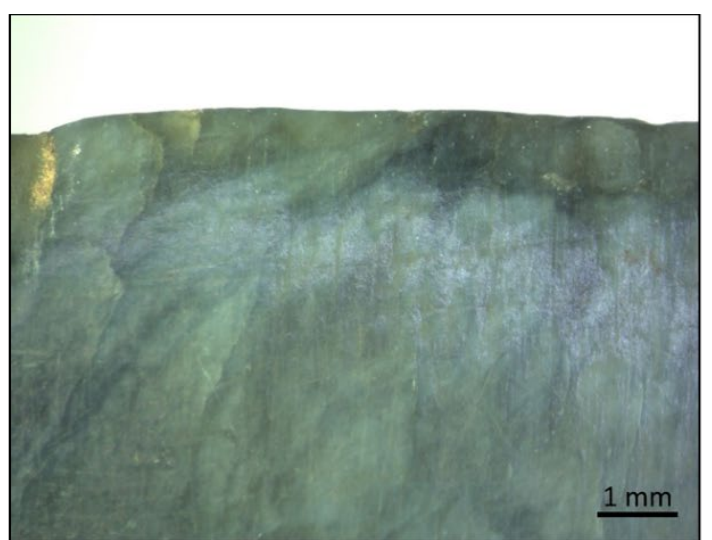

Photo 74. Photomicrograph of 35CO2-427 showing striations and negative flake scars at the bit end of the tool, 12.6x.

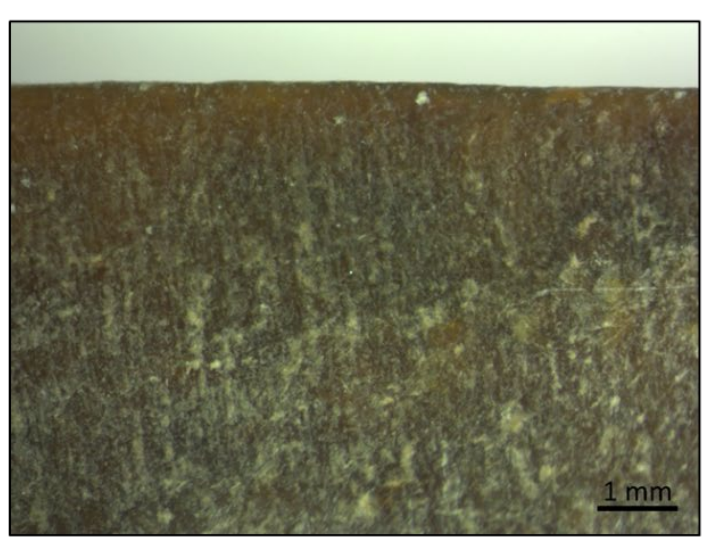

Photo 76. Photomicrograph of adze $35 \mathrm{CO} 2-428$ showing striations on the face of the bit end of the tool, 12.6x. 


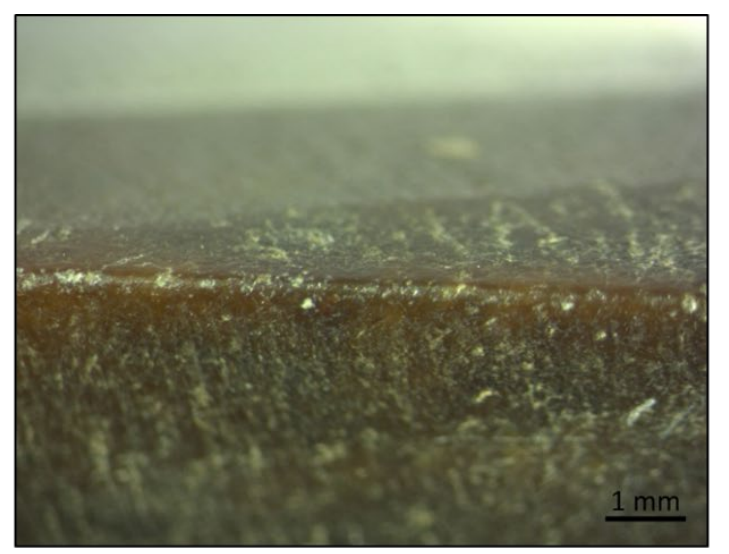

Photo 77. Photomicrograph of 35CO2-428 showing faceting and damage to the bit end of the tool, 12.6x.

$\vec{\cup}$

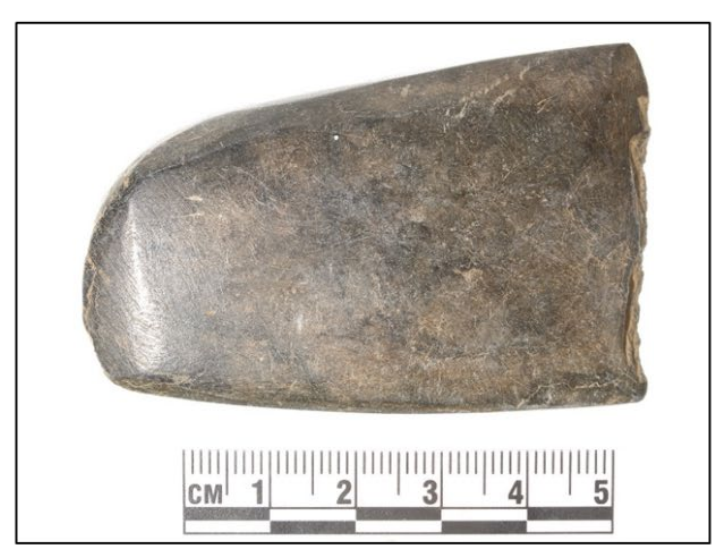

Photo 79. Adze 35CO2-430.

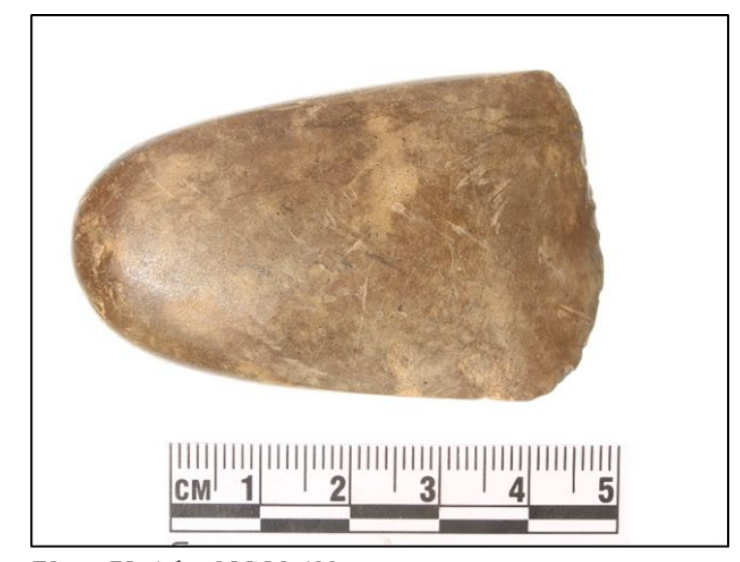

Photo 78. Adze 35CO2-429.

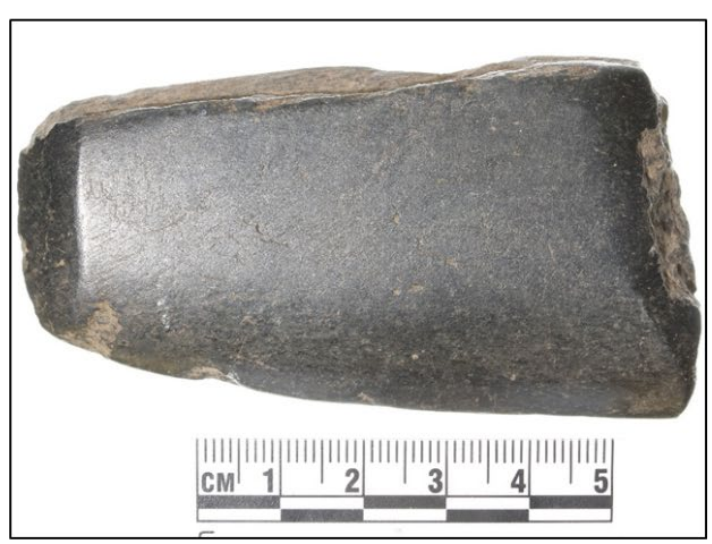

Photo 80. Adze 35CO2-431. 

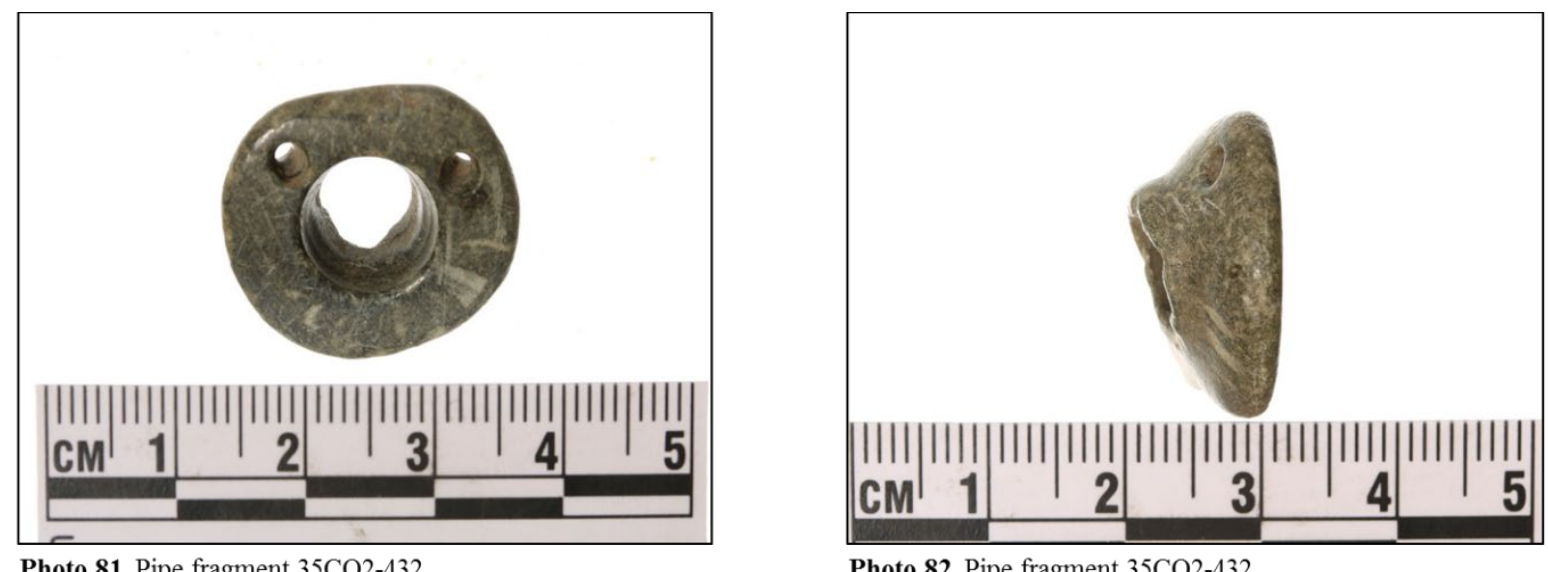

६
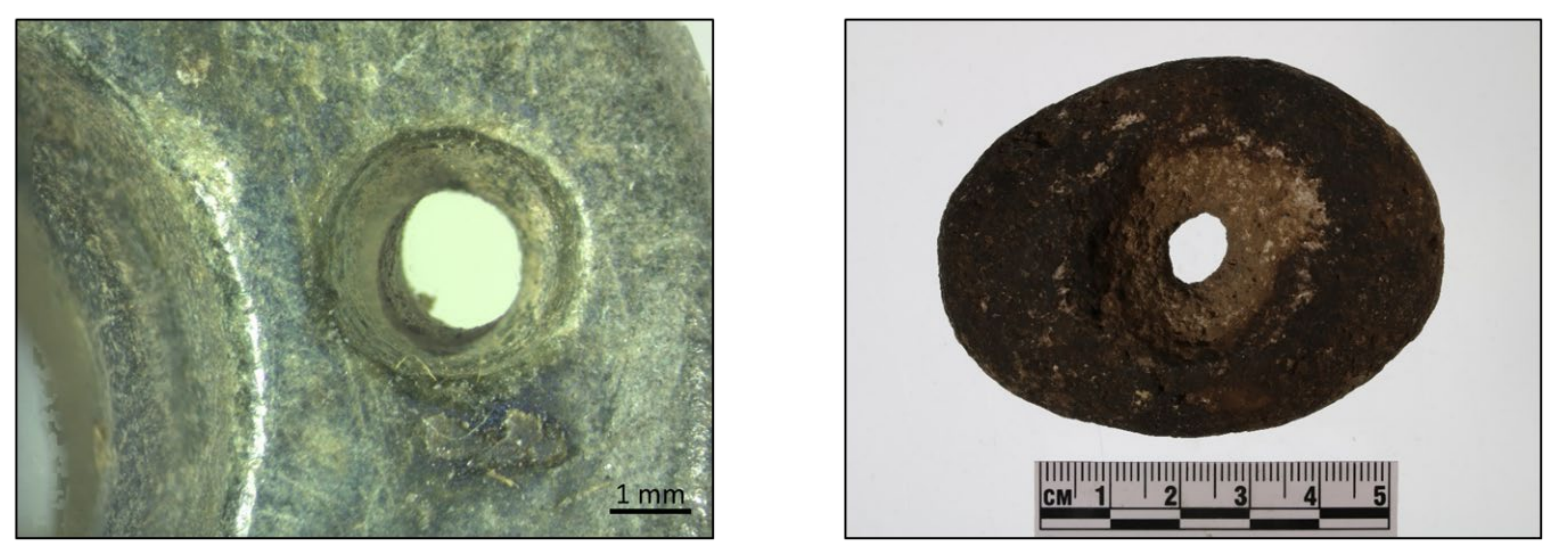

Photo 83. Photomicrograph of 35CO2-432 showing striations within pipe perforation, $12.6 \mathrm{x}$

Photo 84. Perforated net weight 35CO2-438. 


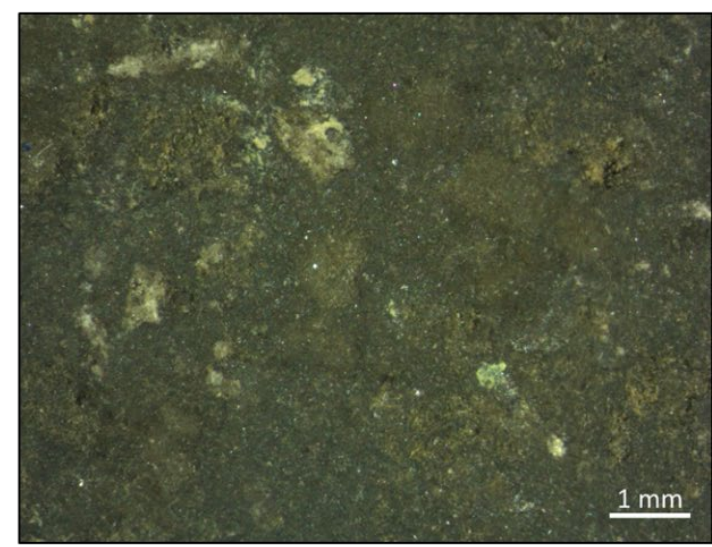

Photo 85. Photomicrograph of 35CO2-438 showing grain crushing and faceting, $25.2 \mathrm{x}$.

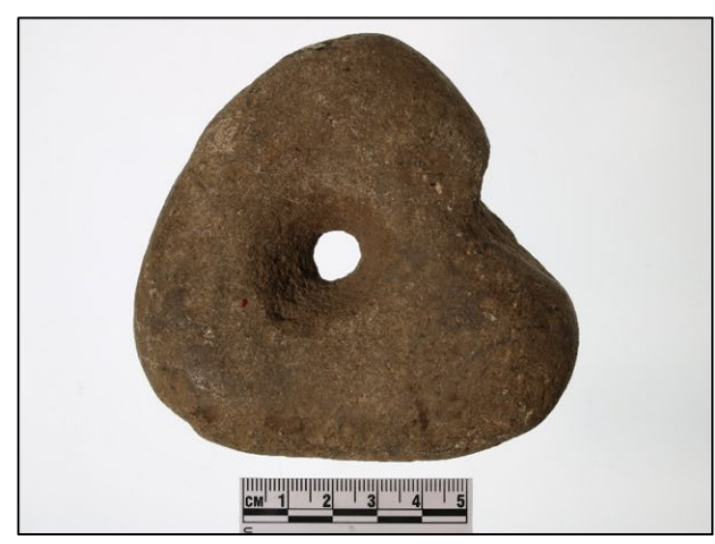

Photo 87. Perforated net weight 35CO2-439.

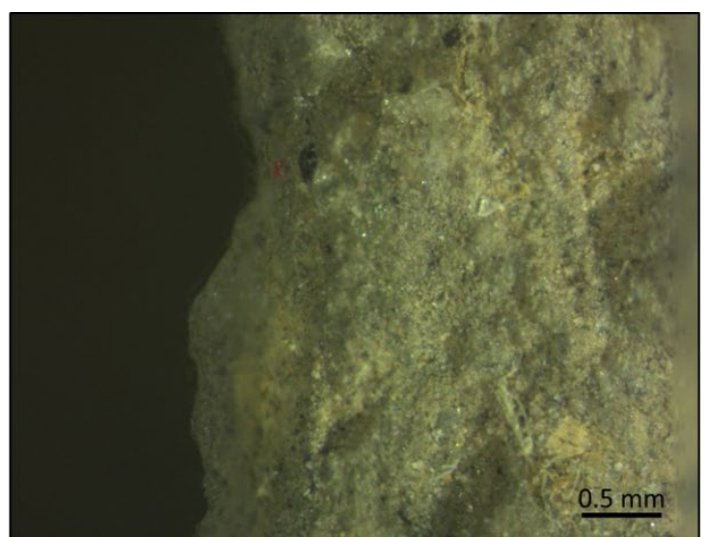

Photo 86. Photomicrograph of 35CO2-438 showing grain rounding on the unmodified tool surface, $12.6 \mathrm{x}$.

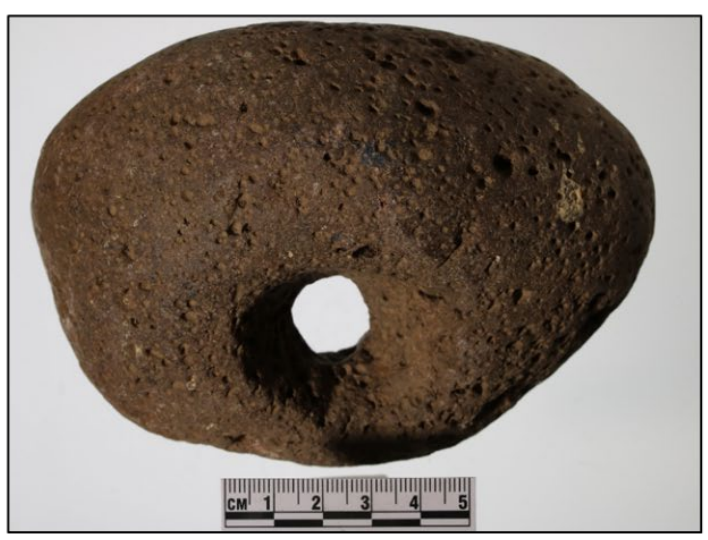

Photo 88. Perforated net weight 35CO2-440. 


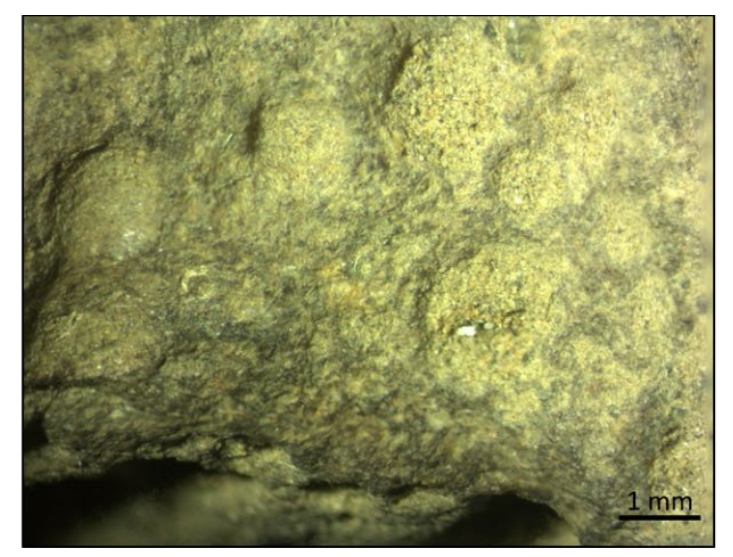

Photo 89. Photomicrograph of 35CO2-440 showing vesicles and grain rounding at perforation, $12.6 \mathrm{x}$.

\section{$\varpi$}

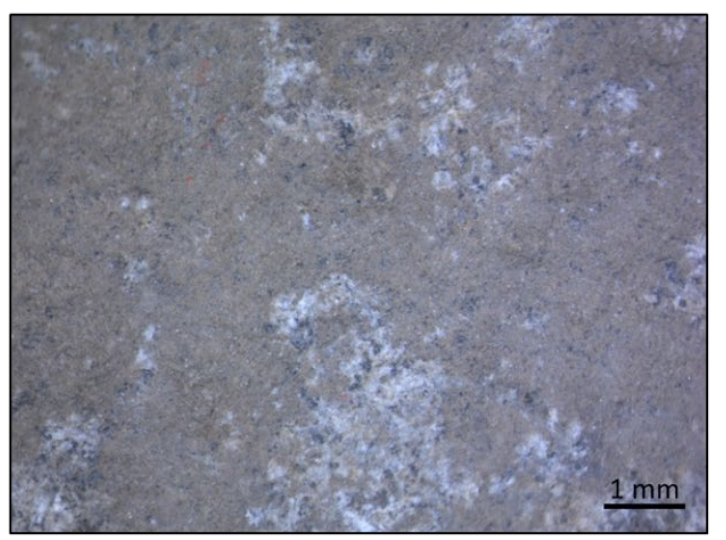

Photo 91. Photomicrograph of 35CO2-441 showing base of pestle use surface, $12.6 \mathrm{x}$

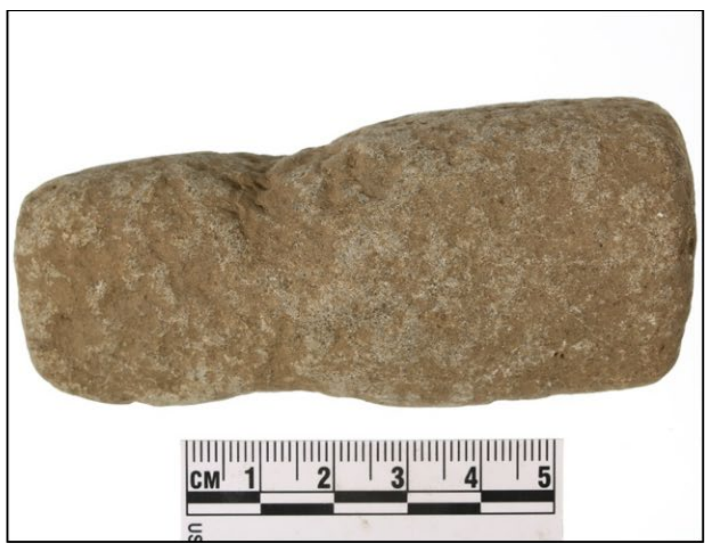

Photo 90. Multi-use tool 35CO2-441.

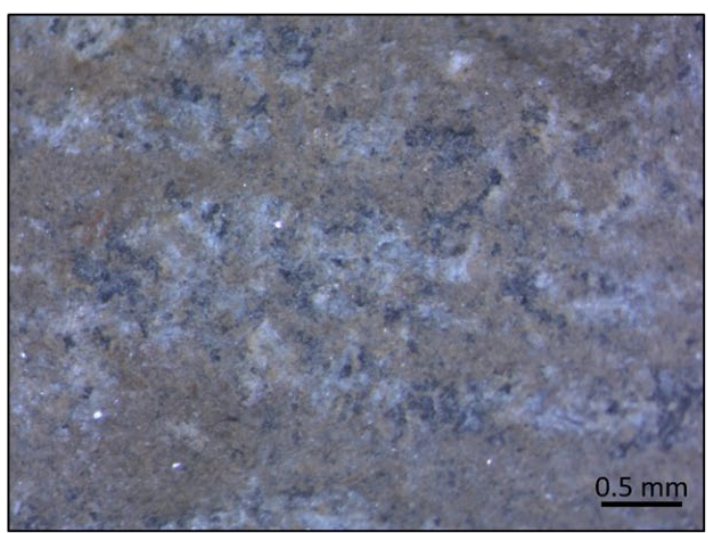

Photo 92. Photomicrograph of 35CO2-441 showing striations from possible abrader use, $25.2 \mathrm{x}$. 


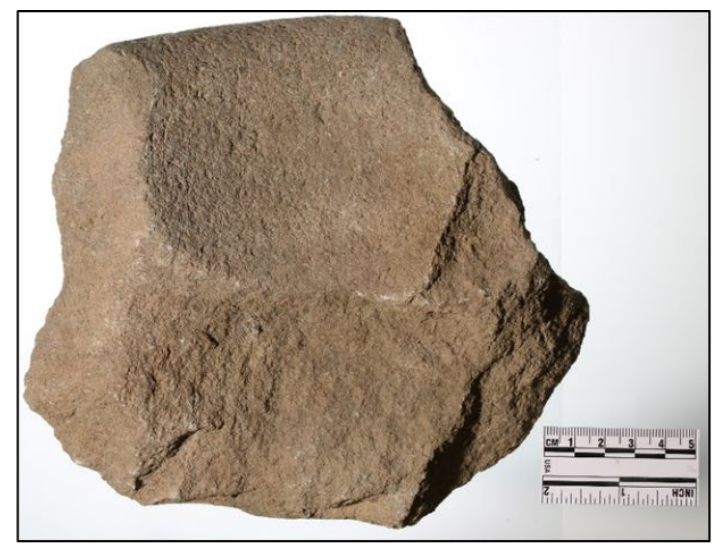

Photo 93. Bowl fragment 35CO2-442.

$\overline{8}$

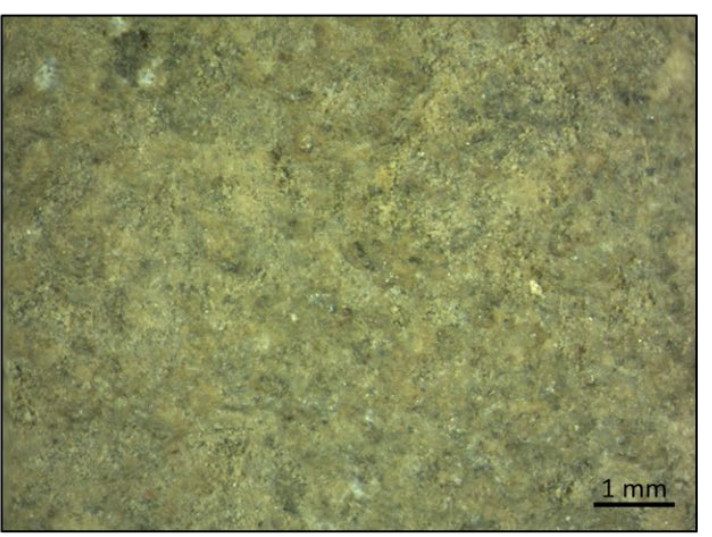

Photo 95. Photomicrograph of 35CO2-442 showing grain rounding and polish on basin interior, 12.6x.

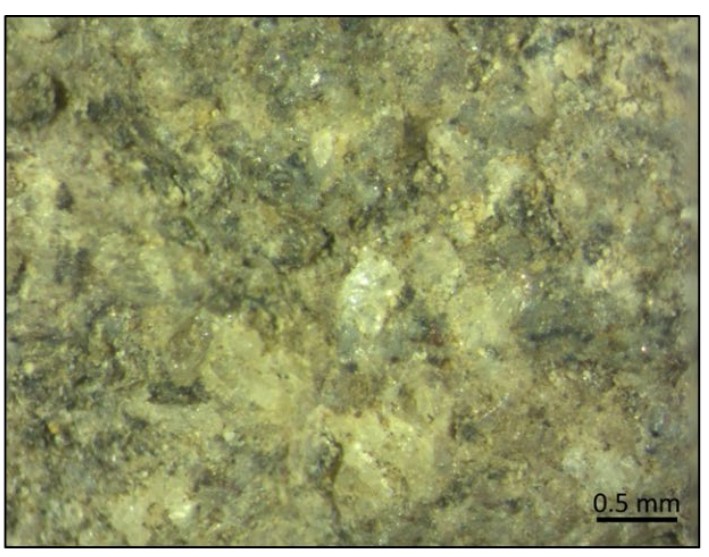

Photo 94. Photomicrograph of 35CO2-442 showing grain

rounding and great elevation differences on bowl exterior, $25.2 \mathrm{x}$.

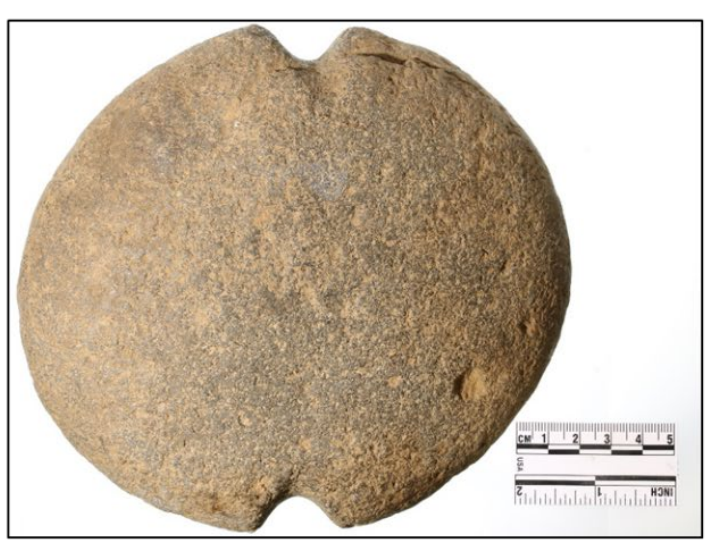

Photo 96. Notched net weight 35CO2-443 


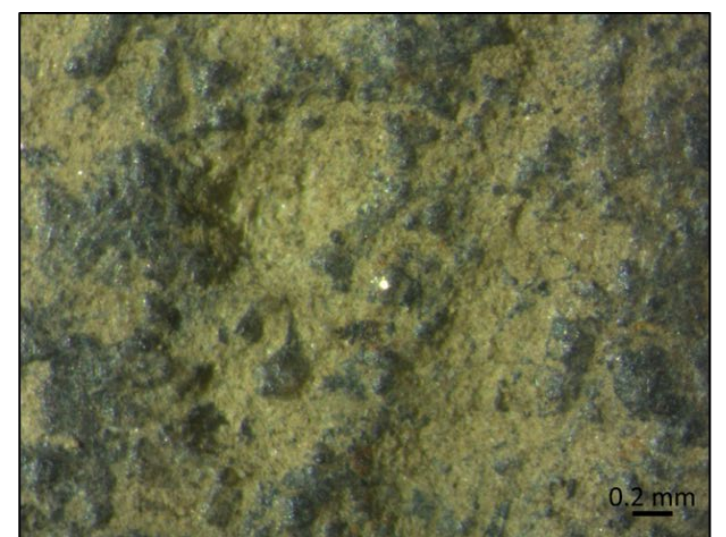

Photo 97. Photomicrograph of 35CO2-443 showing the unmodified surface, $31.5 \mathrm{x}$.

요

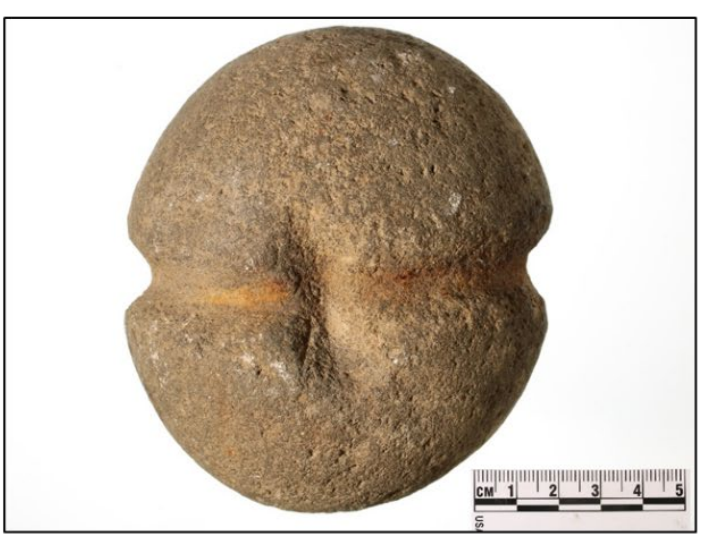

Photo 99. Banded and notched net weight 35CO2-444.

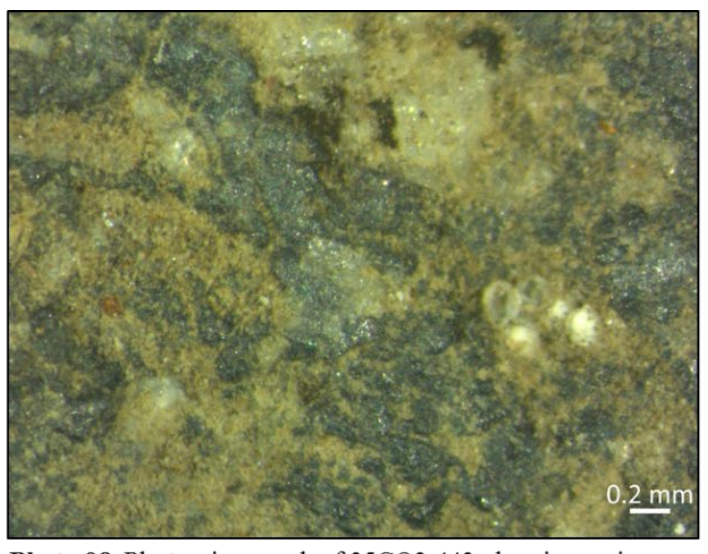

Photo 98. Photomicrograph of 35CO2-443 showing grain rounding and polish at the notching, $31.5 \mathrm{x}$.

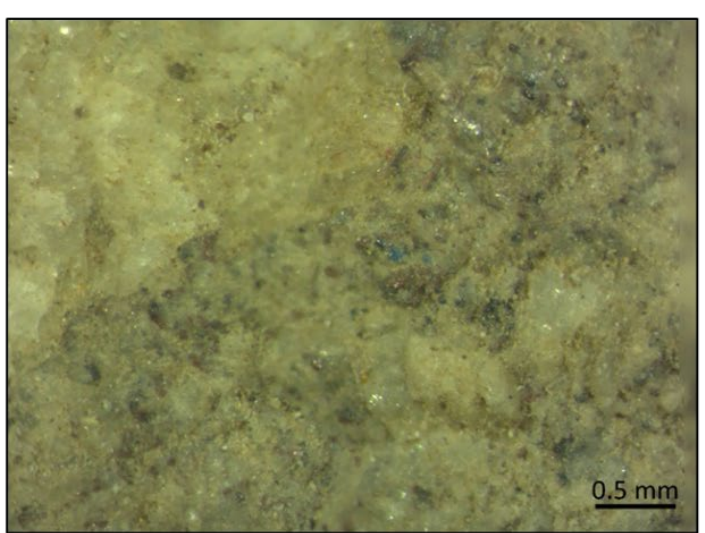

Photo 100. Photomicrograph of non modified surface of net weight 35CO2-444. 


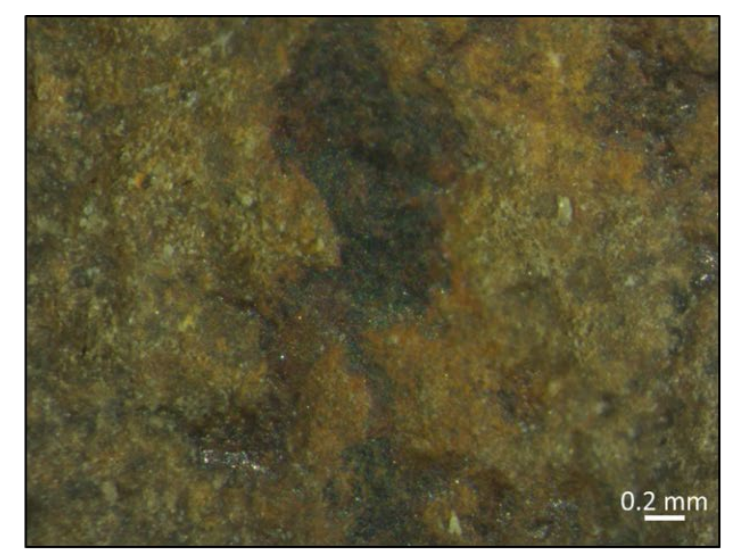

Photo 101. Photomicrograph of iron stained groove showing polish and grain rounding on net weight $35 \mathrm{CO} 2-444,31.5 \mathrm{x}$.

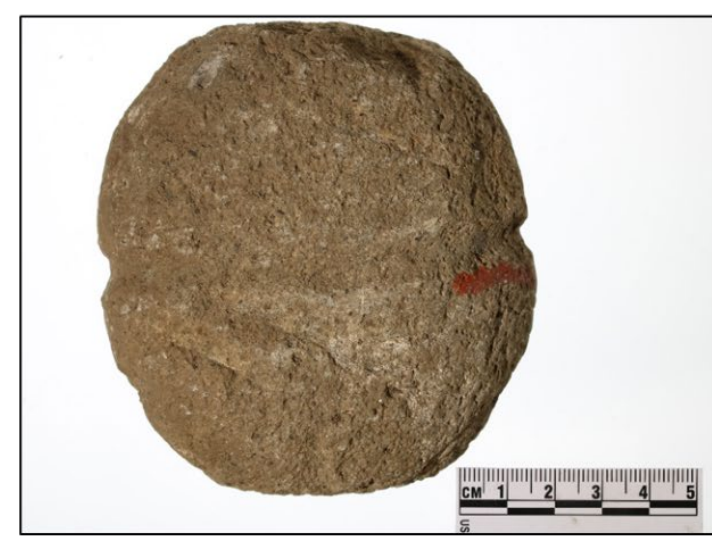

Photo 103. Banded and notched net weight 35CO2-446.

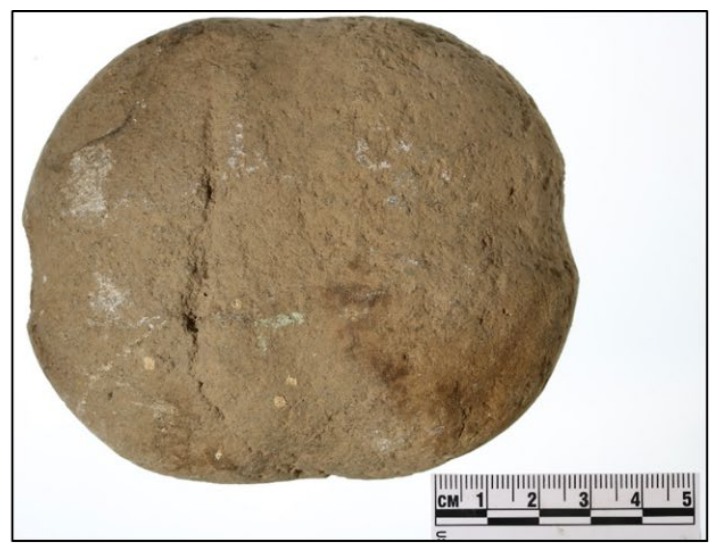

Photo 102. Banded net weight 35CO2-445

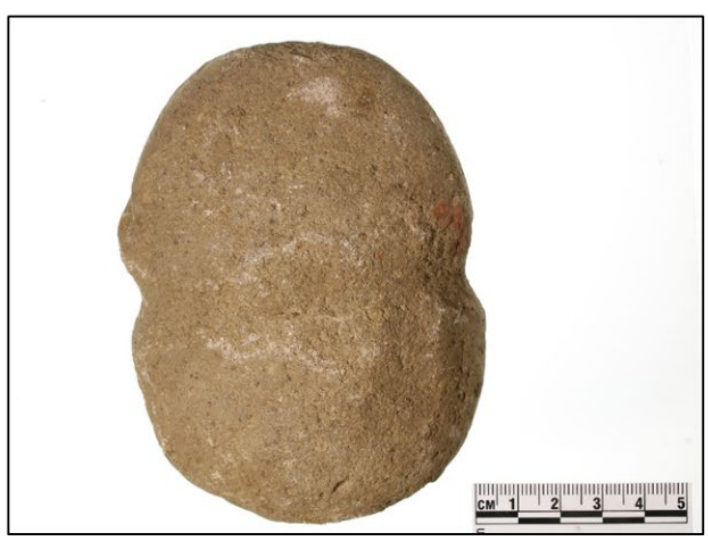

Photo 104. Banded and notched net weight 35CO2-447. 


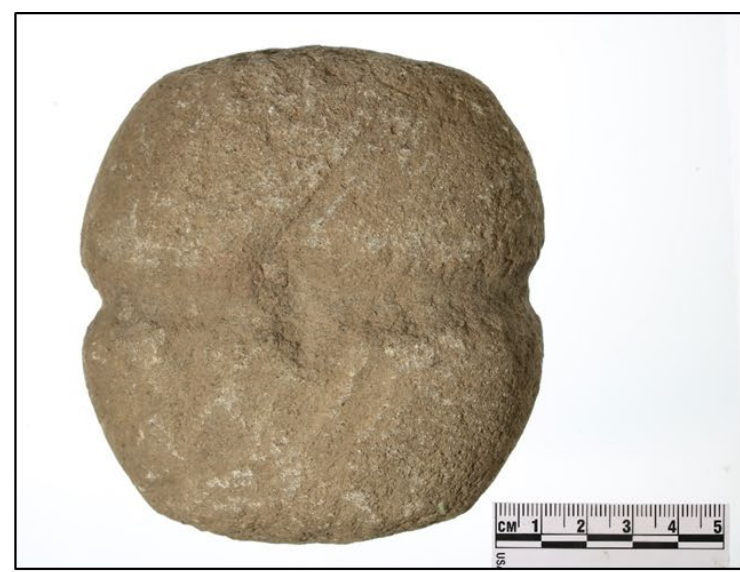

Photo 105. Banded and notched net weight 35CO2-448.

옹

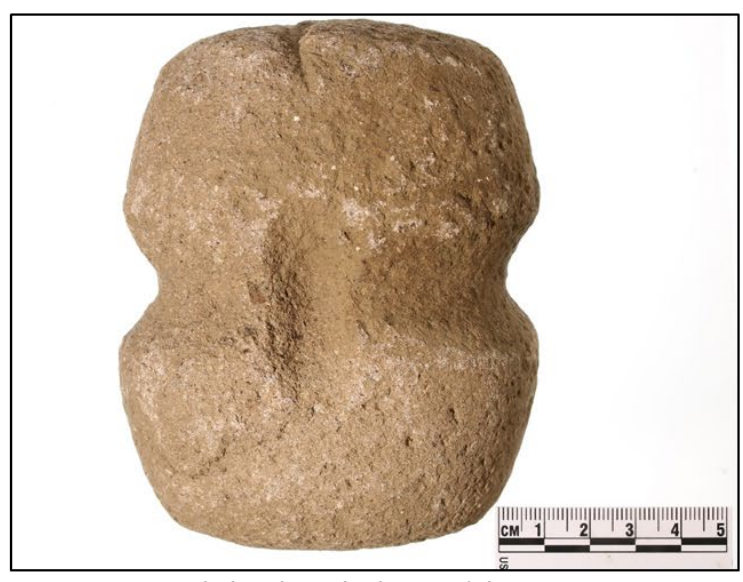

Photo 106. Banded and notched net weight 35CO2-449.

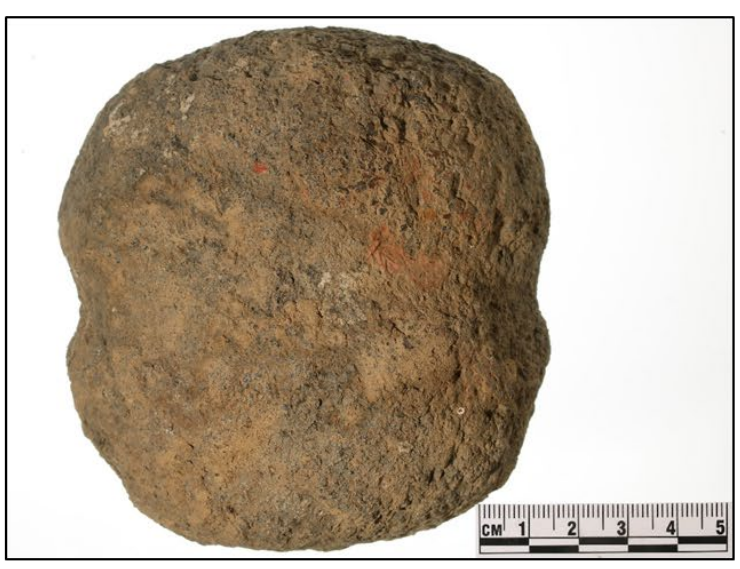

Photo 108. Banded net weight 35CO2-450.
Photo 107. Banded and notched net weight 35CO2-449 showing staining.

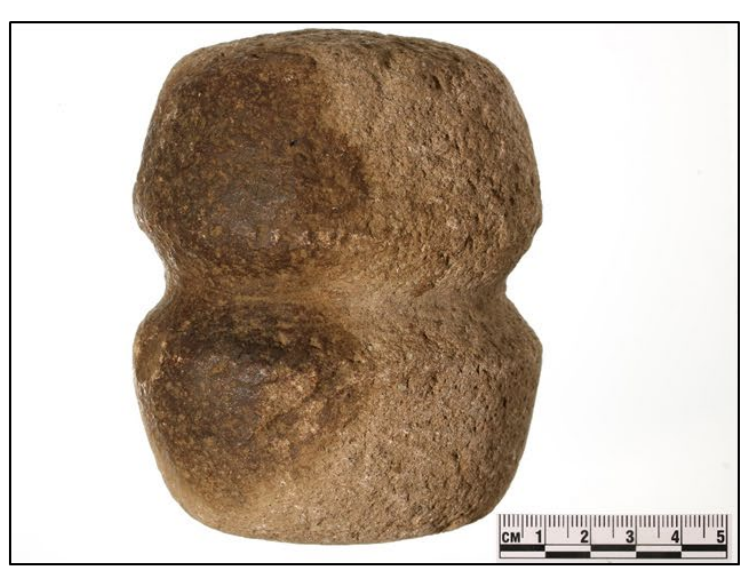




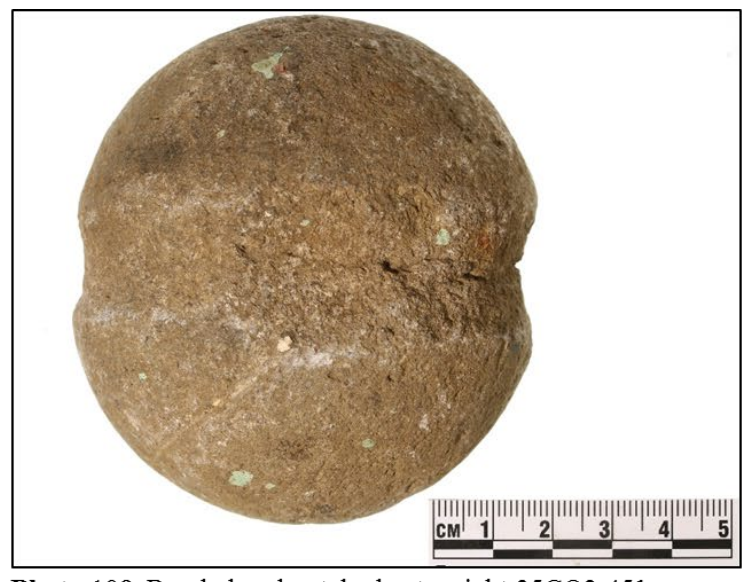

Photo 109. Banded and notched net weight 35CO2-451.

이

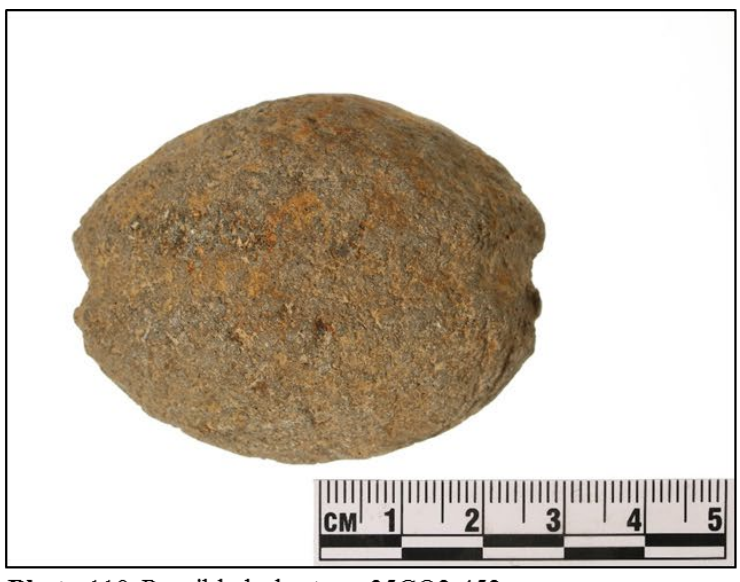

Photo 110. Possible bola stone 35CO2-452.

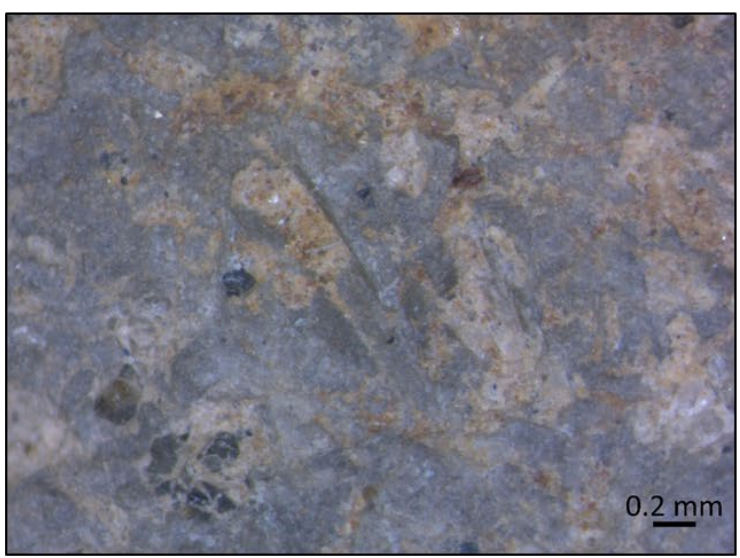

Photo 112. Photomicrograph of groove on possible bola stone $35 \mathrm{CO} 2-452$ showing possible chopper scar, $31.5 \mathrm{x}$.
Photo 111. Photomicrograph of unmodified surface of bol stone $35 \mathrm{CO} 2-452$.

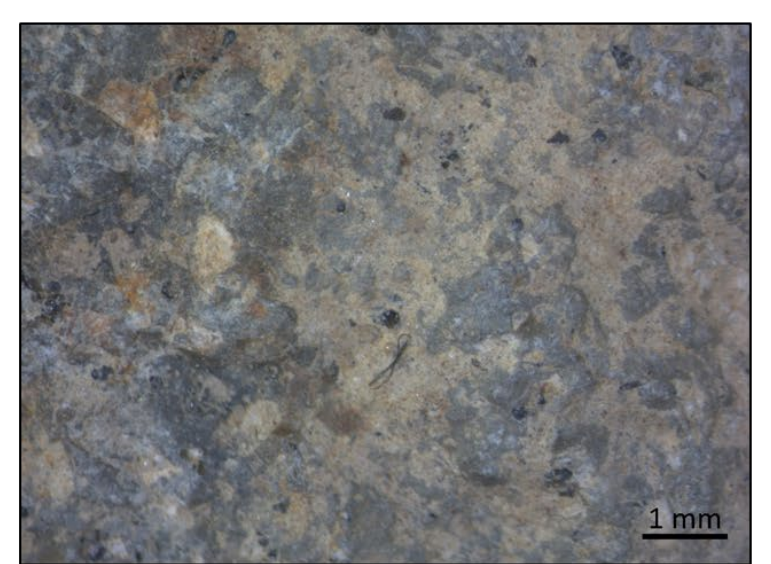




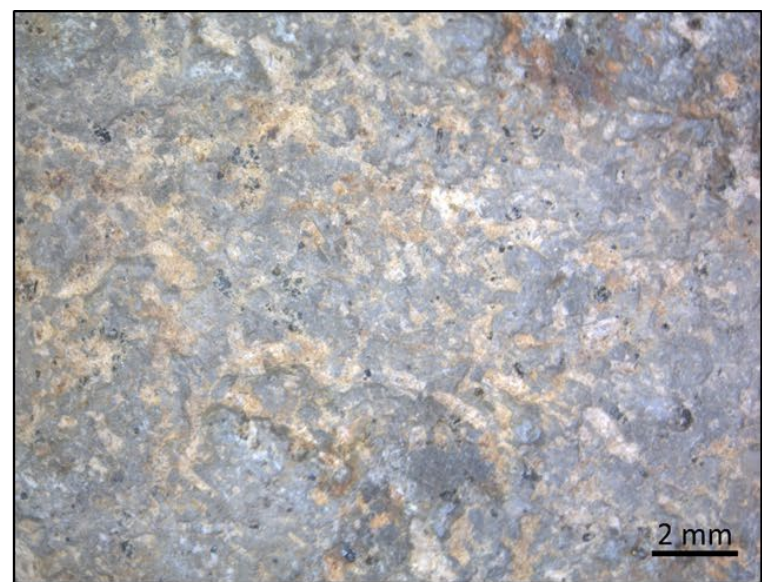

Photo 113. Photomicrograph of groove on possible bola stone $35 \mathrm{CO} 2-452$ showing rounded grains and polish, $6.3 \mathrm{x}$.

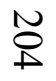

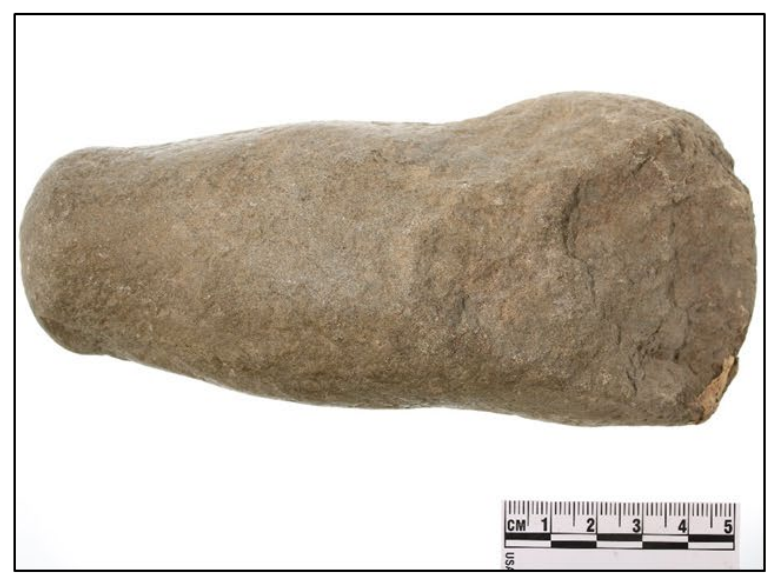

Photo 115. Maul 35CO2-453 showing fractured distal end.

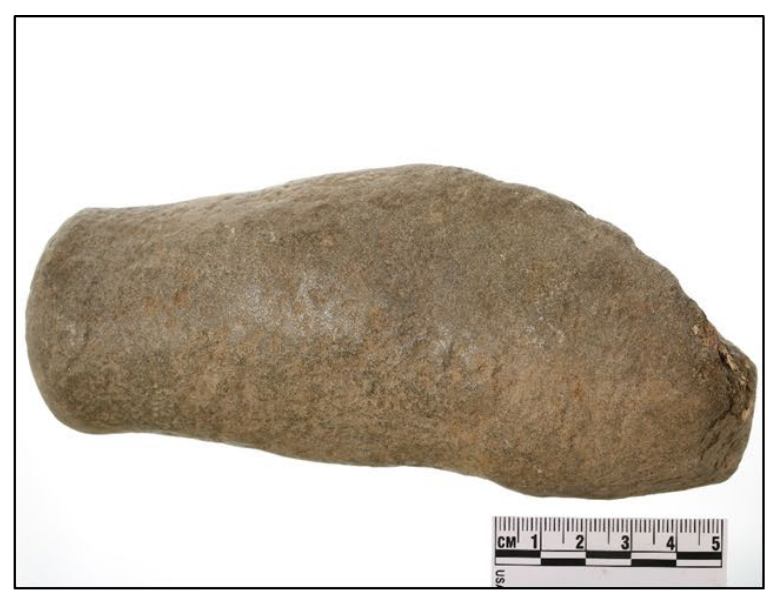

Photo 114. Maul 35CO2-453.

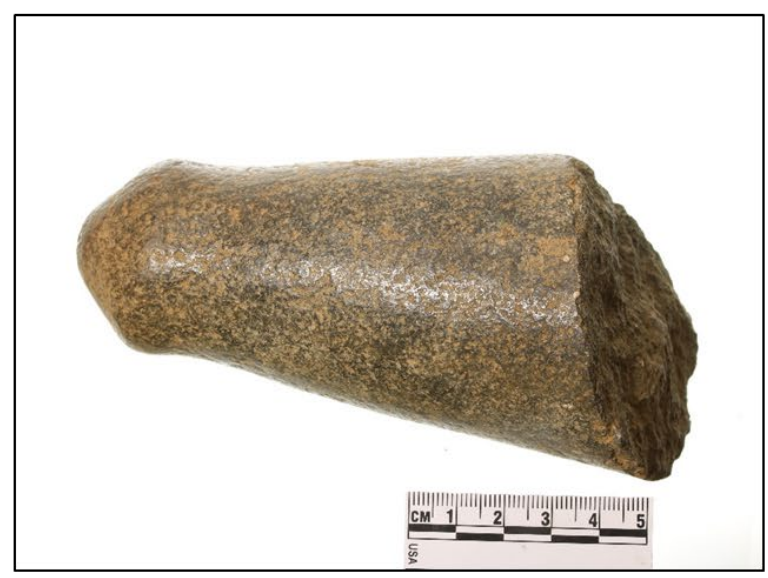

Photo 116. Maul/pestle 35CO2-454 


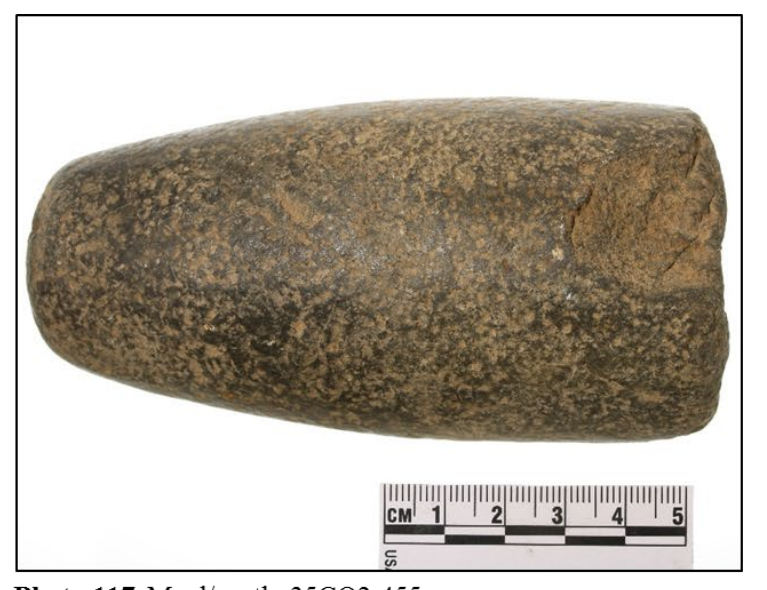

Photo 117. Maul/pestle 35CO2-455.

ํ.

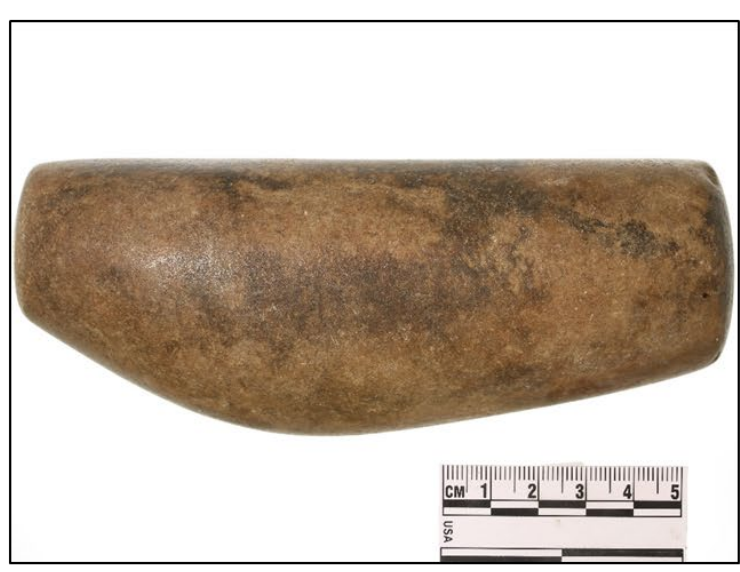

Photo 119. Pestle 35CO2-457.

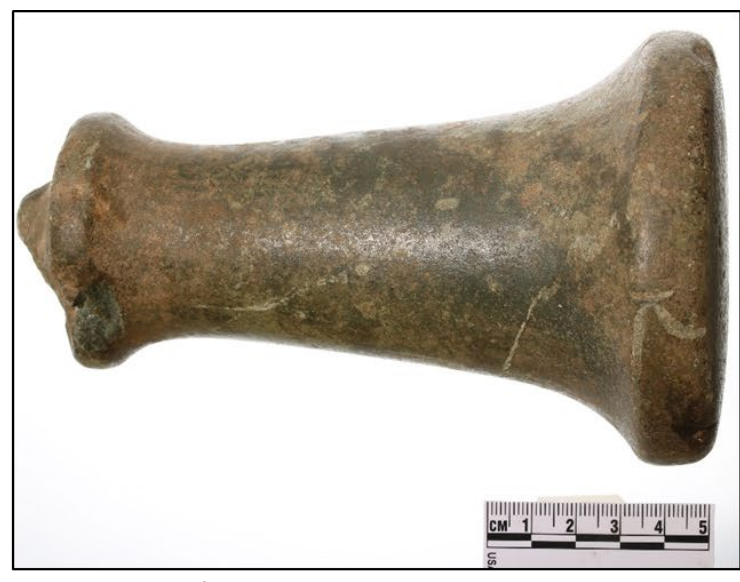

Photo 118. Maul 35CO2-456.

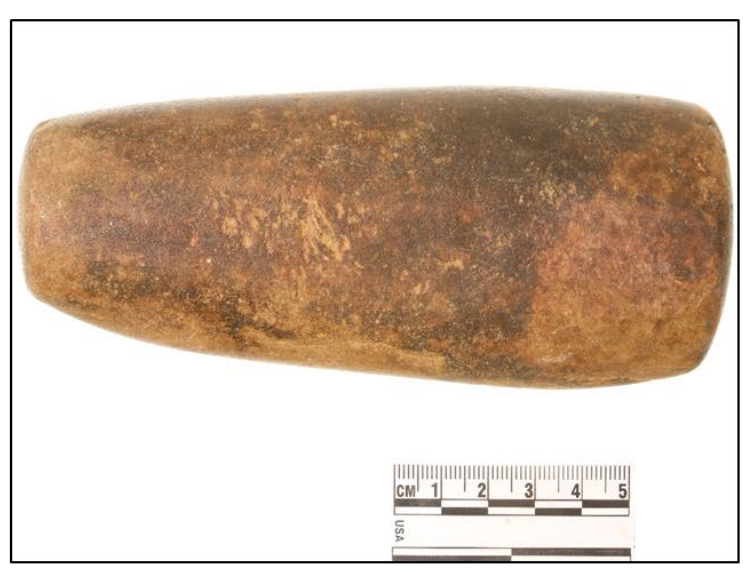

Photo 120. Pestle 35CO2-457 showing concentrated pitting likely from anvil use. 


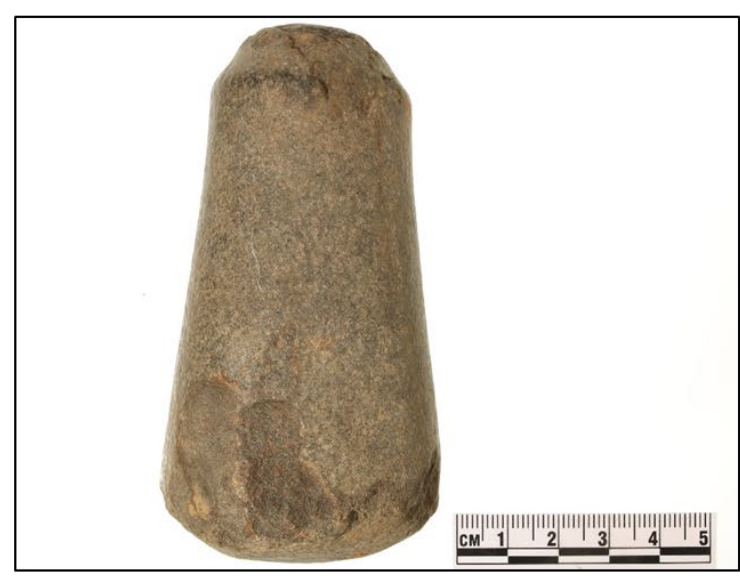

Photo 121. Maul/pestle 35CO2-458.

용

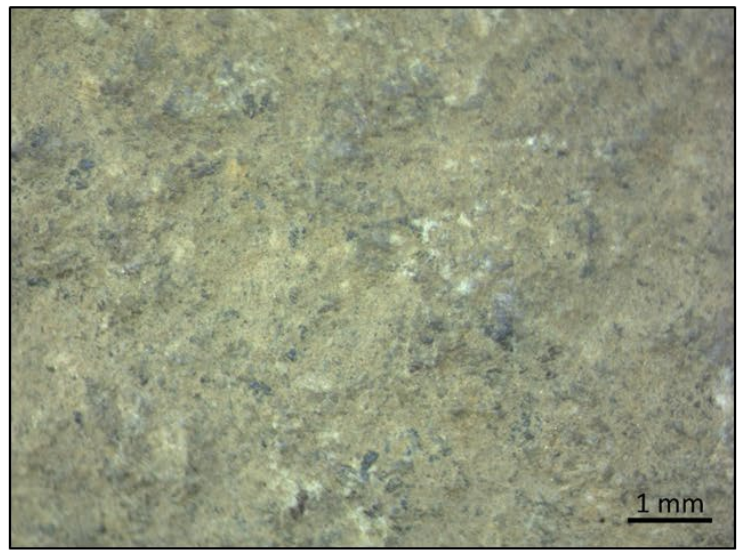

Photo 123. Photomicrograph of shaft of 35CO2-459 showing grain rounding and little elevation difference, $12.6 \mathrm{x}$.

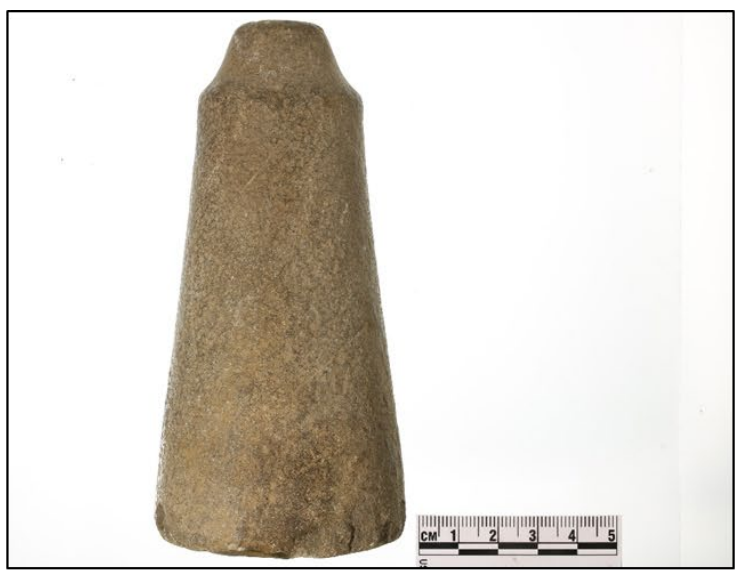

Photo 122. Maul/pestle 35CO2-459.

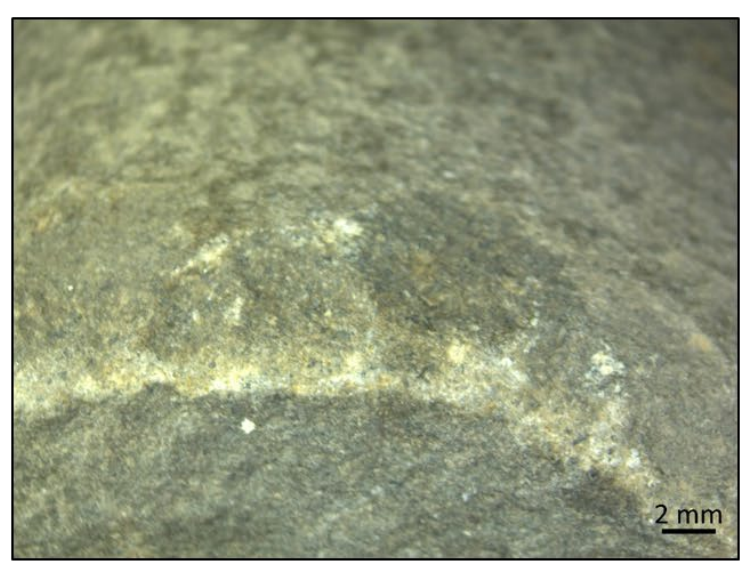

Photo 124. Photomicrograph of use wear at break on the distal end of tool 35CO2-459, 4.095x. 


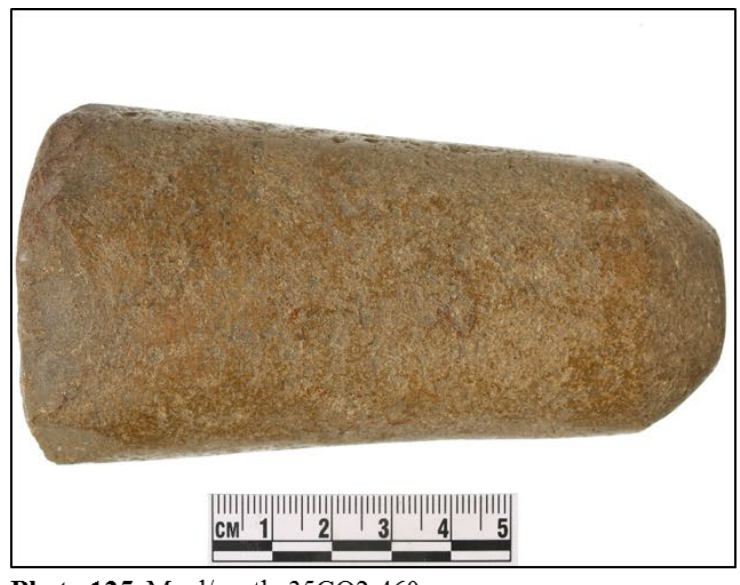

Photo 125. Maul/pestle 35CO2-460.

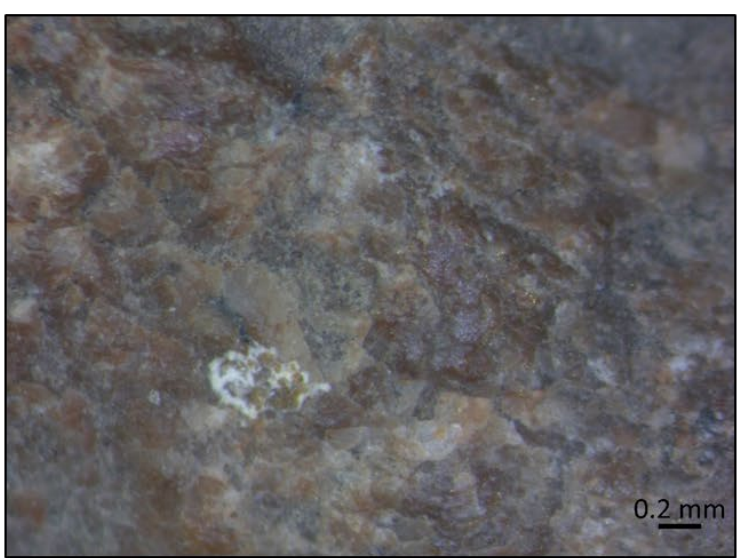

Photo 127. Photomicrograph of base of tool 35CO2-460 showing polish and grain rounding, $31.5 \mathrm{x}$.

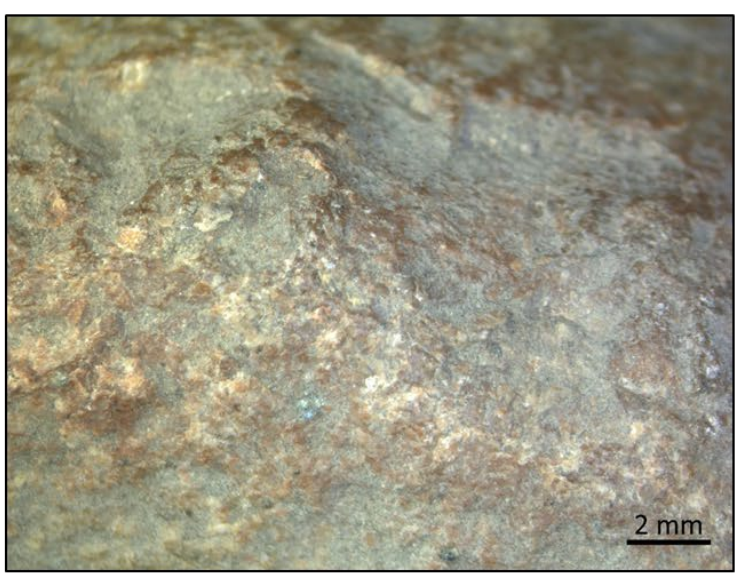

Photo 126. Photomicrograph of rejuvenated break on $35 \mathrm{CO} 2-$ 460 showing negative flake scars, $6.3 \mathrm{x}$.

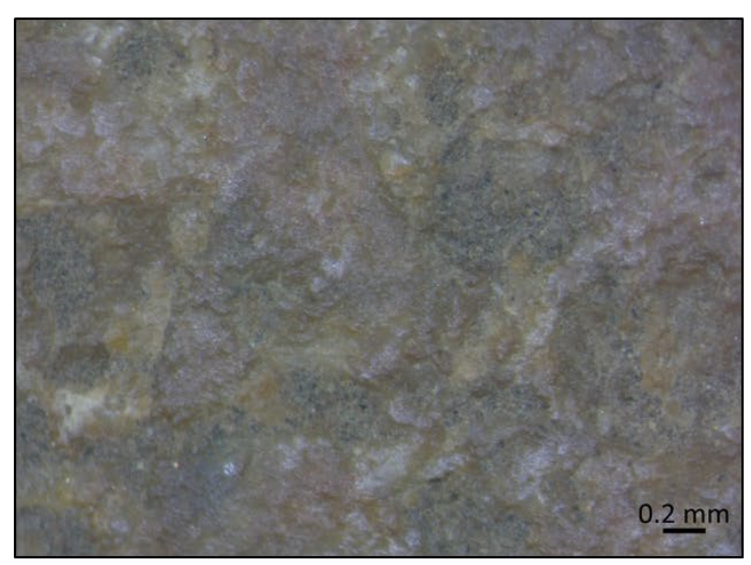

Photo 128. Photomicrograph showing grain rounding and polish on the shaft of tool $35 \mathrm{CO} 2-460,31.5 \mathrm{x}$. 


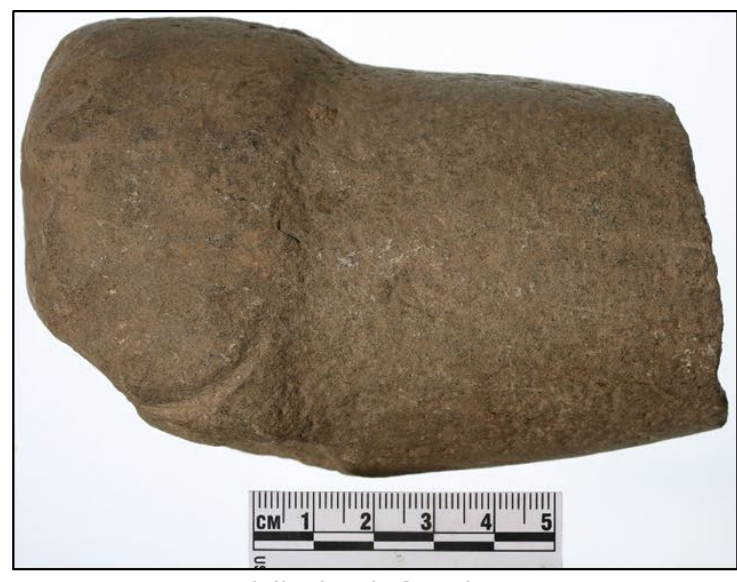

Photo 129. Fractured distal end of maul 35CO2-461.

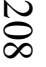

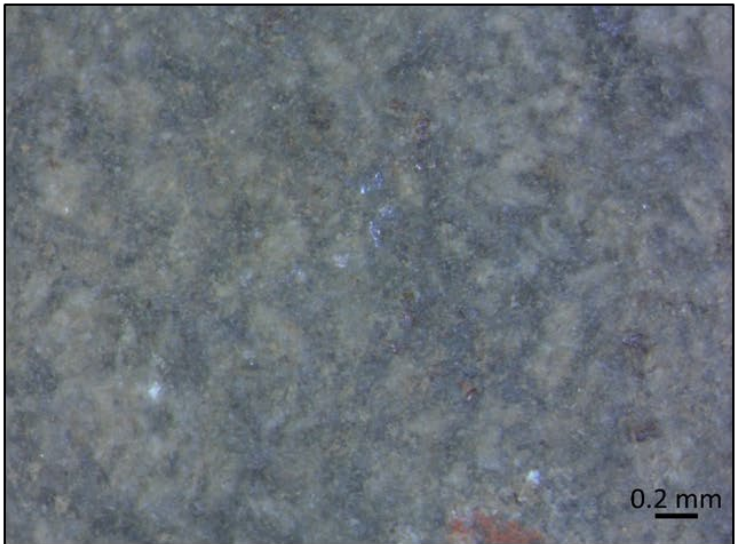

Photo 131. Photomicrograph of grain rounding and polish on the bit end of tool $35 \mathrm{CO} 2-462,31.5 \mathrm{x}$.

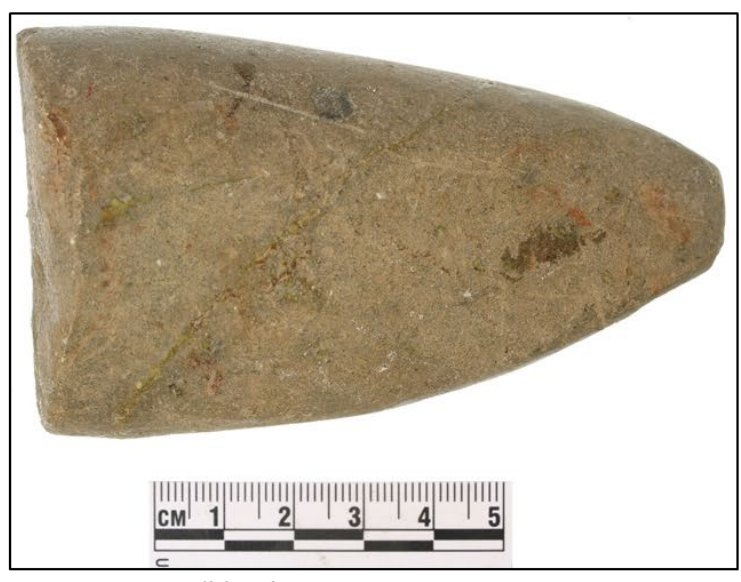

Photo 130. Possible adze 35CO2-462.

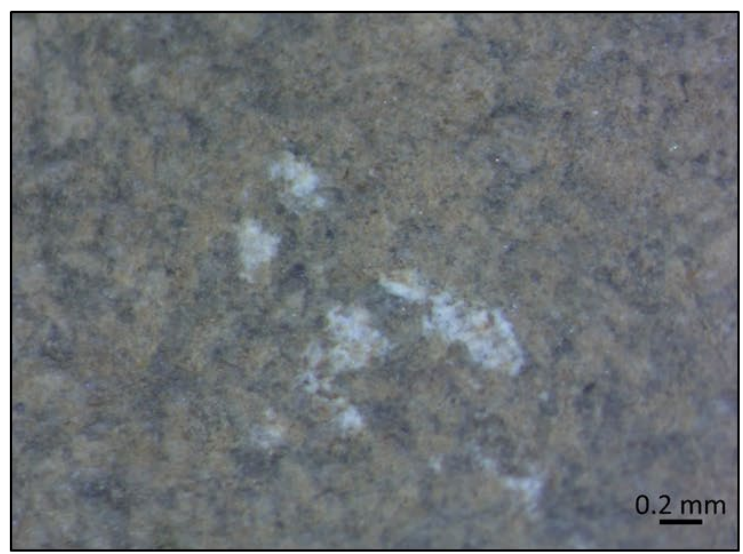

Photo 132. Photomicrograph of pitting and polish on shaft of tool $35 \mathrm{CO} 2-462,31.5 \mathrm{x}$. 


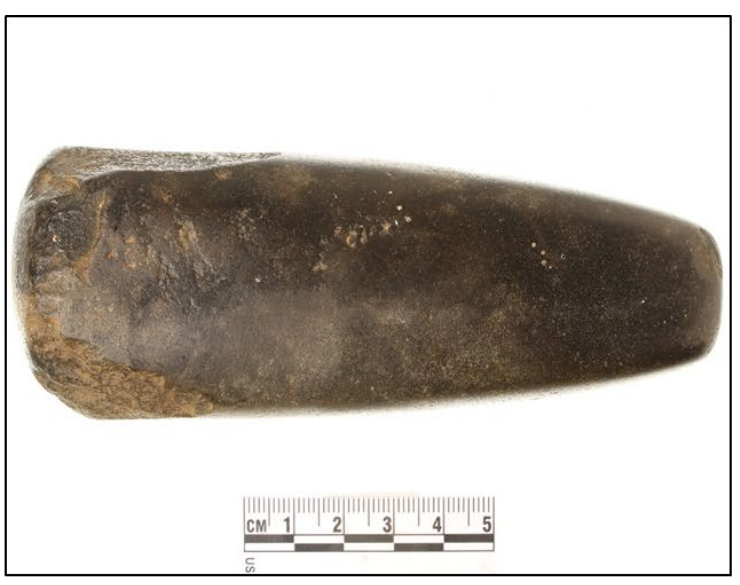

Photo 133. Pestle 35CO2-463.

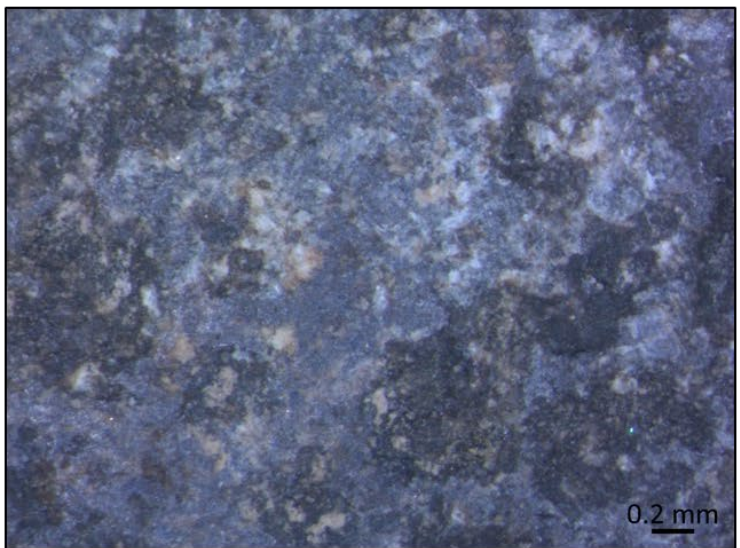

Photo 135. Photomicrograph of use wear on the distal end of tool 35CO2-463 showing grain rounding, $31.5 \mathrm{x}$.

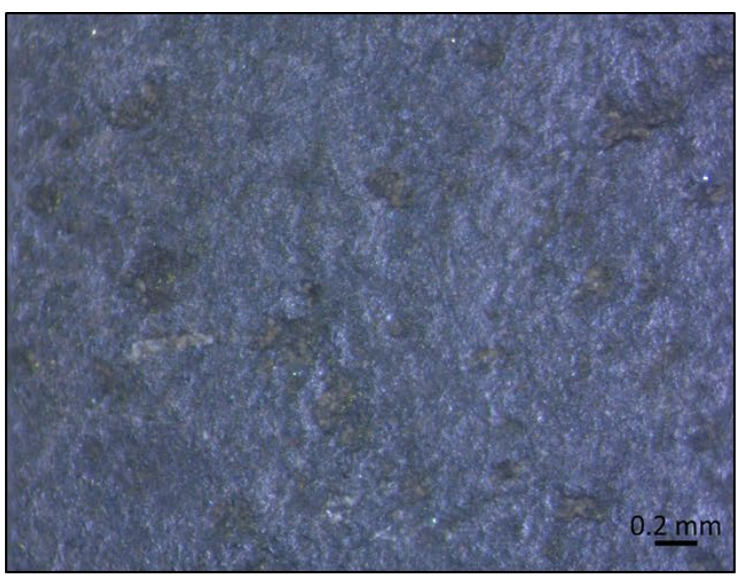

Photo 134. Photomicrograph of gouging and possible anvil use on shaft of 35CO2-463, 31.5x.

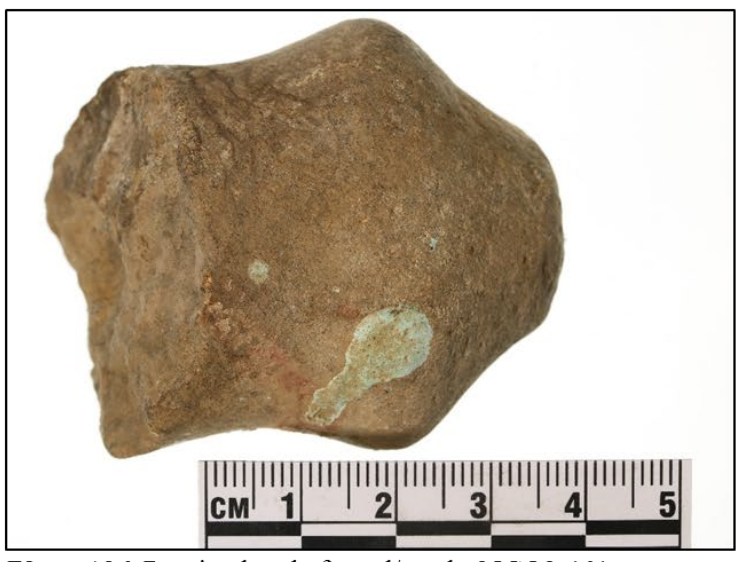

Photo 136. Proximal end of maul/pestle 35CO2-464. 


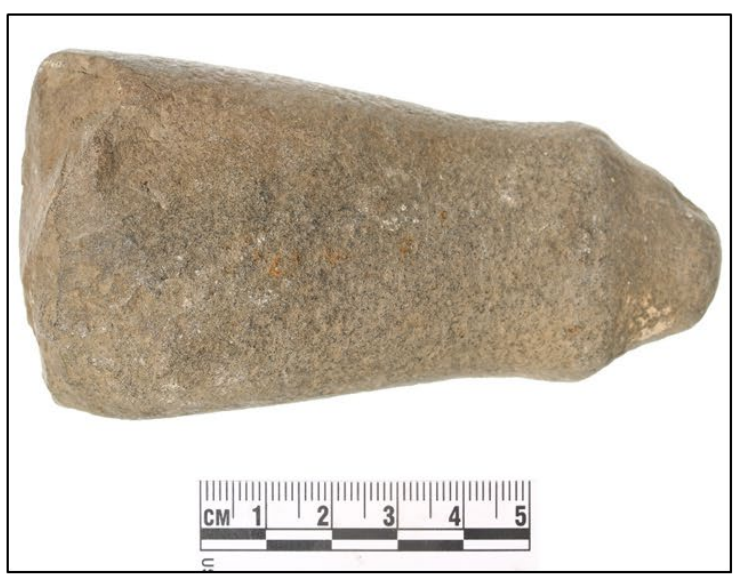

Photo 137. Maul/pestle 35CO2-465.

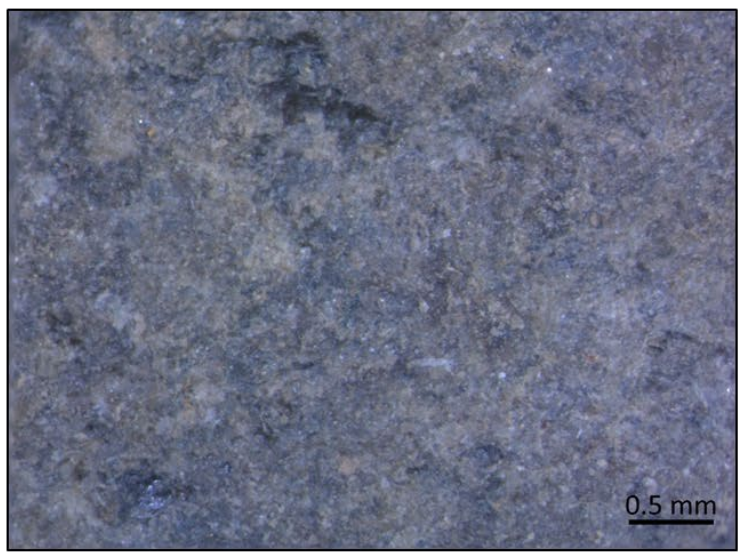

Photo 139. Photomicrograph of tool 35CO2-466 showing grain rounding and polish on shaft, $25.2 \mathrm{x}$.

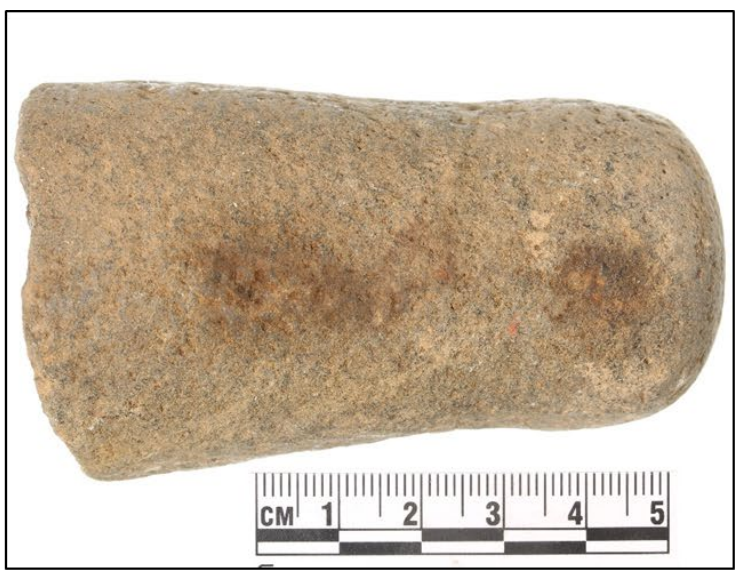

Photo 138. Maul/pestle 35CO2-466.

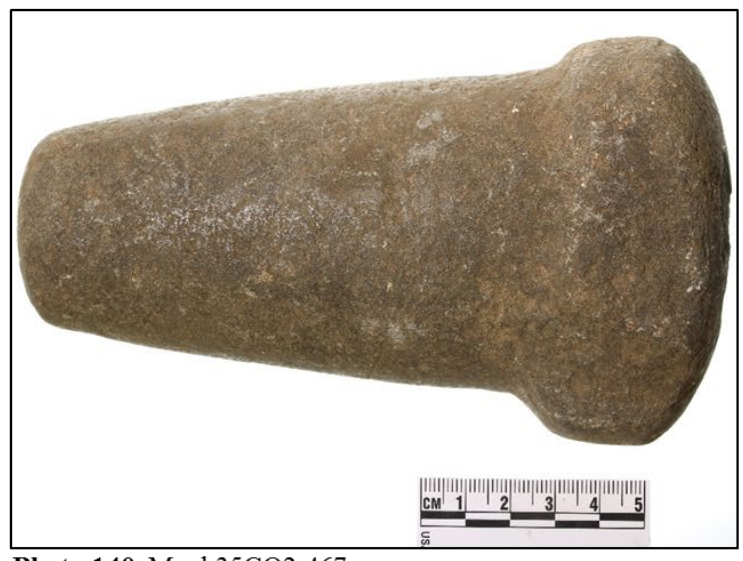

Photo 140. Maul 35CO2-467. 


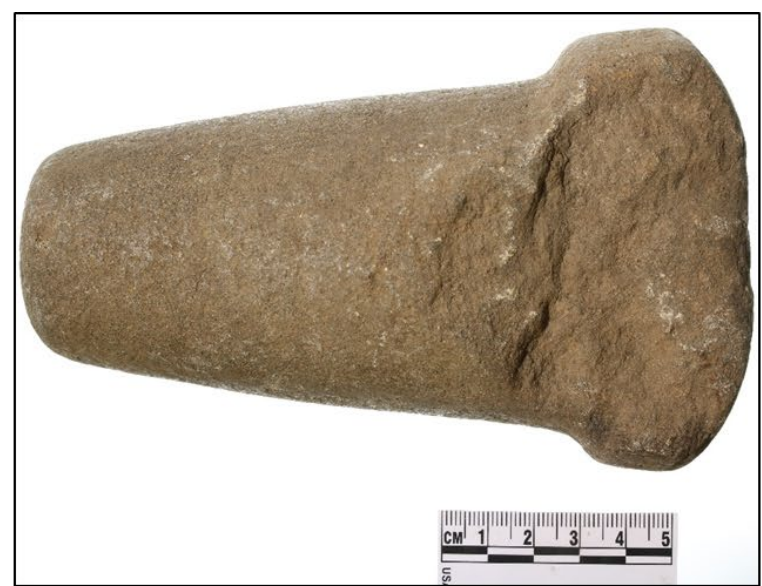

Photo 141. Maul 35CO2-467 showing fracture at distal end.

$\stackrel{N}{\Xi}$

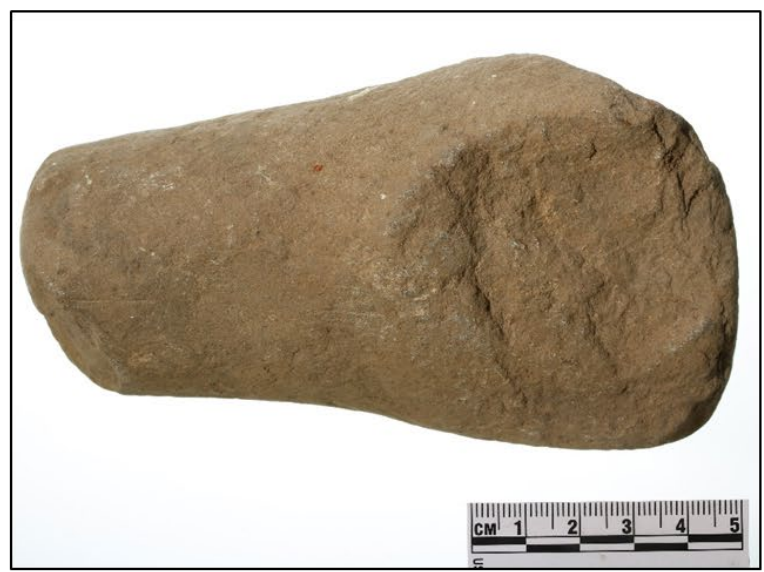

Photo 143. Distal end of fractured maul 35CO2-468.

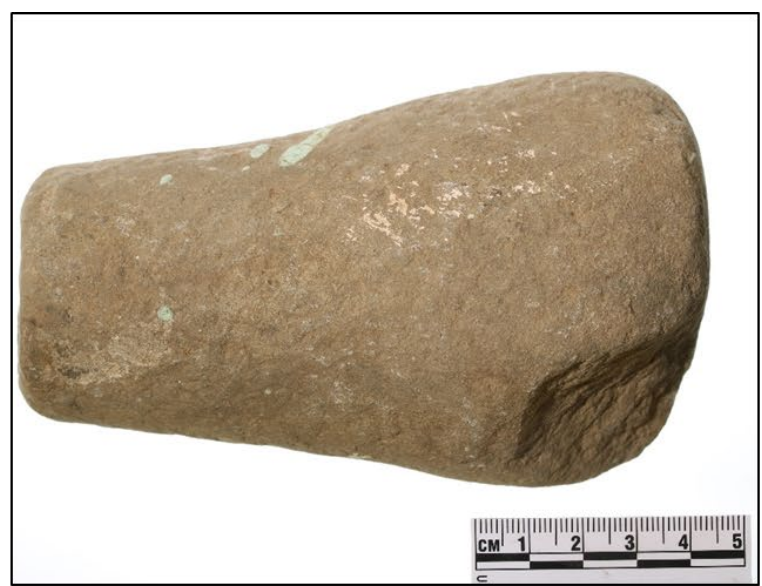

Photo 142. Distal end of fractured maul 35CO2-468

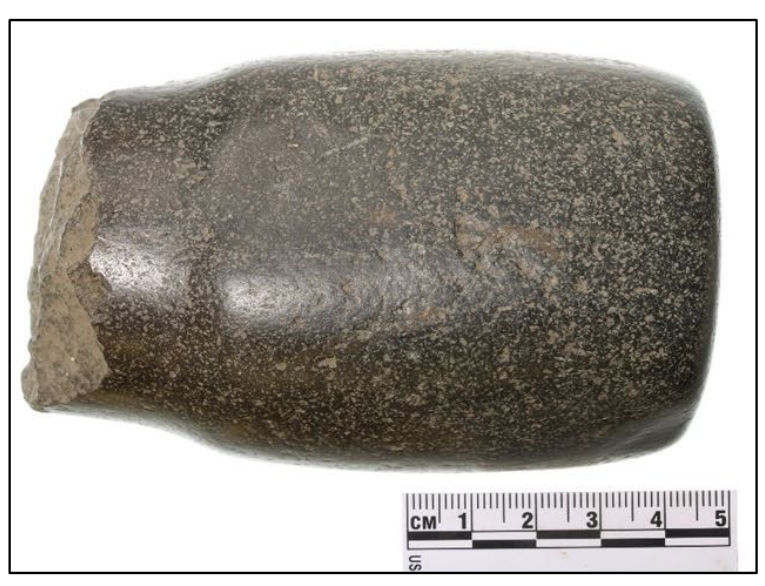

Photo 144. Distal end of fractured maul 35CO2-469. 


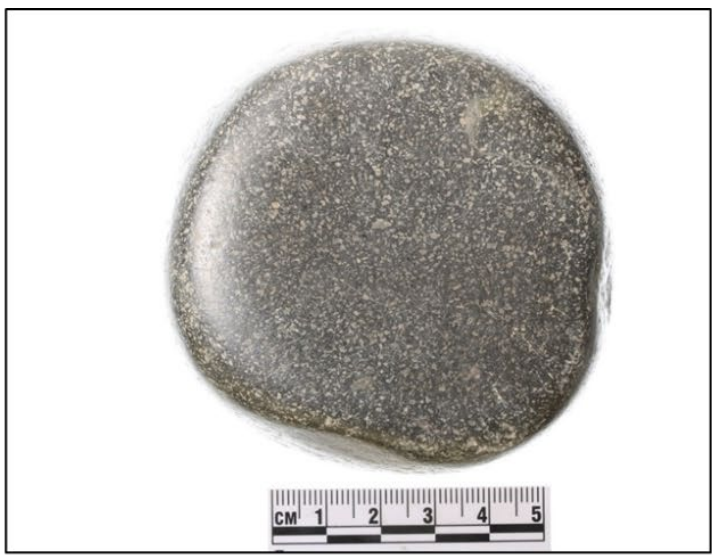

Photo 145. Distal working surface of maul 35CO2-469.

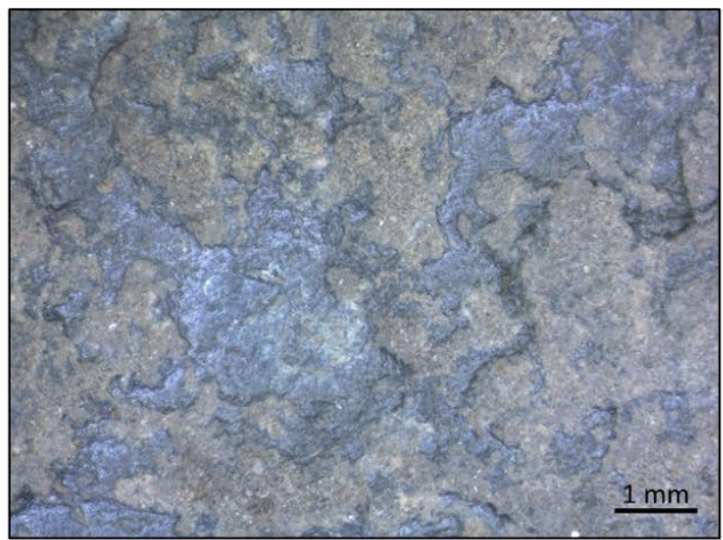

Photo 147. Photomicrograph of shaft of 35CO2-469 showing pitting and polish, $12.6 \mathrm{x}$.

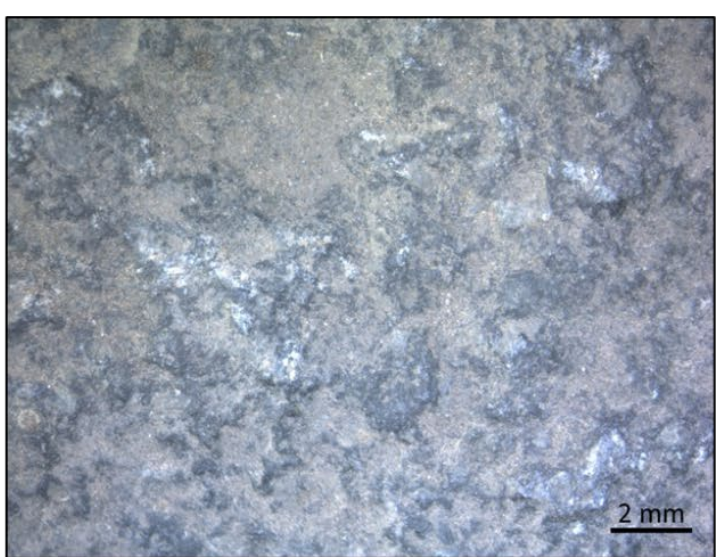

Photo 146. Photomicrograph of interior tool stone at break on $35 \mathrm{CO} 2-469,6.3 \mathrm{x}$.

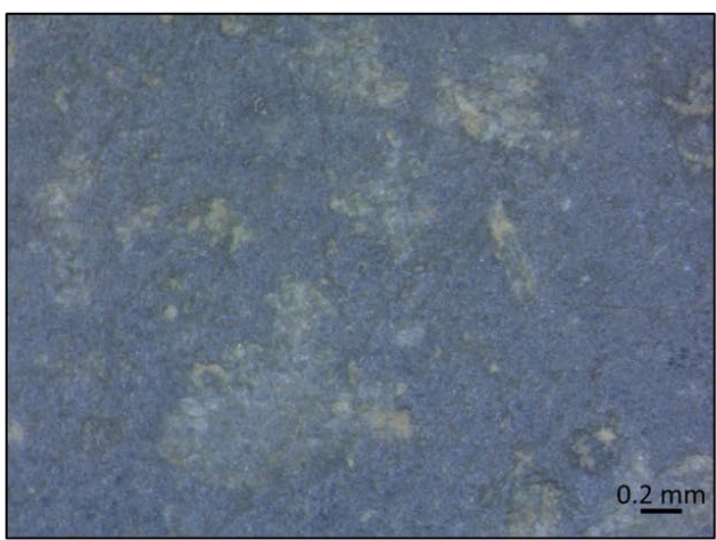

Photo 148. Photomicrograph of use wear on the distal end of tool 35CO2-469 showing grain rounding and little elevation difference, $31.5 \mathrm{x}$ 


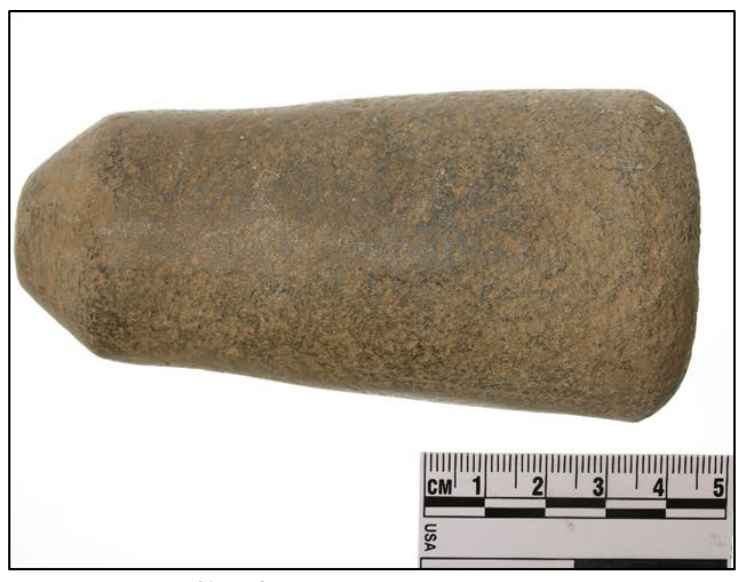

Photo 149. Maul/pestle 35CO2-470

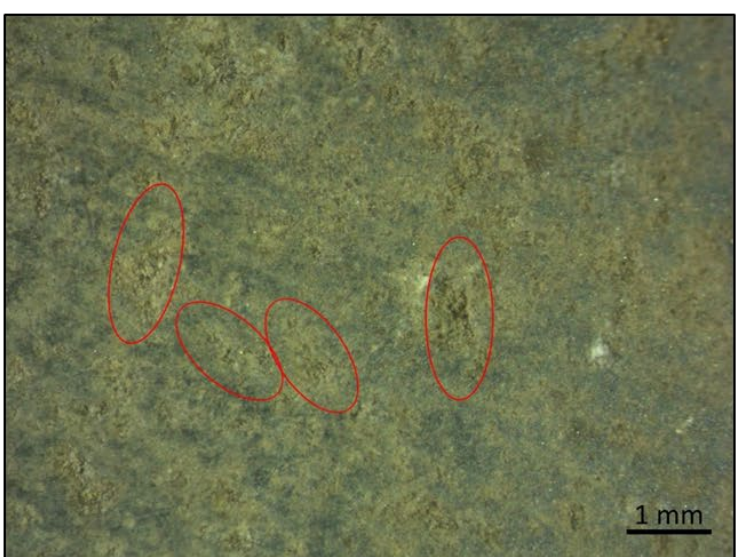

Photo 151. Photomicrograph of grain rounding and remnant chopper scars on the shaft of $35 \mathrm{CO} 2-470,12.6 \mathrm{x}$.

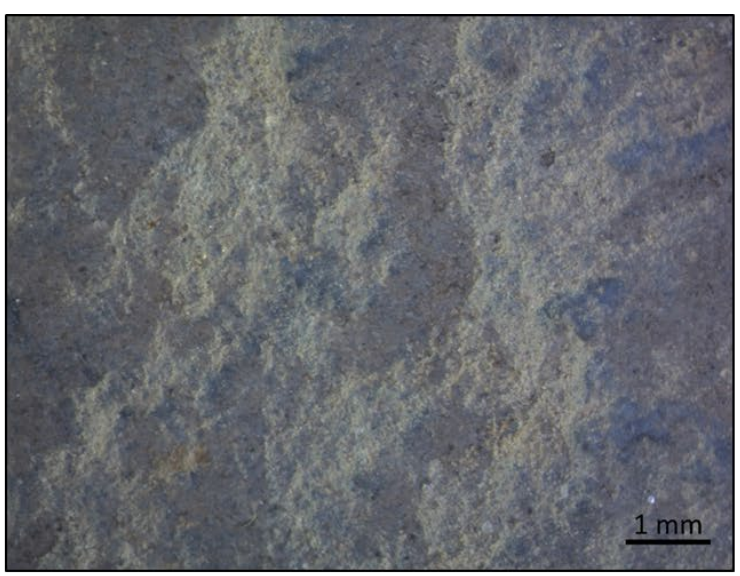

Photo 150. Photomicrograph of great elevation differences and light polish on asperities on distal end of tool $35 \mathrm{CO} 2-470$,

12.6x.

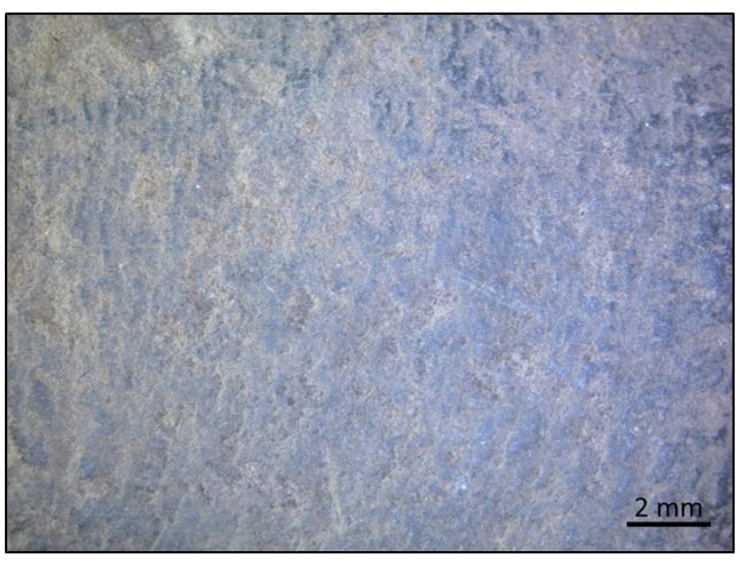

Photo 152. Photomicrograph of grain rounding and light polish at the proximal end of tool $35 \mathrm{CO} 2-470,6.3 \mathrm{x}$. 


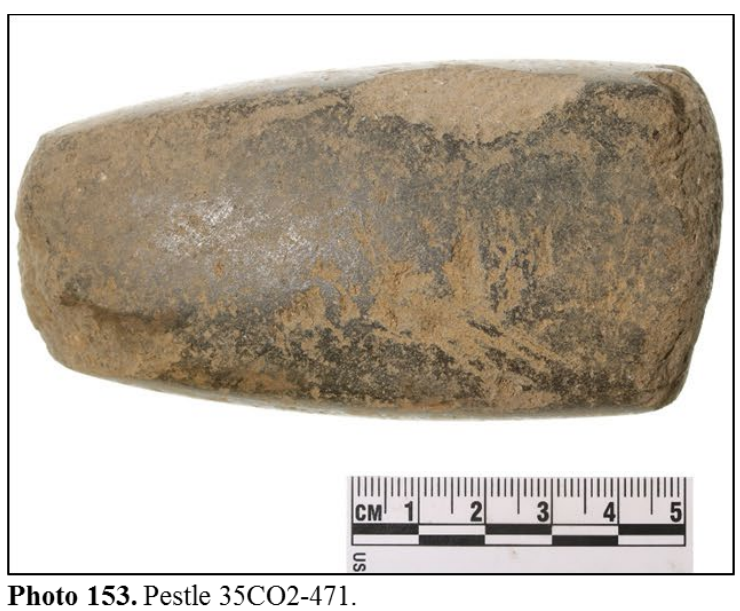

$\stackrel{N}{+}$

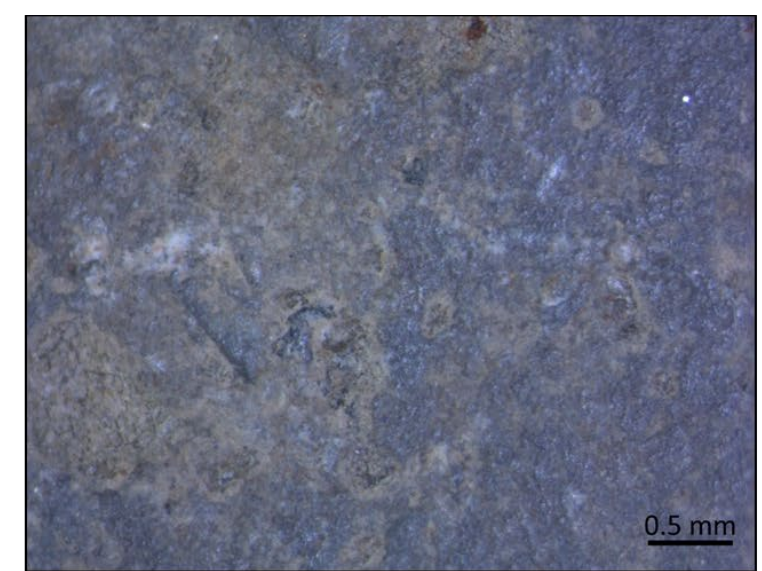

Photo 154. Photomicrograph of concentrated pitting on the shaft of pestle $35 \mathrm{CO} 2-471,25.2 \mathrm{x}$.

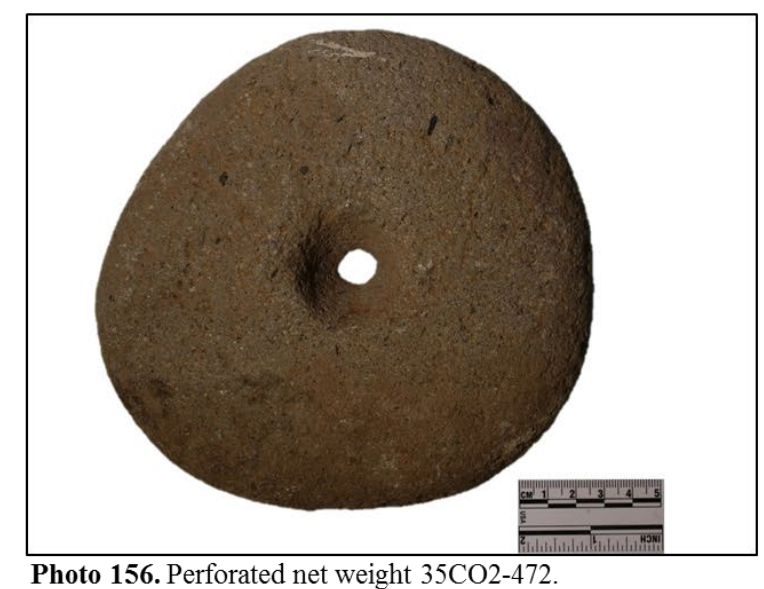

Photo 156. Perforated net weight 35CO2-472.
Photo 155. Photomicrograph of distal end of tool 35CO2-471 showing grain rounding and great elevation differences, $12.6 \mathrm{x}$.

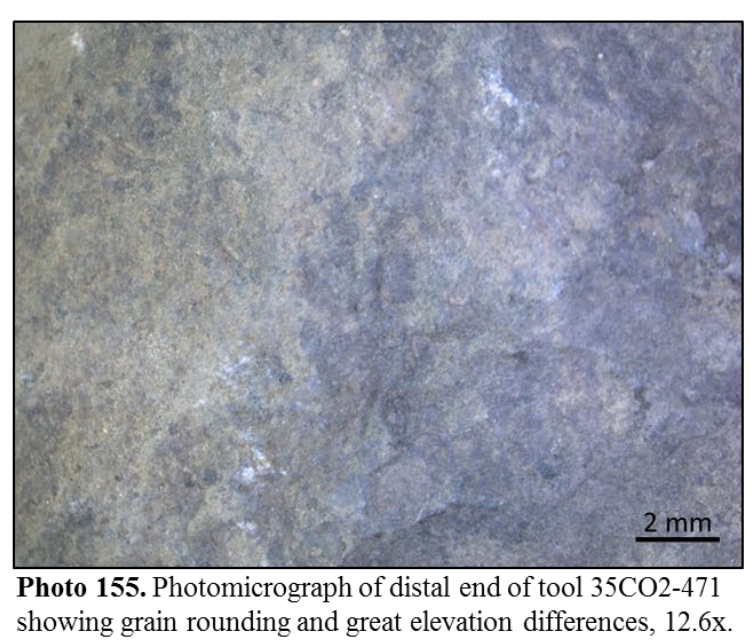




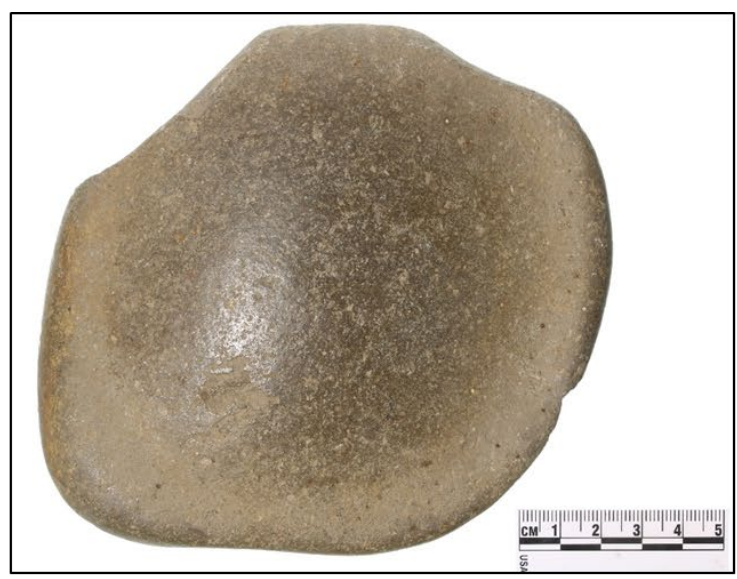

Photo 157. Undetermined object 35CO2-473.

U

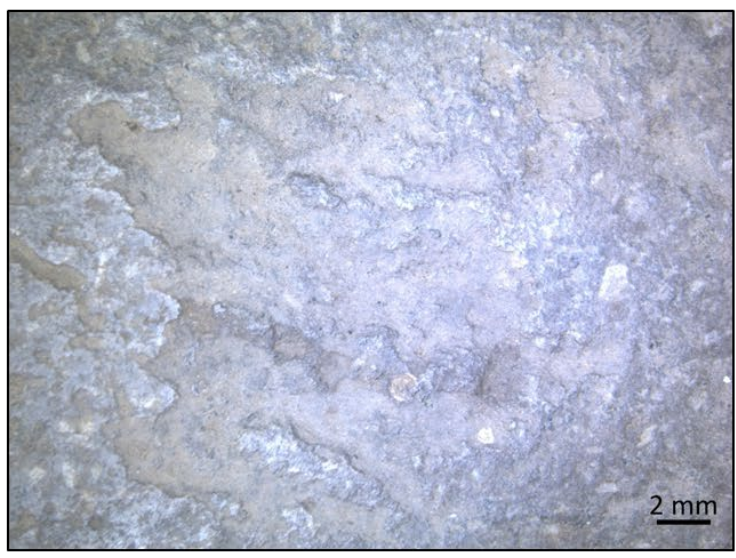

Photo 159. Photomicrograph of concentrated pitting and polish on the convex surface of tool 35CO2-473, 4.095x.

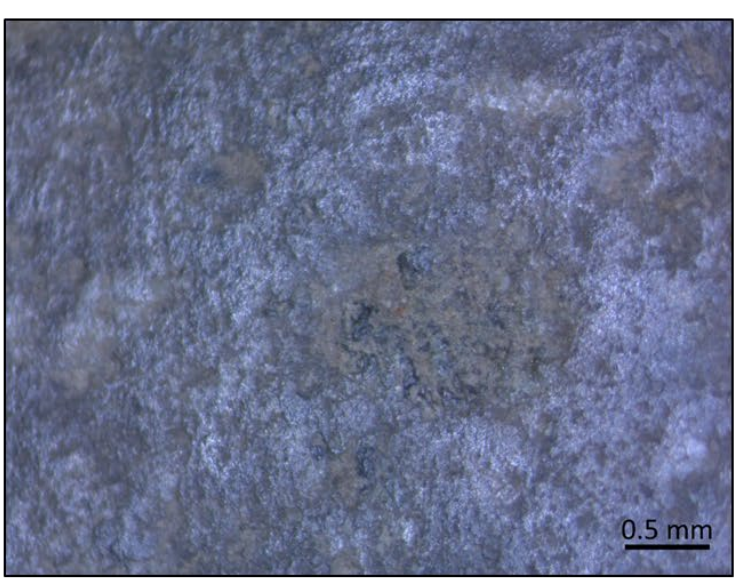

Photo 158. Photomicrograph of polish on the convex surface of tool $35 \mathrm{CO} 2-473,25.2 \mathrm{x}$

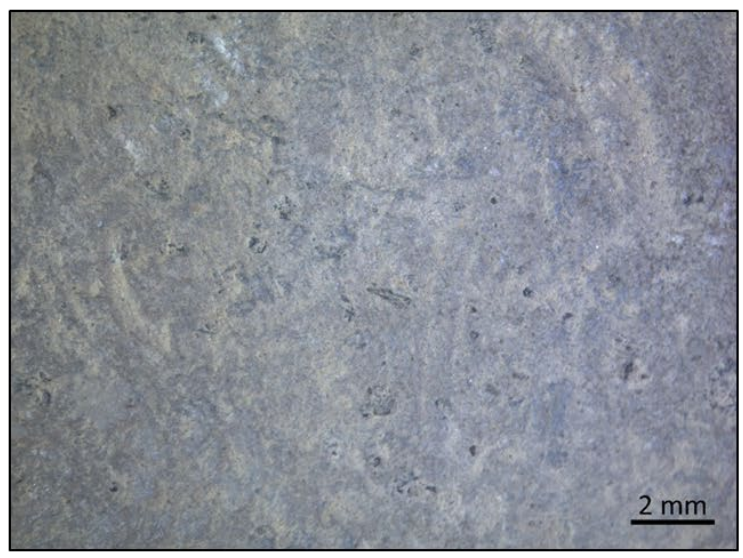

Photo 160. Photomicrograph of striations and gouging on the flat surface of tool $35 \mathrm{CO} 2-473,6.3 \mathrm{x}$ 


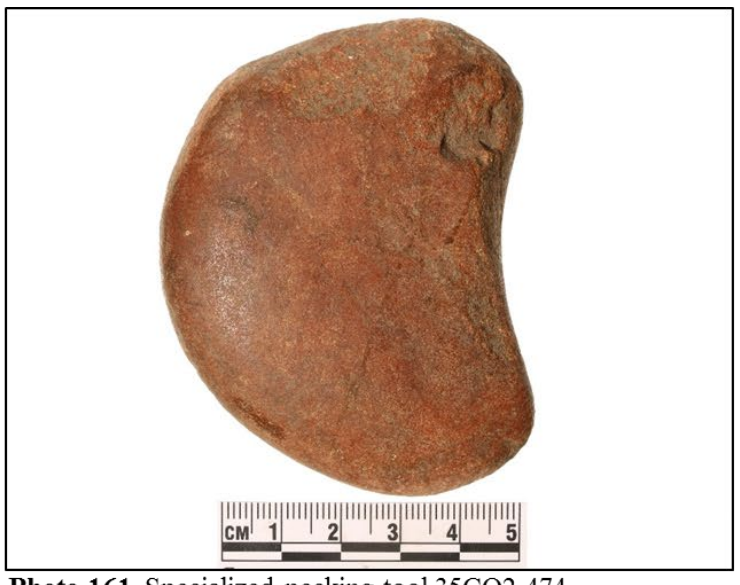

Photo 161. Specialized pecking tool 35CO2-474.

$\frac{N}{\sigma}$

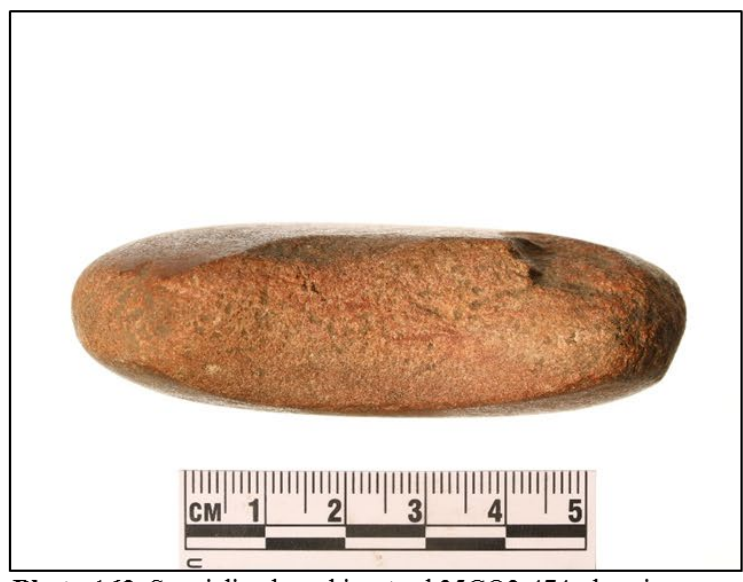

Photo 162. Specialized pecking tool 35CO2-474 showing use wear along the pebble periphery.

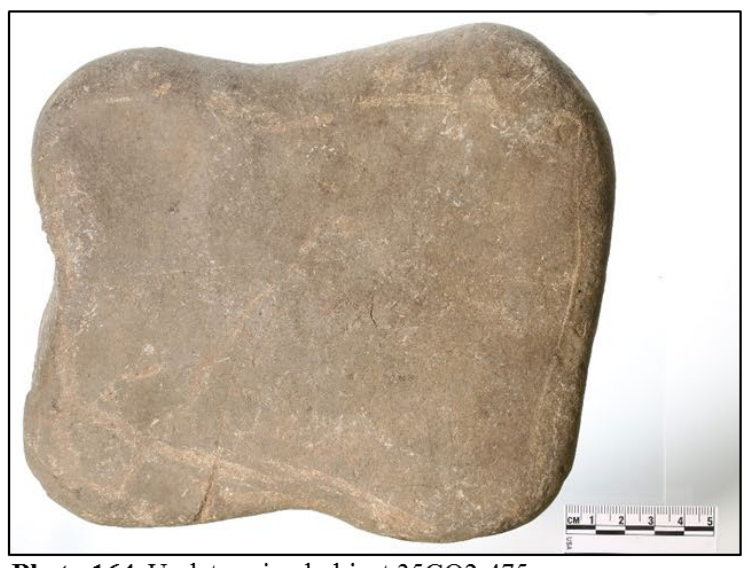

Photo 164. Undetermined object 35CO2-475.

wear along pebble periphery.

||||||||||||||||||||||||||||||||||||||||||||||||||||

$$
\begin{array}{ll|l|l|l|l|l|l|}
\mathrm{CM} & 1 & 2 & 3 & 4 & 5 \\
\hline
\end{array}
$$




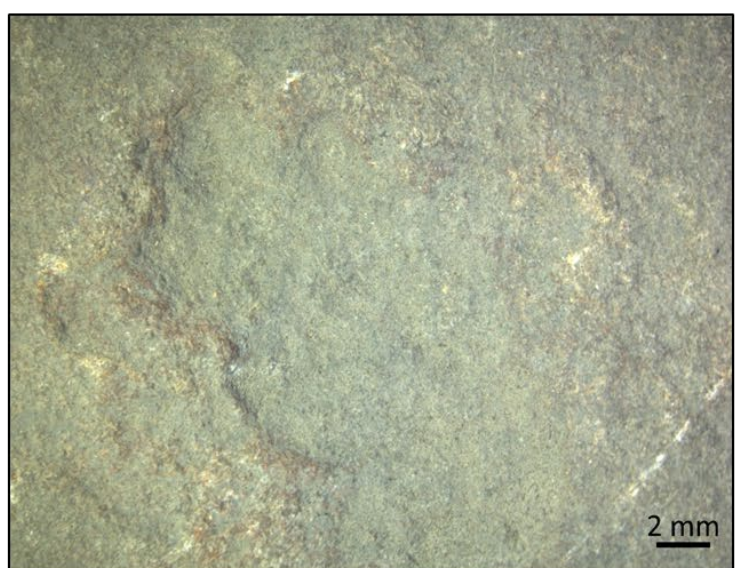

Photo 165. Photomicrograph of pitting and striations on tool $35 \mathrm{CO} 2-475,4.095 \mathrm{x}$

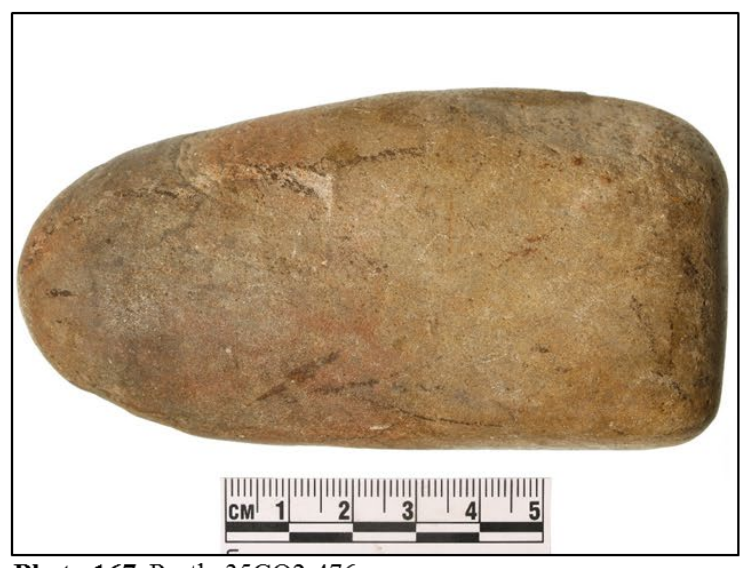

Photo 167. Pestle 35CO2-476.

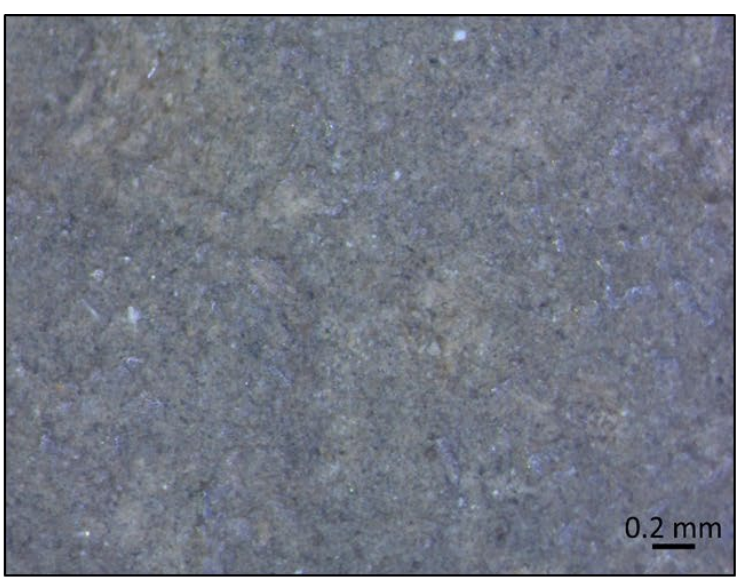

Photo 166. Photomicrograph of grain rounding and polish from the circular depression on tool $35 \mathrm{CO} 2-475,31.5 \mathrm{x}$.

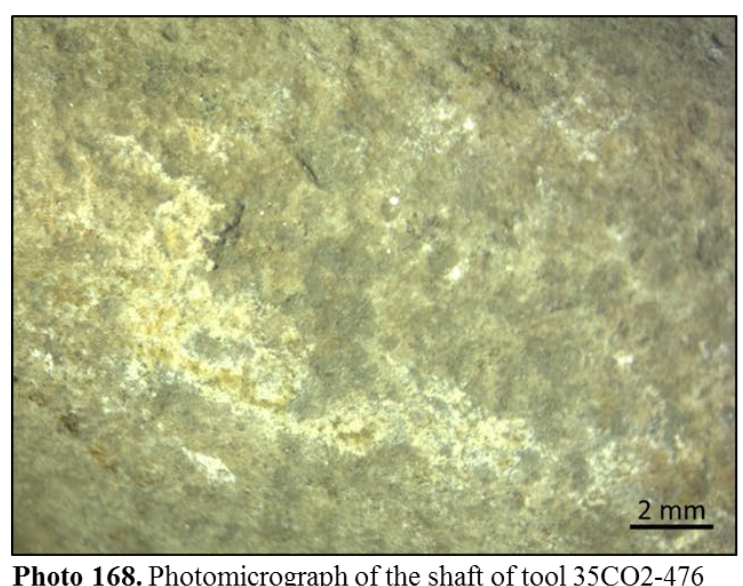

Photo 168. Photomicrograph of the shaft of tool 35CO2-476 showing great elevation differences and grain crushing, $6.3 \mathrm{x}$. 


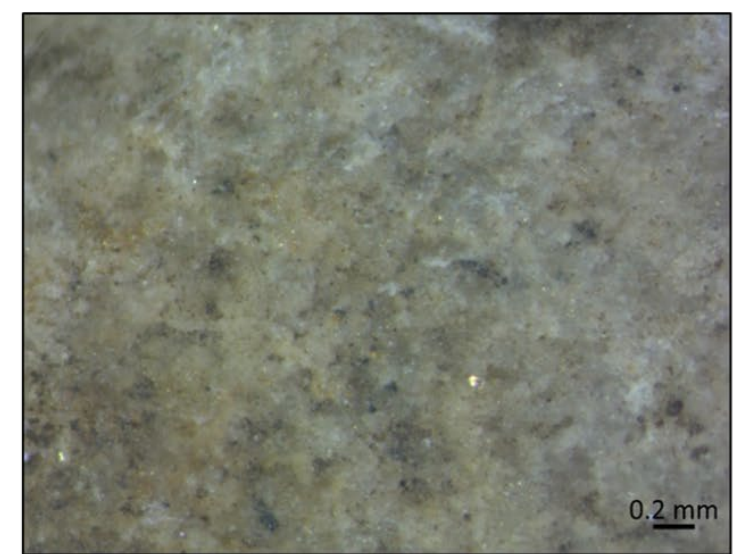

Photo 169. Photomicrograph of the distal end of tool 35CO2476 showing grain crushing, $31.5 \mathrm{x}$.

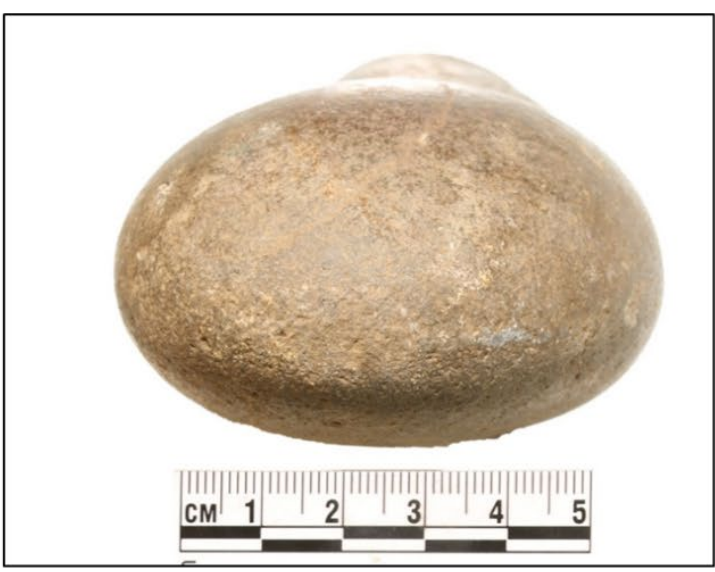

Photo 171. Use wear on distal end of tool 35CO2-477 showing facet and concentrated pitting.

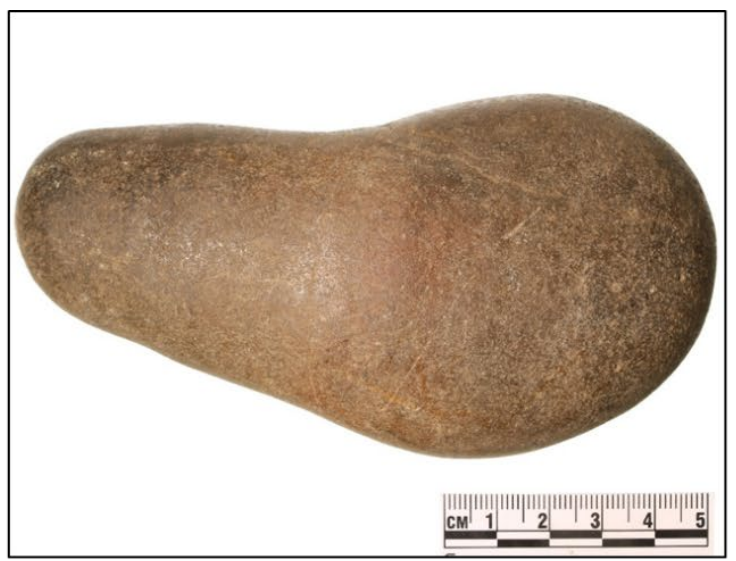

Photo 170. Hammer stone 35CO2-477.

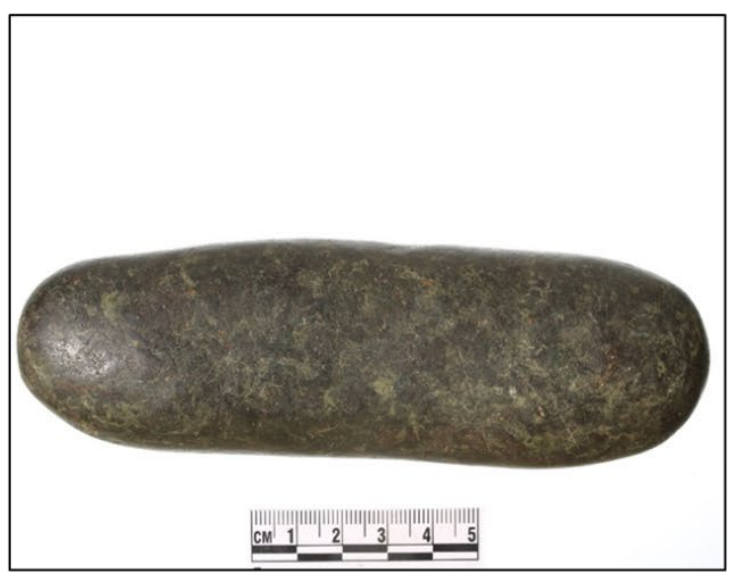

Photo 172. Manuport 35CO2-478 


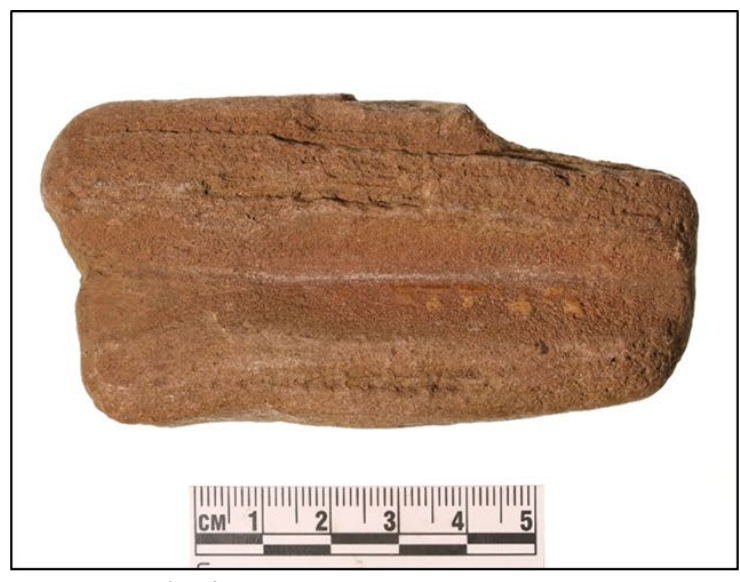

Photo 173. Abrader 35CO2-479.

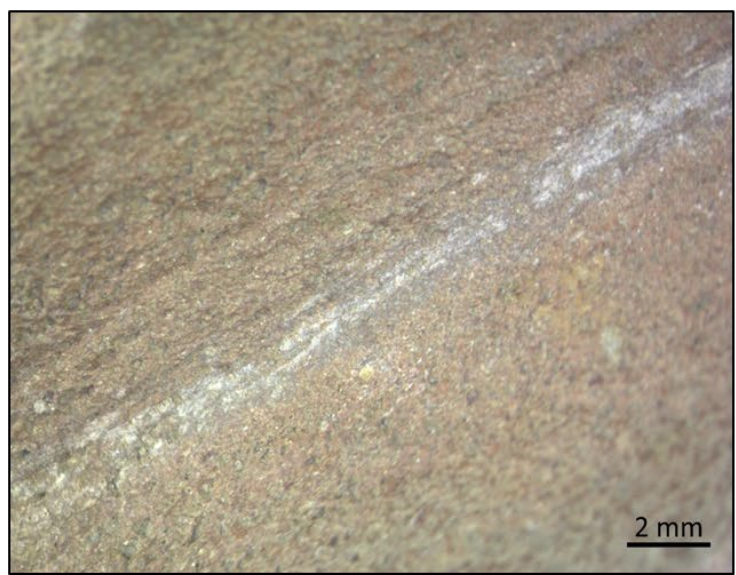

Photo 175. Photomicrograph of the grooved surface of tool $35 \mathrm{CO} 2-479,6.3 \mathrm{x}$.

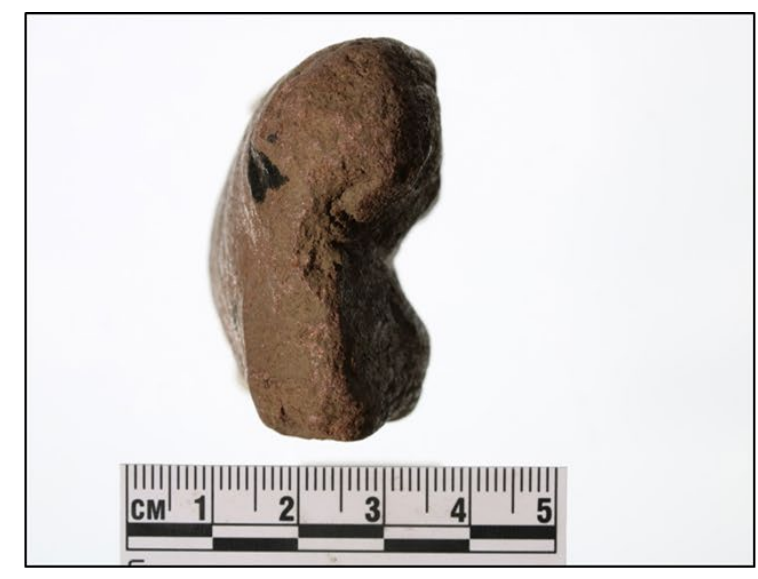

Photo 174. Abrader 35CO2-479.

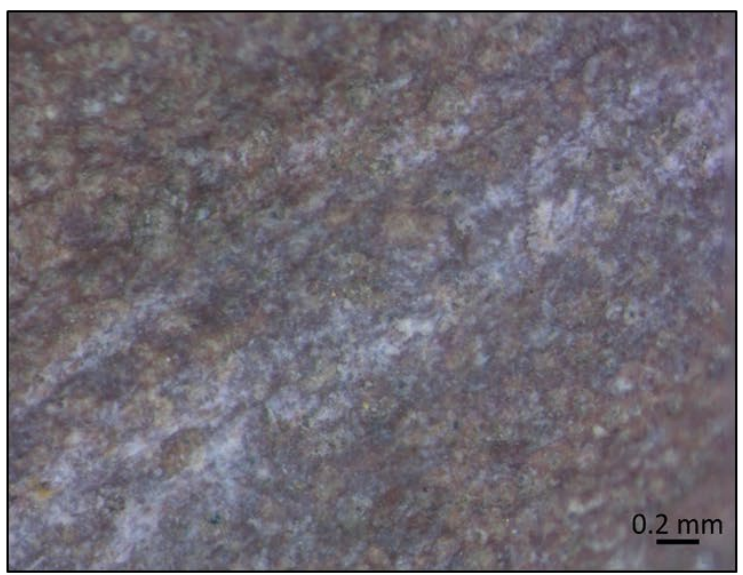

Photo 176. Photomicrograph of the grooved surface of tool $35 \mathrm{CO} 2-479,31.5 \mathrm{x}$ 


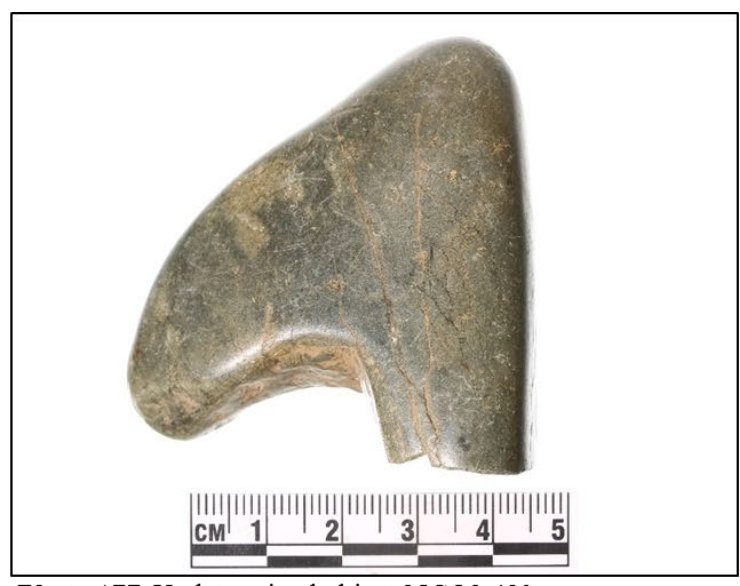

Photo 177. Undetermined object 35CO2-480.

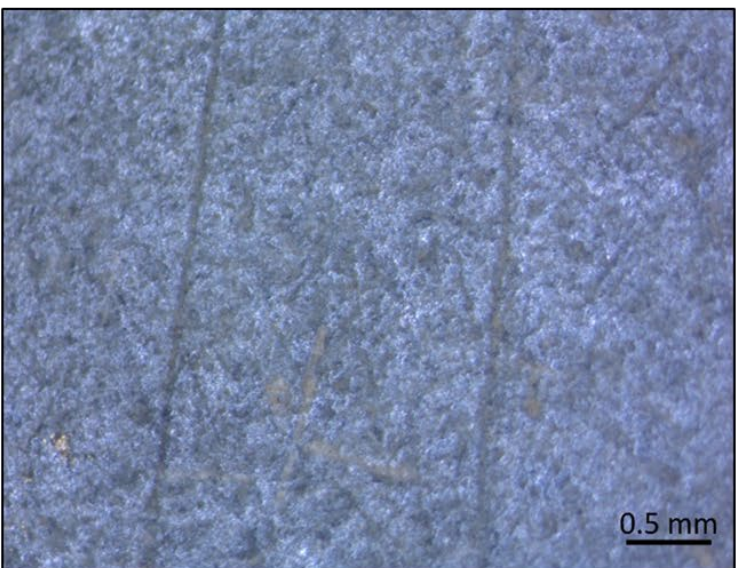

Photo 179. Photomicrograph of striations and polish on the flat surface of $35 \mathrm{CO} 2-480,25.2 \mathrm{x}$.

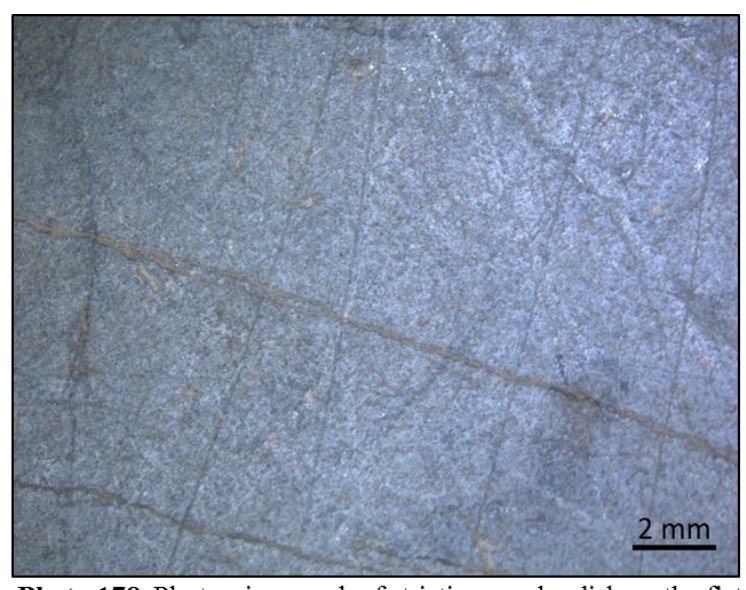

Photo 178. Photomicrograph of striations and polish on the flat surface of $35 \mathrm{CO} 2-480,6.3 \mathrm{x}$.

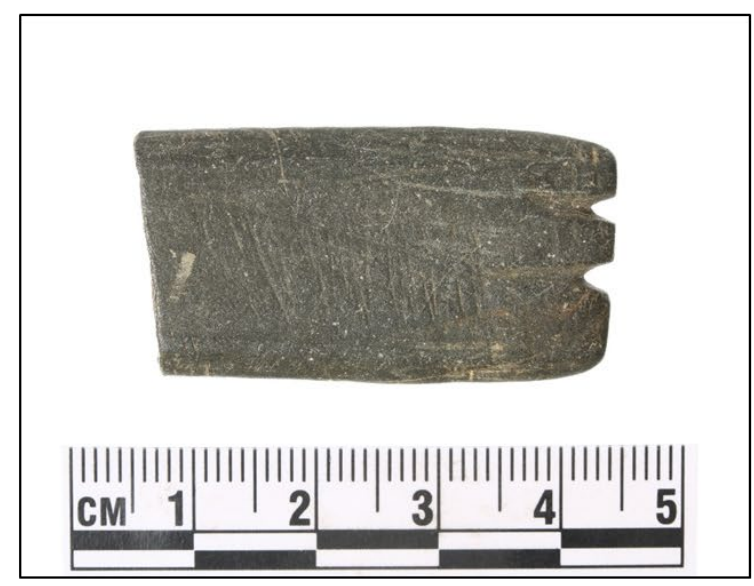

Photo 180. Undetermined object 35CO2-481. 


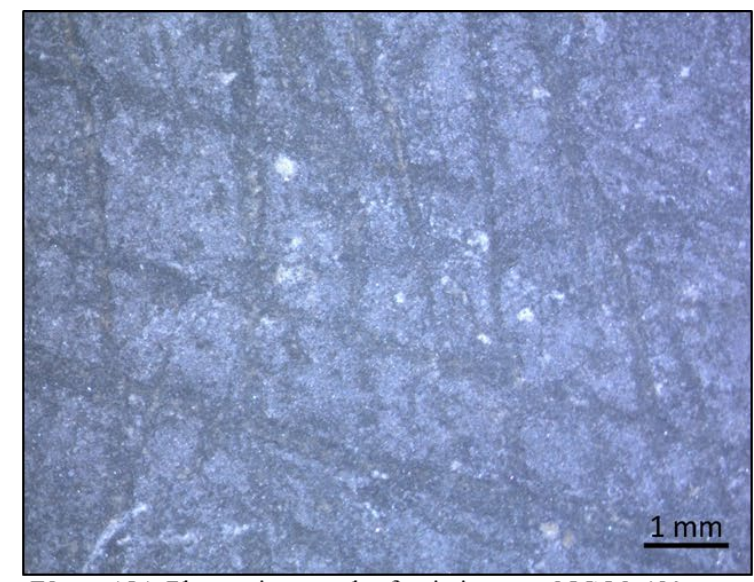

Photo 181. Photomicrograph of striations on 35CO2-481, 12.6x.

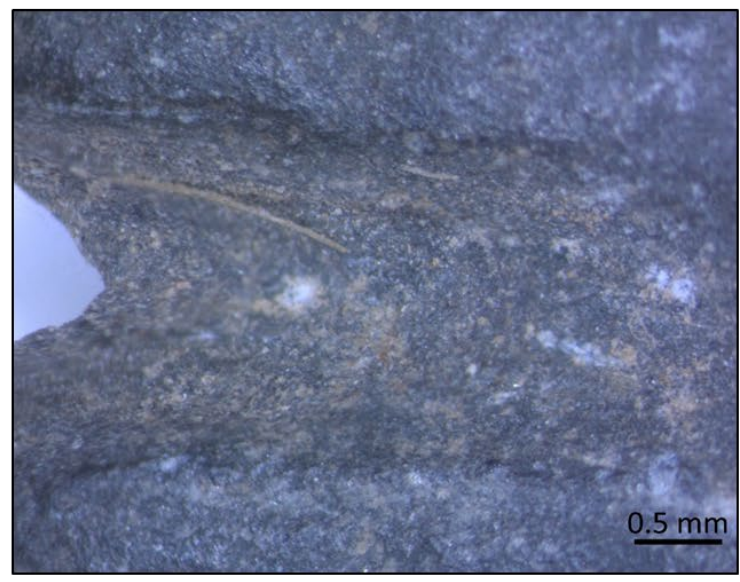

Photo 183. Photomicrograph of striations and groove on $35 \mathrm{CO} 2-481,25.2 \mathrm{x}$.

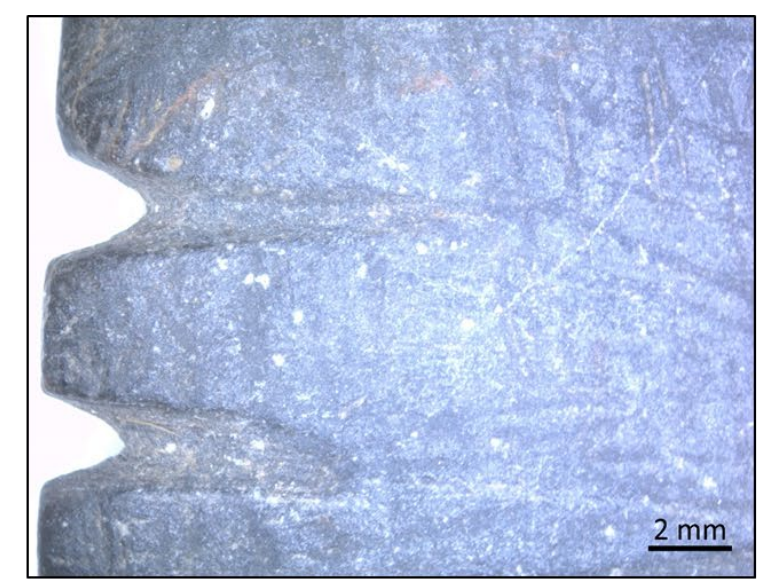

Photo 182. Photomicrograph of striations and grooves on $35 \mathrm{CO} 2-481,6.3 \mathrm{x}$.

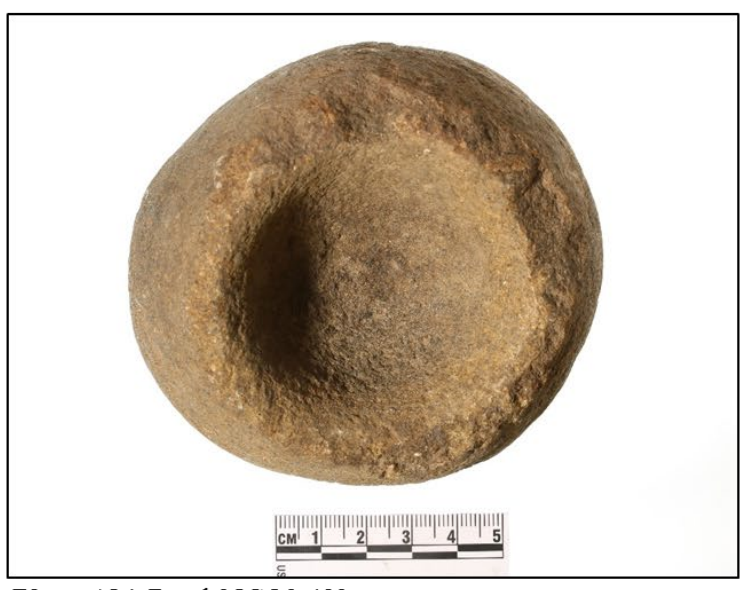

Photo 184. Bowl 35CO2-482. 


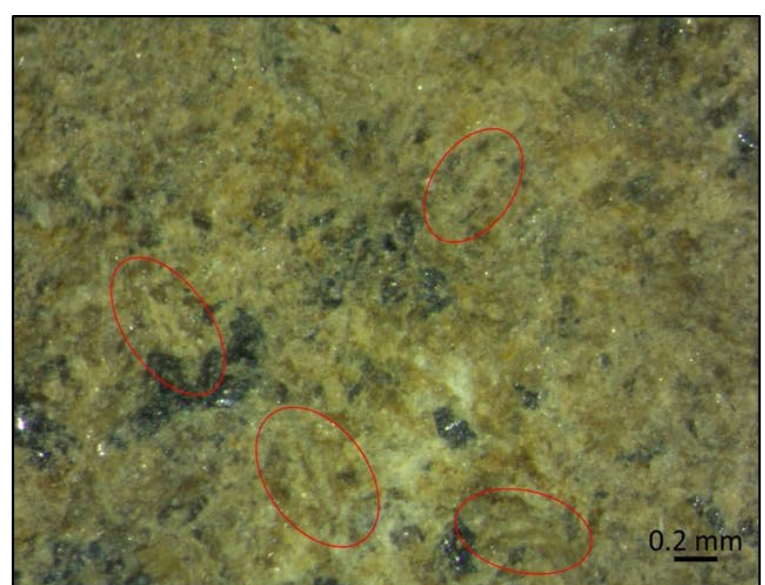

Photo 185. Photomicrograph of the base of bowl 35CO2-482 showing remnant chopper scars, $31.5 \mathrm{x}$.

N

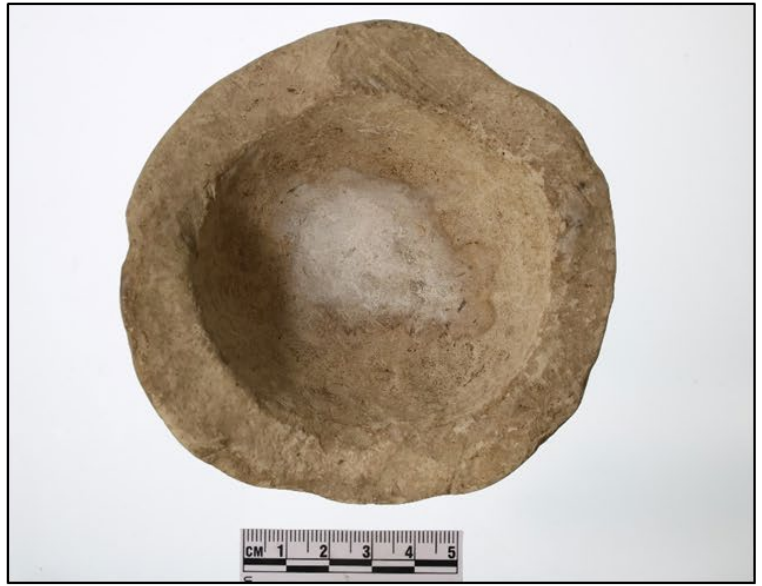

Photo 187. Bowl 35CO2-483.

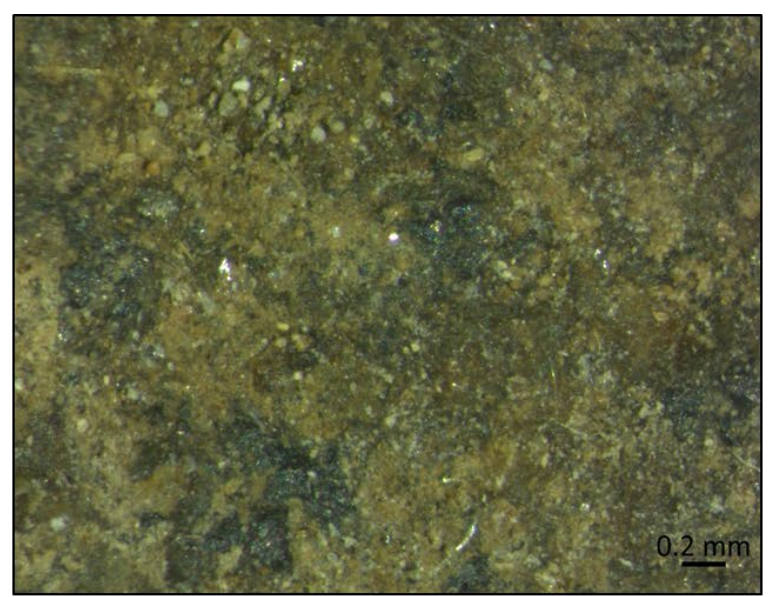

Photo 186. Photomicrograph of basin showing polish and grain rounding on bowl 35CO2-482, 31.5x.

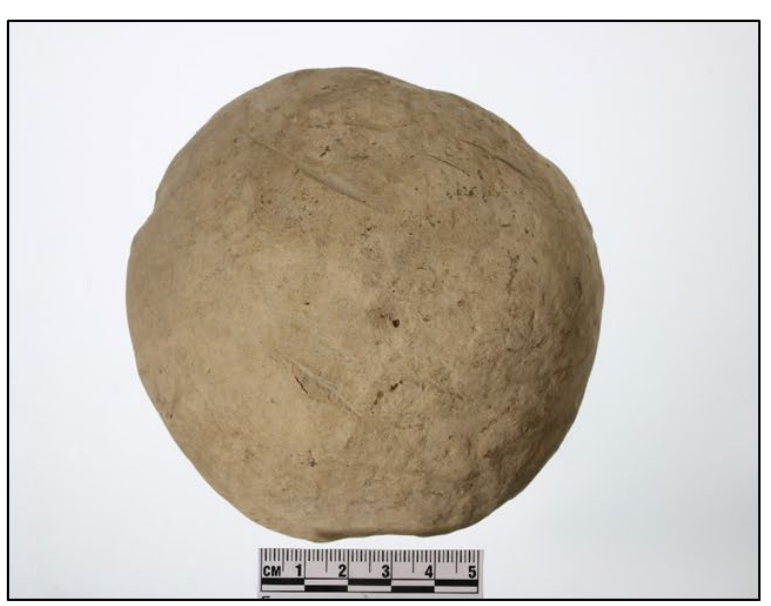

Photo 188. Base of bowl 35CO2-483. 


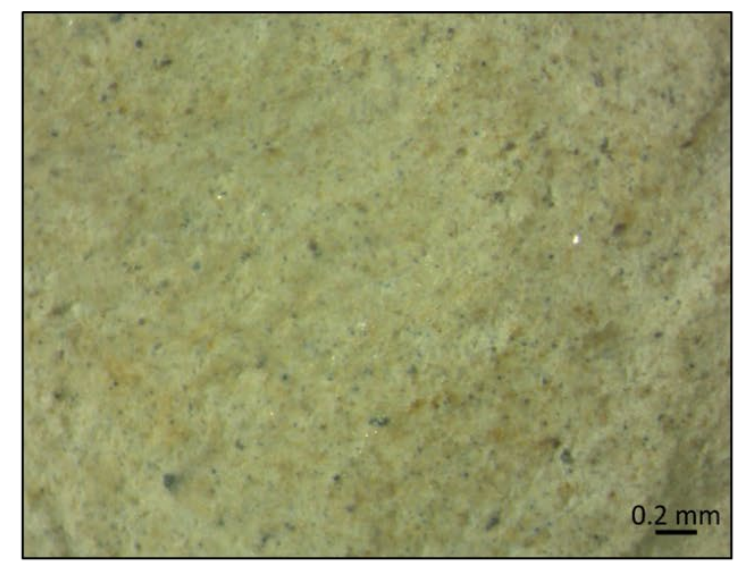

Photo 189. Photomicrograph of the base of bowl 35CO2-483 showing sharp asperities and possible post-depositional damage, $31.5 \mathrm{x}$.

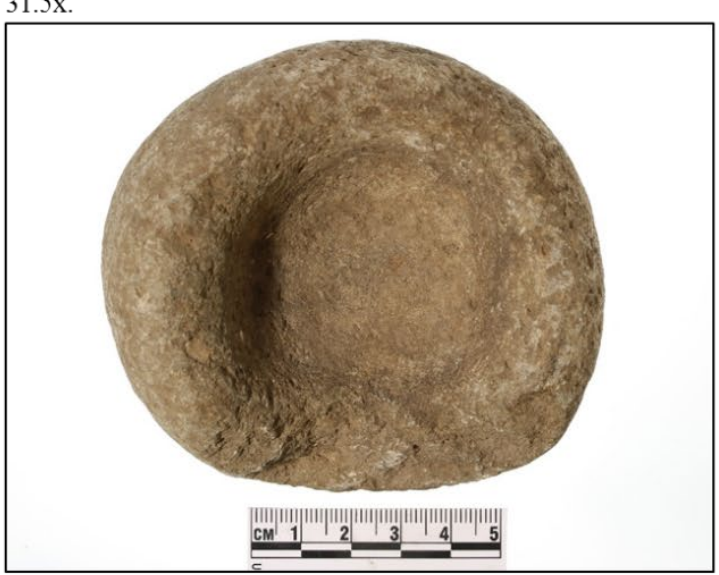

Photo 191. Bowl 35CO2-484.

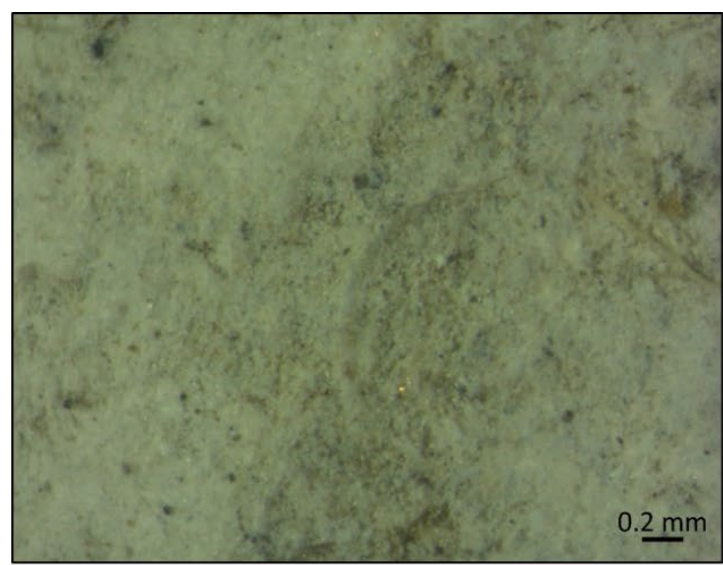

Photo 190. Photomicrograph of basin showing grain rounding and little elevation difference, $31.5 \mathrm{x}$.

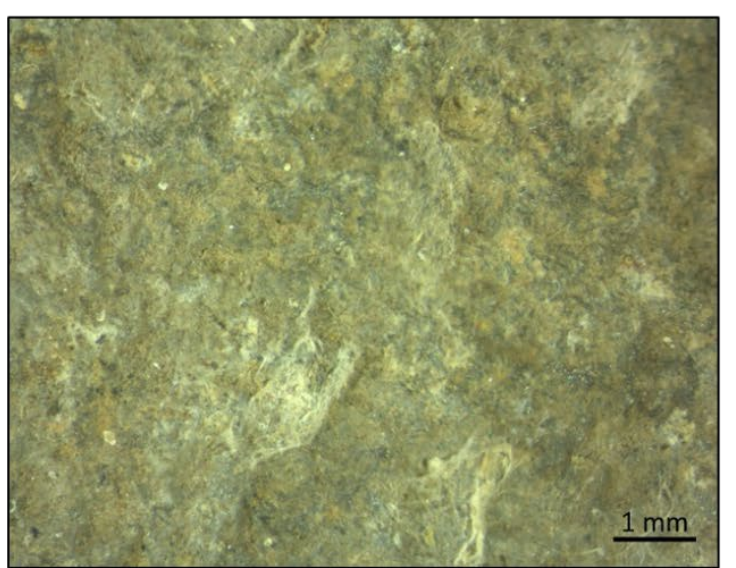

Photo 192. Photomicrograph of the unmodified base of bowl $35 \mathrm{CO} 2-484$ showing sharp asperities and great elevation differences, 12.6x. 


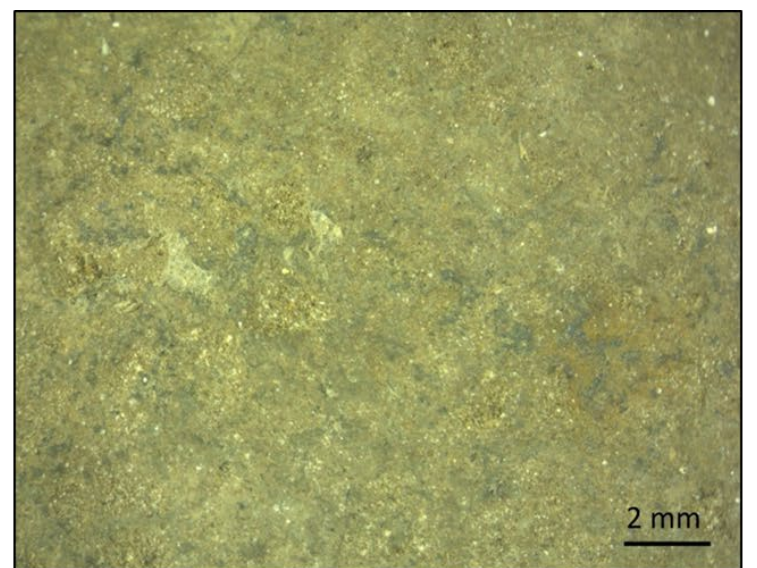

Photo 193. Photomicrograph of the basin of bowl 35CO2-484

showing rounded grains and polish, $6.3 \mathrm{x}$.

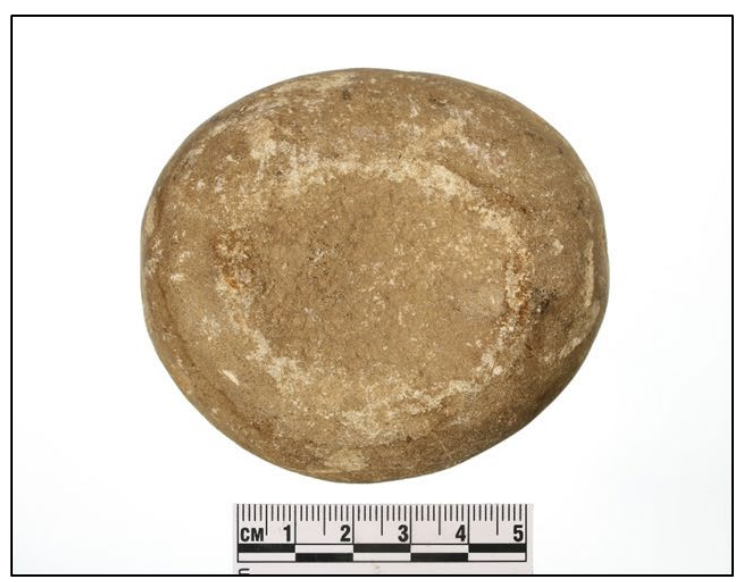

Photo 195. Base of bowl 35CO2-485.

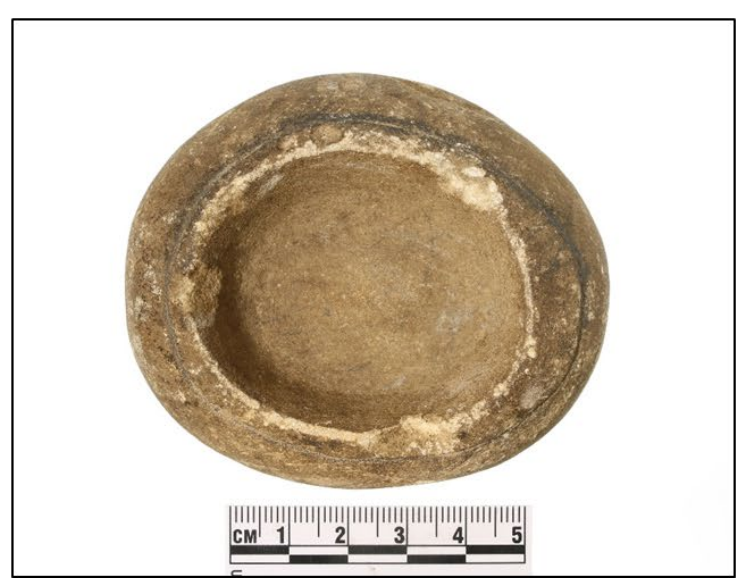

Photo 194. Bowl 35CO2-485.

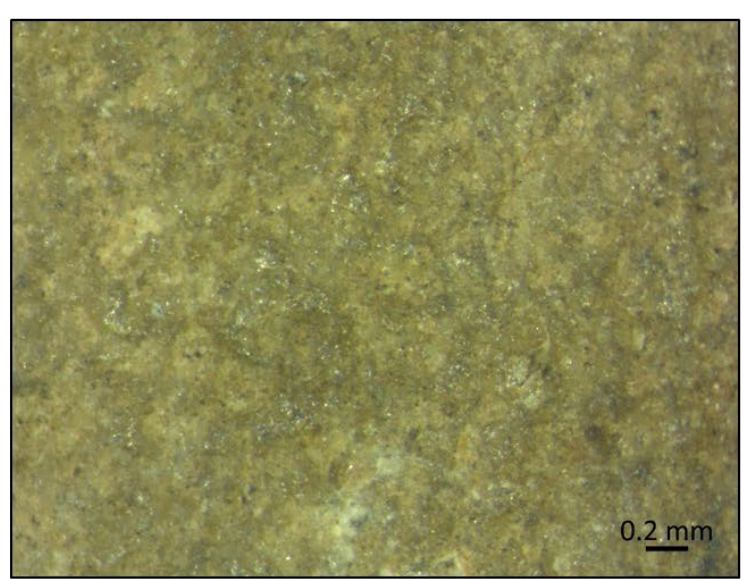

Photo 196. Photomicrograph of the basin of bowl 35CO2-485 showing rounded grains and polish, $31.5 \mathrm{x}$. 


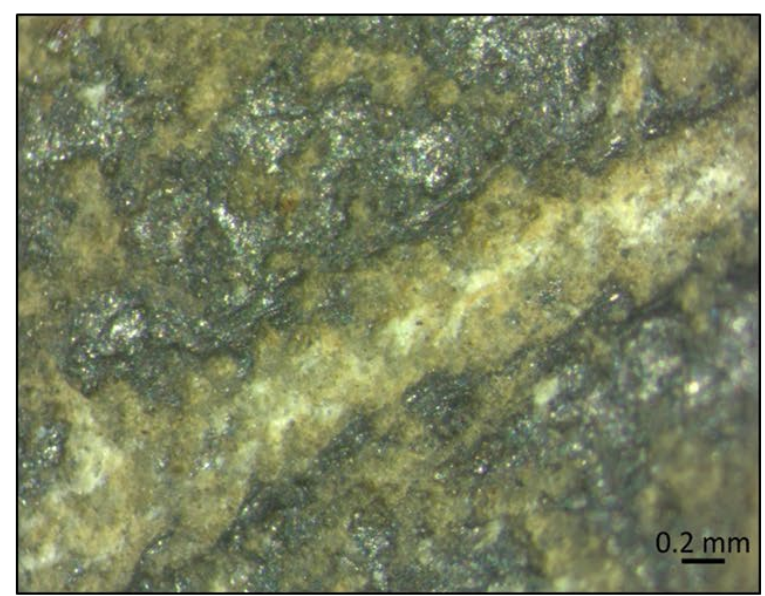

Photo 197. Photomicrograph of the incised line at the rim of

bowl 35CO2-485 showing the groove, pigment, and polish,

N

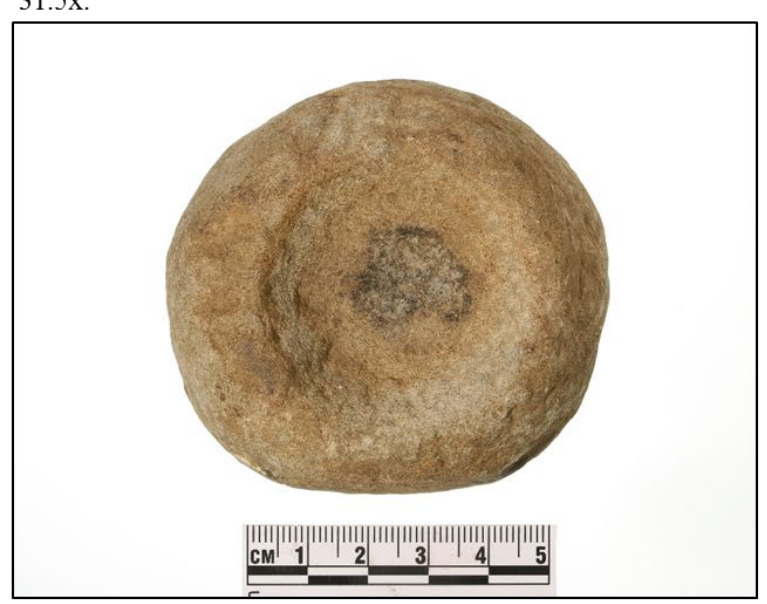

Photo 199. Bowl 35CO2-486.

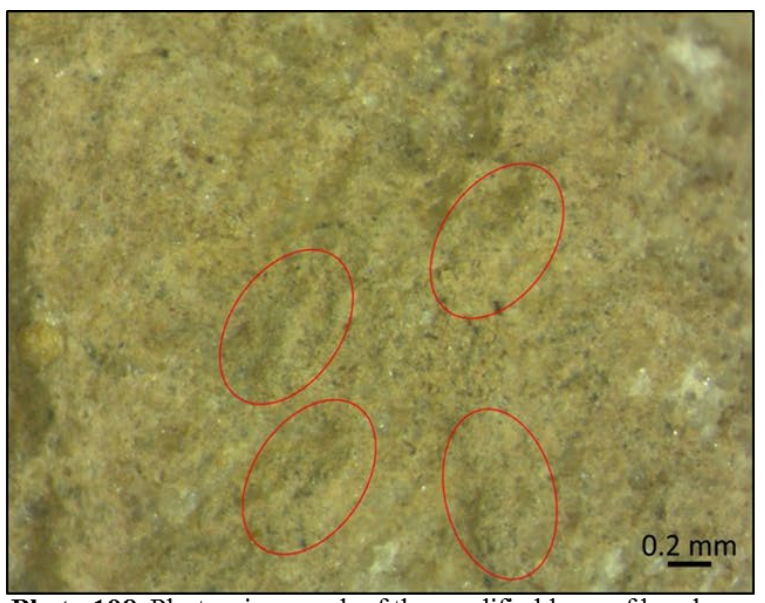

Photo 198. Photomicrograph of the modified base of bowl

$35 \mathrm{CO} 2-485$ showing possible chopper scars and great elevation differences, $31.5 \mathrm{x}$.

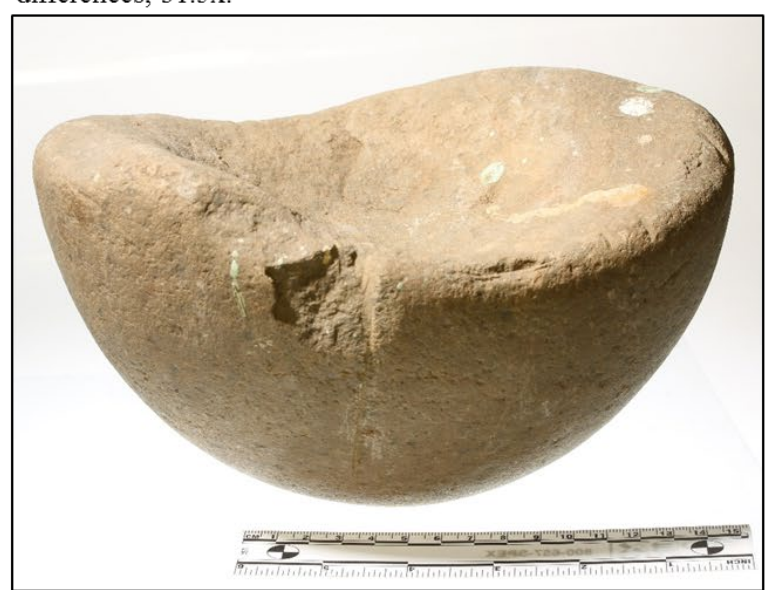

Photo 200. Bowl 35CO2-487. 


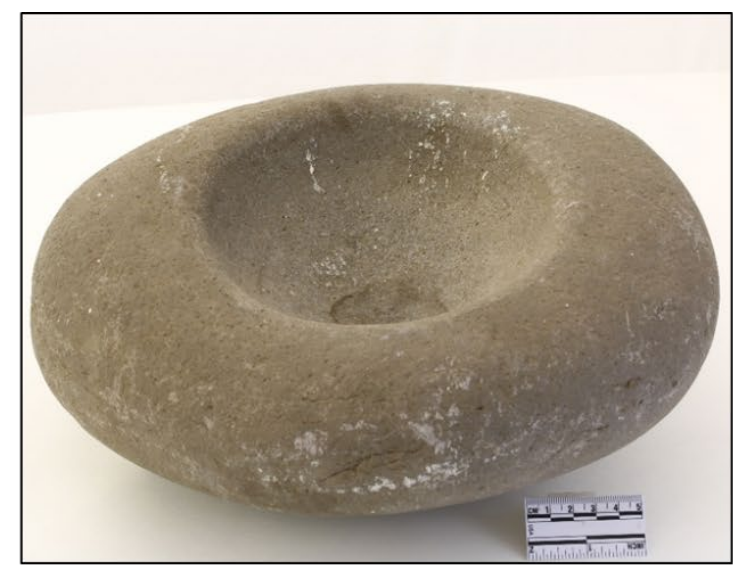

Photo 201. Bowl 35CO2-488.

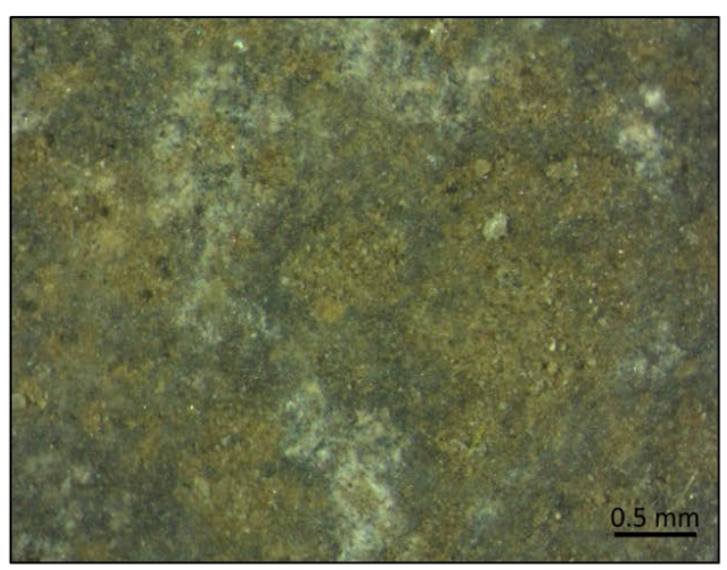

Photo 203. Photomicrograph of the basin of bowl 35CO2-488 showing great elevation differences, pitting, and light polish, $25.2 \mathrm{x}$

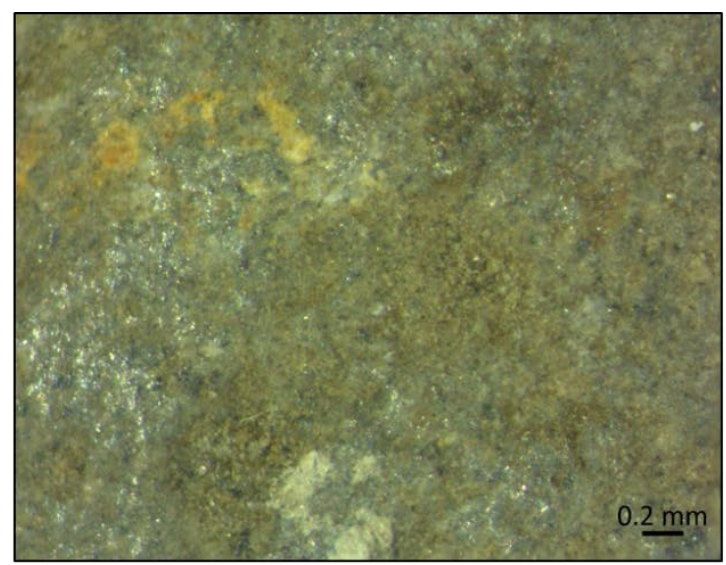

Photo 202. Photomicrograph of the exterior of bowl 35CO2-488 showing little elevation difference, grain rounding, and polish, $31.5 \mathrm{x}$

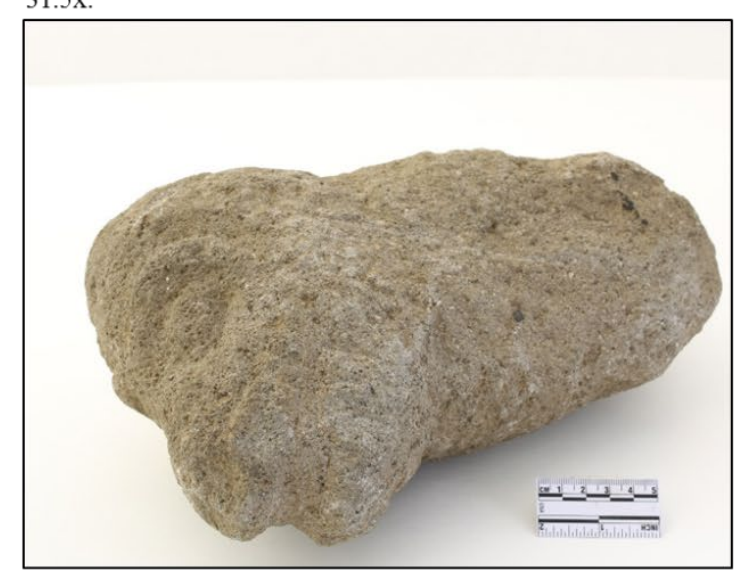

Photo 204. Sea lion mobile stone sculpture 35CO2-489. 


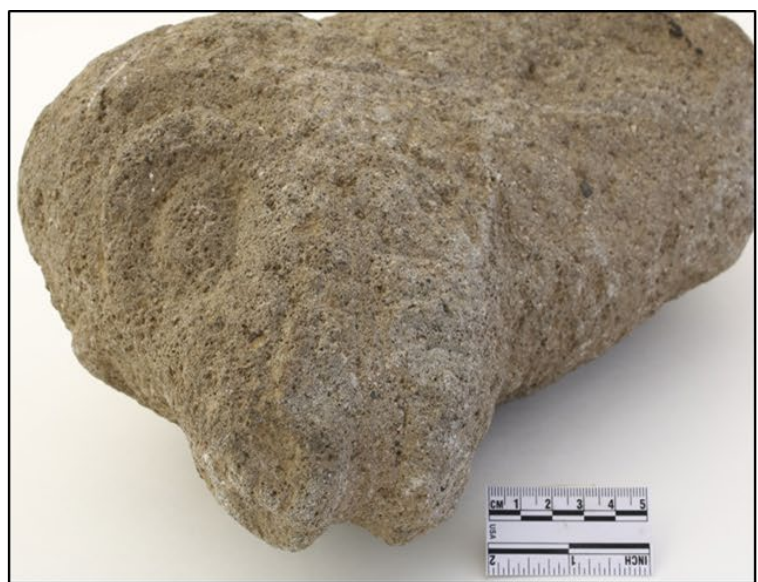

Photo 205. Sea lion mobile stone sculpture 35CO2-489.

$N$

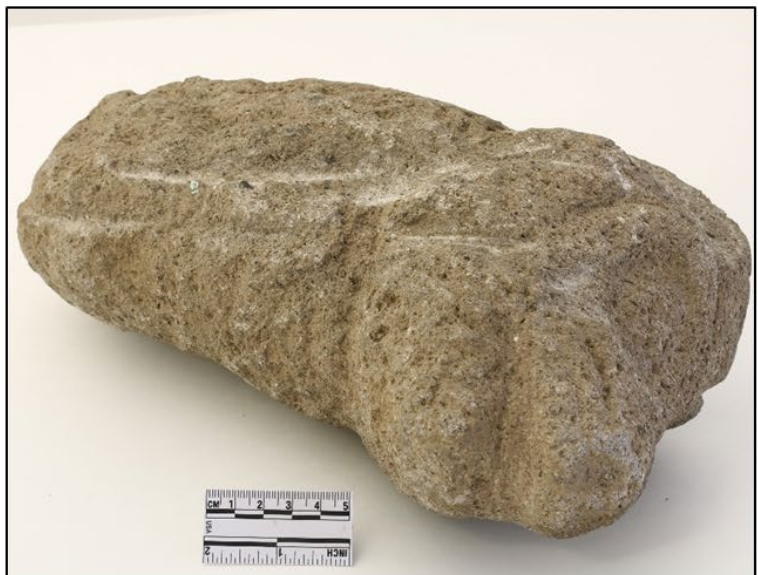

Photo 207. Sea lion mobile stone sculpture 35CO2-489.

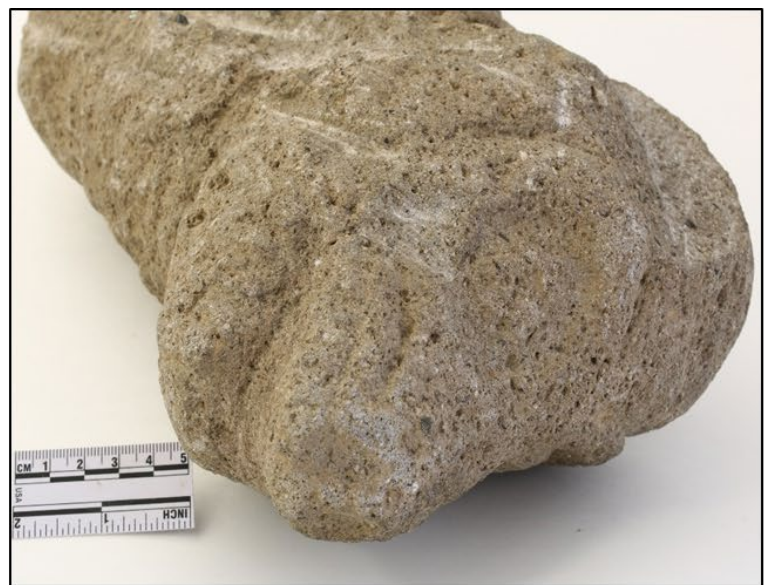

Photo 206. Sea lion mobile stone sculpture 35CO2-489.

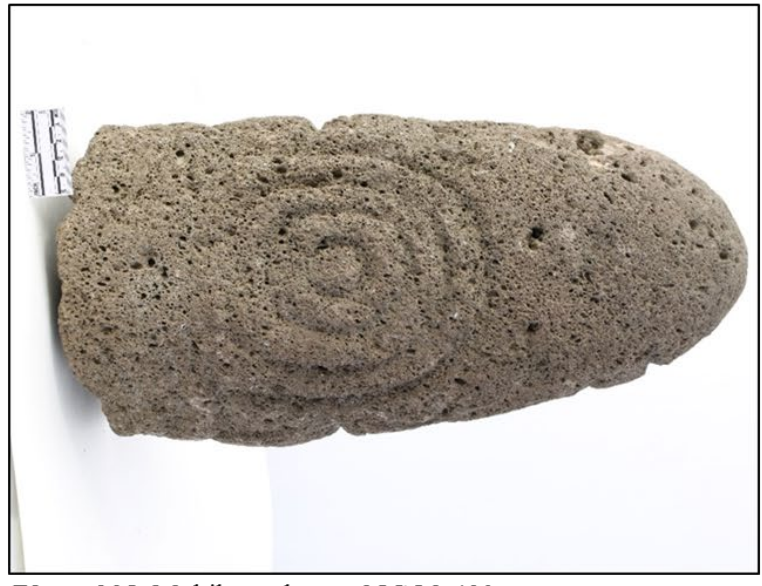

Photo 208. Mobile sculpture 35CO2-490. 


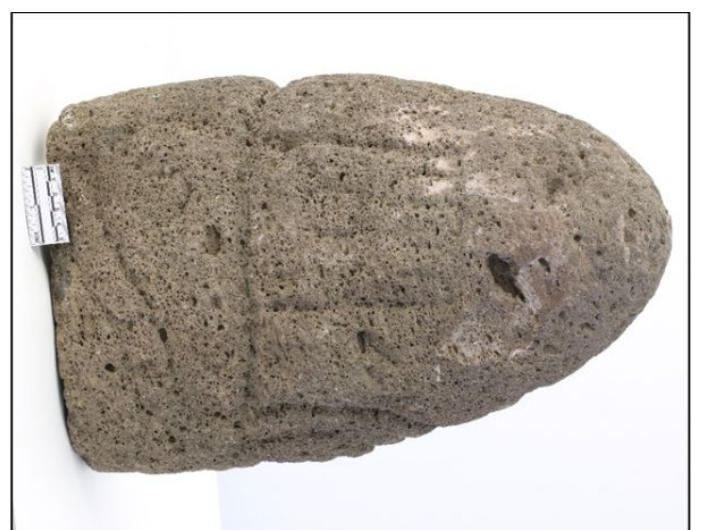

Photo 209. Mobile stone sculpture 35CO2-490.

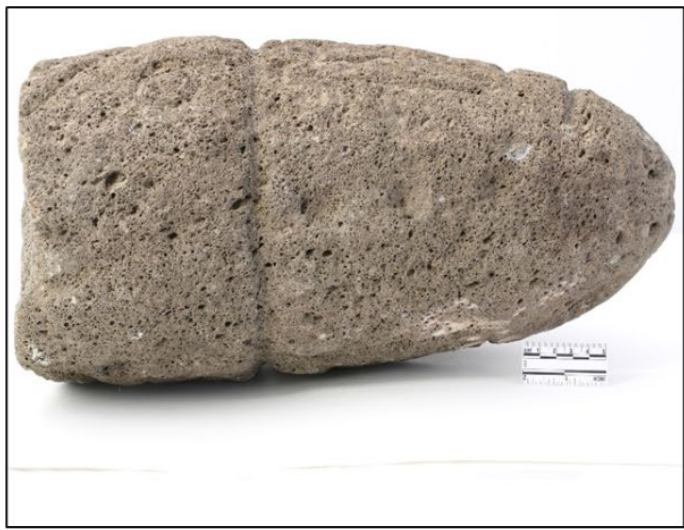

Photo 211. Mobile stone sculpture 35CO2-490.

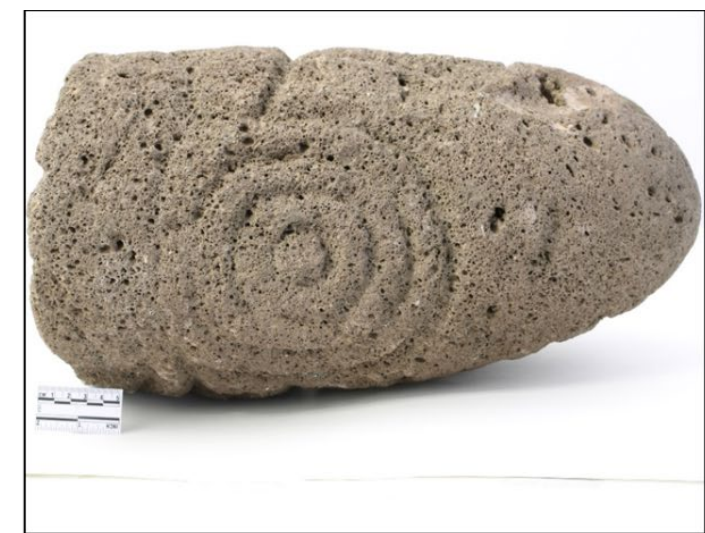

Photo 210. Mobile stone sculpture 35CO2-490.

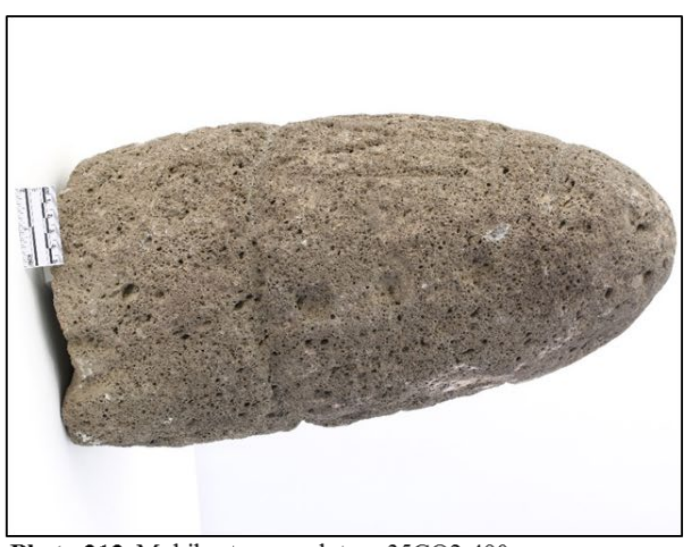

Photo 212. Mobile stone sculpture 35CO2-490 


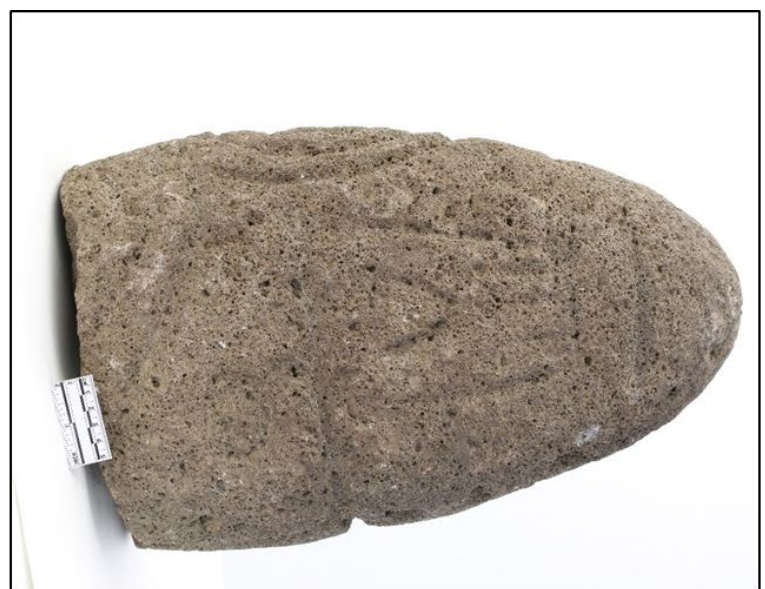

Photo 213. Mobile stone sculpture 35CO2-490.

N

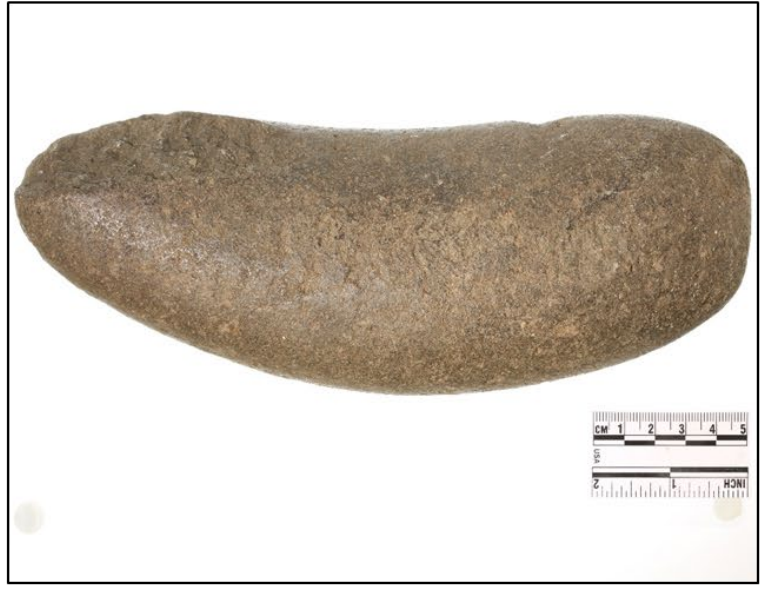

Photo 215. Multi use tool 35CO2-491.

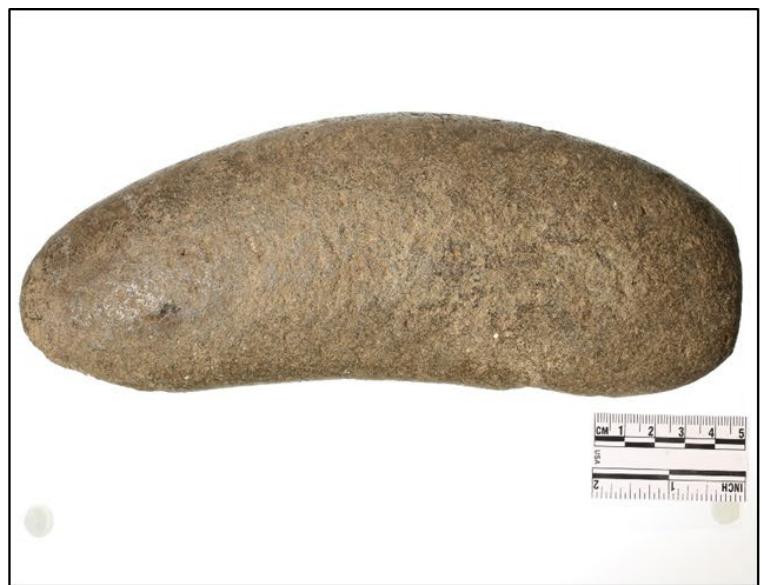

Photo 214. Multi use tool 35CO2-491.

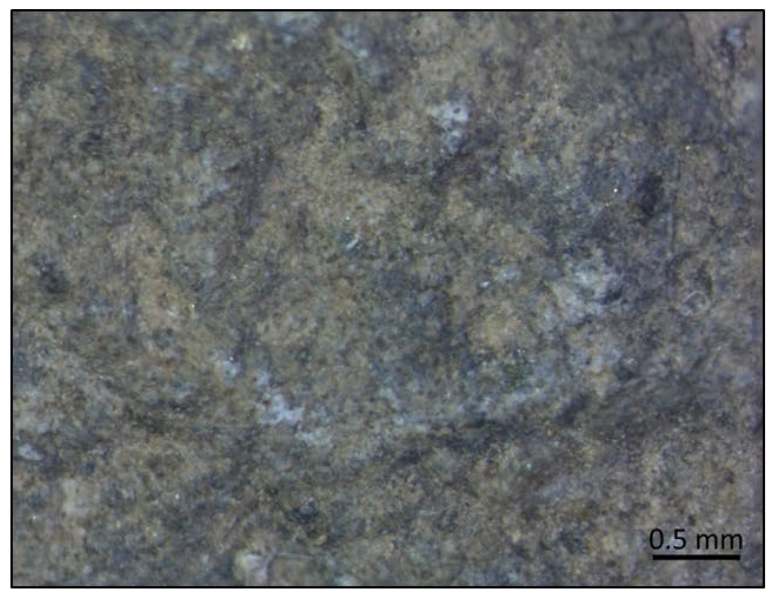

Photo 216. Photomicrograph of tool 35CO2-491 showing pestle use surface, rounded grains, and little elevation difference, $25.2 \mathrm{x}$. 


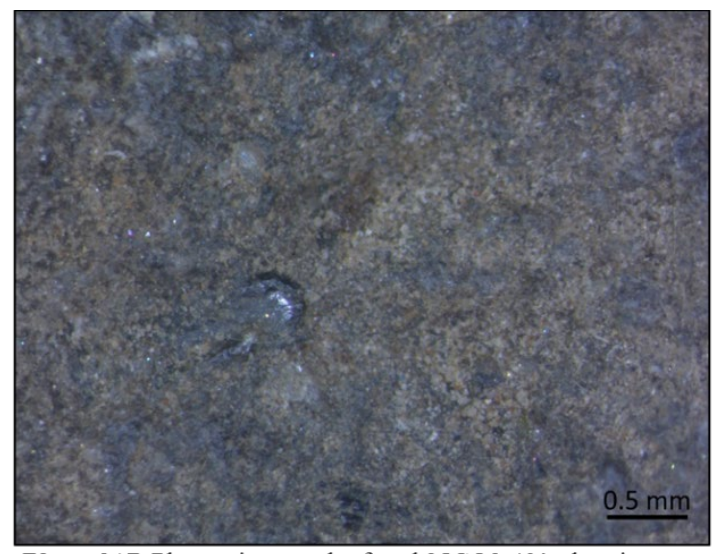

Photo 217. Photomicrograph of tool $35 \mathrm{CO} 2-491$ showing concentrated pitting, great elevation difference, and polish,

$25.2 \mathrm{x}$. 